\title{
IntechOpen
}

\section{Veterinary Medicine and Pharmaceuticals}

Edited by Samuel Oppong Bekoe, Mani Saravanan, Reimmel Kwame Adosraku and P K Ramkumar 



\title{
Veterinary Medicine and Pharmaceuticals
}

\author{
Edited by Samuel Oppong Bekoe, \\ Mani Saravanan, Reimmel Kwame \\ Adosraku and P K Ramkumar
}



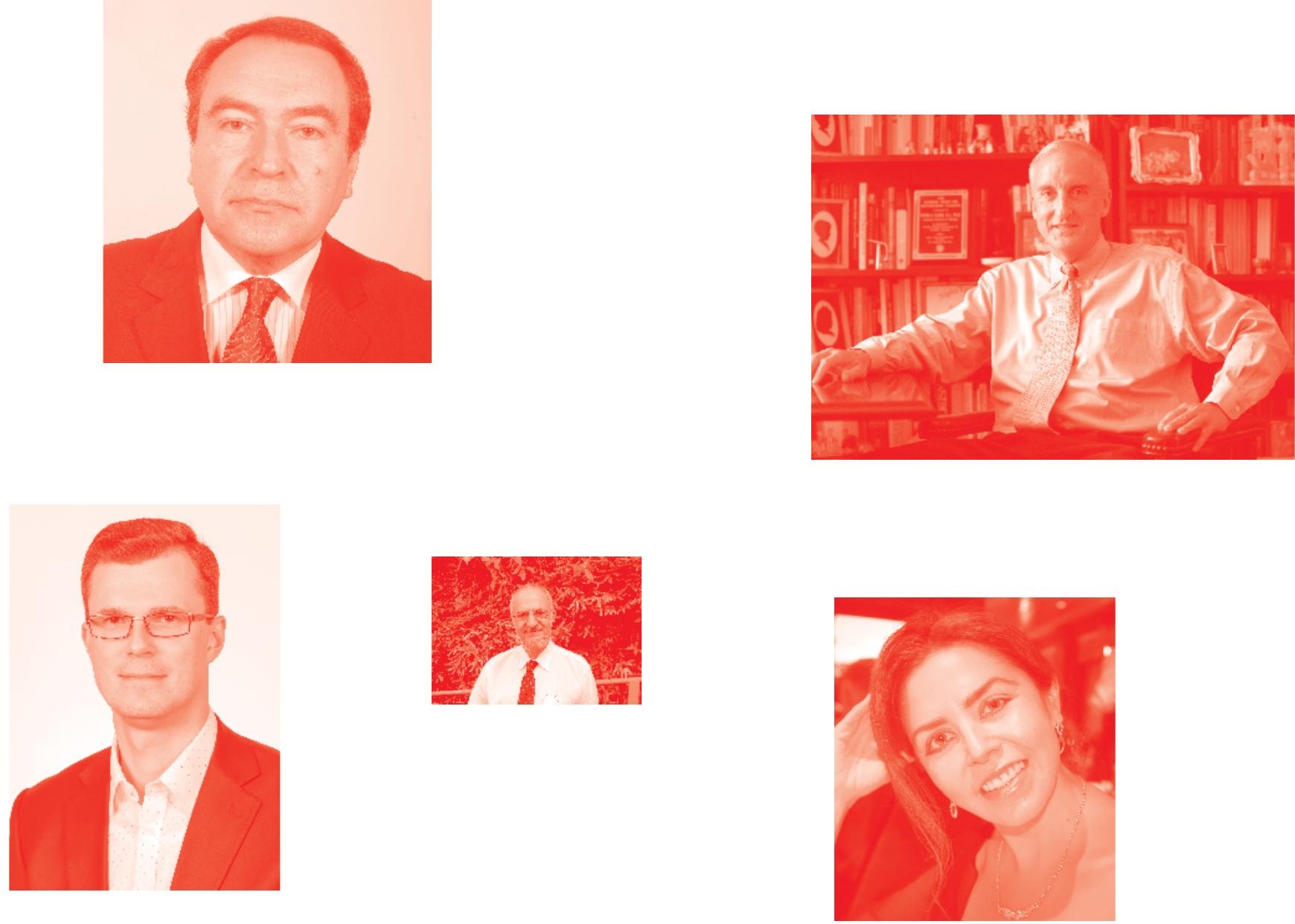

Supporting open minds since 2005
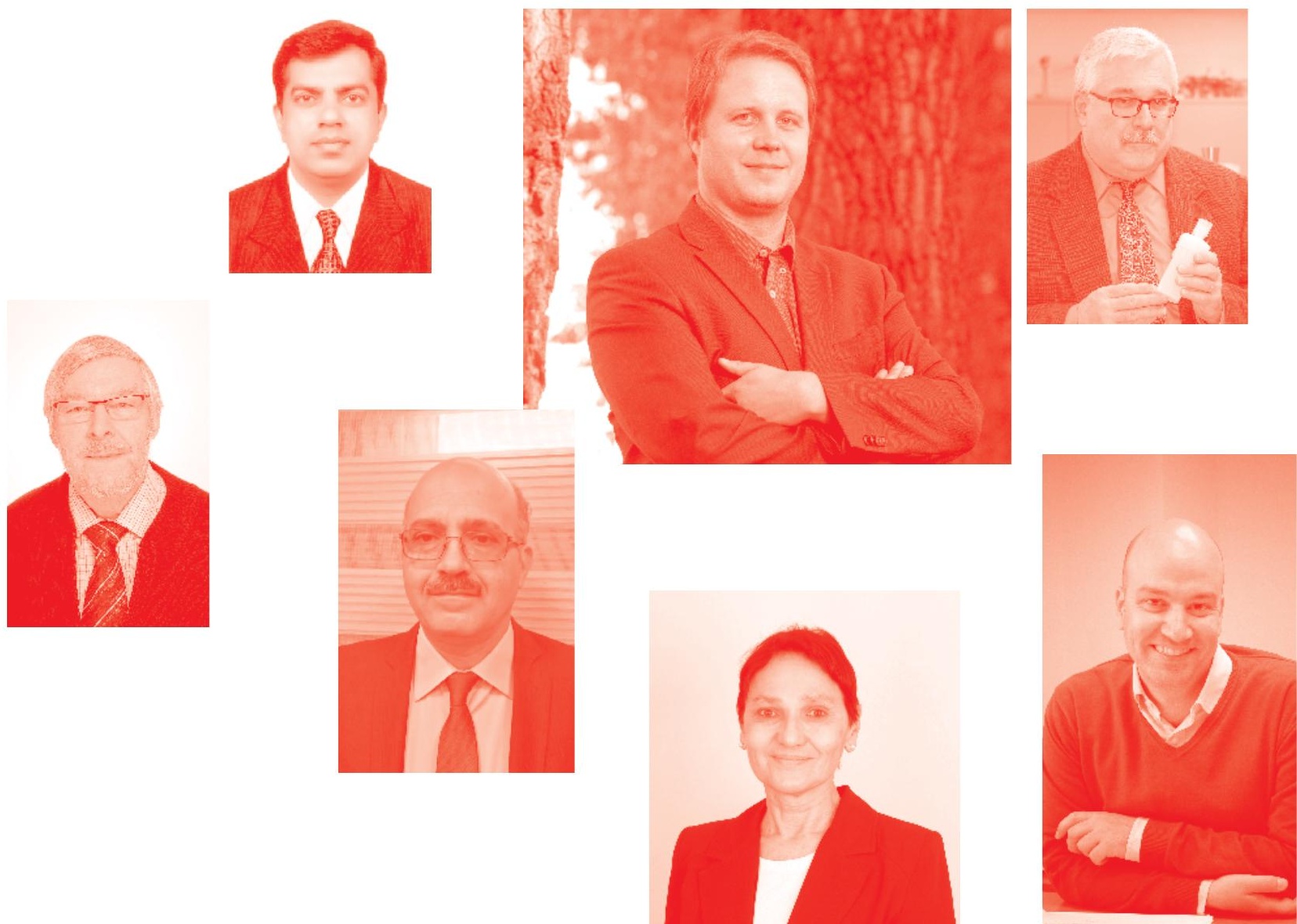
Veterinary Medicine and Pharmaceuticals

http : //dx. doi. org/10.5772/intechopen. 79335

Edited by Samuel Oppong Bekoe, Mani Saravanan, Reimmel Kwame Adosraku and P K Ramkumar

Contributors

Shiv Raj Singh Rathore, K.K. Datta, S.S. Shekhawat, Rozaihan Mansor, Kok-Song Lai, Loo Enli, Mani Saravanan, Poonam Vishwakarma, Nandini M. K, Rosemary Nwoha, Andrew Bamidele Falowo, Oluwakamisi Festus Akimoladun, Clement Adebajo Meseko, Haritha Yadav, Iosif Vasiu, Roman Dąbrowski, Flavius Alexandru Tăbăran, Raul Alexandru Pop, Flore Chirilă, Gheorghe Florinel Brudaşcă, Asta Tvarijonaviciute, Nicodim Iosif Fiţ, Ishart Younus, Samuel Oppong Bekoe

( ) The Editor(s) and the Author(s) 2020

The rights of the editor(s) and the author(s) have been asserted in accordance with the Copyright, Designs and Patents Act 1988. All rights to the book as a whole are reserved by INTECHOPEN LIMITED. The book as a whole (compilation) cannot be reproduced, distributed or used for commercial or non-commercial purposes without INTECHOPEN LIMITED's written permission. Enquiries concerning the use of the book should be directed to INTECHOPEN LIMITED rights and permissions department (permissions@intechopen.com).

Violations are liable to prosecution under the governing Copyright Law .

\section{(cc) BY}

Individual chapters of this publication are distributed under the terms of the Creative Commons Attribution 3.๑ Unported License which permits commercial use, distribution and reproduction of the individual chapters, provided the original author(s) and source publication are appropriately acknowledged. If so indicated, certain images may not be included under the Creative Commons license. In such cases users will need to obtain permission from the license holder to reproduce the material. More details and guidelines concerning content reuse and adaptation can be found at http : //www . intechopen . com/copyright-policy . html .

\section{Notice}

Statements and opinions expressed in the chapters are these of the individual contributors and not necessarily those of the editors or publisher. No responsibility is accepted for the accuracy of information contained in the published chapters. The publisher assumes no responsibility for any damage or injury to persons or property arising out of the use of any materials, instructions, methods or ideas contained in the book.

First published in London, United Kingdom, 2020 by IntechOpen

IntechOpen is the global imprint of INTECHOPEN LIMITED, registered in England and Wales, registration number: 11086078 , 7th floor, 10 Lower Thames Street, London,

EC3R 6AF, United Kingdom

Printed in Croatia

British Library Cataloguing-in-Publication Data

A catalogue record for this book is available from the British Library

Additional hard and PDF copies can be obtained from orders@intechopen.com

Veterinary Medicine and Pharmaceuticals

Edited by Samuel Oppong Bekoe, Mani Saravanan, Reimmel Kwame Adosraku and P K Ramkumar

p. cm.

Print ISBN 978-1-78985-439-8

Online ISBN 978-1-78985-440-4

eBook (PDF) ISBN 978-1-83880-@62-8 


\section{We are IntechOpen, \\ the world's leading publisher of Open Access books}

Built by scientists, for scientists

\section{$4,700+$}

Open access books available

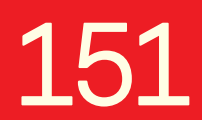

Countries delivered to
$120,000+$

International authors and editors

Our authors are among the

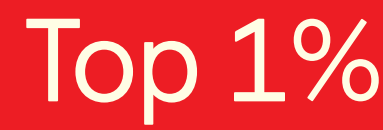

most cited scientists

Contributors from top 500 universities
$135 \mathrm{M}+$

Downloads

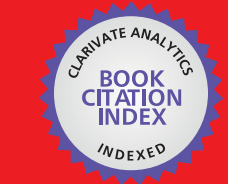

WEB OF SCIENCE ${ }^{\mathrm{MM}}$

Selection of our books indexed in the Book Citation Index in Web of Science ${ }^{\mathrm{TM}}$ Core Collection (BKCI)

\section{Interested in publishing with us? \\ Contact book.department@intechopen.com}

Numbers displayed above are based on latest data collected.

For more information visit www.intechopen.com 



\section{Meet the editors}

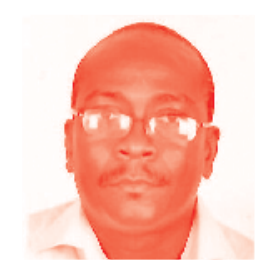

Samuel Oppong Bekoe (PhD) - I have been a Lecturer (since 2005), and am currently a Senior Lecturer (since 2016) with the Department of Pharmaceutical Chemistry, KNUST, Ghana. My research activities involve the quality assessment of pharmaceuticals, the monitoring and evaluation of antimicrobial resistance, the Safe Water for Good Health project, the development of analytical methods for the determination of pharmaceuticals in various matrices with the use of liquid chromatography with a range of detectors (MS, UV, etc.) and extraction procedures such as the solid phase extraction. I have been involved in the training and supervision of both undergraduate and postgraduate students. I have co-authored a number of publications from these research activities.

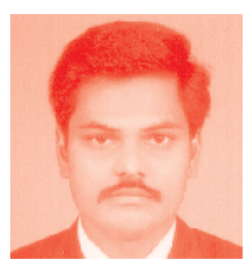

Dr. Mani Saravanan, BVSc., MVSc, PhD (Veterinary Medicine), works as an assistant professor in the Department of Veterinary Clinical Complex, Veterinary College and Research Institute, Tanuvas, Tamilnadu, India. He has specialization in veterinary internal medicine with special reference to liver and gastrointestinal disorders. He completed his $\mathrm{PhD}$ at the Indian Veterinary Research Institute, Izatnagar, India. He has research experience in canine gastroenterology and bovine gastrointestinal disturbances, and expertise in gastrointestinal endoscopy and abdominal ultrasound. Dr. Saravanan has published at both national and international levels, namely 32 research papers, 42 clinical articles, 5 review articles, and 4 book chapters. He is an editorial board member and reviewer of reputed journals. He is also a life member of various scientific societies, namely the TamilNadu State Veterinary Council, Veterinary Council of India, Indian Society for Veterinary Medicine, Society for Community Mobilization for Sustainable Development, Indian Society for Advancement of Canine Practice, and Agricultural Scientific Tamil Society.

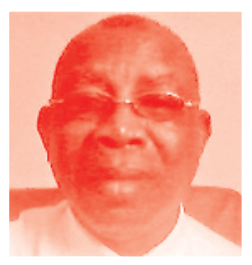

Reimmel Kwame Adosraku obtained his Bachelor of Pharmacy Degree from the Kwame Nkrumah University of Science and Technology (KNUST) in 1980 and the Master's in 1984. On completion of his programme he joined the faculty as a Lecturer that same year.In 1994, Prof. Adosraku was awarded a PhD Degree in Pharmaceutical Chemistry at the University of London School of Pharmacy, Brunswick Square, London, UK. His work in academia has been extensive, with institutions both home and abroad. He has served as Head of the Department of Pharmaceutical Chemistry at the Faculty of Pharmacy for four terms. He serves on a number of Boards including Faculty of Science Board, Faculty of Pharmacy and the College of Health Sciences Board. Prof. Adosraku was a member of the Committee that assessed application for accreditation of Pharmacy School for two Universities in the country. On the International front, he is an 
External Examiner in the Department of Pharmaceutical Chemistry, University of Sierra Leone, Freetown, Sierra Leone and a Member of the West African Health Organization (WAHO) Expert Committee evaluating Drug Quality Control Laboratories in West African countries $(2010$ - 2011). He offers professional consultancy services to various organizations in Ghana and abroad including BioResources International, USA and Ghana Standards Board. He also has several technical publications to his credit. Currently, he is an Associate Professor in Pharmaceutical Chemistry at KNUST.

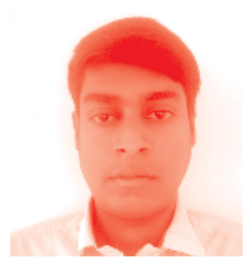

Dr. P.K. Ramkumar, BVSc and AH, MVSc (Veterinary Medicine), works as an assistant professor in the Department of Veterinary Clinical Complex, Veterinary College and Research Institute, Tanuvas, Tamilnadu, India. He has specialization in veterinary medicine with special reference to calf diarrhea. He completed his Master's degree program at the Indian Veterinary Research Institute, Izatnagar, India. Dr. Ramkumar has research experience in canine cardiology, transition cow management, and veterinary homeopathy, and expertise in canine abdominal ultrasound and electrocardiography. He has published at both national and international levels, namely 5 research papers and 10 clinical articles. He is a life member of various scientific societies, namely TamilNadu State Veterinary Council, Indian Society for Veterinary Medicine, and Agricultural Scientific Tamil Society. 


\section{Contents}

Preface

Section 1

Veterinary Pharmaceuticals

Chapter 1

Prologue: Veterinary Pharmaceuticals

by Samuel Oppong Bekoe

Chapter 2

Antimicrobial Usage and Resistance in Dairy Cattle Production by Enli Loo, Kok Song Lai and Rozaihan Mansor

Chapter 3

Importance of Socio-Economic and Institutional Factors in the

Use of Veterinary Services by the Smallholder Dairy Farmers in Punjab by Shiv Raj Singh, Kamal Kumar Datta and Supern Singh Shekhawat

Chapter 4

Veterinary Pharmaceuticals and Antimicrobial Resistance in

Developing Countries

by Meseko Clement, Makanju Olabisi, Ehizibolo David and Muraina Issa

Chapter 5

Veterinary Drug Residues in Meat and Meat Products: Occurrence, Detection and Implications

by Andrew Bamidele Falowo and Oluwakamisi Festus Akimoladun

Chapter 6

Foot-and-Mouth Disease Virus (FMDV) and Its Treatment with

Plant Extracts

by Ishrat Younus, Sidra Maqbool, Sarah Jameel Khan, Humera Sarwar,

Shagufta Nesar, Rida Fatima, Sidra Siddique and Moona Baig

Section 2

Veterinary Medicine

Chapter 7

81

Prologue on DISEASES OF DOGS - for Practioners

by Mani Saravanan 
Chapter 8

An Update on Canine Duodenal Disorders

by Mani Saravanan

Chapter 9

Overview of Canine Babesiosis

by Poonam Vishwakarma and M.K. Nandini

Chapter 10

Review on Ascites in Pets

by Rosemary Ijeoma Ogechi Nwoha

Chapter 11

Pericardial Effusion in Dogs

by Gurram Sreeramamurthy Haritha

Chapter 12

How Reliable Are Laboratory Test When Diagnosing

Bitch Mastitis?

by Iosif Vasiu, Roman Dabrowski, Flaviu Alexandru Tăbăran,

Raul Alexandru Pop, Flore Chirilă, Gheorghe Florinel Brudaşcă, Asta Tvarijonaviciute and Nicodim Iosif Fit, 


\section{Preface}

Veterinary pharmaceuticals are compounds or substances employed in the diagnosis, prevention, control, and treatment of animal diseases. Generally, they are mainly medicines needed to keep animals healthy.

Animals form a significant part of the food chain. Animals serve as food, and also form part of the environment. Humans are exposed to various forms of infectious diseases, resistant microorganisms, and residual levels of veterinary pharmaceuticals through the consumption of food animals. Thus, human existence and the quality of life experienced by humans have a correlation with the exposure to animals and animal food.

The management of animal health with human-specific pharmaceuticals was common until the development of veterinary-specific pharmaceutical agents. The economic benefits of veterinary pharmaceuticals to manufacturers', sovereign nations, and business-oriented persons remain enormous.

However, the public health-related implications of the widespread and intensive use of veterinary pharmaceuticals mainly to increase yields in food producing animals, has compelled nations and regulatory agencies (national and international) to come up with safer and stricter measures for regulating veterinary pharmaceuticals.

The main objective of this book is to expose the research and academic environments, in the use, application, and consequences of routine application of veterinary pharmaceuticals.

This book covers a wide range of issues on veterinary diseases and their management, especially with secondary metabolites or bioactive compounds from plant extracts, socio-economic and institutional factors that inform and influence farmers' decisions on using veterinary services, and the antimicrobial resistance pandemic and related public health issues, especially in developing countries. Other relevant concerns with respect to the occurrence and analytical detection techniques employed in the effective determination of residual levels of veterinary pharmaceuticals in food has also been covered. Furthermore, aspects of dairy cattle production and the probable transfer of antimicrobial resistant genes to humans has also received significant attention in this book.

Topics in each chapter are arranged in clear language and provide:

- a comprehensive, balanced write-up of current issues in veterinary pharmaceuticals and specific disease conditions they are used for

- reliable information on the occurrence, detection, and implications of veterinary drug residues in the food chain 
- the relevance of socio-economic and institutional factors needed to be considered by farmers in the use of veterinary services with implications on the use and application of veterinary pharmaceuticals

- background information on the use of plant extracts in the management of specific viral diseases (such as foot and mouth disease virus) that affect animals

- public health implications on the routine and unregulated use of veterinary pharmaceuticals.

It is our belief that this text will continue to:

- provide researchers, scientists, and undergraduate and post-graduate students with a solid foundation on the public health implications of the use of veterinary pharmaceuticals

- motivate health-based and public health-based academic programs to continue to produce innovative standards, ideas, and technologies in the management and handling of veterinary pharmaceuticals

- expose scientists to the latest trends in managing various diseases that affect animals.

This book would be valuable to students of veterinary medicine, pharmacy, chemistry, biochemistry, pharmacology, medicinal chemistry, and public health.

I must use this platform to congratulate all authors whose works made this book possible.

It must be noted that all sources of information are well documented and acknowledged.

Special gratitude also goes to our publishers (IntechOpen) for their immense support.

Comments on this book are welcome.

\section{Samuel Oppong Bekoe and Reimmel Kwame Adosraku Kwame Nkrumah University of Science and Technology, Kumasi, Ghana}

It is an excellent book for veterinary students, researchers, and practitioners with cutting-edge references to the signs, diagnoses, treatment, and better care of dogs. The book contains core information to evaluate major clinical issues concerning dogs. Information has been updated and diagnostic plans have been refined and revised on the basis of the newest diagnostic techniques. 
The depth of information provided with excellent photos in all chapters provide detailed information in a number of important areas. In particular, we hope that the book also serves as a practical source for advancing the diagnosis and treatment of ascites, pericardial effusion, duodenal disorders, and canine mastitis.

The editors are grateful to the authors for sharing their valuable information in the form of book chapters.

Dr. Mani Saravanan and Dr. PK. Ramkumar

Tamil Nadu Veterinary and Animal Sciences University,

India 

Section 1

\section{Veterinary Pharmaceuticals}





\title{
Prologue: Veterinary Pharmaceuticals
}

\author{
Samuel Oppong Bekoe
}

\section{Introduction}

Pharmaceuticals in general have contributed significantly to improvements in the quality of life of both humans and animals. Pharmaceuticals used for either human or veterinary purposes have the ability to delay the onset of disease, relieve symptoms, and cure and prevent complications. In all, the quality of life gets improved with the use and application of pharmaceuticals.

Veterinary pharmaceuticals are needed not only for the ultimate economic benefits they provide but for ensuring that animals are healthy. Quite a significant number of veterinary drugs are available for different purposes and application. These include antibiotics used to fight and destroy bacteria; anthelmintics used to destroy internal parasites; insecticides used to destroy ticks, lice, fleas, and mites; and hormones used for growth and fertility promotion [1].

Broadly, four main categories of veterinary pharmaceuticals have been identified, and these are (i) prophylaxis agents used to prevent diseases, (ii) metaphylaxis agents used to control the spread of illness, (iii) therapeutic agents for the treatment of various forms of diseases, and (iv) growth promoters used to stimulate growth rate [1].

The development, formulation, preparation at point of use, quality assessment, dosage forms, distribution, stability, use and storage, occurrence, and persistence in the environment as well as their disposal and regulatory control require skilled knowledge and expertise to ensure their effective handling.

There is therefore the need to ensure that animal food for human consumption contain very minimal level and if possible devoid of any potential hazardous veterinary drug residues.

This would help ensure the successful achievement of human health needs.

The transfer of potentially hazardous veterinary pharmaceutical residues from animal food (in residual levels) to humans through the food chain could pose detrimental health issues to humans.

Public health-related issues and potential risks to humans (intrinsic toxicity, residual levels, and antimicrobial resistance especially and environmental contamination from waste of animals) from un-guarded and routine administration of veterinary pharmaceuticals have necessitated the need for stringent global, international, and national regulations as well as safety standards for veterinary pharmaceuticals.

Veterinary pharmaceuticals are usually formulated considering certain key factors such as the anatomy of the animal, bioavailability of the drug molecule, and other pharmacodynamic and pharmacokinetic parameters. For example, one cannot lay hands easily on an injectable or powder form of oxytetracycline employed for human purposes. Oxytetracycline is presented in the form of 
capsules and tablets for humans. However, feed premixes, injectables, soluble powders, and tablet dosage forms of oxytetracycline have been formulated for animals.

The active ingredients (in veterinary medicines) may also differ in kind and amount compared to human medicines [2]. For instance, doses as low as $50 \mathrm{mg}$ for oxytetracycline may be administered to animals, which is far below the recommended daily dosage for humans.

The approval processes for veterinary pharmaceuticals and human drugs are separate in most cases, though similar [2].

It is increasingly becoming evident that data on the quantities of veterinary pharmaceuticals employed from national levels are lacking. Such data are obtained or provided on voluntary basis and very little transparency is involved [3-5].

Furthermore, political, commercial, and economic interests of veterinary pharmaceutical manufacturers do not always commensurate with the required public health interests.

Thus, a well-coordinated strategy needed to identify reliable scientific data with the right correlated research designs and methods from relevant stakeholders is needed to address such pertinent issues. With this background, holistic contributions from researchers, scientists, and well-meaning stakeholders would be required in addressing the myriad of issues arising from the use of veterinary pharmaceuticals. Such agenda must, thus, include contributions from experts in clinical sciences (e.g., veterinary medicine and human medicine), basic sciences (e.g., genetics and microbiology), social sciences (e.g., anthropology and sociology), economics (e.g., health and agriculture), public health (e.g., epidemiology and nursing), and policy makers (e.g., legislative and regulatory) to achieve desired goals.

The in-depth information, data, and some policy directions needed to address such issues are what this book provides. For example, the challenge of finding new bioactive compounds from plant sources, needed to treat infectious diseases, hitherto, not responding to already available antimicrobial agents, is covered in this book.

The use of various plant extracts in the management of foot and mouth disease virus is well discussed in this book.

Moreover, lots of exposure on current trends in analytical techniques needed for the determination of residual levels of veterinary pharmaceuticals in animal food products is also well expounded.

The contents of this book, together with ongoing and future research, would in the long term help provide and address well-structured scientific agenda and objectives related to veterinary pharmaceuticals. This would ultimately help surmount challenges associated with the manufacture, use, and collection of data associated with veterinary pharmaceuticals. 


\section{Author details}

Samuel Oppong Bekoe

Department of Pharmaceutical Chemistry, Faculty of Pharmacy and

Pharmaceutical Sciences, Kwame Nkrumah University of Science and Technology,

Kumasi, Ghana

*Address all correspondence to: sobekoe.pharm@knust.edu.gh;

sobek03@gmail.com

\section{IntechOpen}

(C) 2020 The Author(s). Licensee IntechOpen. This chapter is distributed under the terms of the Creative Commons Attribution License (http://creativecommons.org/licenses/ by/3.0), which permits unrestricted use, distribution, and reproduction in any medium, provided the original work is properly cited. (cc) BY 


\section{References}

[1] Ajibola AO. Essential Medicinal Chemistry. 3rd ed. Ibadan-Nigeria:

Hope Publication; 2005. p. 347-349, 447, 483-525. ISBN: 978-8080-02-2

[2] Palmer B. Explainer. 2011. Retrieved from Explainer: http://www.slate. com/ articles/news_and_politics/ explainer/2011

[3] Landers TF, Cohen B, Wittum TE, Larson EL. A review of antibiotic use in food animals: Perspective, policy, and potential. Public Health Reports. 2012;127(1):4-22

[4] Aarestrup F. Sustainable farming: Get pigs off antibiotics. Nature. 2012;486(7404):465-466

[5] Van Boeckel TP, Brower C, Gilbert M, Grenfell BT, Levin SA. Global trends in antimicrobial use in food animals. PNAS. 5 May 2015;112(18):5649-5654. Available from: http://www.pnas.org/ cgi/doi/10.1073/pnas.1503141112 


\title{
Antimicrobial Usage and Resistance in Dairy Cattle Production
}

\author{
Enli Loo, Kok Song Lai and Rozaihan Mansor
}

\begin{abstract}
Antimicrobial resistance (AMR) has been a public health threat globally, with millions of lives lost due to AMR infections each year. The cases of AMR continue to escalate and cause devastating effect to both humans and animals. AMR contributes to high morbidity and mortality of the livestock, which results in staggering economic losses to the livestock producers. The main factor for AMR to arise in this industry is mainly due to the eagerness of livestock producers to meet high demand by using antimicrobials to promote animal growth and disease prevention. From a public health perspective, AMR in dairy cattle can also jeopardize human population due to the potential dissemination of AMR pathogens to humans via consumption of infected dairy products or direct contact with infected dairy cattle. At the current rate of unrestricted antimicrobial usage, AMR will be expedited and soon we will run out of effective treatment for even the simplest infection. World Health Organization (WHO) has issued a set of guidelines for the use of medically important antimicrobials on animals to mitigate the adverse consequences of AMR on human. Thus, this chapter will explain antimicrobial usage in dairy cattle production and the recent approaches and challenges on AMR.
\end{abstract}

Keywords: antimicrobial resistance, antimicrobial usage, dairy cattle, antimicrobial, one health

\section{Introduction}

AMR is undoubtedly one of the greatest health threats perceives by mankind. It causes increased morbidity, mortality and social and economic burdens [1-4]. For decades, antimicrobials were used not only in treating humans but also in veterinary medicine, agriculture and aquaculture, which had been linked to the global rise of AMR. By 2050, it is estimated that AMR will result in 10 million deaths per year and contribute to a shocking economic cost of 100 trillion USD, if we do not take action to tackle this devastating crisis [4]. In animals, the use of antimicrobials includes treatment and control of clinical bacterial infections as well as disease prevention and growth promotion. Although the evidence and mechanism of such benefits have not been clearly demonstrated, the apparent growth promotion 
benefits of antimicrobials when using antimicrobials in animals have resulted in higher usage of antimicrobials in animals, even in the absence of disease. The danger of using antimicrobials in animals to humans was uncertain until 1997 when experts concluded that the usage of antimicrobials in food-producing animals causes AMR selection, in a consultation on "medical impact of the use of antimicrobials in food animals" organized by WHO in Berlin, Germany [5]. Since then, various studies have further supported the theory in which AMR selection and dissemination from animals can be attributed to uncontrolled antimicrobial usage in animals [6-10]. An example in dairy cattle production shows dairies from the conventional production have a higher prevalence of AMR enteric bacteria than dairies from the organic production as more antimicrobials are usually being used in the conventional practice [9].

In general, AMR is the capability of a microorganism to resist the inhibitory activity of an antimicrobial at a normal susceptibility level. AMR occurs in previously susceptible strain due to a prolonged adaptation of the microorganism on the antimicrobial, which results in the evolution of the particular stain to survive in such condition. This can be acquired via mutation of the gene or horizontal gene transfer from another microorganism, which includes conjugation, transformation and transduction. The subsequent AMR selection in bacteria in animals can then be disseminated to humans because of the food chain relationships [10]. Moreover, this cross-species transmission can also occur via direct contact between humans and animals or shared environmental sources that are contaminated. In dairy cattle production, the dairy products can also be contaminated with AMR strains in several ways like directly from the environment such as soil, water and fecal material or cross-contamination during food processing [9]. This ultimately causes public health concern regarding the consequences of antimicrobial use in animals on food safety issue.

In 2005, WHO's committee had set up a few criteria to classify medically important antimicrobials in human medicine [11]. Among the classifications, the criteria for critically important antimicrobials were used to establish the WHO List of Critically Important Antimicrobials for Human Medicine, also known as the WHO CIA List. A guideline based on the WHO CIA List was formed to minimize the adverse consequences of unrestrictive usage of medically important antimicrobials in human medicine, and since then it has been updated regularly, with the latest fifth edition being published in 2017. To combat the increasingly significant health threat posed by AMR, the 68th World Health Assembly adopted a global action plan in May 2015 that proposed interventions to tackle AMR and also emphasized on the "One Health" approach in addressing AMR.

In order to address this important health risks at the animal-human-ecosystem interfaces, a complementary partnership between the Food and Agriculture Organization (FAO), the World Organization for Animal Health (OIE) and WHO was made to prevent, detect, control, eliminate and manage disease risks to human transferred directly or indirectly from domestic and wild animals [12]. Part of the OIE strategy on AMR and to support prudent use of antimicrobials includes four main objectives, namely, improving awareness and understanding, strengthening knowledge through surveillance and research, supporting good governance and capacity building and encouraging implementation of international standards [13]. Realizing the importance and its impact of this global issue in human and animal population, Malaysia is extremely committed with the cross-sectoral action plan and thus has drafted the Malaysian Action Plan on AMR (MyAP-AMR) to support the global action plan in 2017 under collaboration between Ministry of Health and Ministry of Agriculture and Agro-Based Industry, Malaysia [14]. 


\section{Usage of antimicrobials in dairy cattle production}

Antimicrobials are one of the modern interventions utilize by veterinarians and farmers to improve animal health and also the quality of animal products. The usage of antimicrobials has significantly ameliorated the well-being of animals, which results in better health and higher productivity of the animals [15]. In dairy cattle production, the usage of antimicrobials is highly indicated, mostly in treating diseases affecting the dairy cattle, such as mastitis. Besides disease treatment, antimicrobials have also been used to prevent diseases and promote growth in the dairy cattle production $[16,17]$.

\subsection{Treatment and disease prevention in dairy cattle}

Bovine mastitis, usually caused by Staphylococcus aureus, is the most commonly treated diseases in dairy cattle. In fact, it has become the biggest consumers of antimicrobials in dairy cattle production due to its massive economic impact to the industry [18]. In UK dairy cattle production, an annual loss of $€ 9.03$ billion or an average of $€ 279$ per case was reported due to summer mastitis, a type of mastitis that occurs during the warmer months [19]. Meanwhile, the total economic cost is much higher in US dairy, which is $\$ 444$ for an average mastitis case [20]. There are a few costs that contribute to the economic impacts due to mastitis such as milk production losses, drug treatments and diagnoses, discarded milk, culling and also labour costs, but production losses are the major constituent of the economic impact of mastitis [21,22]. Clinical mastitis and subclinical mastitis can result in significant milk production losses, but subclinical mastitis has a higher prevalence and it is difficult to estimate its economic impacts due to the variability in case definition and screening intensity [20,23]. Clinical mastitis can be identified based on the clinical examination on dairy cattle for local or systemic signs of mastitis such as swelling and redness of the udders or abnormal milk secretions. It is harder to characterize subclinical mastitis as milk secretions are not visually abnormal, thus it is usually diagnosed based on the inflammatory markers and somatic cell counts in the milk. Antimicrobial treatment of mastitis in dairy cattle depends on the etiology of the disease. Appropriate antimicrobials such as $\beta$-lactams like penicillin and third-generation cephalosporin, aminoglycosides like amikacin and gentamicin, and fluoroquinolones are used in treating mastitis. Dairy cattle mastitis has been more susceptible to a wide range of antimicrobials and less prone for the selection pressure of AMR than the same isolates in humans. This is due to the use of intra-mammary infusion treatment compared to the conventional parenteral treatment with the former has a limited bacterial exposure and the later has a huge risk of exposing the infected udder to other bacteria from a different environment [18]. Besides, the blood-milk barrier in bovine udder also limits the distribution of specific antimicrobials away from the infected sites [18], thus preventing bacterial selective pressure to occur in other sites. Besides mastitis, endometritis is another disease that affects dairy cow which requires antimicrobial treatment occasionally. Bovine endometritis is a post-partum uterine disease that affects the uterine endometrium. It can also be classified into clinical and subclinical cases by evaluating the vaginal mucus using an intravaginal device followed by a scoring system for clinical endometritis [24], and the proportion of polymorphonuclear leucocyte in the endometrial cytological slide, with $>5 \%$ of cells will be characterized as subclinical endometritis [25], respectively. It has a detrimental effect to the economics due to the reduced reproductive performance in diseased cattle [25]. Generally, a broad spectrum antibiotic therapy will be chosen to fight against the main pathogens that cause bovine endometritis, such as Actinobacillus pyogenes and some Gram-negative 
anaerobes. Intrauterine cefapirin and oxytetracyclines can be used in endometritis for its good penetration to the endometrium.

However, sometimes the usage of antimicrobials in infected dairy cattle can be too late to treat the infected cattle back to health. Cases of subclinical mastitis will not be clinically obvious to detect, thus missing the right timing to administer antimicrobials to get rid of the pathogens. Besides, some dairy cattle that recovered completely from subclinical mastitis with antimicrobials can still have a low milk production and not increase for years [26]. Therefore, it is always better to prevent a disease from occurring in the herd rather than treating it. It is also rational to do so because it reduces the economic losses due to mastitis. Prevention use or prophylactic use of antimicrobials in dairy cattle refers to the administration of antimicrobials in healthy dairy cattle considered to be at risk, before the onset of any infectious diseases. The dairy cattle production in the USA has more than $90 \%$ of dairy farmers practised dry cow therapy at the end of lactation on the dairy cattle to prevent intra-mammary infections during the dry period [27]. The application of antimicrobials shows a significant reduction in the rate of intra-mammary infections during the dry period $[27,28]$. Furthermore, antimicrobials can also be used for control treatment, also known as metaphylaxis, to prevent the spread of disease in the dairy cattle. It is usually given as a mass treatment to the healthy groups when part of the group is diagnosed with clinical disease, to prevent disease progression and spread in the herd. Conclusively, antimicrobials play an important role in the treatment, prevention and control of disease in dairy cattle production.

\subsection{Growth promotion in dairy cattle}

Growth promoters are any substances given to animals as supplements or nutrients to enhance their growth rate, without the specific intention of treating, preventing or controlling diseases. They were once used widely and uncontrollably in the food-producing animal industry like in dairy cattle production [29]. The growth-promoting effect of antimicrobials was discovered back in the 1940s when experimented chickens showed promising signs of growth after feeding with fermentation by-products of penicillin and streptomycin [30]. The practice of using antimicrobials then becomes widespread in the food-producing animal industry for the eagerness of farmers to obtain high profits in a shorter time by maximizing animal growth rates. In dairy cattle production, antimicrobials are used as feed additives in dairy cattle to enhance their digestive tract activity. Antimicrobials suppress competitive microorganism in the digestive tract that competes nutrients with the host or produces undesirable toxic substances to the host. This provides an optimum environment in the digestive tract of the dairy cattle that allows them to absorb all the food intake completely and effectively. The increase in nutrient utilization thus enhances the growth rate of dairy cattle. However, the public health concern about the usage of antimicrobials as growth promoters rises as prolonged use of antimicrobials increases the risk of AMR. To prevent AMR from jeopardizing the future of human medicine, many countries have taken action to reduce or ban the usage of antimicrobials as growth promoters in animals. Sweden became the first country to ban all usage of growth-promoting antimicrobials in food-producing animals in 1986 after the recommendations of the UK Swann Commission regarding the prohibition of antimicrobials as animal growth promoters in 1969. In 1997, the use of avoparcin was prohibited in the EU as evidence showed the use of avoparcin, a glycopeptide, closely related to vancomycin causes selection of the resistance gene (VanA). The EU further prohibited all use of antimicrobials for growth-promoting benefits in animals in 2006 in order to control the emergence of AMR. 
The prohibition of antimicrobial usage for growth promotion in food-producing animals still remains a controversial debate [31-33]. It is still unconvinced about the potential issue of AMR from using antimicrobials as growth promoters in animals because the dose used is small than the therapeutic dose to select for resistance [33]. On the other hand, there are also some opinions about the prohibition on growth promoters that might actually increase the prophylactic usage of antimicrobials as some users might try to "play with the rules" [4].

\section{Monitoring antimicrobial usage in dairy herds}

With the emergence of AMR from antimicrobial usage in food-producing animals, many countries have formulated and implemented their surveillance and monitoring programmes to identify the extent of antimicrobial usage in their countries. It serves as the first step in reducing the unnecessary usage of antimicrobials in animals. These programmes differ between countries as several factors such as government policies and resource availability have to be considered to ensure flexibility in deciding how to reduce antimicrobial usage. A survey done by the OIE in 2012 had highlighted that only $27 \%$ of the participating countries were able to provide quantities of antimicrobials used in animals in their respective countries [34], which showed how poorly the development of the surveillance and monitoring system on veterinary antimicrobial usage in some of the countries.

The prohibition of avoparcin as a growth promoter in food-producing animals in 1997 had resulted in more attention being focused to the usage of antimicrobials in animals and the potential link to the emergence of AMR. However, the lack of reliable data has still underestimated the magnitude of public health threat caused by antimicrobial usage in animals. In 1995 the Danish government became the first to establish a national surveillance programme called the Danish Integrated Antimicrobial Resistance Monitoring and Research Programme (DANMAP) with the aims to monitor the trend of antimicrobial usage and the prevalence of AMR in food-producing animals, identify the potential link between antimicrobial usage and AMR in food-producing animals and understand the route of transmission for it to occur and areas for future research. The animal data obtained from DANMAP mainly focus on pigs and cattle as they are the two major food-producing animals in Denmark. DANMAP 2015 report showed an approximately 13 tonnes of antimicrobial consumption or $12 \%$ of total antimicrobial consumption in food-producing animals used in cattle. This amount was just second to the antimicrobial consumption in pigs, which was $75 \%$ of the total antimicrobial consumption [35]. As the majority of antimicrobial usage in cattle is used to treat mastitis which occurs in dairy cattle, the administration of antimicrobials in dairy cattle increases every year while the same usage in the production of beef and veal remains at the same level [35]. In Denmark, the use of fluoroquinolones in animals is restricted as a last resort after the implementation of strict regulation in 2002. Since then, the usage of fluoroquinolones in food-producing animals including dairy cattle dropped drastically to $18 \mathrm{~kg}$ in 2005, compared to $114 \mathrm{~kg}$ in 2001 [36]. Despite the reduced usage of quinolones in cattle, there was an increase in quinolone-resistant infection caused by Campylobacter jejuni from 2006 to 2014. Besides, the use of tetracycline in the cattle remained the same in 2015 as in 2014, but the prevalence of tetracycline-resistant $C$. jejuni increased from 2014 to 2015 [35]. These suggested that antimicrobial usage in animals might not be the only factor causing the emergence of AMR in animals.

In the EU, after the prohibition of all growth-promoting antimicrobial usage in animals in 2006, a more thorough and detailed surveillance on other antimicrobial usage was required in order to identify the potential risk of causing AMR and 
optimize antimicrobial usage. Therefore, the European Medicines Agency (EMA) had launched the European Surveillance of Veterinary Antimicrobial Consumption (ESVAC) programme in 2009 to collect and report data on antimicrobial usage from its member states. A report on antimicrobial sales and usage will be published yearly to inform antimicrobial policy and responsible antimicrobial usage to its member states. The seventh ESVAC report, with 30 participating European countries, showed a drop of $13.4 \%$ in the sales of antibiotics for animal usage between 2011 and 2015 [37]. As third and fourth generation of cephalosporins are listed in the WHO CIA List, the dairy cattle production in the Netherlands had taken the initiative to prohibit the usage of such antimicrobials completely in drying off dairy cattle. This prohibition also applied in the pig sector, which resulted in both sectors contributing a significant drop of $98 \%$ in the sales of third- and fourth-generation cephalosporins from 2011 to 2015 in the Netherlands [37]. Also, surveillance conducted in 90 dairy farms in the same country also showed half of the farms have a below average and decreasing trend in antimicrobials usage between 2010 and 2012. The decrease in the trend of antimicrobial usage was due to the early detection of increasing trend in antimicrobial usage among dairy farmers before 2010 via the surveillance programmes, which then allowed local veterinarians to take action by spreading the awareness of antimicrobial usage in animals to the farmers [38]. In the UK dairy cattle sector, the Cattle Health and Welfare Group had conducted a study in 2015 to collect antibiotics usage data from dairy farmers in order to develop a more robust surveillance and monitoring system in the dairy sector in the future. The UK Veterinary Antibiotic Resistance and Sales Surveillance (UK-VARSS) 2015 report found that the sales of antibiotics for dairy cattle reduced by $6 \%$ between 2014 and 2015 [39]. However, an increase in sales by 18\% was shown between 2015 and 2016 in UK-VARSS 2016 [40]. A significant change in sales within the period of 1 year can suggest an increase in antibiotic usage in dairy farms, although the sales of antibiotics are generally an overestimate if to use in determining its usage in dairy farms. Thus, a new monitoring tool, known as the Nottingham University Dairy Antimicrobial Usage Calculator was developed in 2018 following a quantitative analysis on antimicrobial usage in the UK dairy herds [41] which allows dairy farmers to closely monitor the antibiotic usage in their herds.

Japan launched the Japanese Veterinary Antimicrobial Resistance Monitoring System (JVARM) in 1999 due to a lack of nationwide information on AMR in food-producing animals in Japan. The latest data from JVARM was published in the Nippon AMR One Health Report (NAOR) 2017, and it showed that antimicrobialresistant strains of Salmonella spp. and Escherichia coli were quite prevalent in diseased cattle from 2011 to 2015 in Japan [42]. Overall, the usage of veterinary antimicrobials showed a decreasing trend from 2009 to 2013, with tetracyclines being the most consumed antimicrobials in animals. In Malaysia, the Department of Veterinary Services Malaysia (DVS) and Ministry of Health are responsible in monitoring the antimicrobial usage in animals. However, there is still a lack of a more reliable, nationwide surveillance and monitoring system developed by the DVS to monitor antimicrobial usage in food-producing farms, including dairy farms to ensure the safety of livestock products for human consumption.

\section{AMR issue}

Antimicrobial-resistant infections that were only limited in the hospital or healthcare setting in the past have now become a primary public health threat that affects a wider community. The rapid and devastating spread of AMR to the community can be linked with the increasing usage of antimicrobials, as antimicrobials are no longer 
only being used in human medicine but also in veterinary medicine and agricultural sectors. In fact, agriculture could probably contribute to most of the antimicrobial consumption than medical usage due to the booming of agricultural industry in the past few years. The global antibiotic consumption in agriculture is estimated to be around 63,000 to 240,000 tonnes per year [43], but this is more likely to be an underestimate due to the poor monitoring and surveillance system on antimicrobial usage in many countries. A $67 \%$ increase in antimicrobial usage in agriculture from 2010 to 2030 is also estimated if the trends of antimicrobial usage continue [44].

Antimicrobial usage in animals, like in dairy cattle production, could lead to the potential resistant infections in humans. A report published in 2014 estimated a total of 700,000 people succumb to antimicrobial-resistant infections every year, and this will increase to 10 million by 2050 [45]. The main concern of antimicrobial usage in animals focuses on the possibility for the transfer of resistant bacterial strains from animals to humans to occur. Unrestricted and inappropriate usage of antimicrobials in animals can lead to selection pressure of antimicrobials in animals, as in the usage of antimicrobials in humans. Then, transfer of resistant strains from animals to humans allows resistant diseases to occur in humans. In dairy cattle production, this transfer can potentially occur via either direct contact on the infected sites or consumption of infected dairy products such as unpasteurized milk. Contamination of environmental reservoirs also allows the dissemination of resistant bacteria from dairy cattle to humans. Animal wastes that are excreted can contain resistant bacteria from the animal's gut and also unmetabolized antibiotics. Studies have suggested that $75-90 \%$ of the antibiotics used in animals might not be metabolized in the gut and then excreted out in the waste [46]. This will be an issue as the animal wastes containing resistant bacteria and antibiotics can enter to the sewage system or water sources, which aids the emergence of antimicrobial-resistant bacteria in the environment.

Antimicrobial usage in humans and animals often overlap as the infections are caused by the same or similar pathogens. Thirty-one of the 41 antimicrobials authorized for animal usage in the USA in 2012 were essential for human use [47]. Antibiotics that are being used extensively in the dairy farms to treat mastitis, such as penicillin, cephalosporin and tetracycline, are also important in treating the same pathogens in humans. Therefore, it is not surprising when AMR arises from the dairy herds causes increase morbidity and mortality in human population affected by the resistant pathogens due to the less effective antimicrobial treatment. Besides, the dual-use antimicrobials for humans and animals also show the lack of animalspecific antimicrobial for animal that will not threaten human health. In fact, it is not rational and practical to do so. Even if an antimicrobial for animals is successfully developed through animal research, there will always be a desire to make it for human usage due to the larger market for human antimicrobials. Even for human antimicrobials against infectious diseases, there has been a decline in investment and funding by the government and private sectors in the past few years. In the USA, less than 5\% (1.8 billion USD) of research and development funds in pharmaceutical sectors was invested in antimicrobial research between 2003 and 2013. This is largely due to the change in perception in most of the developed countries that prioritize more in non-communicable diseases like obesity and heart diseases, which are also one of the greatest challenges to public health. With the higher global usage of antimicrobials and slower development of new antimicrobials, we will soon run out of treatment options against these superbugs, risking ourselves to return to the pre-antibiotic era. It is already clearly evident when doctors are using the last resort treatment like carbapenem and colistin to treat resistant infections. Colistin, which has been avoided for years due to its potential renal-damaging effect, is now used as the real last resort for carbapenem-resistant infection, but cases with colistin resistance have started to emerge in recent years [48]. 
Another issue with AMR is the economic impact in the healthcare and agricultural sectors. Increased morbidity and mortality of infectious diseases lead to more economic burden [1-4]. By 2050, AMR will have an enormous cost of 100 trillion USD to the world economy, not to mention the 10 million deaths per year due to AMR [4]. With the emergence of AMR, other medical interventions that are dependent on the availability of effective antimicrobials for lower risk of complications will also be affected. Antimicrobial prophylactic measures cannot be taken in chemotherapy treatment, major surgeries and organ transplants, which can compromise the immune system and increase the risk of infection. These problems combined with other consequences of AMR can cumulatively contribute a total of 210 trillion USD by 2050 [45]. This looming global crisis, possess with threats to the healthcare and economy, needs to be considered carefully for action plans to be implemented.

\section{Solutions to AMR}

The medical consequences of antimicrobial usage in food animals were first recognized by the WHO in 1997 [5]. Since then, the WHO Global Principles, with the participation of FAO and OIE, and the WHO CIA List were established to provide recommendations in antimicrobial usage reduction in food animals and minimize the usage of medically important medicine for humans in food animals, respectively. Recognizing the increasing health threat caused by AMR, the 68th World Health Assembly adopted a global action plan in May 2015 to combat AMR and ensure the availability of quality-assured medicine for effective treatment and infectious disease prevention for as long as possible [49]. The global action plan has a variety of interventions, which focus on antimicrobial global awareness and surveillance as well as reducing its usage in tackling this global health threat. In line with the global action plan, it is crucial for other countries to make these as the primary focus when developing their national action plans in order to achieve the goals.

The first strategic objective set out in the global action plan is to improve the awareness and understanding of AMR in the public. The booming of agricultural sectors in recent years causes the farmers to become more eager in enhancing their farms' productivity. As a result, growth-promoting antimicrobials are used widely in food-producing animals to enhance animal growth without the intention to treat any infectious diseases. Although the EU had prohibited all growth-promoting antimicrobials in food-producing animals in 2006, other countries that are not in the EU are still actively practising antimicrobial usage for growth promotion due to the lack of political will to adopt new policies. Data from OIE shows that the Americas, with a few agricultural giant countries like the USA and Brazil, are by far the largest region buyer for growth-promoting antimicrobials in livestock [34]. Besides, the convenience of purchasing antimicrobials over the counter also leads to some unnecessary usage of antimicrobials in the healthcare. Therefore, with the increase in antimicrobial demands, both in the healthcare and agricultural sector, it is essential for the users to understand the proper antimicrobial usage and the consequences of unnecessary antimicrobial usage. To achieve the objective, a nationwide AMR awareness campaign that is globally consistent with its core message has to be designed to disseminate message regarding the issue of AMR, in a way that is tailored locally based on the national AMR action plan in each country. It is also crucial for the campaign to be able to convince users for a behaviour change regarding the usage of antimicrobials. Besides, making AMR issue a core component in getting qualification or certification in the veterinary or agricultural practice is also important to ensure the professionals from the fields are knowledgeable with the issue of AMR. 
Before making interventions or policies to tackle the emergence of AMR, a set of comprehensive and reliable data on the antimicrobial usage, AMR rate and biological mechanism of AMR in each country will be useful in determining its benefits and cost-effectiveness. Thus, the global action plan aims to strengthen the knowledge on AMR through surveillance and research. In line with it, OIE, with the support from FAO and WHO, will collect data on antimicrobial usage in animals. There are different levels in a surveillance system, with each level provides different information in improving patient health or delivering better health policies, thus serving as the basic foundation in disease management. Despite of its importance, many countries are still relying on poor surveillance system to monitor the antimicrobial usage in animals. Only $27 \%$ of the participating countries were able to provide quantitative data on antimicrobial usage in animals in a survey conducted by OIE in 2012 [34]. Besides, the surveillance system in most of the countries shows gaps in recoding and collecting information on AMR as there are no globally agreed standards for data collection and reporting. In line with the global action plan on AMR, the Global Antimicrobial Resistance Surveillance System (GLASS) was launched in 2015 to support this objective by providing a more standardized and harmonized approach in AMR data collection and recording as well as AMR data sharing at a global level. The rapid sharing of information on AMR globally on a regular basis will allow easier detection of AMR emergence and dissemination in other countries, thus minimizing the impact.

It is clearly evident that increased usage of antimicrobials leads to higher risk of AMR emergence. With more antimicrobial-resistant infections affecting the people, more antimicrobials will be required to enhance the treatment, thus forming a vicious cycle which exacerbates the consequences. Therefore, it is vital to break the chain of transmission in infectious diseases if we want to reduce the usage of antimicrobials and limit the development of antimicrobial-resistant strains. The global action plan of AMR aims to reduce the incidence of infection by improving sanitation, hygiene and infection prevention measures. These measurements can be done by instilling the right attitude to the people, just like in the pre-antibiotic era when preventive measures were prioritized due to treatment limitation. In the healthcare setting, better sanitation and handwashing are as important as disease treatment or patient isolation to prevent the spread of infectious diseases from patients to patients. On the other hand, this strict practice should be followed in the agricultural sectors, especially those involve with food processing to ensure the safety of the animal products. Investing in sewerage and sanitation infrastructure in the farms prevents contamination of the water sources by animal wastes that contain dangerous pathogens and unmetabolized antimicrobial leftovers [46]. This ensures adequate access to safe water for the population, which can also directly affect the sustainability of the economic growth in a country and the life expectancy of its people [4]. Besides, vaccination should be used as a preventive measure to induce immunity within a herd, which will lower the risk of infection and the need of antimicrobial treatment.

Reducing the usage of antimicrobials is indeed the primary solution to tackle AMR. It is essential to reduce the usage of antimicrobials now with the projected increase in its usage with high market demands in the next few years. While all the countries in the EU has enforced strict regulation in the usage of antimicrobials in animals like complete prohibition on growth-promoting antimicrobial usage in animals, many countries in America and Asia still lack of similar regulation to control antimicrobial usage in animals. Enforcing a globally agreed regulation will be challenging due to different political will, therefore the FAO, OIE and WHO tripartite collaboration [12] should continue providing international action and consultation in these countries to establish regulations in antimicrobial distribution 
and prescription, which also tailored to their national action plans on AMR. Along with this, the WHO CIA List of medically important antimicrobials [11] should be taken into account in controlling such antimicrobial usage in agriculture and their marketing authorization. Financial incentives can be provided to assist farmers with optimized antimicrobial usage in their farms. Besides, antimicrobial stewardship programmes should be implemented in healthcare and agricultural sectors to ensure users are always up to date with the right choice of antimicrobials.

The global action plan foresees the needs of increased investment in new medicines and other medical interventions to fight against antimicrobial-resistant pathogens if the current trends of antimicrobial usage and AMR emergence persist. The plan aims to develop an economic case for this sustainable investment in the relevant fields. To achieve this, economic assessments are needed to compare the required cost for implementation and the consequential cost of no action, and this should be focused primarily in the least developed and developing countries with restrained financial resources. A good sanitation investment can easily improve life expectancy of a population by ensuring access to clean water, which is less costly than disease prevention and treatment [4]. The World Bank can play a role in the tripartite collaboration to access the economic impacts, in order to convince the countries to support the global action plan. The lack of investment for the development of new antimicrobials will cause hindrance in combating AMR if it spreads uncontrollably. The rapid development of AMR in pathogens causing restrictive antimicrobial usage has led to fears in the pharmaceutical industries to increase investment in antimicrobial development. Most of the major pharmaceutical companies rather shift their interests to drug development in chronic diseases and cancer treatment with promising returns. To encourage their participation in antimicrobial research and development, collaborative public-private partnerships can be established to ensure renewed investment with mutually agreed, fair and equitable benefits to both parties. The new antimicrobials will need to be governed based on the antimicrobial stewardship principles to ensure its effectiveness for as long as possible. Affordability and applicability of the antimicrobials should be considered carefully to ensure equitable access in all the countries without the risk of exploitation.

\section{Conclusion}

Antimicrobial usage in food-producing animals is one of the factors that causes the emergence of AMR and should be prioritized when tackling the AMR issue. There should not be any doubt in determining the severity of using growth promoters in food-producing animals if we practice the proper antimicrobial stewardship, which promotes the appropriate usage of antimicrobials. Besides, all countries need to be on the same side to tackle this global health threat, and in order to achieve this, efforts from each country have to be in line with the WHO's global action plan on AMR, which focuses on improving public awareness, strengthening knowledge on AMR through surveillance, reducing incidence of AMR infection, optimizing antimicrobial usage and developing sustainable investment for new AMR interventions. Ultimately, these strategies will not totally prevent the emergence of AMR but will prolong the effectiveness of quality-assured antimicrobials and delay the development of resistant strains in pathogens.

\section{Conflict of interest}

The authors declare that there is no conflict of interest in the text. 


\section{Author details}

Enli Loo ${ }^{1}$, Kok Song Lai ${ }^{2}$ and Rozaihan Mansor ${ }^{3 *}$

1 Perdana University, Seri Kembangan, Selangor, Malaysia

2 Health Sciences Division, Abu Dhabi Women's College, Higher Colleges of Technology, Abu Dhabi, United Arab Emirates

3 Department of Farm and Exotic Animals Medicine and Surgery, Faculty of Veterinary Medicine, Universiti Putra Malaysia, UPM Serdang, Selangor, Malaysia

*Address all correspondence to: rozaihan@upm.edu.my

\section{IntechOpen}

(C) 2019 The Author(s). Licensee IntechOpen. This chapter is distributed under the terms of the Creative Commons Attribution License (http://creativecommons.org/licenses/ by/3.0), which permits unrestricted use, distribution, and reproduction in any medium, provided the original work is properly cited. (cc) BY 


\section{References}

[1] De Kraker ME, Davey PG, Grundmann H, BURDEN Study Group. Mortality and hospital stay associated with resistant Staphylococcus aureus and Escherichia coli bacteremia: Estimating the burden of antibiotic resistance in Europe. PLoS Medicine. 2011;8(10):e1001104. DOI: 10.1371/ journal.pmed.1001104

[2] Cosgrove SE. The relationship between antimicrobial resistance and patient outcomes: Mortality, length of hospital stay, and health care costs. Clinical Infectious Diseases. 2006;42(Supplement_2):S82-S89. DOI: $10.1086 / 499406$

[3] Eliopoulos GM, Cosgrove SE, Carmeli Y. The impact of antimicrobial resistance on health and economic outcomes. Clinical Infectious Diseases. 2003;36(11):1433-1437. DOI: $10.1086 / 375081$

[4] O’Neil J. Tackling Drug-Resistant Infections Globally: Final Report and Recommendations. London: Review on Antimicrobial Resistance; 2016

[5] World Health Organization. The Medical Impact of the Use of Antimicrobials in Food Animals: Report of a WHO Meeting, Berlin, Germany, 13-17 October 1997. Geneva: World Health Organization; 1997

[6] Carattoli A. Animal reservoirs for extended spectrum $\beta$-lactamase producers. Clinical Microbiology and Infection. 2008;14(s1):117-123. DOI: 10.1111/j.1469-0691.2007.01851.x

[7] Silbergeld EK, Graham J, Price LB. Industrial food animal production, antimicrobial resistance, and human health. Annual Review of Public Health. 2008;29:151-169. DOI: 10.1146/annurev. publhealth.29.020907.090904

[8] Srinivasan V, Nam HM, Sawant AA, Headrick SI, Nguyen LT, Oliver SP.
Distribution of tetracycline and streptomycin resistance genes and class 1 integrons in Enterobacteriaceae isolated from dairy and nondairy farm soils. Microbial Ecology. 2008;55(2):184-193

[9] Call DR, Davis MA, Sawant AA. Antimicrobial resistance in beef and dairy cattle production. Animal Health Research Reviews. 2008;9(2):159-167. DOI: $10.1017 / \mathrm{S} 1466252308001515$

[10] Verraes C, Van Boxstael S, Van Meervenne E, Van Coillie E, Butaye P, Catry B, et al. Antimicrobial resistance in the food chain: A review. International Journal of Environmental Research and Public Health. 2013;10(7):2643-2669. DOI: 10.3390/ ijerph10072643

[11] World Health Organization. Critically Important Antimicrobials for Human Medicine: Ranking of Antimicrobial Agents for Risk Management of Antimicrobial Resistance Due to Non-human Use. Geneva: World Health Organization; 2017

[12] FAO, OIE, WHO. The FAOOIE-WHO Collaboration: Sharing responsibilities and coordinating global activities to address health risks at the animal-human-ecosystems interfaces. A Tripartite Concept Note. Geneva: World Health Organization; 2010

[13] World Organisation for Animal Health. The OIE Strategy on Antimicrobial Resistance and the Prudent Use of Antimicrobials. Paris: World Organisation for Animal Health; 2016

[14] Ministry of Health, Malaysia, Ministry of Agriculture and Agro-Based Industry, Malaysia. Malaysian Action Plan on Antimicrobial Resistance (MyAP-AMR) 2017-2021. Putrajaya: Ministry of Health Malaysia; 2017

[15] Hao H, Cheng G, Iqbal Z, Ai X, Hussain HI, Huang L, et al. Benefits 
and risks of antimicrobial use in food-producing animals. Frontiers in Microbiology. 2014;5:288. DOI: $10.3389 /$ fmicb.2014.00288

[16] Hughes P, Heritage J. Antibiotic growth-promoters in food animals. In: FAO Animal Production and Health Paper. 2004. pp. 129-152

[17] Herago T, Agonafir A. Growth promoters in cattle. Advances in Biological Research. 2017;11(1):24-34

[18] De Briyne N, Iatridou D. Antimicrobial use in food-producing animals: Replies to EFSA/EMA questions on the use of antimicrobials in food-producing animals in EU and possible measures to reduce antimicrobial use. Brussels: Federation of Veterinarians of Europe; 2016

[19] Halasa T, Huijps K, Østerås O, Hogeveen $\mathrm{H}$. Economic effects of bovine mastitis and mastitis management: A review. Veterinary Quarterly. 2007;29(1):18-31. DOI: $10.1080 / 01652176.2007 .9695224$

[20] Rollin E, Dhuyvetter KC, Overton MW. The cost of clinical mastitis in the first 30 days of lactation: An economic modeling tool. Preventive Veterinary Medicine. 2015;122(3):257-264. DOI: 10.1016/j. prevetmed.2015.11.006

[21] Heikkilä AM, Nousiainen JI, Pyörälä S. Costs of clinical mastitis with special reference to premature culling. Journal of Dairy Science. 2012;95(1):139-150. DOI: $10.3168 /$ jds.2011-4321

[22] Huijps K, Lam TJ, Hogeveen H. Costs of mastitis: Facts and perception. Journal of Dairy Research. 2008;75(1):113-120. DOI: 10.1017/ S0022029907002932

[23] Barlow J. Mastitis therapy and antimicrobial susceptibility: A multispecies review with a focus on antibiotic treatment of mastitis in dairy cattle. Journal of Mammary Gland Biology and Neoplasia. 2011;16(4):383-407

[24] McDougall S, Macaulay R, Compton C. Association between endometritis diagnosis using a novel intravaginal device and reproductive performance in dairy cattle. Animal Reproduction Science. 2007;99(1-2):9-23. DOI: 10.1016/j.anireprosci.2006.03.017

[25] Gilbert RO, Shin ST, Guard CL, Erb HN, Frajblat M. Prevalence of endometritis and its effects on reproductive performance of dairy cows. Theriogenology. 2005;64(9):1879-1888. DOI: 10.1016/j. theriogenology.2005.04.022

[26] Rose SG, Swinkels JM, Kremer WD, Kruitwagen CL, Zadoks RN. Effect of penethamate hydriodide treatment on bacteriological cure, somatic cell count and milk production of cows and quarters with chronic subclinical Streptococcus uberis or Streptococcus dysgalactiae infection. Journal of Dairy Research. 2003;70(4):387-394. DOI: 10.1017/ S0022029903006460

[27] USDA. Antibiotic Use on US Dairy Operations, 2002 and 2007. Fort Collins, CO: USDA; 2008. p. 5

[28] Berry EA, Hillerton JE. The effect of selective dry cow treatment on new intramammary infections. Journal of Dairy Science. 2002;85(1):112-121. DOI: 10.3168/jds. S0022-0302(02)74059-9

[29] Courtheyn D, Le Bizec B, Brambilla G, De Brabander HF, Cobbaert E, Van, de Wiele M, et al. Recent developments in the use and abuse of growth promoters. Analytica Chimica Acta. 2002;473(1-2):71-82. DOI: 10.1016/ S0003-2670(02)00753-5

[30] Jukes TH, Williams WL. Nutritional effects of antibiotics. Pharmacological Reviews. 1953;5(4):381-420 
[31] Chattopadhyay MK. Use of antibiotics as feed additives: A burning question. Frontiers in Microbiology. 2014;5:334. DOI: 10.3389/ fmicb.2014.00334

[32] Phillips I, Casewell M, Cox T, De Groot B, Friis C, Jones R, et al. Does the use of antibiotics in food animals pose a risk to human health? A critical review of published data. Journal of Antimicrobial Chemotherapy. 2004;53(1):28-52. DOI: 10.1093/jac/ dkg483

[33] Wallinga D, Burch DG. Does adding routine antibiotics to animal feed pose a serious risk to human health? The BMJ. 2013;347:f4214. DOI: 10.1136/bmj.f4214

[34] World Organisation for Animal Health. OIE Annual Report on the Use of Antimicrobial Agents in Animals. Paris: World Organisation for Animal Health; 2016

[35] Bager F, Birk T, Høg BB, Jensen LB, Jensen AN, de Knegt L, Korsgaard H. DANMAP 2014- Use of Antimicrobial Agents and Occurrence of Antimicrobial Resistance in Bacteria from Food Animals, Food and Humans in Denmark. Copenhagen: Danish Ministry of Food, Agriculture and Fisheries and Danish Ministry of Health; 2015

[36] Agersø Y, Emborg HD, Heur OE, Jensen VF, Seyfarth AM, Hammerum AM, Bagger-Skjøt L, Rogues AM, Brandt C, Skov RL, Monnet DL. DANMAP 2005-Use of Antimicrobial Agents and Occurrence of Antimicrobial Resistance in Bacteria from Food Animals, Foods and Humans in Denmark. Copenhagen: Danish Ministry of Food, Agriculture and Fisheries and Danish Ministry of Health; 2006

[37] European Medicines Agency. Sales of Veterinary Antimicrobial Agents in 30 European Countries in 2015. London: European Medicines Agency; 2017
[38] Kuipers A, Koops WJ,

Wemmenhove H. Antibiotic use in dairy herds in the Netherlands from 2005 to 2012. Journal of Dairy Science. 2016;99(2):1632-1648. DOI: 10.3168/ jds.2014-8428

[39] Veterinary Medicines Directorate. UK Veterinary Antibiotic Resistance and Sales Surveillance Report (UK-VARSS 2015). London: Veterinary Medicines Directorate; 2016

[40] Veterinary Medicines Directorate. UK Veterinary Antibiotic Resistance and Sales Surveillance Report (UK-VARSS 2016). London: Veterinary Medicines Directorate; 2017

[41] Hyde RM, Remnant JG, Bradley AJ, Breen JE, Hudson CD, Davies PL, et al. Quantitative analysis of antimicrobial use on British dairy farms. Veterinary Record. 2017;181(25):683. DOI: 10.1136/ vr.104614

[42] The AMR One Health Surveillance Committee. Nippon AMR One Health Report (NAOR) 2017. Tokyo: Tuberculosis and Infectious Diseases Control Division, Health Services Bureau, Ministry of Health, Labour and Welfare; 2017

[43] Grace D. Review of Evidence on Antimicrobial Resistance and Animal Agriculture in Developing Countries. London: Department of International Development; 2015. DOI: 10.12774/ eod_cr.june2015.graced

[44] Van Boeckel TP, Brower C, Gilbert M, Grenfell BT, Levin SA, Robinson TP, et al. Global trends in antimicrobial use in food animals. Proceedings of the National Academy of Sciences. 2015;112(18):5649-5654. DOI: 10.1073/pnas.1503141112

[45] O’Neil J. Antimicrobial Resistance: Tackling a Crisis for the Future Health and Wealth of Nations. London: Review on Antimicrobial Resistance; 2014 
[46] Marshall BM, Levy SB. Food animals and antimicrobials: Impacts on human health. Clinical Microbiology Reviews. 2011;24(4):718-733. DOI: 10.1128/CMR.00002-11

[47] Food and Drug Administration. Summary Report on Antimicrobials Sold or Distributed for Use in FoodProducing Animals. Maryland: Food and Drug Administration; 2012

[48] Liu YY, Wang Y, Walsh TR, Yi LX, Zhang R, Spencer J, et al. Emergence of plasmid-mediated colistin resistance mechanism MCR-1 in animals and human beings in China: A microbiological and molecular biological study. The Lancet Infectious Diseases. 2016;16(2):161-168. DOI: 10.1016/S1473-3099(15)00424-7

[49] World Health Organization. Global Action Plan on Antimicrobial Resistance. Geneva: World Health Organization; 2015 



\title{
Importance of Socio-Economic and Institutional Factors in the Use of Veterinary Services by the Smallholder Dairy Farmers in Punjab
}

\author{
Shiv Raj Singh, Kamal Kumar Datta \\ and Supern Singh Shekhawat
}

\begin{abstract}
The study has shown the importance of identifying factors that determined the likelihood of using veterinary services in Punjab. Secondary data were used for analysis with the sample size of 1137 dairy households. Estimates of factors influencing the use of veterinary services are reasonably consistent with the farmer decision to use it. The proportional relationship between veterinary services available within the village and use of veterinary services revealed that, distance of veterinary service availability positively influenced the farmer decision to use the veterinary services. There was a positive relationship between herd size and use of veterinary services. More educated farmers are in a better position to use the veterinary services. The principal source of income from agricultural activities was positively influenced by the likelihood to use veterinary services in study area. The model from empirical point of view is very important to predict whether household will be using the veterinary services or not after incorporating the value of the explanatory variables.
\end{abstract}

Keywords: socio-economic, institutions, veterinary services, commercialization, logit

\section{Introduction}

The livestock sector in Punjab contributes 33.38\% to agricultural gross domestic product (GDP), and 7.91\% to state GDP [1]. This indicates that livestock sector is one of the important sectors in the state economy. As per Pingali and Rosegrant [2] "Agricultural commercialization means more than the marketing of agricultural output, it means the product choice and input use decisions are based on the principles of profit maximization". In the same pattern, commercialization of dairy farming involves orientation towards marketing of milk and use inputs more intensively for dairy farming. In dairy farming, four inputs viz. feed, fodder, labor and veterinary services are very important. The smooth transition from subsistence to commercial dairy farming is possible only if well integrated markets exist for the input and output. 
Veterinary services are one of the important inputs for dairy farming. Dairy farmers face different socioeconomic circumstances in their own setting, which are likely to cause differences in the attitudes towards the available alternatives [3]. Other than socio-economic factor in the dairy farming, institutional arrangement play pivotal role for service delivery system. The main reason for carrying out this study was to understand the socio-economic and institutional factors, which influence the decision for use of veterinary service. The objective of the study was, therefore, to assess important factors that determined the use of veterinary services by dairy farmers in Punjab.

\section{Materials and methods}

\subsection{Source of data}

The study is based on the secondary data, available from National Sample Survey Organization (NSSO) on "Situation Assessment Survey of Farmers", in the year 2003 (visit-1). Situation assessment survey of farmers was conducted (rural sector) in two rounds, i.e. visit-1 (January-August, 2003) and another was visit-2 (September-December, 2003). The visit-1 encompasses detailed information on socio-economic, crop husbandry, animal husbandry, access to basic and modern farming resources, and consumption expenditure of Indian farmers.

This particular survey focused on the rural area by keeping rural farm households as the unit of observations. The sampling design used in the NSS data was stratified multi-stage random sampling with districts as strata, villages as first stage units and farm households as the second stage units. Based on stratified multi-stage sampling design, the survey covered 51,771 sample households at all India level, out of which 1137 sample comprised Punjab's households belonging to dairy farming who reared at least one milch dairy animal.

\subsection{Modeling}

Both descriptive statistics and econometric methods were employed for the data analysis. In this study, a logit model was estimated to determine the factors which made the dairy farmers to decide upon the use veterinary services. Veterinary services include artificial insemination, vaccination and treatment of animals. When the dependent variable is a $0-1$ binary variable, the logit or probit model estimation methods can be used. To predict the dependent variable, the farmers were classified into two groups, who used veterinary services and who did not use. The logit model is specified below.

$P_{i}=\frac{1}{1+e^{-z i}}$, where $P_{i}$ is the probability that farmer used veterinary services.

$1-P_{i}=1-\frac{1}{1+e^{-z i}}$, where $1-P_{i}$ is the probability that farmer do not use veterinary services.

$$
\text { The Odd"s ratio }=\left(\frac{P_{i}}{1-P_{i}}\right)=e^{z i} \text {. }
$$

Taking logarithm on both sides,

$$
\operatorname{Ln}\left(\frac{P_{i}}{1-P_{i}}\right)=Z_{i}=\alpha+\beta_{i} \chi_{i}+e_{i}
$$

Where, $\alpha=$ intercept, $\beta=$ vector of response coefficient, $e=$ vector of random disturbance and $X_{i}$ is the set of explanatory variables. 
The binary logistic regression has widely been used to address decision involving binary choice in adoption studies [4]. In this study, the following model was used:

vet_service $=\beta_{0}+\beta_{1}$ village $+\beta_{2}$ family size $+\beta_{3}$ socially forward $+\beta_{4}$ land holding $+\beta_{5}$ principal income $+\beta_{6}$ training $+\beta_{7}$ literate $+\beta_{8}$ like agri. $+\beta_{9}$ herd size + $\beta_{10}$ agri.science centre $+\beta_{11}$ extension workers $+\beta_{12}$ literate ${ }^{*}$ herd size $+\varepsilon_{i}$

where, vet_service is the veterinary service used by the farmers, while $\beta_{1}, \ldots, \beta_{12}$ are coefficients associated with each explanatory variable and $\varepsilon_{\mathrm{i}}$ is the error term. Several factors were hypothesized to influence the farmers' decision to use the veterinary services. The description of these factors is presented in Table 1. The choice of these explanatory variables was mainly based on the general working hypothesis and partly on empirical findings from literature, and, therefore, a positive or negative sign was assigned depending on the potential influence of a particular variable on use of veterinary services.

The marginal probability was calculated by multiplying the coefficient estimate by logit function, by the standard probability density function of the logit model evaluated at the mean values of the explanatory variables. For dichotomous explanatory variables with a value of zero or one, the marginal probability was calculated as the difference arising from standard probability density function for explanatory variable value zero or one for the discrete variable [3].

Interaction terms are used extensively in nonlinear models, such as logit model. Unfortunately, the intuition from linear regression models does not extend to nonlinear models. The marginal effect of a change in both interacted variables (specially, when herd size is continuous variable and literacy is binary variable) is not equal to the marginal effect of changing just the interaction term. More surprisingly, the sign may be different for different observations. The statistical

\begin{tabular}{|c|c|c|}
\hline Variables & Description of the variables & $\begin{array}{l}\text { Expected } \\
\text { signs }\end{array}$ \\
\hline \multicolumn{3}{|l|}{ Dependent variable } \\
\hline Vet_service & Veterinary service used yes $=1$, no $=0$ & \\
\hline \multicolumn{3}{|l|}{ Explanatory variables } \\
\hline Village & Veterinary services available within the village $=1$, otherwise $=0$ & + \\
\hline Family size & Family size $(1-5)=1$, otherwise $=0$ & + \\
\hline Socially forward & Socially forward (general and $\mathrm{OBC})=1$, otherwise $=0$ & + \\
\hline Land holding & Land holding (ha.) (continuous) & + \\
\hline Principal income & Principal source of income from agriculture $=1$, otherwise $=0$ & \pm \\
\hline Training & $\begin{array}{l}\text { Head of household attended any formal training in } \\
\text { agriculture }=1 \text {, otherwise }=0\end{array}$ & + \\
\hline Literate & Literate head of households $=1$, otherwise $=0$ & + \\
\hline Like agri. & Farmer likes agriculture as a profession $=1$, otherwise $=0$ & + \\
\hline Herd size & Herd size of milch dairy animals (continuous) & + \\
\hline Agri. science centre & Whether accessed Agriculture Science Centre $=1$, otherwise $=0$ & + \\
\hline Extension workers & Whether accessed extension workers $=1$, otherwise $=0$ & + \\
\hline Literate ${ }^{*}$ herd size & $\begin{array}{l}\text { Interaction of literacy of head of household and herd size of } \\
\text { milch dairy animals }\end{array}$ & + \\
\hline
\end{tabular}

Table 1.

Description of dependent and explanatory variables used in the analysis and the expected signs. 
significance cannot be determined from the Z-statistic reported in the regression output. Ai and Norton [5] showed that the coefficients for such interaction terms, their signs and their significance levels may all be incorrect when using nonlinear models. Ai and Norton [5] suggested a method to overcome this problem. When one continuous variable and one dummy variable are interacted, the interaction effect is the discrete difference of the single derivative. They also derived the standard errors for the interaction effect in logit models, applying the delta method.

Multicollinearity can undermine the statistical integrity of the model. Multicollinearity in logit models is a result of strong correlations between independent variables. The Variance Inflation Factor (VIF) is generally used to detect the multicollinearity in binary models. In the logit models often VIF value above the 2.5 considered as cut off point for multicollinearity detection [6]. In our analysis only two variables i.e. self-employed in agriculture $(\mathrm{VIF}=3.57)$ and principal source of income from agriculture (3.21) are collinear on the basis of value of VIF and we drop self-employed in agriculture variable from the analysis. The resultant value of VIF for principal source of income from agriculture was 1.62 in the permissible limit.

\section{Results and discussion}

\subsection{Important dairy farmers characteristics}

Descriptive statistics on dairy farmers' characteristics are presented in Table 2. Among overall 1.65 million dairy farmers, $70.91 \%$ dairy farmers used veterinary services in the survey period. Around $43.64 \%$ dairy farmers were able to access veterinary services within the village itself. Half of dairy farmer household size (number of persons) was between 1 and 5. Large number (52.73\%) of dairy farmers were self-employed in agriculture with the average land holding size of 1.55 ha. However, 56.97\% dairy farmers' principal source of income was agriculture alone. Head of the family played an important role in decision making process and hence, it is very important to study important characteristics of dairy households' heads. From Table 2, it is reflected that $47.88 \%$ heads of dairy households were literate but less than $1 \%$ head of households had training in agriculture. In the survey, $61.21 \%$ dairy farmers admitted that they liked agriculture as a profession. Average herd size (number of animals) of milch animal per dairy farmer was about 3.51. Access to Agriculture Science Centre (Krishi Vigyan Kendra) and contact with extension workers may be proxies for access to information. From Table 2, it is reflected that only fraction $(0.95 \%)$ of dairy farmers access the Agriculture Science Centre, personally. However, extension worker's contact with the dairy farmers is somehow satisfactory.

\subsection{Factor(s) influencing the choice of veterinary services}

Empirical estimates derived from the binary logit model are presented in Table 3. Empirical estimate signs correspond as depicted in Table 1. Given that the model included several binary variables, the chosen level of statistical significance was 1 and 5\%. Out of 12 influential factors 4 are statistically significant at 1 and $5 \%$ level of significance.

The Odds ratio is useful to determine the number of dairy farmers who used veterinary services. The Odds ratio is defined as the ratio of probability that dairy farmers used veterinary services to that of who did not use veterinary services. As number of dairy farmers in the sample is 1137 and 777 farmers are used veterinary 
Importance of Socio-Economic and Institutional Factors in the Use of Veterinary Services...

DOI: http://dx.doi.org/10.5772/intechopen.82310

\begin{tabular}{lcc}
\hline Characteristics & Number & Percentage \\
\hline Sample households (million) & 1.65 & \\
\hline Veterinary services used (million) & 1.17 & 70.91 \\
\hline Veterinary services available within the village (million) & 0.72 & 43.64 \\
\hline Family size (1-5) (million) & 0.86 & 51.12 \\
\hline Self-employed in agriculture (million) & 0.87 & 52.73 \\
\hline Socially forward (million) & 1.17 & 70.91 \\
\hline Average land holding (ha.) & 1.55 & \\
\hline Principal source of income from agriculture (million) & 0.94 & 56.97 \\
\hline Head of household attended any formal training in agriculture (thousand) & 16.15 & 0.98 \\
\hline Literate head of households (million) & 0.79 & 47.88 \\
\hline Farmer likes agriculture as a profession (million) & 1.01 & 61.21 \\
\hline Average herd size of milch dairy animals (no.) & 3.51 & \\
\hline Whether accessed Agriculture Science Centre (thousand) & 15.65 & 0.95 \\
\hline Whether accessed extension workers (thousand) & 34.47 & 2.09 \\
\hline${ }^{*}$ Figures in percentage indicate percentage to sample households. & & \\
\hline
\end{tabular}

Table 2.

Selected institutional and socio-economic characteristics of dairy farmers using veterinary services.

\begin{tabular}{|c|c|c|c|c|}
\hline Characteristics $^{\mathrm{b}}$ & Coefficients $^{\mathrm{a}}$ & S. E. & $\mathrm{Z}$ & $\mathbf{P}>\mathrm{Z}$ \\
\hline Veterinary services available within the village & 0.3896 & 0.1346 & 2.89 & $0.004^{* * *}$ \\
\hline Family size (1-5) & -0.1606 & 0.1366 & -1.18 & 0.24 \\
\hline Socially forward & -0.1353 & 0.1619 & -0.84 & 0.403 \\
\hline Land holding & 0.03844 & 0.0424 & 0.91 & 0.365 \\
\hline Principal source of income from agriculture & 0.578 & 0.1715 & 3.37 & $0.001^{* * *}$ \\
\hline $\begin{array}{l}\text { Head of household attended any formal } \\
\text { training in agriculture }\end{array}$ & -0.4072 & 0.6669 & -0.61 & 0.541 \\
\hline Literate head of households & 0.5338 & 0.232 & 2.3 & $0.021^{* *}$ \\
\hline Farmer likes agriculture as a profession & -0.0837 & 0.1478 & -0.57 & 0.571 \\
\hline Herd size of milch dairy animals & 0.1143 & 0.0476 & 2.4 & $0.016^{* *}$ \\
\hline Whether accessed Agriculture Science Centre & -0.3964 & 0.7081 & -0.56 & 0.576 \\
\hline Whether accessed extension workers & 0.7937 & 0.7276 & 1.09 & 0.275 \\
\hline $\begin{array}{l}\text { Interaction of literacy of head of household and } \\
\text { herd size of milch dairy animals }\end{array}$ & 0.0076 & 0.0625 & 0.12 & 0.903 \\
\hline Constant & 1.1764 & 0.7976 & 1.47 & 0.14 \\
\hline \multicolumn{5}{|c|}{$\begin{array}{l}{ }^{a} n=1137, \text { Log likelihood }=-661.21, \text { LR }_{\text {chi }}{ }^{2}(12)=97.24, \text { Prob }>\text { chi }{ }^{2}=0.0000, \text { Pseudo } R^{2}=0.0685 . \\
{ }^{b} \text { Significant at } 1 \%\left({ }^{* * *}\right) \text { and } 5\left({ }^{* *}\right) \text {. }\end{array}$} \\
\hline
\end{tabular}

Table 3.

Binary logit model coefficient estimates for determinants of farmers' use of veterinary services.

services, the probability $(P)$ that a farmer is used veterinary services can be computed as $P=\frac{777}{1137}=0.68$. The probability $(1-P)$ that a farmer is not used veterinary services is $1-P=0.32$. Given $P$, the Odds ratio $(\mathrm{O})$ can be derived as $\mathrm{O}=\frac{P}{1-P}=\frac{0.68}{0.32}=2.13$; it means if one farmers choose not to use veterinary services, then more than two farmers used veterinary services. 
The observed proportional relationship between veterinary services available within the village and use of veterinary services implied that distance of availability positively influenced the farmer's decision. The positive relationship was observed between literacy levels of family head and use of veterinary services. It implied that improving the literacy level of dairy households would increase the likelihood of veterinary service usage. Farmers who kept large number of dairy animals were more particular on use of veterinary services. In reality, farmers with large herds are relatively cautious regarding the use of veterinary services since this has economic implications on their enterprises. This also indicates that as commercial dairy farming increases it opens up new opportunities for veterinary doctors. The interaction term of educated head of households and herd size is positively related with the use of veterinary services but non-significant (Z-statistic is 0.12 ). The non-significance of interaction term implies that persons who are educated and have large herd size are not likely to use veterinary services. In case of few observations, the interaction effect is statistically significant, which are smaller in number whereas, it is nonsignificant for large number (Figure 1). However, after estimating the interaction effect, we learned that mean interaction effect is negative $(-0.0028)$ and varies widely. The principal source of income from agriculture positively influenced the likelihood to use veterinary services in study area. It is indicated that as the income from agriculture increased demand for veterinary services also increased.

Table 4 presents marginal effect for the variables, which were presented in Table 3 with significant coefficients for the use of veterinary services. These probabilities show how changes in specific variables affected the probabilities of a dairy farmers reacting positively towards use of veterinary services. Marginal effect computed for continuous variables were not comparable with those computed for binary variables. The prediction probability of model was very high (0.71) for the use of veterinary services. The dairy farmer's response towards the use of veterinary services was highly influenced $(12.05 \%)$ by the unit increase in income from agricultural activities. The result of marginal effect also indicated that, the unit increase in the literacy level of the family head increased the probability of veterinary services use by $11.05 \%$. The next most influential variable was increase in veterinary services availability in the villages which enhanced the probability by $8.07 \%$ for the use of veterinary services.

This study has shown the importance of identifying factors that determine the likelihood of using veterinary services by dairy farmers in Punjab. Descriptive analysis revealed that, for the majority of dairy farmers the principal source of income was agriculture and they possessed small landholding. Dairy farming offers an opportunity to these marginalized famers to diversify farming business and to secure livelihood. Based on the logit model, dairy farmers using veterinary services were classified as following: dairy farmers having more likelihood of using veterinary services had large herd size. The proportional relationship between veterinary services available within the village and use of veterinary services implied that distance of veterinary service availability positively influenced the farmer decision to use the veterinary services. Therefore, the number of veterinary institutions delivering veterinary services should be increased at village level. The positive relationship was observed between literacy levels of family head and use of veterinary services. It implied that improving the literacy level of dairy households increased the likelihood to use veterinary services. The principal source of income from agriculture positively influenced the likelihood of veterinary service use by dairy farmers. It is indicated that as the income from agriculture activity increased the dairy farmers more likely used veterinary 
Importance of Socio-Economic and Institutional Factors in the Use of Veterinary Services... DOI: http://dx.doi.org/10.5772/intechopen.82310

services. Those dairy farmers who were self-employed in agricultural activities were more potent to the use of veterinary services in the Punjab. The model from empirical point of view is very important to predict whether household will be using the veterinary services or not after incorporating the value of the explanatory variables. With the given set of NSSO data, the predicted model showed that $71 \%$ of the farmers used the veterinary services as one of the important input in order to commercialize dairy farming.

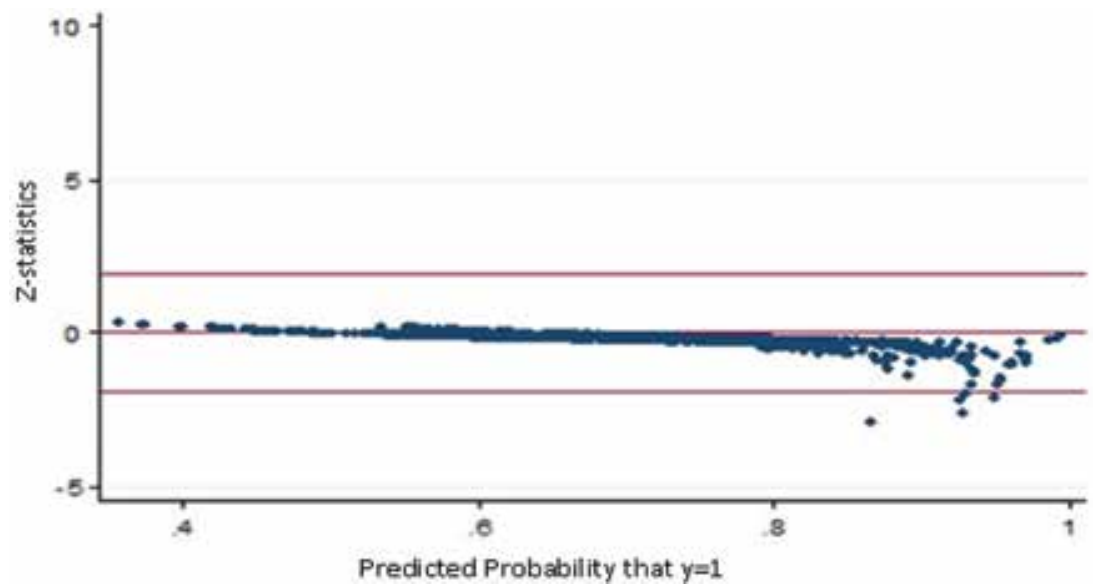

Figure 1.

Z-statistics of interaction effect (literacy of head of household and herd size of milch dairy animals) after logit.

\begin{tabular}{lcccc}
\hline Characteristics $^{\mathbf{a}}$ & $\begin{array}{c}\text { Marginal } \\
\text { effect }\end{array}$ & S. E. & Z & P $>$ Z \\
\hline Veterinary services available within the village & 0.0807 & 0.02757 & 2.93 & $0.003^{* * *}$ \\
\hline Family size (1-5) & -0.0334 & 0.02838 & -1.18 & 0.239 \\
\hline Socially forward & -0.0279 & 0.0331 & -0.84 & 0.398 \\
\hline Land holding & 0.008 & 0.0088 & 0.91 & 0.364 \\
\hline Principal source of income from agriculture & 0.1205 & 0.0357 & 3.38 & $0.001^{* *}$ \\
\hline $\begin{array}{l}\text { Head of household attended any formal training in } \\
\text { agriculture }\end{array}$ & -0.091 & 0.1578 & -0.58 & 0.564 \\
\hline Literate head of households & 0.1105 & 0.0476 & 2.32 & $0.021^{* *}$ \\
\hline Farmer likes agriculture as a profession & -0.0174 & 0.0306 & -0.57 & 0.57 \\
\hline Herd size of milch dairy animals & 0.0238 & 0.0099 & 2.4 & $0.016^{* *}$ \\
\hline Whether accessed Agriculture Science Centre & -0.0885 & 0.167 & -0.53 & 0.596 \\
\hline Whether accessed extension workers & 0.1373 & 0.0996 & 1.38 & 0.168 \\
\hline $\begin{array}{l}\text { Interaction of literacy of head of household and herd } \\
\text { size of milch dairy animals }\end{array}$ & 0.0016 & 0.013 & 0.12 & 0.903 \\
\hline
\end{tabular}

Marginal effects after logit $y=$ Prob. (whether used veterinary services yes $=1)$ (predict) $=0.71$.

${ }^{a}$ Significant at $1 \%\left({ }^{* * *}\right)$ and $5\left({ }^{* *}\right)$.

Table 4.

Marginal effects of explanatory variables on the probability of veterinary services used. 


\section{Author details}

Shiv Raj Singh ${ }^{1 *}$ Kamal Kumar Datta ${ }^{2}$ and Supern Singh Shekhawat ${ }^{3}$

1 Department of Agricultural Economics, C.P. College of Agriculture,

S.D. Agricultural University, Gujarat, India

2 Agri Business Management, Central Agricultural University,

School of Post Graduate Studies, Meghalaya, India

3 Krishi Vigyan Kendra, Kotputli, Sri Karan Narendra Agriculture University, Jobner, Jaipur, Rajasthan, India

*Address all correspondence to: shivagritech2007@gmail.com

\section{IntechOpen}

(C) 2020 The Author(s). Licensee IntechOpen. This chapter is distributed under the terms of the Creative Commons Attribution License (http://creativecommons.org/licenses/ by/3.0), which permits unrestricted use, distribution, and reproduction in any medium, provided the original work is properly cited. (cc) BY 
Importance of Socio-Economic and Institutional Factors in the Use of Veterinary Services...

DOI: http://dx.doi.org/10.5772/intechopen.82310

\section{References}

[1] Economic Survey, Economic and Statistical Organization. Government of Punjab; 2009-10

[2] Pingali PL, Rosegrant MW.

Agricultural commercialization and diversification: Processes and policies. Food Policy. 1995;20(3):171-185

[3] Tambi NE, Mukhebi WA, Maina WO, Solomon HM. Probit analysis of livestock producers' demand for private veterinary services in the high potential agricultural areas of Kenya. Agricultural Systems. 1999;59(2):163-176

[4] Suresh A, Gupta DC, Solanki MR, Mann JS, editors. Reducing the risk in livestock production: Factors influencing the adoption of vaccination against bovine diseases. Indian Journal of Agriculture Economics. 2007;62(3):483-491

[5] Ai C, Norton EC. Interaction terms in logit and probit models. Economics Letters. 2003;80(1):123-129

[6] Allison P. Comparing logit and probit coefficients across groups. Sociological Methods and Research. 1999;28(2):186-208 



\title{
Veterinary Pharmaceuticals and Antimicrobial Resistance in Developing Countries
}

\author{
Meseko Clement, Makanju Olabisi, Ehizibolo David \\ and Muraina Issa
}

\begin{abstract}
Veterinary pharmaceuticals include a wide range of anti-infectives and additives in the use for animal health, nutrition, reproduction, and productivity. Antimicrobials are among the most extensively used drugs in developing countries largely due to large population of livestock and the burden of infectious diseases. The introduction of penicillin in 1943 and other antibiotics thereafter provided remedies for many infections in humans and animals, reducing mortality and productivity losses. Since then, a repertoire of antibiotics and antimicrobials has been introduced as chemotherapeutics and/or prophylaxis. This success notwithstanding, many pathogens of consequences are no longer susceptible owing to emergence of antimicrobial-resistant (AMR) microorganisms. This has made treatment of infectious diseases less effective. Beside spontaneous emergence of mutant microorganisms, scientists are wary of AMR caused by intensive use of antibiotics in humans and animals, sometimes in subtherapeutic doses as preventive medicine. In developing countries, environmental exposure and persistent use of antibiotics in food animals may leave residues in the food chain. The consequences include development of AMR. In this chapter, we reviewed antimicrobial use in veterinary medicine and sequela in the emergence of AMR and described the imperative of antimicrobial stewardship in veterinary practice to combat AMR in developing countries.
\end{abstract}

Keywords: veterinary drugs, antimicrobial resistance, stewardship, developing countries

\section{Introduction: veterinary pharmaceuticals and antimicrobials}

Veterinary pharmaceuticals include drugs, medications, and other substances in use to treat or prevent animal diseases for health, growth promotion, and productivity [1]. These drugs can be broadly divided into categories according to the different pathogens or targeted infections. They include antiparasitic drugs, antiinflammatory, reproductive medication, surgical medications, anesthetics, nutritional drugs, and feed additives sometimes used as growth promoters (Table1). Among commonly used drug in veterinary medicine are antibiotics. These drugs and medicaments can be administered in form of injectable, tablet, bolus, drench, and bath/wash or added to feed and drinking water. There are documented evidence of earlier norms and practices of animal husbandry regarding how shepherd and nomads provide 


\begin{tabular}{|c|c|c|c|c|}
\hline Antibiotics & Antiparasitic & Antiinflammatory & Anesthetics & $\begin{array}{l}\text { Growth } \\
\text { promoters }\end{array}$ \\
\hline Terramycin & Banminth & Ibuprofen & Phenobarbital & $\begin{array}{l}\text { Feed grade } \\
\text { antibiotics }\end{array}$ \\
\hline Penicillin & Ivermectin & Meloxicam & Thiamylal & Probiotics \\
\hline Streptomycin & $\begin{array}{l}\text { Diminazene } \\
\text { aceturate }\end{array}$ & Dexamethasone & $\begin{array}{l}\text { Xylazine } \\
\text { hydrochloride }\end{array}$ & Dihydropyridine \\
\hline Colistin & Amprolium & Prednisone & Chlorpromazine & Organic acids \\
\hline Erythromycin & Piperazine & Prednisolone & Diazepam & Amino acids \\
\hline Doxycycline & Albendazole & Aspirin & $\begin{array}{l}\text { Thiopental } \\
\text { sodium }\end{array}$ & Racto-amine \\
\hline Enrofloxacin & Closantel & Phenylbutazone & Pentobarbital & $\begin{array}{l}\text { Sodium- } \\
\text { bicarbonate }\end{array}$ \\
\hline Tylosin & Dermatocide & Dimethylsulfoxide & Chloral hydrate & $\begin{array}{l}\text { Potassium } \\
\text { chloride }\end{array}$ \\
\hline Oxytetracycline & Diazinon & Flunixin & Methohexital & Fatty acids \\
\hline Amoxycillin & Nitroxynil & Meglumine & Methoxyflurane & Zytomil \\
\hline Gentamycin & Cypermethrin & Cortisone & Halothane & $\begin{array}{l}\text { Renature-Z oral } \\
\text { powder }\end{array}$ \\
\hline Chloramphenicol & $\begin{array}{l}\text { Pyrantel } \\
\text { pamoate }\end{array}$ & Methimazole & Diethyl ether & $\begin{array}{l}\text { Vita-Sel-E oral } \\
\text { solution }\end{array}$ \\
\hline Ciprofloxacin & Praziquantel & Celecoxib & Isoflurane & $\begin{array}{l}\text { Eucament plus } \\
\text { oral solution }\end{array}$ \\
\hline Griseofulvin & Mectizan & Colchicine & Enflurane & Chicktonic \\
\hline Norfloxacin & Nitroxyl & Cyclooxygenase & Nitrous oxide & Aminogrow WS \\
\hline \multirow[t]{3}{*}{ Rifampin } & Diclazuril & Pylorus & $\begin{array}{l}\text { Glyceryl } \\
\text { quiacolate }\end{array}$ & Electromix WS \\
\hline & $\begin{array}{l}\text { Novidium } \\
\text { chloride }\end{array}$ & Mavacoxib & Succinyl choline & Introvit A+ WS \\
\hline & Isomethadone & Tepoxalin & Curare & $\begin{array}{l}\text { Introvit-ES-200 } \\
\text { WS }\end{array}$ \\
\hline Furazolidone & $\begin{array}{l}\text { Homidium } \\
\text { chloride }\end{array}$ & Piroxicam & Lidocaine & $\begin{array}{l}\text { Introvit-K-200 } \\
\text { WS }\end{array}$ \\
\hline
\end{tabular}

Source: survey of commonly use veterinary antimicrobials in Nigeria, courtesy of Dr. Jolly Amoche of National Veterinary Research Institute, Vom.

Table 1.

Some veterinary pharmaceuticals distributed in Nigeria.

medication for livestock. Some were written document by priests in monasteries, such as the use of garlic (Allium sativum L.) and ointment made from honey and grease [2]. This is similar to what has now been recognized in modern veterinary medicine as ethno-veterinary or alternative medicine in human and according to the World Health Organization (WHO); $75 \%$ of the world's population are using herbs for basic healthcare [3]. Such practices predate modern day pharmacopeia, which has, however, refined and synthesized the delivery of veterinary and human medicines. Some global industrial leaders in modern veterinary pharmaceuticals include Zoetis (formerly Pfizer Animal Health), Merck, Bayer, Elanco Animal Health, Boehringer Ingelheim Animal Health (Merial), Norvatis Animal Health, and many others. These companies and their subsidiaries are engaged in the multibillion dollars profitable business of drug distribution in developing countries (and also from Asia to Africa) in millions of doses some of which may be overused and contributing to drug resistance $[4,5]$. 
Globally, there are more livestock in the world than human, with livestock systems occupying about $30 \%$ of the planet's ice-free terrestrial surface area [6]. Most of these animals are kept in free range husbandry systems in under-developed countries where the enterprise supports the livelihood of about 600 million small holders [7]. The livestock sector in developing countries is also evolving in response to rapidly increasing demand for livestock products with changes in the demand for livestock products being driven among other factors by human population growth, urbanization, and increasing income $[8,9]$.

A major limiting factor in profitable livestock production in developing country is the burden of infectious diseases. These livestock diseases cause great socioeconomic impact, and the burdens are most of the time exasperated by poor biosecurity in both intensive and open production systems. This has made the use of antimicrobials for treatment of diseases indispensable [10]. It is important to emphasize that the reduction in the burden of infectious livestock diseases has been possible due in part to the use of a wide range effective drugs and vaccines and improvements in diagnostic techniques and services [11].

Therapeutic treatments are targeted at animals that are diseased. In food animals, it is usually often more convenient to treat entire groups by administering medication through feed or water, though individual animals may also be treated. For animals like poultry and fish, mass medication is the most feasible means of treatment but with the possibility of drug dispersal into the environment via leaching and agricultural wastewater [12]. Furthermore, certain mass-medication procedures called metaphylaxis, aimed at treatment of sick animals while medicating others in the group that may not be sick but exposed, can also be counterproductive. Other prophylactic antimicrobial treatments are typically used during high-risk periods for infectious diseases even, while the animals may not be infected also described as nonspecific infection prevention [13]. These practices, however plausible, are currently considered as contributing to emergence of antimicrobial resistance due to subtherapeutic exposure to veterinary pharmaceuticals by both infected and noninfected animals, as well as the environment [14].

Antimicrobial resistance has been described as the ability of bacterial, parasites, viruses, and fungi to survive and spread despite treatment with specific and combination therapy that are normally used against them [15]. The World Health Organization also emphasized that resistance happens when microorganisms change when they are exposed to antimicrobial drugs (such as antibiotics, antifungals, antivirals, antimalarials, and antihelmintics). These microorganisms that develop antimicrobial resistance are sometimes referred to as "superbugs". Antimicrobial resistance may be spontaneous and occur as a natural process, and resistance to antimicrobials dates back as far as when the first generations of antibiotics including penicillin were introduced in 1943/44 by Alexander Fleming [13]. In evolution, selection pressure is bound to cause subpopulation of microorganism with resistance genes to emerge [16]. This selective pressure has been ascribed to appropriate and inappropriate use of antimicrobials but aggravated by (1) intensity of usage, (2) persistence of usage, (3) under usage and subtherapeutic doses that animals are exposed to in prophylactic treatment, and (4) unintended human exposure through antimicrobials in food residues and the environment [10].

The burden of infectious diseases in developing countries and intensive use of antimicrobials to combat this has also been stressed in a study that suggested that up to a third of the global increase $(67 \%)$ in antibiotic consumption will be in food animals, over the period 2010-2030 and attributable to low-middle income countries [17]. This challenge is in view of the high burden of foodborne infectious and zoonotic diseases especially also in developing countries [18]. Veterinary practices use drugs for mitigating these diseases in animals, including food animals that 
have to be maintained in health and productivity (meat, egg, and milk). To prevent these drugs from getting into the food chain and being consumed by humans, "withdrawal time," which is the last time any drug may be administered before egg/milk and meat from such animals are collected and consumed is specified. The withdrawal time for antimicrobials is intended to prevent harmful drug residues in meat, milk, and eggs [19]. These waiting periods need to be observed from the time of treatment to when the animals are slaughtered for food. This is important because food products that contain antimicrobial residues not metabolized leaves residues beyond permissible limits at the end of the withdrawal period may be considered unwholesome for consumption and may contribute to antimicrobial resistance in humans [20].

Veterinary pharmaceuticals, therefore, contribute in many ways to the emergence of antimicrobial resistance either directly in suboptimal usage in animals or indirectly in human who consume subtherapeutic doses in animal products [13]. When resistant organism emerges, it has also been argued that human sources also seed these resistant bacteria to animals and the environment through sewage [21]. A recent study by Marcelino et al. [22] described high levels of antibiotic resistance gene expression among birds living in a wastewater treatment plants. The study observed that birds feeding at a wastewater treatment plant carried greatest resistance gene burden, suggesting that human waste, even after treatment, contributes to the spread of antibiotic resistance genes to the wild. Domestic and wild animals, including rodents, and birds, can acquire these environmental contaminants and pass them on via their excreta to grazing land or feed of food animals, which may in turn end up in human through the food chain [23]. While it is imperative to canvass AMR stewardship through rational and circumspect usage of antimicrobial in animals, it is important to bear in mind that human also present risk to animals. The USFD described the phenomenon of antimicrobial resistance as a very complex and nonvictimless phenomenon, affecting both human and animal health [13].

\section{Livestock diseases and the application of veterinary pharmaceuticals}

In the management of infectious and noninfectious diseases of livestock in developing countries, a number of veterinary pharmaceuticals are administered. The choice of drugs is often determined by efficacy, availability, and cost. These factors are explored by manufacturers mostly based in developed countries from where the drugs are exported to developing countries. This distribution chain is also largely driven by business interest such that drug companies sell volumes that are targeted at frequent, intensive usage that may have deleterious effect such as emergence of AMR.

Intensive use of veterinary chemotherapy on the other hand may be justifiable considering that many bacterial, viral, and parasitic diseases like mycoplasmosis, Newcastle disease, avian influenza, anthrax, coccidiosis, brucellosis, foot and mouth disease (FMD), rift valley fever, etc. threatens socioeconomics, instills fear that shock systems, either by suddenly and rapidly killing large number of animals or causes large-scale drop in demand through fear of zoonotic diseases [24, 25]. On the other hand, the growing concern that animals are major sources of human diseases and that around 60\% of all animal diseases are zoonotic [26] make treatment of such diseases in animals an essential control measure before it is transmitted to human, and to reduce their capacity to cause epidemics and pandemics.

The livability and economic impacts of animal disease disaster is well documented, for instance, highly pathogenic avian influenza recently killed millions of poultry birds in Nigeria (including other countries in West Africa) and wiped out entire farms [27]. The costs of epidemic African swine fever in Cote d'Ivoire was estimated at 
\$9.2 million; Nipah virus in Malaysia \$114 million, while contagious bovine pleuropneumonia in Botswana costs about $\$ 300$ million [25]. In the absence of preventive measures such as biosecurity and vaccination, the use of antimicrobial especially for nonviral infections is essential for profitable livestock production and to prevent infections that may be transmitted from animals to human as attested to by WHO [28].

\section{Development of AMR in veterinary practice}

The global antimicrobial resistance (AMR) crisis is predicted to kill roughly 10 million people annually by 2050 due to antibiotic-resistant infections, with Africa alone accounting for about 4.15 million [29]. This is estimated to cost the global economy about $\$ 100$ trillion [30] with about 28.3 million people pushed into extreme poverty [31]. The alarming rate of AMR in developing countries can be attributed to gross misuse of antimicrobials in human and animals [32]. Although resistance can still develop even at an appropriate antimicrobial use, however the situation can be made worse whenever there is excessive and unnecessary usage [33]. The global revolution in livestock and aquaculture is an underlying factor for frequent antimicrobial use and subsequent development of AMR. This is also driven by population increase, urbanization, improving economic conditions, and globalization. Countries like Brazil, China, and India are currently the hotspots for livestock intensification, while Nigeria, Myanmar, Peru, and Vietnam are future spots (Van [17]). In developing countries, most nonhuman-medical use of antimicrobials is almost certainly in livestock and farmed fish production and it is likely that most veterinary use is in intensive production rather than pastoralist or small-holder systems [34]. In Nigeria and other developing countries in sub-Saharan Africa, Asia and Middle East, there is paucity of information on antimicrobial drug resistance in farm animals, although little information exists on residue level [35-38]. However, there is information on antimicrobial drug resistant microbes isolated from human patients from different parts of Nigeria $[39,40]$. Previous report by Adesokan et al. [41] on pattern of antimicrobial usage in livestock production in three states of South-Western Nigeria between the period of 2010 and 2012 showed an increased use of tetracyclines (33.6\%) followed by fluoroquinolones $(26.5 \%)$ and betalactams/aminoglycosides (20.4\%). Similar trend was also reported in Africa for tetracycline \& beta-lactams [42]. However, studies by Idowu et al. [35] showed level of tetracycline residues between the ranges of $0.1-1.0 \%$ in chicken eggs.

The process of AMR development is very complex, and all of the factors that contributed to the events are not fully understood. It is clear that genetic change or mutation in microbial DNA may often cause resistance to antimicrobial agents, and this change might also be passed to the offspring or transferred to other related or even unrelated microorganisms [43]. This is known as "selection pressure" where the use of antimicrobial drugs in health care, agriculture, or industrial settings favor the survival of resistant strains (or genes) over susceptible ones, thus leading to a relative increase in resistant bacteria within microbial communities [44]. This is because no matter how effective an antimicrobial is, it rarely kills $100 \%$ of the organisms, meaning some may still survive due to genetic change, which can be passed forward. Currently, science has not fully proved the causes of different types of AMR that are causing great public health risks. The widespread use of antimicrobials in food production system especially in food-producing animals is another cause of AMR [45]. The extensive use of antimicrobials in animal production as growth promoters widely exposes the microbes to the drugs, thus enhancing the development of microbial resistance causing health consequences in both animals and humans. However, the scientific evidence of how and to what extent such drug 
exposure affects human health still remains unclear. It is interesting to note that antimicrobial resistance would not develop in animals if antimicrobial drugs were never used in them [12].

There is danger to public health if resistant organism from animals can also cause disease in human exposed by a way of food consumption or direct contact with food-producing animals, companion animals, or through environmental spread [46]. The threat to public health also exists even if the organisms do not cause disease in human, because they may still be able to transfer the resistant genes from food-producing animals to unrelated human pathogenic bacteria as well as normal commensals [47]. It is then clear that the increase use of antimicrobials in animal production for variety of purposes such as for therapeutic and nontherapeutic use has contributed to increasing AMR in bacteria affecting man and animals [48]. In Africa and other developing countries, studies have suggested a strong correlation between the use of antimicrobials in veterinary practice and the development of AMR [49], because it is shown that a larger proportion of antimicrobial medications have been used in animals than humans mainly for food production purposes [50]. There is presence of high antimicrobial residue in meat and milk meant for human consumption correlating with the detection of multidrug resistance (MDR) bacteria in animals and their products [51] as well as in humans in contact with the animals [52-54]. This is also because a large proportion of the population in developing countries lives in close proximity with livestock, which enhance the chances of transfer of resistant microorganisms from animals to humans [55, 56]. Similarly, the increasing use of antimicrobials as prophylaxis in aquaculture in developing countries further contributed to the emergence of AMR causing problems in human, animal, and environmental health [57]. The risk to humans further exists especially when similar antimicrobial is used in both animals and humans, or there is presence of cross resistance between antimicrobial used in human and veterinary practice. Using antimicrobials that are also used in human medicine for growth promotion is especially conducive to AMR because exposure of many animals to low dosages makes resistance more likely to emerge [34].

For some antimicrobials, there is development of resistance by bacteria through plasmid-mediated transferable resistance [58]. The minimum inhibitory concentrations (MIC) for a target pathogen might be considerably different from those of commensals, and thus, the resistance gene in commensals may be selected and transferred to humans and then to human pathogens leading to development of AMR [59]. Despite the fact that the exchange of genetic materials and the short generation time of organism contributed to the development of AMR by many bacteria [60], some drugs such as penicillin still retains excellent activity on certain organism (e.g., Streptococcus agalactiae) after about 6 decades of usage [61].

AMR development can often be caused by inhibition of specific antimicrobial pathways such as cell wall synthesis, nucleic acid synthesis, ribosome function, protein synthesis, foliate metabolism, and cell membrane function by the organism [62-64]. The various steps involved in the production, distribution, prescription, dispensing, and finally consumption of the drug by human patient or its use in animal production often contributed to the emergence of AMR especially when there is imprudent or irresponsible practice along the supply chain [65]. Part of veterinary medical education is to understand how antimicrobials affect microorganisms, and how they can be used responsibly to protect human and animal health [66]. In food production systems, veterinarians are on the frontline when it comes to keeping nation's food supply safe. Advances in animal health care and management have greatly improved food safety over the years and have reduced the need for antimicrobials in food production systems [67]. Nevertheless, 
antimicrobials are an important part of the veterinarian's toolkit, and so veterinarians are aware that they should be used judiciously and in the best interest of animal and public health [66]. More importantly in the development of AMR is the quality of antimicrobials. Though difficult to implement, it has been suggested that incidence of microbial resistance can be reduced if the antimicrobials that are used in human health are not used in veterinary practice [68]. Moreover, the practices of mass treatment of all animals in a group when only one animal is sick (metaphylaxis) as well as the treatment of all animals when they are exposed to conditions that can make them likely to be ill (prophylaxis) will result in an increased antimicrobial use and as such would encourage the development of resistance [69].

Although the development of animal-related AMR is associated with the quality and quantity of antimicrobial usage in veterinary practice, there are other underlining factors that can influence AMR development:

- Lack of awareness: in developing countries, there is little or no awareness or concern in the use of antimicrobials as compared to developed nations who recognize AMR as a global challenge. Omulo et al. [70] showed that only $24 \%$ of studies in Africa are related to AMR in animals or their products. In East Africa for example, despite the relevance of antibiotic procurement in health budgets, there was still a slow progress in research focusing on AMR of enteric pathogens. There is still lack of awareness among many veterinarians and other food producing personnel on the negative impact to human health as a result of extensive use of antimicrobials in animals [71].

- Lack of information: the information is lacking in developing countries concerning the existence and prevalence of AMR in animals and animal products and the negative health consequence as well as the cost of AMR illness in people and animals.

- Fake and substandard drugs: there is much concern over counterfeits and substandard drugs in animal health care, but there is insufficient data to understand its importance. Counterfeits and substandard products, which contain active ingredient at a lower level, will increase the chance of developing resistance. There is no comprehensive information on fake/substandard veterinary drugs.

- Lack of adequate 'One Health' integration between animal and human healthcare: in developing countries, there is poor collaboration in healthcare sectors between human and veterinary practice especially on collection and sharing of data on antimicrobial usage. However, at international level, good collaboration exists in the area of AMR between human and animal world health bodies like WHO, OIE, and FAO.

- Lack of substitution to the use of antimicrobials: alternative to the use of antimicrobials is lacking in developing countries unlike the developed nations that had successfully banned the use of antimicrobials as growth promoters and replaced with alternative growth promoters and good practice without having negative impact on the performance of their livestock industries. This could hardly be achieved in developing nations that have propensity to source antimicrobials from the black markets, which may be of poor quality, thus exacerbating the problem and creating a considerable increase in disease, with consequent mortality and morbidity losses [34]. 


\section{Prevention of AMR in veterinary practice}

In a bid to ensure measurable containment of AMR, there is a global formal declaration on AMR calling for the development of action plans on AMR by both international and national bodies. The Global Action Plan on Antimicrobial Resistance was approved in May 2015 by the World Health Assembly with the key strategies to increase global AMR awareness as well as developing policies that will attract more investment in the area of new medical interventions [72]. There is also a call to all Member States for establishing National Action Plans for AMR by 2017 of which about 57 countries have formalized such plans so far. The 2016 meeting of the UN General Assembly was another milestone focusing on multidisciplinary solution to the problems of AMR [73]. Moreover, the G20 called for the creation of a Global Research and Development (R\&D) Collaboration Hub on AMR in July 2017 that could coordinate international funding efforts [74], and the search for the appropriate individuals to lead that hub began early this year. In line with the global agreement to develop National Action Plan on AMR, Nigeria (with some other developing nations) keyed into this agreement in 2017 through a 'One Health' approach [75] and then enrolled into a Global Antimicrobial Resistance Surveillance System (GLASS). The Action Plan addresses five strategic objectives:

1.improving awareness and understanding of AMR through effective communication, education, and training

2. strengthening the knowledge and evidence base through surveillance and research

3. reducing the incidence of infection through effective sanitation, hygiene, and preventive measures

4. optimizing the use of antibiotics in human and animal health

5. preparing the economic case for sustainable investment and increasing investment in new medicine, diagnostic tools, vaccines, and other interventions

Several challenges exist regarding AMR containment in developing country like Nigeria; however, the development of this action plan is an important positive step in the right direction as it aims to address the problem at all level of governance and society [75].

Veterinarians play an important role in limiting and minimizing the spread of antimicrobial resistance (AMR). Because vets are often the first point of contact for livestock owners seeking animal medical attention, they can therefore play a part in addressing the problem of AMR [45]. One of the ways to reduce the risk of transfer of AMR from animals to humans is by minimizing the zoonotic transfer of bacteria [76]. This could be achieved by practicing stringent hygiene in the farms and any meat processing plants including the abattoirs and the markets. Thorough and effective cooking of meat product can also reduce the risk of AMR [77]. There is need to strengthen the information resources in developing countries to support health workers, patients, animal owners, and attendants as well as the general public to help in reducing the risk of AMR arising from the use of antimicrobials in animals. This will enable the society to better understand the importance and value of antimicrobials. The excessive and inappropriate use of antimicrobials in veterinary practice should be discouraged. Because antimicrobials are an extremely valuable resource in livestock production, their prudent use in animals will continue to provide benefits to society and will help ensure high 
standards of welfare for those animals in the care of veterinarians [78]. Since exposure of bacteria to subtherapeutic concentrations of antimicrobials is thought to increase the speed of the selection of resistance, this should always be avoided [14, 15, 79]. Appropriate pharmacokinetic and pharmacodynamic relations for antimicrobials used in animals should be developed [12]. Optimal dosage strategies for eliminating zoonotic organisms in animals will reduce the risk of transferring resistance to humans [80].

According to Delia [34], broad consensus on the management of AMR in human and animal healthcare will require to:

- reduce antibiotic use in humans and animals through public health improvement such as hygiene and sanitation, immunization, infection control, as well as good housing and environment.

- regulate the sale and use of antibiotics through prescription.

- encourage research and development of new antimicrobials.

- minimize the level of environmental contamination of antimicrobials emanating from manufacturing process as well as agricultural, hospital, and community use.

- develop integrated global policies on the use of antibiotics.

- ban the nontherapeutic use of antimicrobials as growth promoters in agriculture.

Currently, there is no adequate information on animal production losses due to disease burden and the extent at which it could be prevented through proper use of antibiotics or their alternatives.

Although in Europe and other developed nations, the use of alternatives to antimicrobials as growth promoters is a success; their applicability in developing countries is not fully understood.

Despite the huge investments in the control of diseases in developing countries through vaccination, vector control, and the use of resistant breeds, evaluation from the angle of reduction in the usage of veterinary drug is lacking. In developing countries, the incidence and composition of substandard and fake drugs as well as their effects on treatment failure and resistance development is not well known. Similarly, the level of resilience of livestock farmers in developing countries to ban or restrict access to antimicrobials is equally not well known. It should be noted that policy and regulation alone is unlikely to improve use of vet drugs and the options for improving the use of vet drugs in agriculture and their effectiveness, feasibility, and affordability are not well understood.

\subsection{Rational drug use}

There have been success factors in the improvement of drug use in human health through wide range of intervention studies. Similarly, the World Animal Health Organization (OIE) and other world veterinary bodies also developed frameworks on rational use of vet drugs to which there is a limit veterinarians can make profit from antimicrobial sale for food animal production [71]. This is not the case in developing countries where the sale and use of veterinary antimicrobials is facing challenges for improvement. It was found from series of intervention studies that training remains the most common strategy for improving drug use, but this gave little success unless when combined with other strategies like changing the market condition [1]. 


\subsection{Governance of antimicrobial use}

Antimicrobial use in human and veterinary practice requires holistic approach in order to improve drug governance. There is need to list the critical or essential drugs in human and veterinary practice with requirement for prescription and guidelines such as banning the use of medically important antibiotics in agricultural practice and off-label use of antimicrobials as well as monitoring antimicrobial use and resistance. Not much success has been recorded in this regard in developing countries especially in livestock production and aquaculture due to little investments. According to OIE, better governance of veterinary antimicrobials comes from empowering veterinarians and limiting prescription to them. Most of the private veterinary service providers in developing countries are not operating at a significant scale and as such are often employed directly by agriculture and agro-allied companies making them to be less independent. The few that are successful are not operating with the guidelines of current OIE policy [81]. The community animal health workers (CAHWs), that have proven to be effective, are very expensive to train and may not be politically acceptable [82]. This is because there is lack of resources to support them by public veterinary services, and the private veterinarians often see them as potential competitors. A study investigated rational drug use by farmers and found that farmers in West Africa were mainly responsible for buying and using antimicrobials, and providing simple information on correct drug use could lead to improved drug usage as well as reduced amount of underdosages, which is an important factor for the development of AMR [83].

\subsection{Antimicrobial alternatives in veterinary practice}

As previously mentioned, developed countries banned the use of medically important antibiotics as well as growth promoters in animal production, which has led to better farming practices as well as reduction in AMR of medically important microbes found in farm animals. With this natural experiment, it demonstrated that routine antimicrobial usage is not a precondition for healthy animals as long as there is better hygiene and sanitation with good housing condition, and the use of antibiotics is only limited to clinical condition. The benefit of antimicrobials as growth promoters may sound reasonable only under poor management and hygiene situations [71]. Although the type of intensive livestock production in developing countries makes them rely more on nontherapeutic use of antimicrobials, there are many other promising innovations that could support profitable and productive agriculture with less reliance on antimicrobials use such as:

- The use of nonantibiotic growth promoters like enzymes in feed, competitive exclusion products as well as probiotics and prebiotics

- The use of other animal health technologies such as vaccines, vector control, disinfectants, phyto-therapy, as well as phage-therapy, which are underutilized in developing countries. The phage products can readily be designed to thwart development of resistance. They have been used as antibacterial agents for nearly 100 years in the former Soviet Union, and they are now undergoing a renaissance in other countries due to the growing AMR problem [33, 84-87].

- The use of robust diagnostic techniques for improved drug selection and identification of AMR pathogens 
- The management and bio-security innovations like all-in-all-out systems, pathogen-free systems, stocking density reduction, and improved waste management systems.

- The use of genetically disease resistant animals as well as avoidance of monocultures of genetically similar animals.

All these intervention strategies will improve animal welfare as well as reducing environmental externalities of animal agriculture. A more radical suggestion is to decrease the amount of consumption of animal source food or shift from intensive to organic animal production.

\section{Veterinary antimicrobial stewardship in developing countries}

The safeguarding of antimicrobial agents for future generations is of utmost priority as AMR threatens the very core of modern medicines and the sustainability of an effective, global public health response to the enduring threats from infectious diseases [72]. In many developing countries of the world, gaps exist among health care professionals on the current status of antibiotic resistance in their area due to lack of a systematic surveillance at country, provincial, and district level [88]. There is a paucity of clinical data on antibiotic resistance, and this is particularly the case in resource-poor settings. Tons of antibiotics are used annually in clinical and agricultural settings worldwide. The estimates of the total annual global consumption of antimicrobials in animal production vary considerably due to poor surveillance and data collection in many countries [89]. In 2013, food animals alone consumed over 130,000 tons of antibiotics [90]. It cannot be ignored that two-thirds of the estimated future growth of usage of antimicrobials is estimated to be within the animal production sector, with use in pig and poultry production predicted to double [89]. Nigeria, Pakistan, India, Bangladesh, China, and Egypt are the developing countries with massive consumption of antibiotics [88].

The implementation of rational and restricted use of antibiotics is lacking in most developing countries where you have the largest market of antimicrobial drugs and reports of the highest rate of antibiotic resistance [86,87]. Due to these developments, antimicrobial stewardship programs have emerged as an essential means to attenuate the threat of a real possibility of the specter of a "postantibiotic era" [91, 92].

Antimicrobial stewardship is a harmonized program (the optimal selection, dosage, and drug regimen) that fosters the proper use of antimicrobials (including antibiotics) with the goal of optimizing clinical outcomes, reducing microbial resistance, and lessening the spread of infections produced by multidrug-resistant organisms. The main objectives of antimicrobial stewardship are to attain excellent patient outcomes associated with antimicrobial use while reducing toxicity and other unfavorable events, thereby curbing the discriminatory pressure on bacterial population that propels the emergence of multidrug-resistant strains $[93,94]$.

Antimicrobial stewardship programs (ASPs) are a cornerstone of the response to the AMR crisis in human medicine but are still largely underdeveloped in veterinary medicine [95]. Antimicrobial stewardship is important to both animal health and food safety. Just like humans, animals get infections that require treatment with antibiotics. The rise of antimicrobial resistance is a serious threat to public health [30]. It is imperative that antibiotic stewardship programs seeking to preserve the effectiveness of existing antibiotics in human health also consider strategies that reduce overuse of antibiotics in the agricultural sector as antimicrobials are used in terrestrial animal production practices to preserve animal and public health, but also as growth 
promoters at a subtherapeutic level [89]. Other aspects to be considered with regard to antimicrobial use include the distinction between therapeutic and nontherapeutic use, between the diverse existing production systems and between specifics related to the different animal species and their eco-geographical location [72, 89].

According to the WHO, FAO, and OIE global tripartite database for antimicrobial resistance country self-assessment in 2016-2017, 42\% of the countries on question regarding antimicrobial stewardship and regulation in animals and crop production responded that no national policy or legislation regarding the quality and efficacy of antimicrobials and their use in animals, and crops was available [101]. Responses to other veterinary-related questions showed a huge gap in the preparedness for combating AMR and also the lack of policy making and implementation of a successful antimicrobial stewardship program.

Various strategies have been shown to improve appropriateness of antimicrobial use and cure rates, decrease failure rates, and reduce healthcare-related costs in human hospitals [96-98]. According to Guardabassi \& Prescott [95], the following successful strategies used in human hospitals can be adopted with focus on their implementation in veterinary practice.

- educational approaches

- development and implementation of guidelines

- preprescription approval

- postprescription review

- computer-based decision support

It should be noted that one strategy does not exclude the other and that multiple strategies can be successfully used in combination.

A good antimicrobial stewardship program (ASP) needs remarkable input in research and training by all stakeholders including national and international veterinary organizations, funding concerns, and animal health industries [95]. At governmental levels, the growth and execution of ASPs need coordination of the task of national public health and veterinary authorities, veterinary clinics, organizations, and private practitioners. The concept of antimicrobial stewardship and of its continuous improvement is in its relative infancy in various sectors of veterinary practice in developing countries, but every veterinary component of the agricultural sector has the responsibility and access to a wide range of resources to develop an ASP.

Stewardship of antimicrobial drugs in human healthcare and veterinary settings is essential to slow the emergence of resistance and extending the useful life of effective antimicrobials according to FDA Center for Veterinary Medicine [99]. All developing countries should be committed to advancing efforts to implement good antimicrobial stewardship practices in veterinary settings as part of their role to protect human and animal health. Each program must be region-specific and constantly under review given that resistance patterns change, requiring changes to local policy of, for example, empirical antibiotic choice [100].

Therefore, the goals in all countries should be to align antimicrobial drug product use with the principles of antimicrobial stewardship, foster antimicrobial stewardship in veterinary settings, and enhance monitoring of antimicrobial resistance and use in animals to further preserve antimicrobial drugs to ensure human and animal health [99]. 


\section{Conclusion and recommendation}

Resistance to antimicrobial agents arises in some instance through excessive use in animals as chemotherapeutics, and as subtherapeutic additives in feeds. Prolong exposure of microorganisms to sublethal doses of antimicrobials can result in spontaneous emergence of resistance gene and its subsequent transfer among animals, environment and animal products in food chain, and transfer of resistance to human. A pragmatic approach to slow down the development of antimicrobial resistance is to control abuse of antimicrobials through a number of measures. First, it is important to recognize that veterinary pharmaceuticals are important beyond animals and include human health and the environment, hence the need for "One Health" guidiance and regulation. Secondly, it is necessary to reduce drugs that are used as prophylaxis and should rather improve research and innovation for vaccine development, application and explore other alternatives to chemotherapies. The use of feed grade antibiotics and additives in feed as growth promoters also need to be discouraged in developing countries and instead promote organic, home grown livestock husbandry to complement intensive and factory farming. Alternatives to growth-promoting and prophylactic uses of antimicrobials in agriculture include improved management practices, wider use of vaccines, probiotics, and phage virus. Monitoring programs, prudent usage that are controlled, and educational campaigns are some of the approaches that can minimize further development of antimicrobial resistance in developing countries especially. These can be achieved through mutual and 'One Health' understanding of the challenges and informed solution through antibiotic stewardship by promoting collective action of all parties with interest including producers, consumers, and mediators.

\section{Author details}

Meseko Clement*, Makanju Olabisi, Ehizibolo David and Muraina Issa

National Veterinary Research Institute, Vom, Nigeria

*Address all correspondence to: cameseko@yahoo.com

IntechOpen

(C) 2019 The Author(s). Licensee IntechOpen. This chapter is distributed under the terms of the Creative Commons Attribution License (http://creativecommons.org/licenses/ by/3.0), which permits unrestricted use, distribution, and reproduction in any medium, provided the original work is properly cited. (cc) BY 


\section{References}

[1] Shah NM et al. Can interventions improve health services from private providers in low and middle-income countries? A comprehensive review of the literature. Health Policy and Planning. 2011;26(4):275-287. DOI: 10.1093/heapol/czq074

[2] Vucevac-Bajt V, Karlovic M.

Traditional methods for the treatment of animal diseases in Croatia.

Revue Scientifique et Technique (International Office of Epizootics). 1994;13(2):499-512

[3] Pan SY, Litscher G, Gao SH, et al. Historical perspective of traditional indigenous medical practices: The current renaissance and conservation of herbal resources. Evidence-based Complementary and Alternative Medicine. 2014:20. http://dx.doi. org/10.1155/2014/525340

[4] David H, Lexchin J. The pharmaceutical industry as a medicines provider. The Lancet. 2002;360(9345):s1590-s1595

[5] Gaurvika MLN, Joel GB, Paul NN, James H. Poor-quality antimalarial drugs in Southeast Asia and subSaharan Africa. The Lancet Infectious Diseases. 2012;12(6):488-496

[6] Steinfeld H, Gerber P, Wassenaar T, Castel V, Rosales M, de Haan C.

Livestock's Long Shadow:

Environmental Issues and Options.

Rome, Italy: FAO; 2006

[7] Thornton PK, Jones PG, Owiyo TM, Kruska RL, Herrero M, et al. Mapping Climate Vulnerability and Poverty in Africa. Nairobi, Kenya: ILRI; 2006. Available from: http://www.dfid.gov.uk/ research/mapping-climate

[8] Delgado C. Rising demand for meat and milk in developing countries: Implications for grasslands-based livestock production. In: DA MG, editor. Grassland: A Global Resource. The Netherlands: Wageningen Academic Publishers; 2005. pp. 29-39

[9] Thornton PK. Livestock production: Recent trends, future prospects. Philosophical Transactions of the Royal Society of London. Series B, Biological Sciences. 2010;365(1554):2853-2867

[10] McDermott PF, Zhao S, Wagner DD, Simjee S, Walker RD, White DG. The food safety perspective of antibiotic resistance. Animal Biotechnology. 2002;13(1):71-84. DOI: 10.1081/ ABIO-120005771

[11] Perry B, Sones K. Global Livestock Disease Dynamics Over The Last Quarter Century: Drivers, Impacts And Implications (Background Paper for the SOFA). Rome, Italy: FAO; 2009

[12] Marshall BM, Levy SB. Food animals and antimicrobials: Impacts on human health. Clinical Microbiology Reviews. 2011;24(4):718-733

[13] Economou V, Gousia P. Agriculture and food animals as a source of antimicrobial-resistant bacteria. Infection and Drug Resistance. 2015;8:49-61. DOI: 10.2147/IDR.S55778

[14] Levy SB, Marshall B. Antibacterial resistance worldwide: Causes, challenges and response. Nature Medicine. 2004;10:S122-S129

[15] Founou Luria Leslie, Founou Raspail Carrel, Essack Sabiha Yusuf. Antibiotic Resistance in the Food Chain A Developing Country-Perspective. Frontiers in Microbiology. 2016;7:881. Available from: https://www.frontiersin. org/article/10.3389/fmicb.2016.01881. DOI $=10.3389 /$ fmicb.2016.01881

[16] Cantón R, María-Isabel M. Emergence and spread of antibiotic 
resistance following exposure to antibiotics. FEMS Microbiology Reviews. 2011;35(5):977-991. DOI: 10.1111/j.1574-6976.2011.00295.x

[17] Van Boeckel TP et al. Global trends in antimicrobial use in food animals. Proceedings of the National Academy of Sciences of the United States of America. 2015;18:5649-5654

[18] Adak GK, Meakins SM, Yip H, Lopman BA, O’Brien SJ. Disease risks from foods, England and Wales, 19962000. Emerging Infectious Diseases. 2005;11:365-372

[19] National Research Council (US) Committee on Drug Use in Food Animals. The Use of Drugs in Food Animals: Benefits and Risks. 5. Drug Residues and Microbial Contamination in Food: Monitoring and Enforcement. Washington, DC: National Academies Press (US); 1999. Available from: https://www.ncbi.nlm.nih.gov/books/ NBK232575/

[20] Crawford LM. The impact of residues on animal food products and human health. Revue Scientifique et Technique (International Office of Epizootics). 1985;4(4):669-685

[21] Harwood VJ, Brownell M, Perusek W, Whitlock JE. Vancomycinresistant Enterococcus spp. isolated from wastewater and chicken feces in the United States. Applied and Environmental Microbiology. 2001;67(10):4930-4933

[22] Marcelino V, Michelle W, Aeron CH, Daniel G, Marcel K, John-Sebastian E, et al. High levels of antibiotic resistance gene expression among birds living in a wastewater treatment plant. BioRxiv2018. DOI: 10.1101/462366

[23] Ian P, Mark C, Tony C, Brad D, Christian F, Ron J, et al. Does the use of antibiotics in food animals pose a risk to human health? A critical review of published data. Journal of Antimicrobial Chemotherapy. 2004;53(1):28-52. DOI: 10.1093/jac/dkg483

[24] Meseko C, Olaleye D, Capua I, Cattoli G. Swine influenza in subSaharan Africa-Current knowledge and emerging insights. Zoonoses and Public Health. 2014;61:229-237. DOI: 10.1111/zph.12068

[25] Perry B, Grace D. The impacts of livestock diseases and their control on growth and development processes that are pro-poor. Philosophical Transactions of the Royal Society B: Biological Sciences. 2009;364(1530):2643-2655

[26] Taylor LH, Latham SM, Woolhouse ME. Risk factors for human disease emergence. Philosophical Transactions of the Royal Society of London. Series B, Biological Sciences Royal Society. 2001;356:983-989. DOI: 10.1098/ rstb.2001.0888

[27] Monne I, Meseko C, Joannis T, Shittu I, Ahmed M, Tassoni L, et al. Highly pathogenic avian influenza a (H5N1) virus in poultry, Nigeria. Emerging Infectious Diseases. 2015;21(7):1275-1277

[28] World Health Association (WHO). The Medical Impact of the Use of Antimicrobials in Food Animals. World Health Organization; 1997. Available from: http://whqlibdoc.who.int/ hq/1997/WHO_EMC_ZOO_97.4.pdf [Accessed 18 November 2018]

[29] O’Neill J. Antimicrobial resistance: Tackling a crisis for the health and wealth of nations. Review on Antimicrobial Resistance. 2014. London, UK. Available from: https:// amr-review.org/sites/default/files/ AMR\%20Review\%20Paper\%20-\%20 Tackling $\% 20 \mathrm{a} \% 20$ crisis $\% 20$ for $\% 20$ the $\% 20$ health\%20and\%20wealth\%20 of\%20nations_1.pdf [Accessed: 19 November 2018] 
[30] O’Neill J. Tackling drug-resistant infections globally: Final report and recommendations. Review on Antimicrobial Resistance. 2016. London, UK. Available from: https://amr-review. org/sites/default/files/160518_Final\%20 paper_with\%20cover.pdf [Accessed: 15 November 2018]

[31] Adeyi OO, Baris E, Jonas OB, Irwin A, Berthe FC, Le G, et al. DrugResistant Infections: A Threat To Our Economic Future. Vol. 2: Final Report (English). Washington, D.C., World Bank Group; 2017. Available from: http://documents.worldbank.org/ curated/en/323311493396993758/finalreport [Accessed: 19 November 2018]

[32] Byarugaba DK. A view on antimicrobial resistance in developing countries and responsible risk factors. International Journal of Antimicrobial Agents. 2004;24:105-110

[33] Laxminarayan R, Duse A, Wattal C, Zaidi AKM, Wertheim HFL, Sumpradit $\mathrm{N}$, et al. Antibiotic resistance-The need for global solutions. The Lancet Infectious Diseases. 2013;13:1057-1098

[34] Delia G. Review of Evidence on Antimicrobial Resistance and Animal Agriculture in Developing Countries. International Livestock Research Institute; 2015. DOI: 10.12774/eod_ cr.june2015.graced

[35] Idowu F, Junaid K, Paul A, et al. Antimicrobial screening of commercial eggs and determination of tetracycline residue using two microbiological methods. International Journal of Poultry Science. 2010;9(10):959-962

[36] Ibrahim A, Junaid A, Garba M. Multiple antibiotic residues in meat from slaughtered cattle in Nigeria. The Internet Journal of Veterinary Medicine. 2009;8(1):1-5

[37] Kabir J, Umoh JU, Umoh VJ. Characterization and screening for antimicrobial substances of slaughtered cattle in Zaria, Nigeria. Meat Science. 2002;64(4):435-439

[38] Sosa AJ, Byarugaba DK, AmabileCuevas CF, Hsueh PR, Kariuki S, Okeke IN. Antimicrobial Resistance in Developing Countries. LLC, 233 Spring Street, New York, NY 10013, USA: Springer Science Business Media; 2010

[39] Mohammed A, Adeshina GO, Ibrahim YK. Incidence and antibiotic susceptibility pattern of bacterial isolates from wound infections in a tertiary hospital in Nigeria. Tropical Journal of Pharmaceutical Research. 2013;12(4):617-621

[40] Olowe OA, Eniola KIT, Olowe RA, Olayemi AB. Antimicrobial susceptibility and beta-lactamase detection of MRSA in Osogbo, SW Nigeria. Nature and Science. 2007;5(3):44-48

[41] Adesokan HK, Akanbi IO, Akanbi IM, Obaweda RA. Pattern of antimicrobial usage in livestock animals in south-West Nigeria: The need for alternative plans. Onderstepoort Journal of Veterinary Research. 2015;82(1):1-6

[42] Darwish WS, Eldaly EA, El-Abbasy MT, Ikenaka Y, et al. Antibiotic residues in food: The African scenario. Japanese Journal of Veterinary Research. 2013;61(supplement):S13-S22

[43] Fanny B et al. Identification of 76 novel B1 metallo- $\beta$-lactamases through large-scale screening of genomic and metagenomic data. Microbiome. 2017;5:134. https://doi.org/10.1186/ s40168-017-0353-8

[44] Witte W. Medical consequences of antibiotic use in agriculture. Science. 1998;279:996-997

[45] Timothy FL, Bevin C, Thomas EW, Elaine LL. A review of antibiotic use in food animals: Perspective, 
policy, and potential. Public Health Reports. 2012;127(1):4-22. DOI: $10.1177 / 003335491212700103$

[46] Sorensen TL et al. Transient intestinal carriage after ingestion of antibiotic-resistant Enterococcus faecium from chicken and pork. The New England Journal of Medicine. 2001;345:1161-1166

[47] Marshall BM, Ochieng DJ, Levy SB. Commensals: Underappreciated reservoirs of resistance. Microbe. 2009;4:231-238

[48] Food and Agriculture Organization. Drivers, Dynamics and Epidemiology of Antimicrobial Resistance in Animal Production [Internet]. FAO; 2016. Available from: http://www.fao.org/3/ai6209e.pdf [Accessed: 04 January 2017]

[49] Aarestrup F. Sustainable farming: Get pigs off antibiotics. Nature. 2012;486:465-466

[50] Mitema ES, Kikuvi GM, Wegener HC, Stohr K. An assessment of antimicrobial consumption in food producing animals in Kenya. Journal of Veterinary Pharmacology and Therapeutics. 2001;24:385-390

[51] Mezali L, Hamdi TM. Prevalence and antimicrobial resistance of salmonella isolated from meat and meat products in Algiers (Algeria). Foodborne Pathogens and Disease. 2012;9:522-529

[52] Addis Z, Kebede N, Sisay Z, Alemayehu H, Wubetie A, Kassa T. Prevalence and antimicrobial resistance of salmonella isolated from lactating cows and in contact humans in dairy farms of Addis Ababa: A cross sectional study. BMC Infectious Diseases. 2011;11:222. https://doi. org/10.1186/1471-2334-11-222

[53] Fortini D, Fashae K, GarcíaFernández A, Villa L, Carattoli A.
Plasmid-mediated quinolone resistance and $\beta$-lactamases in Escherichia coli from healthy animals from Nigeria. Journal of Antimicrobial Chemotherapy. 2011;66:1269-1272

[54] Kikuvi GM, Ombui JN, Mitema ES. Serotypes and antimicrobial resistance profiles of salmonella isolates from pigs at slaughter in Kenya. Journal of Infection in Developing Countries. 2010;4:243-248

[55] Doyle ME. Multidrug-resistant pathogens in the food supply.

Foodborne Pathogens and Disease.

2015;12:261-279

[56] Simango C, Rukure G. Potential sources of campylobacter species in the homes of farm workers in Zimbabwe. The Journal of Tropical Medicine and Hygiene. 1991;94:388-392

[57] Cabello FC. Heavy use of prophylactic antibiotics in aquaculture: A growing problem for human and animal health and for the environment. Environmental Microbiology. 2006;8:1137-1144

[58] Ramirez MS, Traglia GM, Lin DL, Tran T, Tolmasky ME. Plasmidmediated antibiotic resistance and virulence in gram-negatives: The Klebsiella pneumoniae paradigm. Microbiology Spectrum. 2014;2(5):1-15

[59] McKellar QA. Antimicrobial resistance: A veterinary perspective.

British Medical Journal. 1998;317:610-611

[60] Linton AH. Antibiotic resistance: The present situation reviewed. Veterinary Record. 1997;100:37

[61] Prescott J, Baggot D. Antimicrobial drug use in bovine mastitis. In: Prescott JF, Baggot JD, editors. Antimicrobial Therapy in Veterinary Medicine. 2nd ed. Iowa: Iowa State University Press; 1993. p. 55361 
[62] Fluit AC, Visser MR, Schmitz FJ. Molecular detection of antimicrobial resistance. Clinical Microbiology Reviews. 2001;14:836-871

[63] Kohanski MA, Dwyer DJ, Collins JJ. How antibiotics kill bacteria: From targets to networks. Nature Reviews. Microbiology. 2010;8:423-435

[64] Roberts MC. Tetracycline resistance determinants: Mechanisms of action, regulation of expression, genetic mobility, and distribution. FEMS Microbiology Reviews. 1996;19:1-24

[65] Quick J, Bremer K. Quality control of essential drugs. The Lancet. 1997;350:1106

[66] FDA-CVM. Supporting Antimicrobial Stewardship in Veterinary Settings: Goals for Fiscal Years 20192023. 2018

[67] Ronald RM, Suzhen L.

Antimicrobial resistance in livestock: Advances and alternatives to antibiotics. Animal Frontiers. 2018;8(2):30-37

[68] Karen LT, Niamh PC, Diego BN, Susan CC, Paul ER, Herman WB, et al. Restricting the use of antibiotics in food-producing animals and its association with antibiotic resistance in food-producing animals and human beings: A systemic review and metaanalysis. The Lancet Planetary Health. 2017;1 (8):316-327

[69] Palumbi SR. Humans as the World's greatest evolutionary force. Science. 2001;293(5536):1786-1790

[70] Omulo $S$ et al. A review of 40 years of enteric antimicrobial resistance research in eastern Africa: What can be done better? Antimicrobial Resistance and Infection Control. 2015;4:1

[71] McEwen SA. Improve antibiotic use in animals. In: Antibiotic Resistance: Synthesis of Recommendations by Expert Policy Groups. Geneva, Switzerland: APUA; 2001

[72] WHO. Global Action Plan on Antimicrobial Resistance. 2015. Available from: http://www.wpro.who. int/entity/drug_resistance/resources/ global_action_plan_eng.pdf [Accessed: 19 November 2018]

[73] WHO. United Nations High-Level Meeting on Antimicrobial Resistance. 2016. Available from: http://www.who. int/antimicrobial-resistance/events/ UNGA-meeting-amr-sept2016/en/ [Accessed: 19 November 2018]

[74] Wellcome and Gates Foundation. Wellcome and Gates Foundation to Support New Global Body to Tackle Superbugs. 2017. Available from: https:// wellcome.ac.uk/press-release/wellcomeand-gates-foundation-supportnew-global-body-tackle-superbugs [Accessed: 19 November 2018]

[75] Federal Ministry of Agriculture, Environment and Health (FMAEH). National Action Plan for Antimicrobial Resistance, 2017-2022. 2017.

Available from: https://www. medbox.org/ng-policies-others/ nigeria-national-action-plan-forantimicrobial-resistance-2017-2022/ preview?

[76] Brian O. Strategies to reduce the use of antibiotics in animals. The Pharmaceutical Journal. 2014;293(7836). DOI: 10.1211/ PJ.2014.20067064. Available from: https://www.pharmaceutical-journal. com/news-and-analysis/features/ strategies-to-reduce-the-use-ofantibiotics-in-animals/20067064. article?firstPass=false

[77] Brad S, Gail RH, Avinash K, Carmen DC, Lance BP, James RJ. Antibiotic Resistance in Humans and Animals. Discussion Paper of National Academy of Medicine. 2016. Available from: https://nam.edu/wp-content/ 
uploads/2016/07/Antibiotic-Resistancein-Humans-and-Animals.pdf

[78] Barza MD et al. The need to improve antimicrobial use in agriculture:

Ecological and human health consequences. Barza M, Gorbach SL, editors. Clinical Infectious Diseases. 2002;34(Suppl 3):S76-S77. Arlington, VA: Infectious Diseases Society of America

[79] Lessar TS, Rotschafer JC, Strand LM, Solem LD, Zaske DF. Gentamicin dosing errors with four commonly used nomograms. Journal of the American Medical Association. 1982;248:11903

[80] McEwen SA, Fedorka-Cray PA. Antimicrobial use and resistance in animals. Clinical Infectious Diseases. 2002;34(Suppl 3):S93-S106

[81] Lewis S. The role of the agro-vet shop in animal health information delivery in Kenya [MSc dissertation]. University of Edinburgh; 2001

[82] Leyland T et al. Community-Based Animal Health Workers in the Horn of Africa: An Evaluation for the US Office for Foreign Disaster Assistance. UK, Great Holland: Feinstein International Center, Tufts University Africa Regional Office, Addis Ababa and Vetwork; 2014

[83] Grace D et al. Training farmers in rational drug-use improves their management of cattle trypanosomosis: A cluster-randomised trial in South Mali. Preventive Veterinary Medicine. 2008;83:83-97

[84] Abedon ST, Kuhl SJ, Blasdel BG, Kutter EM. Phage treatment of human infections. Bacteriophage. 2011;1:66-85

[85] Kutter E, De Vos D, Gvasalia G, Alavidze Z, Gogokhia L, Kuhl S, et al. Phage therapy in clinical practice: Treatment of human infections. Current Pharmaceutical Biotechnology. 2010;11:69-86
[86] Reardon S. Phage therapy gets revitalized. Nature. 2014;510:15-16

[87] Reardon S. Antibiotic resistance sweeping developing world. Nature. 2014;509:141-142

[88] Syed MA, Bana NF. Developing countries need action plans to combat the challenge of antimicrobial resistance. iMedPub Journals. 2016;7(2):12. Available from: http:// www.acmicrob.com/

[89] FAO. Antimicrobial Resistance: Animal Production. 2018. Available from: www.fao.org/antimicrobialresistance/key-sector/animalproduction/en. [Accessed: 03 November 2018]

[90] Van Boeckel TP, Glennon EE, Chen D, Gilbert M, Robinson TP, Grenfell BT, et al. Reducing antimicrobial use in food animals. Science. 2017;357(6358):1350-1352

[91] Gallagher J. Antibiotic Resistance: World on Cusp of 'Post-Antbiotic Era'. BBC News, Health; 2015. Available from: www.bbc.co.uk

[92] O’Brien DJ, Gould IM. Maximizing the impact of antimicrobial stewardship: The role of diagnostics, national and international efforts. Current Opinion in Infectious Diseases. 2013;26:352-358. DOI: 10.1097/QCO.0b013e3283631046

[93] Gerding DN. The search for good antimicrobial stewardship. Joint Commission Journal on Quality Improvement. 2001;27(8):403-404

[94] Neil F, Society for Healthcare Epidemiology of America, Infectious Diseases Society of America. Policy statement on antimicrobial stewardship by the Society for Healthcare Epidemiology of America (SHEA), the Infectious Diseases Society of America (IDSA), and the Pediatric Infectious Diseases Society (PIDS). Infection 
Control and Hospital Epidemiology. 2012;33:322-327

[95] Guardabassi L, Prescott JF.

Antimicrobial stewardship in small animal veterinary practice: From theory to practice. Veterinary Clinics: Small Animal Practice. 2015;45:361-376. DOI: 10.1016/j.cvsm.2014.11.005

[96] MacDougall C, Polk RE. Antimicrobial stewardship programs in health care systems. Clinical Microbiology Reviews. 2005;18: 638-656

[97] Owens RC Jr. Antimicrobial stewardship: Concepts and strategies in the 21st century. Diagnostic Microbiology and Infectious Disease. 2008;61:110-128

[98] Tamma PD, Cosgrove SE. Antimicrobial stewardship. Infectious Disease Clinics of North America. 2011;25:245-260

[99] Food and Drug AdministrationCentre for Veterinary Medicine (FDACVM). The Judicious Use of Medically Important Antimicrobial Drugs in FoodProducing Animals; 2012. Available from: https://www.fda.gov/downloads/ AnimalVeterinary/GuidanceCompliance Enforcement/GuidanceforIndustry/ UCM216936.pdf

[100] Aryee A, Price N. Antimicrobial stewardship-Can we afford to do without it? British Journal of Clinical Pharmacology. 2014;79(2):173-181. DOI: 10.1111/bcp. 12417

[101] WHO, FAO, OIE. Global Tripartite Database for Antimicrobial Resistance Country Self-Assessment. Export of Year One Data 2016-2017. 2017. Available from: https://amrcountryprogress.org/ [Accessed: 23 May 2017] 


\title{
Veterinary Drug Residues in Meat and Meat Products: Occurrence, Detection and Implications
}

\author{
Andrew Bamidele Falowo \\ and Oluwakamisi Festus Akimoladun
}

\begin{abstract}
Application of veterinary drugs in livestock production is inevitable as they are essential for treatment of diseases, prevention of diseases, modification of physiological functions, improvement of growth and productivity as well as for ensuring food safety. However, recent reports have revealed that the use of veterinary drugs in large amounts and consistently could result in deposition of antimicrobial residues in muscle and organs of animal. Consumption of these residues in animal products may pose health risk to consumers including development of antibiotic resistance bacteria, allergy, reproductive disorder and hypersensitivity reaction. It is in line with this that this chapter seeks to examine the cause, occurrence, mode of detection, health implication and possible solution to veterinary drugs residues in meat and meat products.
\end{abstract}

Keywords: antimicrobial residue, meat and meat product, veterinary drugs, consumers' health, antimicrobial resistance

\section{Introduction}

The use of veterinary drugs in livestock production is inevitable as they are essential for treatment of diseases (therapeutic), prevention of diseases (prophylaxis), modification of physiological functions (such as tranquilizers, anesthetic drugs), improvement of growth and productivity (growth promoters) as well as for ensuring food safety [1]. The veterinary drugs are used throughout the world and they comprise a broad variety of classes of chemical compounds including vaccines, antimicrobials, antiparasitics and $\beta$-agonists [2]. These drugs have been used to strengthen profitability and productivity of modern food-animal production by facilitating earlier weaning, higher animal densities, carcass yield and meat quality as well as the use of cheaper feed sources [2]. Among the antimicrobials that are commonly used in livestock production are tetracyclines, amprolium, penicillin, streptomycin, sulphonamides, tylosin, aminoglycosides, $\beta$-lactams, macrolides and lincosamides, quinolones, sulfonamides and tetracyclines $[3,4]$ while that of antiparasitic agents include anthelmintics or coccidiostats, stilbenes, amphenicols, nitrofurans, nitroimidazoles, carbamates, pyrethroids and sedatives.

Antimicrobials are medicine (natural, synthetic or semi-synthetic origin) that inhibits the growth of or destroys microorganisms when applied at low 
concentrations without causing host damage [5]. In the course of this study, "antimicrobial" will be considered an equivalent term to "antibiotic". Many antimicrobials that are used in livestock are identical or closely related to antimicrobials used in humans. Most of the antimicrobials use in livestock can lead to development of antimicrobial-resistant bacteria in muscle food, which can then be transmitted to humans via food and other transmission routes [1].

At present the global average annual consumption of antimicrobials per kilogram of animal produced is estimated at $>100 \mathrm{mg} / \mathrm{kg}$ [6]. It has also been showed that about $80 \%$ of all the antibiotics administered in veterinary field are used as growth promoters and in most cases, this exceeds the total antibiotics use for human medical care [6]. In a study, Aarestrup [7] observed that global consumption of antibiotic in animals is twice that of humans. In fact, in developed countries like USA, Food and Drug Administration [8] reported that about $80 \%$ of counties total antimicrobial consumption are used in food animals. On estimate, Van Boeckel et al. [9] found that about 45, 148 and $172 \mathrm{mg} / \mathrm{kg}$ of antimicrobial per animal are used annually for cattle, chicken and pig production globally, respectively. It has been predicted that global consumption of antimicrobial by livestock will increase $67 \%$ from 63,151 tons in 2010 to 105,596 tons by 2030 [9].

However, recent reports have revealed that the use of antimicrobial drugs in large amounts and consistently could result in deposition of antimicrobial residues in muscle and organs of animal [10]. Consumption of these residues in animal products (especially through meat and meat products) may cause health risk to consumers including development of antibiotic resistance and hypersensitivity reaction. FAO/WHO reported that antimicrobial residues edible animal products has grown beyond permissible level (very high) is in developing countries [11]. In order to curtail this, the European legislation has set maximum residue limits for veterinary drug residues in different animal food products (European Commission Council Regulation (EEC), [12]). Nisha [13] highlighted that the maximum veterinary residue limits for tetracycline, oxytetracycline, streptomycin, gentamicin, sulphonamides, quinolones, among others, to be 100, 100, 200, 200, 100 and $75 \mu \mathrm{g} / \mathrm{kg}$ respectively. It is therefore imperative that animal products (particularly meat and milk) should be analyzed to ensure that residues do not exceed maximum residue limits. Since unintentional consumption of antimicrobial residues in food products leads to drug resistance of bacteria that are pathogenic to humans with consequence of serious threat to human health [14]. It is in line with this that this chapter will focus on recent findings on causes, occurrences, mode of detections, health implication and possible solution to veterinary drugs residues in meat and meat products.

\section{Drivers of antimicrobial residues in meat and meat products}

\subsection{Outbreak of livestock diseases}

Livestock production is one of the fastest growing agricultural sectors in most countries of the world. However, the health and growth of this livestock are plagued by many diseases caused by different infectious microorganisms globally. The past decade has seen the rise of many new diseases, with more of new potential pathogens anticipated to occur by $2020[15,16]$. The outbreak of infectious microorganisms has necessitated widespread use of antimicrobial drugs to protect and maintain the health of the animal during production and also ensure safe food after harvest. Since animals that are sick and untreated grow more slowly and may eventually results in mortality, imposing a considerable economic burden on producers 
and government by dramatically reducing income and means of livelihood to farm owner and workers [17]. In treatment and prevention of these diseases, FAD [18] observed in a study that $60 \%$ of domestic sales and distribution of medically important antimicrobials in year 2016 were used in food-producing animals in in United States. Of this estimate, the same author reported that Tetracyclines accounted for $70 \%$ of these sales, penicillins for $10 \%$, macrolides for $7 \%$, sulfas for $4 \%$, aminoglycosides for $4 \%$, lincosamides for $2 \%$, and cephalosporins and fluoroquinolones each for less than $1 \%$. Often time, the amount of antimicrobial use in livestock depends on the number of animals, the production system, prevailing risk factors for disease and ability to acquire antimicrobial agents income [17]. However, misuse or excessive use of antimicrobials among livestock and in adherent to withdrawer time has resulted to spread of antimicrobial residues (either the parent compound or its metabolite) in muscles especially meat and meat products [19, 20].

The occurrence of antimicrobial residues in muscle food pose a risk to human health by being acutely or cumulatively allergenic, organotoxic, mutagenic, teratogenic or carcinogenic [11]. In fact, report has shown that antimicrobial resistant bacteria can represent a reservoir of resistance genes transferable to pathogenic or commensal bacteria in digestive tract [21], and therefore compromise the effective treatment of bacterial infections. This could be a serious threat to disease treatment in humans and animals. Therefore, it is imperative that precise antimicrobial drugs be used in livestock production for overall decrease in animals suffering due to infectious diseases.

\subsection{Excessive demand for meat and meat products}

Meat represents a substantial portion of the diet of most people worldwide. Its consumption has significant health benefits as good source of proteins, essential amino and fatty acids, vitamins and minerals and other bioactive compounds [22] The worldwide average meat consumption is estimated at $42.9 \mathrm{~kg}$ per capita, with industrial countries consuming about $76.1 \mathrm{~kg}$, twice the quantity in developing countries $(33.6 \mathrm{~kg})[23,24]$. However, it has been indicated that the consumption of meat and meat products will double by 2050. Meat consumption will continue to expand due to increase in population growth across the world, with the developing world having most demand growth over the coming decades [25]. In an attempt to produce sufficient meat to meet this demand, antimicrobials are being increasingly used for the treatment of livestock diseases and increase productivity (growth promoters). Currently, more than 300 antimicrobials, anti-coccidials, feed additives and hormone-type agents are used in livestock production globally [26-28].

According to OECD/FAO [25] statistic, about 323 metric tons of meat was produced globally in 2017 and this has been projected to be $15 \%$ higher in 2027. Most of this increase in the next decade will emanate due to higher demand in beef and sheep meat than poultry and pig meat [25]. It has also been reported that much of the increase in production will originate from United States, India, Argentina, Mexico, China, Turkey and the Russian Federation. Report has showed that the increase in antimicrobial consumption is due to the growing number of animals raised for food production coupled with increase in consumer demand for livestock products including meant and meat products [9]. On average, worldwide consumption of antimicrobials in food animal production was estimated at 63,151 $( \pm 1560)$ tons in 2010 and by 2030 , it has been projected to increase by $67 \%$, to $105,596$ ( \pm 3605$)$ tons or even double in countries such Brazil, India, Russia, South Africa and China [9]. In Asia for instance, antimicrobial consumption in chicken and pig production has been projected to grow by $129 \%$ and $124 \%$, respectively, by 2030 [9]. Antimicrobial resistant strains have been isolated in food animals in both 
the developed and developing countries especially where the use of antimicrobials for growth promotion remains largely unregulated [19, 29]. Skockova et al. [29] in their study found that some strains of Escherichia coli isolated from retail meats (pork, poultry, beef, venison) were resistant to one or more groups of antimicrobial agents (tetracycline, b-lactams and quinolones) [29]. In addition, Moniri and Dastehgoli [30] isolated a fluoroquinolone-resistant Escherichia coli from broilers due to their exposure to fluoroquinolones drugs. Because of use of antimicrobial drugs in livestock production, bacteria originating from food animals frequently carry a resistance to a range of antimicrobial agents, including those commonly used in humans $[29,31]$.

\subsection{Other important drivers}

Beyond above-mentioned drivers, other factors that could be responsible for antimicrobial resistance in meat and meat products include improper dosage of antimicrobials, non-enforcement of laws regulating antimicrobial usage in livestock, weak financial status of livestock farmers, low education and expertise of farmers, and husbandry system (intensive and extensive) [4]. For instance, Alhaji et al. [4] in a study found that majority of the poultry famers did not practices or comply with antimicrobial withdrawal periods before slaughter or marketing of their product for consumption. Noncompliance with antimicrobials withdrawal periods could create low therapeutic doses and high concentration of antimicrobial residues in meat products. By law, animals given an antibiotic should not be processed until the withdrawal period ends. Good management, which includes good hygiene and sufficient feed, can reduce the chances of animals getting disease, hence use of antibiotics. Others include illegal sale of veterinary prescription drugs, marketing or slaughtering of treated/medicated animals intended for rendering purposes, inadequate animal identification and traceability system especially in developing countries [2].

\section{Implications: impact on consumers' health and economy}

Residual amounts of antimicrobials, antibiotics or their toxic metabolites found in meat, organs or other products such as milk and egg of food producing animals after slaughtering is called veterinary drug residues [32]. Consumption of such food products poses a major health risk due to the failure of treatment following the development of resistant microorganisms [33]. Various impacts of antimicrobial residues on human health are reported below.

\subsection{Impact on consumers' health}

\subsubsection{Drug resistance}

The possibility of propagating resistant bacteria through the food chain in treated animals was noticed as early as 1969 by Swan, who reported the development of vancomycin resistance to Enterococci in avoparcin fed animals. Animal feeds containing antibiotics, have been reported to result in antimicrobial resistance, leading to failure of medical treatment both in animals and humans. Situations whereby drugs are completely ineffective have also been reported to be a possibility [34]. Giving the established fact of an animal to human microbial resistance transfer [35], resistant micro-organism can gain entrance, directly through contact, into 
humans or indirectly via animal products and by-products (e.g. milk, egg, etc.). The findings of [36] in a study conducted in Taiwan from slaughtered pigs revealed the rate of antimicrobial resistance to salmonella for these drugs; tetracycline (88.2\%), gentamycin $(82.7 \%)$, chloramphenicol (54.3\%), amoxicillin (34.6\%), nalidixic acid $(30.7 \%)$, ampicillin $(26.8 \%)$, kanamycin (18.1\%), cephalothin $(7.1 \%)$, nitrofurantoin $(6.3 \%)$, ciprofloxacin $(0.8 \%)$ [36]. Failure of antimicrobial therapy due to resistant strain is a future concern [13].

\subsubsection{Allergy or hypersensitivity reactions}

Allergy or immune-mediated response to a chemical agent (e.g. drug) can develop in a sensitized patient. Such allergic reactions are usually mediated by IgE and could be elicited following administration of drugs or macromolecules such as protein, lipids and carbohydrates. Dayan [37] affirmed that human population estimate of about $4-11 \%$ are believed to be allergic to penicillin. Such class of humans consuming meat products having penicillin residues is at risk of developing allergy which can manifest as a skin rash or even severe anaphylaxis [35]. Thong and Tan [38] reported that IgE-mediated allergic anaphylaxis is linked to penicillin and other anesthetic drugs following their administration during perioperative periods. Mild rash to severe toxidermia are some of the skin reactions following human exposure to sulfonamide [39]. However, such adverse reaction was not a direct effect of consuming animal products containing relative trace amounts of sulfonamides. Studies have also shown that damages done to hepatic liver cells can be traced to allergic response to macrolide antibiotics (e.g. erythromycin, clarithromycin) [40].

\subsubsection{Carcinogenic effect}

The term carcinogenic refers to any substance or an agent capable of altering the genetic makeup of an organism so that they multiply and become rancorous while carcinogen refers to any substance that promotes carcinogenesis, the formation of cancer or having carcinogenic activity. Carcinogenic residues functions by covalently binding intracellular components including DNA, RNA, proteins, glycogen, phospholipids and glutathione [49]. The ban of Diethylstilbestrol (DES), an hormone-like compound used for food producing animals, was as a result its strong carcinogenic effect [27]. According to the International Agency for Research on cancer (IARC), evidence abounds to suggest that metronidazole is carcinogenic in animal, but insufficient to do so in humans [41].

\subsubsection{Disruptions of normal intestinal flora}

Intestinal microflora plays an important role in human physiology. They establish control and prevent the colonization of pathogenic bacteria in the gastrointestinal tract [42]. However, studies have shown that antimicrobials administered for therapeutic purposes can potentially alter or change the ecological composition of the intestinal flora $[43,44]$. Degree of change however, depends on the dosage of the antimicrobial drug, route of administration, its bioavailability, metabolism, exposure length to the drug and distribution in the body including excretion route [45]. Disruption of intestinal flora has been reported due to the use of broadspectrum antibiotics. Commonly used drugs like streptomycin, tylosin, metronidazole, nitroimidazole and vancomycin are commonly implicated in human in the diagnosis of gastrointestinal disorders [46]. 


\subsubsection{Mutagenic effect}

Mutagens are chemicals or substances with potentials to cause mutations in a DNA molecule thereby altering the genetic makeup of a cell or organism. Studies have shown alkalizing agents and analogous of DNA bases are mutagenic. There is a growing fear of a possible drug-related gene mutagen or chromosome breakage among human population $[47,48]$.

\subsubsection{Teratogenic effect}

Congenital malformation of the foetus during pregnancy as a result of toxic metabolites of drugs or chemical agents has been reported [47]. Such drugs or teratogens alter the structural and functional integrity of the developing embryo/ foetus during the critical phase of gestation. Studies have shown that benzimidazole (an anthelmintics) is not only mutagenic but also has teratogenic activities and is highly toxic to embryo when ingested at early stages of conception or pregnancy $[49,50]$.

\subsection{Impact on global economy}

Antimicrobials' usage in livestock either at sub-therapeutic or therapeutic dosage and its attendant residues in food animals have become a global issue and concern. The growing awareness about the potential risk of diseases such as cancer and also the distortion of body's functional and system integrity (i.e. endocrine, nervous, reproductive and immune system) [51], resulting from the consumption of such 'compromised' food of animal origin, have reduced consumers' confidence and the resultant adverse impact on global economy. Additionally, the maximum residual limits (MRLs) set by Codex Alimentarius Commission (Codex) for veterinary drug residues as an international food safety standards are however not generally accepted by the committee of nations [52]. The limitation of Codex and World Trade Organization (WTO) to enforce adoption of MRLs [53], has resulted in differences in food safety standards across countries and nations. Such differences usually end as trade disputes [54] leading to a gradual decline in meat and meat products exported.

\section{Detection: mode of examination and equipment or methodologies}

Studies are replete with developments of antimicrobial resistance from food producing animals after consumption. There is also a general upsurge in form of sensitization on the need to minimize exposure to antibiotic residues in food $[55,56]$. Antimicrobial residues in meat and meat products are the results of non-compliance of withdrawal periods, antibiotics overdosing and the continuous use of antibiotics banned for treatment of economic animals [57, 58]. Giving the foregoing above, specific legislation has been set to protect consumers from exposures to potentially harmful residues of veterinary medicines, pesticides and environmental contaminants in food of animal origin. Maximum residual limits (MRLs) have been set for veterinary medicines, pesticides and environmental contaminants (European Regulation (EC) No 470/2009). The Regulation not only seeks to identify but also demand quantitative assessment of antibiotic residues.

Control of antibiotic residues in food of animal origin follows two basic steps: Firstly, the animal product is screened qualitatively or quantitatively. In qualitative 
assessment, the presence of an antimicrobial residue is detected here and it's usually reported as either positive or negative. Identification and quantification of a particular residue is done using the quantitative screening method and it is also reported as a concentration of the residue. If results are positive, a confirmatory procedure is usually followed for specific antibiotics with the aid of a more sensitive physic-chemical method.

\subsection{Microbial screening method}

Though its use dates back as early as 1964 and was adopted initially to monitor the dairy industry with a view to preventing problems in the fermentative dairy industry, it has now been extended as a regulatory residue screening method in slaughter animals even till date. The microbial inhibition assay can cover an entire antibiotic spectrum under one test.

The microbial inhibition assay adopts either the tube test or the plate test. The tube test makes use of a tube, vial or an ampule containing a growth medium inoculated with (spores of) a sensitive test bacterium, supplemented with a $\mathrm{pH}$ or redox indicator. At the appropriate conditions of temperature and $\mathrm{pH}$, there is a color from the acid produced by the growing bacteria. Absence or delay of the color change is indicative of the presence of an antimicrobial residue and is usually a commonly used routine in the milk industry $[59,60]$. It has however been used for analysis of other matrices $[61,62]$. In the plate test, the test sample is spread on the layer of the plate containing inoculated nutrient agar. Presence of an antimicrobial residue is detected by the formation of an opaque layer by the growing bacterial, thus yielding a clear growth-inhibited area around the sample. This method is commonly used in Europe for screening of antibiotics residues in slaughter animals $[63,64]$.

\subsection{Immunological technique}

The immunological techniques work on the principle of antigen-antibody interactions and it is usually very specific and helps in detecting residues from in food producing animals. The enzyme-linked immunosorbent assay (ELISA) is commonly used and detection of antimicrobials is based an enzyme-labeled reagents. ELISA has proven very useful for residual screening in meat especially for tylosin and tetracycline $[65,66]$. ELISA's antigen-quantification could take different forms like the direct and indirect sandwich ELISA. Sandwich ELISA works on the principle of recognizing specific antigens that share similar epitopes with other antigens. The indirect sandwich ELISA has the advantage of being highly specific and sensitive. Radioimmunoassay measures the radioactivity of immunological complex using a counter [67].

\subsection{Chromatographic method}

Liquid chromatography is also useful in the qualitative and quantitative screening of multi-residues in food animals, though its use has rapidly decreased during the last decade [68]. The high-performance liquid chromatography (HPLC) relies on pumps to pass a pressurized liquid solvent containing the sample mixture through a column filled with a solid adsorbent material. Each component in the sample interacts slightly differently with the adsorbent material, causing different flow rates for the different components and leading to the separation of the components as they flow out the column. It has been applied for the detection of antimicrobials in meat, fish and internal organs $[69,70]$. 
Laboratories' use of HPLC has grown very rapidly and has the capacity to analyze multiple residues in a sample within a short time. Also, the equipment is fully automated (injection, elution, washing of column, detection) and controlled with the aid of a computer. Hence, it can be used as a screening technique [68].

Coupling of HPLC with mass spectrometry (MS-MS) has resulted in substantial reduction of analysis time for confirmation in presumed positive samples after initial screening. Such a combination could effectively be used simultaneously for screening and confirmation [71, 72].

\subsection{Biosensors}

This is a recent and modern approach for detecting veterinary residues in meat and dairy products while ensuring their quality and safety. It has applications for high throughputs within biotechnology. The instrument is made up of biological recognition element (bioreceptor), which recognizes the target antimicrobial residue and a signal transduction element (transducer) which converts the recognition event into a measurable signal [73]. It is usually in close contact and connected to data acquisition and processing systems [74]. The instrument is rapid, highly selective, inexpensive, simple and can be handled by an unskilled personnel [75]. The type of bioreceptor or transducer used forms the basis for classifying biosensors. A bioreceptor can be an organic molecular species (e.g. an antibody, enzyme, protein, or nucleic acid) or a living biological system (e.g. cells, tissues or whole organisms) using biochemical recognition mechanism [76]. Enzymatic biosensors are commonly used for the analysis of herbicides contaminants. Kiran and kale [77] reported an enzyme biosensor that was developed to detect penicillin. However, fewer applications for antibiotic residues and food contaminants have been reported. Cellular biosensors employed for the detection of antibiotic residues such as tetracyclines [78, 79], beta-lactam antibiotics [80, 81]; quinolones [80], chloramphenicol and quinolones [82] have proven to be very effective and fast in detecting of multiple residues simultaneously, within a very short period of time. In transducer-biosensor, common and popular varieties developed for antibiotic residues detection in food producing animals include the mass-based, optical and electrochemical.

\section{Possible solution for eliminating antimicrobial residues in meat and meat products}

\subsection{Promotion of disease resistant livestock breeds}

Development and breeding of disease resistant livestock breeds could be a panacea to reduce the use of antimicrobial drugs, antimicrobial residue and antimicrobial resistance in meat and meat products. Some indigenous breeds of cattle, goats and sheep are either tolerant or resistant to specific diseases and parasites, and are also able to withstand very harsh environmental conditions [83]. Evidence has shown that indigenous breeds such as N’Dama cattle, Red Maasai sheep, Meishan pigs, Lohman Brown chickens, Mandarah chickens and Nguni goat are more resistant to ticks (various species) diseases [84], Haemonchus contortus [85] Sarcocystis miescheriana [86], Ascaridia galli [87], Newcastle disease virus/infectious bursal disease [88] and heart water disease [89], respectively than other breeds. According to Zekarias et al. [90] difference in disease resistance among individuals and breeds are based on immunological system and its interaction with physiological and environmental factors. Alhaji et al. [4] found in their study that antimicrobials are rarely used in local bird flocks, making them likely organic and safe from 
antimicrobial residues and resistance. However, most of the indigenous breed are less productive than some imported or exotic breeds and so do not meet producer's needs. It is known in most cases that exotic breeds are easily susceptible diseases and because of this, it is essential to develop breed that are genetically resistant to diseases (either by cross breeding local and exotic animal together), although they may be costly and impossible to achieve in the absence of useful levels of resistance [91]. Selective breeding and management interventions could be a technically feasible approach to manage diseases in livestock.

\subsection{Promotion of in vitro cultured meat}

Another means to reduce antimicrobial residues in meat and meat products is by embracing the production and development of in vitro cultured meat when it is commercially available. Basically cultured meat is produced from embryonic stem cells or adult stem cells without slaughtering the animal [92]. It involves culturing of animal muscle cells in a controlled environment (i.e. in a medium that contains nutrients and energy sources required for the division and differentiation of the cells into muscle cells that form into tissue) $[93,94]$. The development of cultured meat is projected to compliment conventional meat production and diminish the increasing problems associated with meat including health claims (food-borne illnesses, antimicrobial residues, antimicrobial resistance and animal welfare) [94-97]. The production of in vitro culture meat will require the use of fewer livestock to feed the consumers thereby reducing mass production of livestock when commercially available [98]. This in turn will drastically reduce the usage of antimicrobial drugs in prevention and treatment of livestock infection caused by Salmonella, E. coli, Campylobacter and so on. Since meat sold today is raised on factory farms, where animals are fed antimicrobial drugs to keep them disease-free [98], production of in vitro cultured meat could be a better option.

\subsection{Promotion of ethno-veterinary practices as alternative to veterinary drugs}

The role of ethno-veterinary practices in reducing of antibiotic residue and antimicrobial resistance in livestock production is enormous as they are regarded safe and efficacious [99]. They play a significant role in maintaining or restoring animal health in several regions of the world especially in areas where livestock is a main source of income for rural peoples [100]. Ethno-veterinary medicines is often obtained from herbal plants. Recently, there is a greater interest in uses of plants (herbal) due to their accessibility, availability, affordability, efficacy and ease of preparation [100]. Traditional ethno-veterinary medicines have been identified for treatments of small ruminants against ecto- and endo-parasites, gastro-intestinal diseases, viral and bacterial diseases, wounds, sprains and bruises [101]. Furthermore the use of ethno veterinary practices for the treatment of fowl pox in turkey [102], bronchitis [103], hepatotoxicity [104] and foot and mouth disease [104] in ruminants has been established. According to Ranganathan [99], the ethno-veterinary medicine can be advocated to combat issues related to antimicrobial resistance and also minimize the possibility of residues in meat products. Report has shown that the prevalence of antimicrobial resistance was 10-20\% lower where antibiotic use was restricted compared to those where it was not [1].

\subsection{Other measures for solution}

According to Vishnuraj et al. [6], other measures that could be adopted to reduce antimicrobial residues in meat and meat products include (1) reduction of 
antimicrobial usage in livestock production (as many developed countries have banned its usage as growth promoters), (2) enforcement of appropriate withdrawal periods of antimicrobial drugs application by government authorities or regulatory bodies before livestock slaughter (3) creation of mass awareness on implication of antimicrobial drugs residues in meat and meat products among consumers, and individual farmer, (4) livestock producer should be educated on farm management, hygiene practices and antimicrobial usages in order to prevent occurrence of antimicrobial residues in meat production and lastly (5) rapid screening methods should be developed for detecting and segregating samples contains above antimicrobial residues before the food products get to consumers. More so, establishment of framework to proper monitoring of drug usage and surveillance of antimicrobial resistance would be of great advantage [105].

\section{Conclusion}

Findings from this study has shown that the presence of veterinary drug residue in food products is a global health concern as the consequence of using antimicrobial drugs to treat and prevent animal disease extend far beyond the farm. Therefore, the solution to antimicrobial residues will require a coordinated regulatory bodies to monitor the use of antimicrobial drugs to control diseases and also enforce punishment on indiscriminate usage. More so a sensitive, selective and reliable analytical methods to easily detect and monitor antimicrobial residues in meat products should be encouraged.

\section{Acknowledgements}

The authors are grateful to Govan Mbeki Research and Development Centre (GMRDC) of the University of Fort Hare (UFH) for providing financial assistance for this work as part of the UFH's support to the Department of Science and Technology/National Research Foundation (DST/NRF) South African.

\section{Conflict of interest}

None declared by the authors. 
Veterinary Drug Residues in Meat and Meat Products: Occurrence, Detection and Implications DOI: http://dx.doi.org/10.5772/intechopen.83616

\section{Author details}

Andrew Bamidele Falowo ${ }^{1 *}$ and Oluwakamisi Festus Akimoladun ${ }^{1,2}$

1 Department of Livestock and Pasture Science, Faculty of Science and Agriculture, University of Fort Hare, Alice, South Africa

2 Department of Animal and Environmental Biology, Faculty of Science, Adekunle Ajasin University, Akungba Akoko, Ondo State, Nigeria

*Address all correspondence to: anddele2013@gmail.com

\section{IntechOpen}

(C) 2019 The Author(s). Licensee IntechOpen. This chapter is distributed under the terms of the Creative Commons Attribution License (http://creativecommons.org/licenses/ by/3.0), which permits unrestricted use, distribution, and reproduction in any medium, provided the original work is properly cited. (cc) BY 


\section{References}

[1] WHO. World Health Organization Guidelines on Use of Medically Important Antimicrobials in Food-producing Animals. 2017. Available from: http://apps. who.int/iris/bitstream/han dle/10665/258970/9789241550130-eng. pdf;jsessionid=FD58B9CED3B23E5 1C59F325F08A89DEF? sequence $=1$ [Accessed: 15 November 2018]

[2] Moreno L, Lanusse C. Veterinary drug residues in meat-related edible tissues. In: New Aspects of Meat Quality. United Kingdom: Woodhead Publishing Limited; 2017. pp. 581-603. ISBN: 978-0-08-100593-4

[3] Landoni MF, Albarellos G. The use of antimicrobial agents in broiler chickens. The Veterinary Journal. 2015;205:21-27

[4] Alhaji NB, Haruna AE, Muhammada B, Lawan MK, Isol TO. Antimicrobials usage assessments in commercial poultry and local birds in North-Central Nigeria: Associated pathways and factors for resistance emergence and spread. Preventive Veterinary Medicine. 2018;154:139-147

[5] Prajwal S, Vasudevan VN, Sathu T, Irshad A, Nayankumar SR. Kuleswan Pame antibiotic residues in food animals: Causes and health effects. The Pharma Innovation Journal. 2017;6(12):01-04

[6] Vishnuraj MR, Kandeepan G, Rao $\mathrm{KH}$, Chand S, Kumbhar V. Occurrence, public health hazards and detection methods of antibiotic residues in foods of animal origin: A comprehensive review. Food and Agriculture.

2016;2:1235458

[7] Aarestrup F. Sustainable farming: Get pigs off antibiotics. Nature. 2012;486:465-466. DOI: http://dx.doi. org/10.1038/486465a
[8] Food and Drug Administration (FDA). CVM Updates-CVM Reports on Antimicrobials Sold or Distributed for Foodproducing Animals. Maryland, USA: Silver Spring; 2010

[9] Van Boeckel TP, Brower C, Gilbert M, Grenfella BT, Levina SA, Robinsoni TP, et al. Global trends in antimicrobial use in food animals. In: Proceedings of National Academy of Science. Washington, DC. 5 May 2015;112(18):5649-5654. Available from: www.pnas.org/cgi/doi/10.1073/ pnas.1503141112. [Accessed:

15 November 2018]

[10] Sanz D, Razquin P, Condón S, Juan T, Herraiz B, Mata L. Incidence of antimicrobial residues in meat using a broad spectrum screening strategy. European Journal of Nutrition and Food Safety. 2015;5(3):156-165

[11] Federal Ministries of Agriculture, Environment and Health (FMAEH).

Antimicrobial Use and Resistance in Nigeria: Situation Analysis and Recommendations, 2017. Available from: https://ncdc.gov.ng/themes/ common/docs/protocols/56_1510840387

[Accessed: 15 November 2018]

[12] REGULATION H. Council regulation (EEC) no $2377 / 90$ of 26 June 1990 laying down a community procedure for the establishment of maximum residue limits of veterinary medicinal products in foodstuffs of animal origin. Official JL. 1990;224:0001-0008

[13] Nisha AR. Antibiotic residues-A global health hazard. Veterinary World. 2008;1(12):375-377

[14] Vragović N, Bažulić D, Njari B. Risk assessment of streptomycin and tetracycline residues in meat and milk on Croatian market. Food and Chemical Toxicology. 2011;49:352-355 
[15] Woolhouse MEJ et al. Temporal trends in the discovery of human viruses. Proceedings of the Royal Society B: Biological Sciences. 2008;275:2111-2115

[16] Perry BD, Grace D, Sones K. Current drivers and future directions of global livestock disease dynamics. 2013;110(52):20871-20877

[17] Page SW, Gautier P. Use of antimicrobial agents in livestock. Revue Scientifique et Technique (International Office of Epizootics). 2012;31(1):145-188

[18] Food and Drug Admiration (FDA). 2016 Summary Report on Antimicrobials Sold or Distributed for Use in Food-Producing Animals. 2017. Available form: https://www. fda.gov/downloads/.../userfees/ animaldruguserfeeactadufa/ucm588085 [Accessed: 15 November 2018]

[19] Adesokan HK, Agada CA, Adetunji VO, Akanbi IM. Oxytetracycline and penicillin-G residues in catle slaughtered in South-Western Nigeria: Implicatons for livestock disease management and public health. Journal of the South African Veterinary Associaton. 2013;84(1):945-950. DOI: 10.4102/jsava. v84i1.945

[20] Cepurnieks G, Rjabova J, Zacs D, Bartkevics V. The development and validation of a rapid method for the determination of antimicrobial agent residues in milk and meat using ultra performance liquid chromatography coupled to quadrupole-Orbitrap mass spectrometry. Journal of Pharmaceutical and Biomedical Analysis. 2015;102:184-192

[21] Alvarez-Fernandez E, Cancelo A, Díaz-Vega C, Capita R, Alonso-Calleja C. Antimicrobial resistance in $E$. coli isolates from conventionally and organically reared poultry: A comparison of agar disc diffusion and Sensi Test Gramnegative methods. Food Control. 2013;30:227-234

[22] Williams PG. Nutritional composition of red meat. Nutrition and Dietetics. 2014;64:113-119

[23] FAO. Food Outlook-Biannual Report on Global Food Markets. 2014. pp. 1-8. Available from: www.fao.org/ docrep/019/i3751e/i3751e.pd [Accessed: 15 October 2018]

[24] WWF Report. Social, Economic and Environmental Analysis of Soybean and Meat Production in Paraguay. 2016. Available from: www.awsassets.panda. org [Accessed: 19 October 2018]

\section{[25] OECD/FAO. OECD-FAO}

Agricultural Outlook, OECD Agriculture Statistics (Database). 2018. http://dx.doi.org/10.1787/agr-outldata-en. [Accessed: 15 November 2018]

[26] Song JS, Park SJ, Choi JY, Kim JS, Kang MH, Choi BK, et al. Development of analytical method and monitoring of veterinary drug residues in Korean animal products. Korean Journal for Food Science of Animal Resources. 2016;36:319-325

[27] Lee MH, Lee HJ, Ryu PD. Public health risks: Chemical and antibiotic residues-review. Asian-Australasain Journal of Animal Science. 2001;14:402-413

[28] Lee H-C, Chen C-H, Wei J-T, Chiu HY. Analysis of veterinary drug residue monitoring results for commercial livestock products in Taiwan between 2011 and 2015. Journal of Food and Drug Analysis. 2018;26:565-571

[29] Skockova A, Kolackova I, Bogdanovicova K, Karpískova R. Characteristic and antimicrobial resistance in Escherichia coli from retail meats purchased in the Czech Republic. Food Control. 2015;47:401-406 
[30] Moniri R, Dastehgoli K.

Fluoroquinolone-resistant Escherichia coli isolated from healthy broilers with previous exposure to fluoroquinolones: Is there a link? Microbial Ecology in Health and Disease. 2005;17(2):69-74

[31] Hammerum AM, Heuer OE. Human health hazards from antimicrobialresistant Escherichia coli of animal origin. Clinical Infectious Diseases. 2009;48:916-921

[32] Liu CK. Caution with animal drugs to prevent food safety. In: Veterinarian Newsletter. Vol. 2. Animal Health Research Institute, Council of Agriculture; 2011. pp. 15-17

[33] Butaye P, Devriese LA, Haesebrouck F. Differences in antibacterial resistance patterns of enterococcus faecalis and Enterococcus faecium strains isolated from farm and pet animals. Antimicrobial Agents and Chemotherapy. 2001;45:374-1378

[34] Wegener HC, Aarestrup FM, Jensen LB, Hammerum AM, Bager F. Use of antimicrobial growth promoters in food animals and enterococcus faecium resistance to therapeutic antimicrobial drugs in Europe. Emerging Infectious Diseases. 1999;5:329-335

[35] Baynes RD, Dedonder K, Kisell L, Mzyk L, Marmulak T, Smith G, et al. Health concerns and management of select veterinary drug residues. Food and Chemical Toxicology. 2016;88:112-122

[36] Lee SY, Kim OY, Yoon SY, Lee DY, Hur SJ. Changes in resistance to and antimicrobial activity of antibiotics during in vitro human. Digestion. Journal of Global Antimicrobial Resistance. 2018;15:277-282

[37] Dayan AD. Allergy to antimicrobial residues in food: Assessment of the risk to man. Veterinary Microbiology. 1993;35(34):213-326
[38] Thong BY, Tan TC. Epidemiology and risk factors for drug allergy. British Journal of Clinical Pharmacology. 2011;71(5):684-700

[39] Choquet-Kastylevsky G, Vial T, Descotes J. Allergic adverse reactions to sulfonamides. Current Allergy and Asthma Reports. 2002;2:16-25

[40] Darwish WS, Eldaly EA, El-Abbasy MT, Ikenaka Y, Nakayama S. Antibiotic residues in food: The African scenario. Japanese Journal of Veterinary Research. 2013;61:13-22

[41] Bendesky A, Menendez D, Ostrosky-Wegman P. Is metronidazole carcinogenic? Mutation Research.

2002;511(2):133-144

[42] Vollaard EJ, Clasener HAL.

Colonization resistance. Antimicrobial Agents and Chemotherapy. 1994;38:409-414

[43] Carman RJ, Van Tassell MS, Wilkins TD. The normal intestinal microflora: Ecology, variability and stability. Veterinary and Human Toxicology. 1993;35(1):11-14

[44] Edlund C, Nord CE. Effect of quinolones on intestinal ecology. Drugs;1999, 58(2):65-70

[45] Cerniglia CE, Kotarski S. Approaches in the safety evaluations of veterinary antimicrobial agents in food to determine the effects on the human intestinal microflora. Journal of Veterinary Pharmacology. 2005;28:3-20

[46] Cotter PD, Stanton C, Ross RP, Hill C. The impact of antibiotics on the gut microbiota as revealed by high throughput DNA sequencing. Discovery Medicine. 2012;13:193

[47] Booth NH, McDonald LE. Toxicology of drug and chemical residues. In: Veterinary Pharmacology 
and Therapeutics. 6th ed. USA: Iowa State University Press; 1988. pp. 1149-1195

[48] Foster W, Beecroft ML. Chemical exposures and human fertility. In: Infertility Awareness Association of Canada. 2014. Available from: http://www.cwhn.ca/en. [Accessed: 15 November 2018]

[49] Aiello SE, Lines PR, Kehn CM. Anthelmintics. In: The Merck Veterinary Manual. 9th ed. Kenilworth, NJ, USA: Merck \& Co., Inc.; 2005. pp. 2111-2124

[50] El-Makawy A, Radwan HA, Ghaly IS, El-Raouf AA. Genotoxical, teratological and biochemical effects of anthelmintic drug oxfendazole maximum residue limit (MRL) in male and female mice.

Reproduction, Nutrition, Development. 2006;46:139-156

[51] Horrigan L, Robert SL, Walker P. How sustainable agriculture can address the environmental and human health arms of industrial agriculture. Environmental Health Perspectives. 2002;110:445-456

[52] Wilson JS, Otsuki T, Majumdar B. Balancing food safety and risk: Do drug residue affect international trade in beef? In: America Agricultural Economics Association Annual Meeting, Montreal, Canada July 2003. pp. 27-30

[53] Wessel JR. Codex committee on pesticide residues 'a plan for improved participation by governments.

Regulatory Toxicology and

Pharmacology. 1992;16(2):126-149

[54] International Agricultural Trade Research Consortium (IATRC). The Role of Product Attributes in the Agricultural Negotiations. St. Paul, MN: University of Minnesota, Department of Applied Economics, Commissioned. 2001. pp. 17
[55] Van den Bogaard AE, Stobbering EE. Epidemiology of resistance to antibiotics. Links between animals and humans. International Journal of Antimicrobial Agents. 2000;14:327-335

[56] Pena A, Serrano C, Reu C. Antibiotic residues in edible tissues and antibiotic resistance of faecal Escherichia coli in pigs from Portugal. Food Additives and Contaminants. 2004;21:749-755

[57] Guest GB, Paige JC. The magnitude of the tissue residue problem with regard to consumer needs. Journal of the American Veterinary Medical Association. 1991;198:805-808

[58] Paige JC. Analysis of tissue residues. FDA Veterinary. 1994;1979(9):4-6

[59] Vermunt AEM, Stadhouders J, Loeffen GJM, Bakker R. Improvements of the tube diffusion method for the detection of antibiotics and sulfonamide in raw milk. Netherlands Milk and Dairy Journal. 1993;47:31-40

[60] Suhren G, Heeschen W. Detection of inhibitors in milk by microbial tests. A review. Nahrung. 1996;40:1-7

[61] Cantwell H, O'Keeffe M. Evaluation of the Premi ${ }^{\circledR}$ Test and comparison with the one-plate test for the detection of antimicrobials in the kidney. Food Additives and Contaminants. 2006;23:120-125

[62] Kilnic B, Meyer C, Volker H. Evaluation of the EEC four-plate test and Premi test for screening antibiotic residues in trout (Salmo trutta). International Journal of Food Science and Technology. 2007;42(5):635-628

[63] Nouws JFM, Schothorst M, Ziv G. A critical evaluation of several microbiological test methods for residues of antimicrobial drugs in ruminants. Archiv für Lebensmittelhygiene. 30:4-8 
[64] Bogaerts R, Wolf F. Standardized method for the detection of residues of antibacterial substances in fresh meat. Fleischwirtsch. 1980;60:672-673

[65] Mahgoub O, Kadim IT, Ann Mothershaw AI, Zadjali SA, Annamalai $K$. Use of enzyme-linked immune sorbent assay (ELISA) for detection of antibiotic and anabolic residues in goat and sheep meat. World Journal of Agricultural Sciences. 2006;2:298-302

[66] Kadim IT, Mahgoub O, Al-Marzooqi W, Al-Magbaly R, Annamal K, Khalaf S. Enzyme-linked immunosorbent assay for screening antibiotic and hormone residues in broiler chicken meat in Sultanate of Oman. Journal of Muscle Foods. 2009;21(2):243-254

[67] Samarajeewa U, Wei CI, Huang TS, Marshall MR. Application of immunoassay in the food industry. Critical Reviews in Food Science and Nutrition. 1991;1991, 29:403-434

[68] Fidel T, Milagro R. Methods for rapid detection of chemical and veterinary drug residues in animal foods. Trends in Food Science and Technology. 2006;17:482-489

[69] Cinquina AL, Roberti P, Gianetti L, Longo F, Draisci R, Fagiolo A.

Determination of enrofloxacin and its metabolite ciprofloxacin in goat milk by high-performance liquid chromatography with diode-array detection. Optimization and validation. Journal of Chromatography A. 2003;987:221-226

[70] Kirbis A, Marinsek J, Flajs VC. Introduction of the HPLC method for the determination of quinolone residues in various muscle tissues. Biomedical Chromatography. 2005;19:259-265

[71] Hewitt SA, Kearney M, Currie JW, Young PB, Kennedy DG. Screening and confirmatory strategies for the surveillance of anabolic steroid abuse within Northern Ireland. Analytica Chimica Acta. 2002;473:99-109

[72] Thevis M, Opfermann G, Schanzer W. Liquid chromatography/electrospray ionization tandem mass spectrometric screening and confirmation methods for b2-agonists in human or equine urine. Journal of Mass Spectrometry. 2003;38:1197-1206

[73] Velusamy V, Arshak K, Korostynska O, Olivia K, Adley C. An overview of foodborne pathogen detection: In the perspective of biosensors. Biotechnology Advances. 2010;28(2):233-254

[74] Patel PD. Biosensors for measurement of analytes implicated in food safety: A review. TrAC: Trends in Analytical Chemistry. 2002;21:96-115

[75] Valerie G. Advances in biosensor development for the screening of antibiotic residues in food products of animal origin-A comprehensive review. Biosensors and Bioelectronics. 2017;90:363-377

[76] Vo Dinh T, Cullum B. Fresenius. Biosensors and biochips: Advances in biological and medical diagnostics. Journal of Analytical Chemistry. 2000;366(6-7):540-551

[77] Kirian BR, Kale KU. Transformed E. coli JM 109 as a biosensor for penicillin. Indian Journal of Pharmaceutical Sciences. 2002;83(3):205-208

[78] Bahl MI, Hansen IH, Sorensen SJ. Construction of an extended range whole-cell tetracycline biosensor by use of the tet $(\mathrm{M})$ resistance gene. FEMS Microbiology Letters. 2005;253(2):201-205

[79] Virolainen NE, Pikkemaat MG, Elferink JWA, Karp MT. Rapid detection of tetracyclines and their 4-epimer 
derivatives from poultry meat with bioluminescent biosensor bacteria. Journal of Agricultural and Food Chemistry. 2008;56(23):11065-11070

[80] Ben-Yoav H, Elad T, Shlomovits O, Belkin S, Shacham-Diamand Y. Optical modeling of bioluminescence in whole cell biosensors. Biosensors and Bioelectronics. 2009;24(7):1969-1973

[81] Ferrini AM, Mannoni V, Carpico G, Pellegrini GE. Detection and identification of beta-lactam residues in milk using a hybrid biosensor. Journal of Agricultural and Food Chemistry. 2008;56:784788

[82] Shapiro E, Baneyx F. Stressactivated bioluminescent Escherichia coli sensors for antimicrobial agents detection. Biotechnology. 2007;132(4):487-493

[83] Mwai O, Hanotte O, Kwon Y, Cho $\mathrm{S}$. African indigenous cattle: Unique genetic resources in a rapidly changing world. Asian-Australasian Journal of Animal Science. 2015;28(7):911-921

[84] Claxton J, Leperre P. Parasite burdens and host susceptibility of Zebu and N'Dama cattle in village herds in the Gambia. Veterinary Parasitology. 1991;40(3-4):293-304

[85] Baker RL. Genetic resistance to endoparasites in sheep and goats. A review of genetic resistance to gastrointestinal nematode parasites in sheep and goats in the tropics and evidence for resistance in some sheep and goat breeds in sub-humid coastal Kenya. Animal Genetic Resources Information. 1998;24:13-30

[86] Reiner G, Eckert J, Peischl T, Bochert S, Jäkel T, Mackenstedt $\mathrm{U}$, et al. Variation in clinical and parasitological traits in Pietran and Meishan pigs infected with Sarcocystis miescheriana. Veterinary Parasitology. 2002;106(2):99-113
[87] Permin A, Ranvig H. Genetic resistance to Ascaridia galli infections in chickens. Veterinary Parasitology. 2001;102(2):101-111

[88] Hassan MK, Afify MA, Aly MM. Genetic resistance of Egyptian chickens to infectious bursal disease and Newcastle disease. Tropical Animal Health and Production. 2004;36(1):1-9

[89] Irvin AD, McDermott JJ, Perry BD. Epidemiology of ticks and tickborne diseases in eastern, central and southern Africa. In: Proceedings of a Workshop Held in Harare. Nairobi, Kenya: International Livestock Research Institute (ILRI); 1996. pp. 174

[90] Zekarias B, TerHuurne Agnes AHM, Landman Wil JM, Rebel Johanna MJ, Pol Jan MA, Erik G. Immunological basis of differences in disease resistance in the chicken. Veterinary Ressearch. 2002;33(2):109-125. DOI: 10.1051/ vetres:2002001

[91] Cock J, Gitterle T, Salazar M, Rye $\mathrm{M}$. Breeding for disease resistance of Penaeid shrimps. Aquaculture. 2009;286:1-11

[92] Post MJ. Cultured meat from stem cells: Challenges and prospects. Meat Science. 2012;92:297-301

[93] Bhat ZF, Kumara S, Fayaz H. In vitro meat production: Challenges and benefits over conventional meat production. Journal of Integrative Agriculture. 2015;2(14):241-248

[94] Datar I, Betti M. Possibilities for an in vitro meat production system. Innovative Food Science and Emerging Technologies. 2010;11:13-22

[95] Tuomisto HL. Food security and protein supply-cultured meat a solution? Annals of Applied Biology. 2010;102:99-104 
[96] Zaraska M. Lab-grown beef taste test: 'Almost' like a burger. Health and Science, The Washington Post. 2013. Available from: www. washingtonpost.com/health-science/ lab-grown-beef [Accessed: 5 November 2018]

[97] Chiles RT. Intertwined ambiguities: Meat, in vitro meat, and the ideological construction of the marketplace. Journal of Consumer Behavavoiur. 2013;12:472-482

[98] Murthy MSS. Meat without slaughter. Science Reporter. 2012;49(10):56-57. Available from: http://www.niscair.res.in [Accessed: 30 November 2018]

[99] Ranganathan V. Ethno veterinary practices for combating antimicrobial resistance. International Journal of Science, Environment and Technology. 2017;1(6):840-844

[100] Wanzala W, Zessin KH, Kyulec NM, Baumann MPO, Mathias E, Hassanali A. Ethnoveterinary medicine: A critical review of its evolution, perception, understanding and the way forward. Livestock Research for Rural Development. 2005;17(11):1-41

[101] Piluzza G, Virdis S, Serralutzu F, Bullitta S. Uses of plants, animal and mineral substances in Mediterranean ethno-veterinary practices for the care of small ruminants. Journal of Ethnopharmacology. 2015;168:87-99

[102] Basheer Ahamad D, Punniamurthy NSS, Ranganathan V. Pathomorphology and ethno veterinary herbal intervention in an outbreak of Turkey pox. Indian Journal of Veterinary Pathology. 2013;37(1):18-21

[103] Pala NA, Negi AK, Todaria NP. Traditional uses of medicinal plants of Pauri, Garhwal, Uttarakhand. New York Science. 2010;3(6):61-65
[104] Punniamurthy N, Ranganathan V, Basheer Ahamad D, Sathesh KS. Hepatoprotective activity of Caralluma umbellate in chicken. The Indian Veterinary Journal. 2014;91(12):33-35

[105] WHO. WHO Global Principles for the Containment of Antimicrobial Resistance in Animals Intended for Food. 2000. Available from: http://www. who.int/emc 


\title{
Foot-and-Mouth Disease Virus (FMDV) and Its Treatment with Plant Extracts
}

\author{
Ishrat Younus, Sidra Maqbool, Sarah Jameel Khan, \\ Humera Sarwar, Shagufta Nesar, Rida Fatima, Sidra Siddique \\ and Moona Baig
}

\begin{abstract}
Foot-and-mouth disease (FMD) is a contagious viral infection which is caused by foot-and-mouth disease virus (FMDV). The disease appears in cloven-footed animals. Symptoms of the disease are abrupt manifestation of sores on the mouth, nose, feet, etc. Nowadays the control and treatment of FMDV are becoming a worldwide economic problem and challenge for the society. Currently, there is no particular treatment available for FMDV, as well as the limitations and disadvantages in the use of vaccines divert the focus of researchers toward natural sources like plant extracts which possess potential antiviral activity. Various researches documented in the literature demonstrated various plant extracts with antiviral potency against FMDV. In the current chapter, we discussed about FMDV and its possible treatment with plant extracts.
\end{abstract}

Keywords: $F M D V$, treatment, plant extracts

\section{Introduction}

Foot-and-mouth disease (FMD) is a contagious viral infection [1] which is caused by foot-and-mouth disease virus (FMDV). The disease appears in cloven-footed animals. Symptoms of the disease are abrupt manifestation of sores on the mouth, nose, feet, etc. [2]. These symptoms can appear within 2-3 days postexposure and can take up to 7-10 days. FMDV belongs to genus Aphthovirus and family Picornaviridae and has seven species. In the year 2001, about 57 zones were previously influenced by dangerous FMD at the detection of FMDV for the first time in Britain. Later on about 43 animals were encountered with FMD just in a day. So estimate regarding the onset of FMD among animals may be biased [3].

For the prevention and elimination of FMDV, two methods could be adopted, that is, massacre and immunization [4]. The virus can last for an extended period of time especially in cool environment and neutral $\mathrm{pH}$.

The foot-and-mouth disease virus (FMDV) belongs to genus Aphthovirus and family Picornaviridae [5]. FMDV has seven diverse serotypes O, A, C, SAT-1, SAT-2, SAT-3, and Asia-1. Serotype $O$ is the most familiar in the world among all the serotypes. More than 60 strains are found among these serotypes. These serotypes differ 
with each other in different topographic areas. Serotype O was accountable for that Asian epidemic which occurred in the year 1990 and influenced all over the world [1]. FMDV is a single-stranded RNA virus. It contains a protein coat comprising of four capsid proteins designated as VP1, VP2, VP3, and VP4 [4].

Foot and mouth disease (FMD) affects cloven-footed animals. The disease is very fast-growing and transmissible which usually affects pigs, cattle, goats, and sheep. The symptoms include vesicles/blisters on the hoofs, mouth, nose, feet, teats, etc. Ultimately these blisters result in skin erosions. Animals become unable to take food and thus become weak. Other symptoms include salivation, decrease in milk production, and weight loss. This viral problem occurs around the whole globe. FMDV epidemic occurred in different countries of the world like Europe, the United States, and Canada. In the year 1967, FMDV epidemic resulted in mortality of 400,000 pigs in the United Kingdom. Epidemic of FMDV in the United Kingdom causes death of about 70,000 pigs, cattle, and sheep in 70 areas [2].

Foot and mouth disease is a very dangerous communicable disease. It has affected different domestic animals in different areas with very lethal symptoms. Its breakthrough is especially notable in the United Kingdom. In the year 2001, about 57 zones were previously influenced by dangerous FMD at the detection of FMDV for the first time in Britain. Later on about 43 animals were encountered by this FMD just in a day. So estimate regarding the onset of foot and mouth disease among animals may be biased [3].

\section{Plants for treatment of FMDV}

Different plants were evaluated to prevent or eradicate FMDV. An experiment evaluated two parts of ginseng plant, stem and leaves, regarding susceptibility of mice to immunization to vaccine against serotype Asia-1 of FMDV. Ginseng along with its oil was also used to assess collective outcome regarding immunization against FMDV. This research showed that considerable high titer of various antibodies resulted when ginseng along with oil is given in combination. Important antibodies which were evaluated included IgG1, IgG2a, IgG2b, and IgG3.

In a study forty two plants were used to prepare 47 ethanolic extracts which were evaluated for their antiviral potential against KPS/005/2545 strain of type "O" $F M D V$. BHK-21 cell line was used in the experimental study. The virus was used at the rate of $10^{6.37}$ TCID $_{50}$. Transgenic plant (Arabidopsis thaliana) was used to synthesize VP1 with 135-160 amino acid residues. These antigens were found to provide immunization against viral disease [6]. Some plants showed significant antiviral activity against FMDV which included Morinda elliptica and Morinda citrifolia. Other plants failed to exhibit antiviral activity against FMDV [7]. This indicates that plants have antiviral potential and they can be used as antiviral agents against FMDV.

In another reported study, it was mentioned that FMD is a transmissible ailment of animals. Effective control of this disease needs sensitive, specific, and quick diagnostic tools at each tier of control strategy. Various pen-side tests, namely, lateral flow, RT-LAMP, immunostrip tests, and so forth, were also developed for the detection of the virus in field condition [8].

$F M D V$ is transmissible, and to maintain protection against this virus, a study was conducted on guinea pigs and rabbits. The study suggested that immunization of animals with synthetic peptide $141-160$ produces neutralizing antibodies that provide protection against FMDV [9]. Similarly, different synthetic peptide residues 141-158 and 200-213 of VP1 were synthesized from 01 Kaufbeuren strain of FMDV. These peptides were proved to provide protection against FMDV via acting on VP1 carboxyl terminal [10]. 
In the 1930s, the first vaccine was developed against FMDV. The vaccine was developed from live FMDV with formalin in combination with aluminum hydroxide gel. Treatment of animals with this vaccine reduced the outbreak of viral disease [11]. Later on, vaccines have been developed based on the virus capsid structure. These vaccines were synthesized from purified or recombinant DNA techniques, derived or chemically synthesized VP1 peptides, inoculation with DNA expressing VP1 epitopes or interleukin, and plant expressing VP1 [12]. Moreover, a vaccine was developed by deleting RGD receptor site on VP1, which resisted virus binding to the cell [13]. Similarly, a live attenuated vaccine was prepared that lack the L-coding in A-type $A_{12}$ virus. The vaccine resulted in replication of cells but decreased the virulent factor of disease in cattle [14]. On the other hand, a swine inoculated with wild-type $A_{12}$ in combination with oil led to neutralization of FMDV [15].

Different studies have been reported on targeted immunogens that lack infectious nucleic acid. In a reported study, mice were inoculated with active virus $3 C^{\text {pro }}$ in empty capsules. This vaccine produced neutralizing response by producing antibodies [16]. Another study showed improved FMDV antibody response after coadministration of viral capsid along with porcine granulocyte-macrophage colony-stimulating factor [17].

Meanwhile some studies illustrated the recombinant and replication of vaccinia virus containing capsid-coding region of FMDV C1Oberbayern or $\mathrm{C}_{3}$ Argentina85 [18]. To prevent the outbreak, Ad5-vectored vaccine was prepared that reduced viral growth. Furthermore, porcine interferon omegas 7 and 8 have also been reported to reduce $F M D V$ in vitro production in swine kidney cells $[19,20]$.

Nowadays the control and treatment of FMDV have become a worldwide economic problem and a challenge for the society. It not only affects the animals, but humans who eat these animals are also affected. Currently, there is no any particular treatment existing regarding the cure of FMDV. The conventional method involved the use of antibiotics, flunixin, meglumine, and mild disinfectants for treating infected animals. Traditionally for washing the lesions of infected animals, natural soda ash solution, honey, and finger millet flour are used [21].

Vaccination of animals is the first-line treatment for the control of the virus. However, vaccines take several days to elicit its response, and sometimes, a booster dose is required with repeated vaccination. There is no vaccine available which meets the ideal conditions like broad antigenic spectrum, high efficacy, low risk of FMDV release, and low production cost. Inactivated (traditional) and live attenuated (conventional) vaccines are used normally. Inactivated vaccines contain one or more cell culture-derived inactivated virus mixed with the suitable excipients. Inactivated vaccines may be categorized into standard or higher potency vaccines. Standard vaccines provide broad-spectrum coverage against the virus strains, while high-potency vaccine has rapid onset of action and wider range of protection. Live attenuated vaccines are not recommended for use as it reverts the chance of infection and also prevents the recognition of infection in vaccinated animals [22].

Azadirachta indica ( $A I)$, known commonly as neem, belongs to family Meliaceae and has possessed antiviral activity against different viruses $[23,24]$. There is a study that reported the use of different concentrations $(200,100,50,25,12,6$, and $1 \mu \mathrm{g} / \mathrm{ml}$ ) of aqueous and ethanolic leaves extract of Azadirachta indica for evaluating antiviral activity against FMDV in farming animals on BHK-21 (baby hamster kidney) cell culture. Aqueous extract of the said plant showed considerable anti-FMDV activity between the concentration ranges of $12.5-50$ and $50-100 \mu \mathrm{g} / \mathrm{ml}$, whereas ethanolic leaves extract demonstrated strong antiviral activity at concentrations between 6 and $25 \mu \mathrm{g} / \mathrm{ml}$. Antiviral activity was evaluated by examining cytopathic effects and determining cell survival percentages [25]. 
Moringa oleifera, local name is Sonjna, belongs to family Moringaceae and is an effective antiviral agent used against Epstein-Barr virus (EBV), herpes simplex virus (HSV), HIV/AIDS, and hepatitis B virus [26]. The anti-FMDV activity of ethanolic leaves extract of Moringa oleifera was evaluated at different concentrations, respectively $(200,100,50,25,12,6$, and $1 \mu \mathrm{g} / \mathrm{ml})$, on BHK-21 cell culture. Ethanolic leaf extracts of plant showed potent anti-FMDV activity between the concentration ranges of 12-100 and 50-300 $\mathrm{\mu g} / \mathrm{ml}$. However, in another study ethanol leaf extracts of plant showed significant antiviral activity at the concentration ranges from 1 up to $100 \mu \mathrm{g} / \mathrm{ml}$ with $50 \%$ cell survival rate [27].

Alhagi maurorum is a member of family Fabaceae, known by local name camel thorn and camelthorn-bush. The successful in vitro anti-FMDV activity of ethanolic, methanolic, and aqueous-acetic acid extracts of $A$. maurorum was reported at different stages of viral replication cycle, with the main compound found to be 1,2-benzenedicarboxylic acid, diisooctyl ester. Reduction in cytopathic effects (CPEs) and tissue culture infective dose (TCID50) values help in the evaluation of antiviral activity of FMDV on Razi bovine kidney (RBK) cells [28].

The Withania somnifera (WS), or Ashwagandha locally known as "Indian winter cherry" or "Indian ginseng," belongs to the family Solanaceae. Ashwagandha is a well-known South African herb used in the treatment of herpes simplex virus [29] and infectious bursal disease [30]. In literature in vitro activity of aqueous extract of Ashwagandha roots and leaves was reported against FMDV of livestock on BHK-21 cell line. Ashwagandha roots and leaves demonstrated effective anti$F M D V$ activity. The antiviral activity of the plant was confirmed by observing reduction in cytopathic effects when treated with Ashwagandha root and leaf extracts [31].

In literature in vivo anti-FMDV activity of Chinese herbal kombucha is reported against FMDV of swine on baby hamster kidney (BHK-21) cells. Chinese herbal kombucha is a combination of different herbal plants, i.e., Radix Glycyrrhizae, Momordica grosvenorii, Dendranthema morifolium, and Camellia sinensis. Study showed that Chinese herbal kombucha inhibited the replication of FMDV analyzed by using realtime quantitative reverse transcription-PCR (Q-RT-PCR) technique [32].

The ethanolic extract of Spirulina platensis demonstrated the presence of antiviral activity against different isolates of FMDV in baby hamster kidney (BHK) cell culture and in baby mice. The results of this study showed that at $50 \mu \mathrm{g} / \mathrm{ml}$, S. platensis extract revealed $28.5,31$, and $35.7 \%$ reductions in FMDV titers type A, SAT-2, and O, respectively. At the same dose, 50\% inhibition in FMDV was observed in infected baby mice [33].

Glycyrrhiza uralensis or Chinese liquorice is used to treat enterovirus 71 (EV71) and Coxsackie virus A16 (CVA16) of FMD. The essential antiviral component in plant is found to be glycyrrhizic acid, as the antiviral activity is directly dependent on the concentration of glycyrrhizic acid. At $1000 \mu \mathrm{g} / \mathrm{ml}$ concentration of plant extract, $1.0 \mathrm{log}$ reduction in EV71 replication and $1.5 \mathrm{log}$ reduction in CVA16 replication were observed. However, at concentration of $200 \mu \mathrm{g} / \mathrm{ml}, 1.7$ and $2.2 \mathrm{log}$ inhibition in EV71 and CVA16 replication is examined, respectively. Cytopathic effects were observed for determining antiviral activity [34].

Ocimum tenuiflorum (tulsi) of family Lamiaceae and Curcuma longa (turmeric) of family Zingiberaceae also possess potential antiviral activity for FMD. Aqueous extracts of both plants showed effective in vitro antiviral activity against $F M D V$ of livestock on BHK-21 cell line at 1:2 and 1:1 dilutions [31].

Various plant crude extracts were studied for their in vitro antiviral activity against bovine FMDV on BHK-21. The immature fruit extract of Morinda elliptica L. showed $F M D V$ inhibition at concentration of $0.39 \mu \mathrm{g} / \mu \mathrm{l}$ with TCID50 value of $1 \times 10^{3.65}$. The Morinda citrifolia L. extract also showed FMDV inhibition at $0.19 \mu \mathrm{g} / \mu \mathrm{l}$, and TCID50 
value was reported to be $1 \times 10^{3.35}$. Extract from leaves and stem of Amaranthus viridis L. has lowest FMDV inhibition at $0.024 \mu \mathrm{g} / \mu \mathrm{l}$ concentration $\left(1 \times 10^{2.44} \mathrm{TCID} 50\right)$. Extracts obtained from the rhizomes of Boesenbergia rotunda L., flowers of Carthamus tinctorius, and fruits of Citrus reticulata and Elaeocarpus hygrophilus showed inhibition of FMDV at concentration of $0.012 \mu \mathrm{g} / \mu \mathrm{l}$ of all extracts with $1 \times 10^{2.14} \mathrm{TCID} 50$ [7].

\section{Conclusion}

Recently there is no particular treatment available for the treatment of FMDV, and the limitations and disadvantages in the use of vaccines divert the focus of researchers toward natural sources like plant extracts which possess potential antiviral activity. The various research works documented in the literature demonstrated various plant extracts with antiviral potency against FMDV.

\section{Future prospects}

The successful in vivo and in vitro anti-FMDV activities of plant extracts showed that they have the potential to be used to control the virus growth inside the body and also help in managing the lesions associated with these infections. In plant extracts, different chemical constituents are present which could be further isolated and effectively used in the development of powerful and potent antiviral drug against FMDV.

\section{Author details}

Ishrat Younus ${ }^{1 *}$, Sidra Maqbool ${ }^{1}$, Sarah Jameel $\mathrm{Khan}^{1}$, Humera Sarwar ${ }^{2}$, Shagufta Nesar ${ }^{2}$, Rida Fatima ${ }^{2}$, Sidra Siddique ${ }^{2}$ and Moona Baig ${ }^{3}$

1 Department of Pharmacology, Faculty of Pharmacy, Hamdard University, Karachi, Pakistan

2 Department of Pharmaceutics, Faculty of Pharmacy, Hamdard University, Karachi, Pakistan

3 Department of Pharmacology, Faculty of Pharmacy, University of Karachi, Karachi, Pakistan

*Address all correspondence to: ishratyounas@gmail.com

\section{IntechOpen}

(C) 2019 The Author(s). Licensee IntechOpen. This chapter is distributed under the terms of the Creative Commons Attribution License (http://creativecommons.org/licenses/ by/3.0), which permits unrestricted use, distribution, and reproduction in any medium, provided the original work is properly cited. (cc) BY 


\section{References}

[1] Aftosa F. Foot and Mouth Disease. Ames, Iowa: College of Veterinary Medicine, Iowa State University; 2007

[2] Kirk JH. Review of Clinical Signs of Foreign Animal Diseases Which a Mixed Veterinary Practitioner Might Encounter on a Dairy. Veterinary Medicine Extension University of California. CA: Davis Veterinary Medical Teaching and Research Center Tulare; 1992

[3] Gibbens JC, Wilesmith JW. Temporal and geographical distribution of cases of foot and mouth diseases during the early weeks of the 2001 epidemic in great Britian. The Veterinary Record. 2002;2002:151-212

[4] Davies G. Foot and mouth disease. Research in Veterinary Science. 2002;73(3):195-199

[5] ICTV. The Seventh Report of the International Committee on Taxonomy of Viruses. Academic Press; 2000

[6] Carrillo C, Wigdorovitz A, Oliveros JC, Zamorano PI, Sadir AM, Gomez N, et al. Protective immune response to foot-and-mouth disease virus with VP1 expressed in transgenic plants. Journal of Virology. 1998;72(2):1688-1690

[7] Chungsamarnyart N, Sirinarumitr T, Chumsing W, Wajjawalku W. In vitro study of antiviral activity of plant crude-extracts against the foot and mouth disease virus. Kasetsart Journal. 2007;41:97-103

[8] Longjam N, Deb R, Sarmah AK, Tayo T, Awachat VB, Saxena VK. A brief review on diagnosis of foot-and-mouth disease of livestock: Conventional to molecular tools. Veterinary Medicine International. 2011

[9] Bittle JL, Houghten RA, Alexander $H$, Shinnick TM, Sutcliffe JG, Lerner
RA, et al. Protection against footand-mouth disease by immunization with a chemically synthesized peptide predicted from the viral nucleotide sequence. Nature. 1982;298(5869):30-33

[10] DiMarchi R, Brooke G, Gale C, Cracknell V, Doel T, Mowat N. Protection of cattle against footand-mouth disease by a synthetic peptide. Science. 1986;232(4750):639-641

[11] Brooksby JB. Portraits of viruses: Foot-and-mouth disease virus. Intervirology. 1982;18(1-2):1-23

[12] Francis MJ, Hastings GZ, Brown F, McDermed J, Lu YA, Tam JP. Immunological evaluation of the multiple antigen peptide (MAP) system using the major immunogenic site of foot-and-mouth disease virus. Immunology. 1991;73(3):249

[13] McKenna TS, Lubroth J, Rieder E, Baxt B, Mason PW. Receptor binding site-deleted foot-and-mouth disease (FMD) virus protects cattle from FMD. Journal of Virology. 1995;69(9):5787-5790

[14] Piccone ME, Rieder E, Mason PW, Grubman MJ. The footand-mouth disease virus leader proteinase gene is not required for viral replication. Journal of Virology. 1995;69(9):5376-5382

[15] Chinsangaram J, Mason PW, Grubman MJ. Protection of swine by live and inactivated vaccines prepared from a leader proteinase-deficient serotype $A_{12}$ foot-and-mouth disease virus. Vaccine. 1998b;16(16): 1516-1522

[16] Chinsangaram J, Beard C, Mason PW, Zellner MK, Ward G, Grubman MJ. Antibody response in mice inoculated with DNA expressing foot-and-mouth 
disease virus capsid proteins. Journal of Virology. 1998a;72(5):4454-4457

[17] Cedillo-Barrón L, Foster-Cuevas M, Belsham GJ, Lefèvre F, Parkhouse RME. Induction of a protective response in swine vaccinated with DNA encoding foot-and-mouth disease virus empty capsid proteins and the 3D RNA polymerase. Journal of General Virology. 2001;82(7):1713-1724

[18] Berinstein A, Tami C, Taboga O, Smitsaart E, Carrillo E. Protective immunity against foot-andmouth disease virus induced by a recombinant vaccinia virus. Vaccine. 2000;18(21):2231-2238

[19] Li SF, Shao JJ, Zhao FR, Gong MJ, Xie YL, Chang HY, et al. Antiviral activity of porcine interferon delta 8 against foot-and-mouth disease virus in vitro. International Immunopharmacology. 2018;59:47-52

[20] Li SF, Zhao FR, Gong MJ, Shao JJ, Xie YL, Chang HY, et al. Antiviral activity of porcine interferon omega 7 against foot-and-mouth disease virus in vitro. Journal of Medical Virology. 2019;91(2):208-214

[21] Gakuya DW, Mulei CM, Wekesa SB. Use of ethnoveterinary remedies in the management of foot and mouth disease lesions in a dairy herd. African Journal of Traditional, Complementary and Alternative Medicines. 2011;8(2)

[22] Paton DJ, Sumption KJ, Charleston B. Options for control of foot-andmouth disease: Knowledge, capability and policy. Philosophical Transactions of the Royal Society B: Biological Sciences. 2009;364(1530):2657-2667

[23] Faccin-Galhardi LC, Yamamoto KA, Ray S, Ray B, Carvalho Linhares $\mathrm{RE}$, Nozawa $\mathrm{C}$. The in vitro antiviral property of Azadirachta indica polysaccharides for poliovirus. Journal of Ethnopharmacology. 2012;142:86-90
[24] Parida M, Dash P, Upadhyay C, Saxena P, Jana A. Serological \& virological investigation of an outbreak of dengue fever in Gwalior, India. Indian Journal of Medical Research. 2002;116:248-254

[25] Younus I, Ashraf M, Fatima A, Altaf I, Javeed A. Evaluation of cytotoxic and antiviral activities of aqueous leaves extracts of different plants against foot and mouth disease virus infection in farming animals. Pakistan Journal of Pharmaceutical Sciences. 2017; (6):30

[26] Wang L, Chen X, Wu A. Mini review on antimicrobial activity and bioactive compounds of Moringa oleifera. Medicinal Chemistry. 2016;6:578-582

[27] Younus I, Siddiq A, Assad T, Baddar S, Jameel S, Ashraf M. Screening antiviral activity of Moringa oleifera L. leaves against foot and mouth disease virus. Global Veterinaria. 2015;15(4):409-413

[28] Shakiba Y, Rezatofighi SE, Seyyednejad SM, RoayaeiArdakani M. Inhibition of foot-and-mouth disease virus replication by hydroalcoholic and aqueous-acetic acid extracts of Alhagi maurorum. Iranian Journal of Pharmaceutical Sciences. 2018;14(1):85-96

[29] Kambizi L, Goosen BM, Taylor $\mathrm{MB}$, Afolayan AJ. Anti-viral effects of aqueous extracts of Aloe ferox and Withania somnifera on herpes simplex virus type 1 in cell culture. South African Journal of Science. 2007;103:359-360

[30] Pant M, Ambwani T, Umapathi V. Antiviral activity of Ashwagandha extract on infectious bursal disease virus replication. Indian Journal of Science and Technology. 2012;5(5):2750-2751

[31] Deshpande TM, Chaphalkar SR. Antiviral activity of plant extracts 
against FMDV in vitro a preliminary report. International Journal of Institutional Pharmacy and Life Sciences. 2013;3(4):1-18

[32] Fu N, Wu J, Lv L, He J, Jiang S. Antifoot-and-mouth disease virus effects of Chinese herbal kombucha in vivo. Brazilian Journal of Microbiology. 2015;46(4):1245-1255

[33] Daoud HM, Soliman EM. Evaluation of Spirulina platensis extract as natural antivirus against foot and mouth disease virus strains (A, O, SAT2). Veterinary World. 2015;8(10):1260

[34] Wang J, Chen X, Wang W, Zhang Y, Yang Z, Jin Y, et al. Glycyrrhizic acid as the antiviral component of Glycyrrhiza uralensis Fisch. against coxsackie virus A16 and enterovirus 71 of hand foot and mouth disease. Journal of Ethnopharmacology. 2013;147(1):114-121 
Section 2

Veterinary Medicine 



\title{
Prologue on DISEASES OF DOGS - for Practioners
}

\author{
Mani Saravanan
}

\section{Introduction}

Pet animals play a vital role in the human society as a companion, stress buster, guarding, etc. Health-care management of such pet animals is very much essential. Hence the pet animal clinical practice is a challenge to relive the suffering of the pet and to restore its normal routines. In recent years on par with human medicine, newer diagnostic technique and therapeutic protocols were followed to cure various diseases and condition of animals. Ascites, duodenal disorders, canine mastitis and re-emerging disease like Babesia are a timely needed topic in the day to day activities of pet animal clinical practices. This book provides the information on ascites, Babesia, duodenal disorders and mastitis of canines.

\section{Ascites}

Small animal clinicians are frequently presented with abdominal abnormalities. In many cases these abnormalities result from primary intra-abdominal disease, although the clinical signs may be an abdominal manifestation of extra-abdominal disease [1]. Ascites is usually accompanied with chronic hepatic damage, as a result of portal hypertension, hypoalbuminaemia and increased renal sodium and water retention. It also occurred in congestive heart failure, protein losing enteropathy, protein losing nephropathy, neoplasia, peritonitis, haemorrhage, and rupture of gall bladder or urinary bladder [2]. Ascites occurs when there is an alteration in starling's forces, including increased venous or lymphatic hydrostatic pressure, vascular permeability, increased intraperitoneal oncotic pressure and decreased capillary oncotic pressure [3].

The diagnosis of liver disorders is often very vague and non-specific, especially in the early or mild stage of hepatobiliary diseases, because the clinical signs do not correlate with hepatic parenchyma damage. In the varied functional activities of liver, there was no single test that can accurately identify hepatic damage or its underlying cause; hence, a set of tests are necessary to assess ascites due hepatobiliary disorder. Liver dysfunction can be diagnosed and monitored by hepatic markers, hepatic blood flow estimation, prothrombin time, serum bilirubin, transaminases [4], serum alkaline phosphatise, $\gamma$-glutamyl transferase [5], glucose [6], total protein and albumin levels [7]. Complete blood counts, serum biochemical profile, urine analysis, faecal analysis and survey of abdominal radiography or ultrasonography [8] are being considered for screening value.

The gross appearance of the fluid may be helpful in determining the pathological process. Examination of ascitic fluid consists of colour, specific gravity, total protein, albumin, nucleated cell count and serum ascitic albumin gradient (SAAG). The actual cause of ascites is a greater difficulty to the clinicians [9]. 
Extensive literature has been published in various animals on ascites of hepatobiliary dysfunctions and their remedies. The main aim of the treatment protocol is to eliminate the causative factors by reducing hepatic inflammation, fibrosis and hepatic regeneration and curtail its complications. Low sodium diet and diuretics, namely, furosemide and spironolactone, are the most commonly used to reduce ascites. Certain animals failed to respond diuretics due to high serum aldosterone liver cirrhosis [10]. The consequence of ascites due to hepatobiliary disorders are refractory ascites and hepatorenal syndrome (HRS), which leads short survival of patient [11]. Abdominocentesis is performed if the ascites is life-threatening [12]. Other therapeutic management of ascites in humans are large volume paracentesis, intravenous albumin infusion, transjugular intrahepatic portosystemic shunt (TIPS), peritoneovenous shunt and liver transplantation [11, 13]. But these therapeutic measures are under experiment in animals, and each of the methods has its own disadvantage, that is, incomplete recovery from ascites and cost-ineffective.

\section{Canine mastitis}

Inflammation of the mammary gland is a common problem in bitches. It's caused by bacterial and fungal pathogens along with immunodeficiency [14, 15]. The clinical manifestation of mastitis is classified as acute, chronic, subclinical and gangrenous mastitis. Causes for the mastitis are poor hygienic, trauma and systemic infections. The most common route of infection is the ascending route followed by trauma and haematogenous route [16].

Complete physical examination of mammary glands should be done for their symmetry, temperature, size, consistency and colour. In the case of abnormal milk secretion, evaluate its colour, consistency and smell. Cytological examination of milk should be performed. In chronic mastitis a microbiological culture of the milk and antibiotic sensitivity should be performed to identify the pathogens and initiate the appropriate therapeutic protocols. The most common isolated pathogens are staphylococci, streptococci and E. coli in mastitis milk [16]. Mammary radiography and ultrasound examination are also recommended for such case to neoplasia and to exclude metastases to the lungs. Fine-needle biopsy is usually recommended if mammary neoplasia is suspected, though useful.

FNAC can precisely assess the degree of inflammation as well as detect abnormalities inside the mammary gland [17]. Acute phase proteins (CRP or SAA) in serum and milk samples seem to be the most accurate inflammatory biomarkers to diagnose canine mastitis, as their concentrations are significantly higher in bitches suffering from mastitis than in healthy bitches. Other inflammatory biomarkers like cyclooxygenases or interleukins seem to be promising both in diagnosis of mastitis and differentiation between mastitis and mammary tumours [18].

\section{Babesiosis}

Babesiosis is one among the deadly tick-borne haemaprotozoan infection in dogs. Causative agents of canine babesiosis are Babesia canis, B. gibsoni and B. vogeli [19]. Babesia infection could cause autoimmune disorder like immune-mediated haemolytic anaemia (IMHA) and immune-mediated thrombocytopenia (IMTP) in dogs, and it may occur individually or concurrently. If they occur together, they call it as Evans syndrome [20]. Evans syndrome with Babesia in canines leads to the destruction of RBCs and platelets, oxidative stress and endothelial injury [21, 22]. 
Flow cytometry method is considered to be more rapid, cost-effective, sensitive methods to diagnose IMHA and ITP in humans and animals [23, 24].

\section{Duodenal disorders}

Commonly recorded canine duodenal disorders are inflammatory bowel disease, lymphangiectasia, ulcer, foreign body, giardia, parasites, small intestinal bacterial overgrowth and neoplasia [25]. Duodenal disorders are difficult to identify clinically because of the non-specific symptoms. They may or may not be identifiable through routine radiographic, ultrasonographic or laboratory evaluation methods, because many diseases of duodenum primarily involve the mucosal surface. Thus diagnosis and treatment of the duodenal disorders are challenging for the canine practitioners [26]. Duodenoscopy is an efficient way of identifying the abnormalities of mucosal irregularities and obtaining mucosal biopsy and duodenal juice for routine histopathological and bacteriological studies [27-29].

\section{Conclusions}

- Newer therapeutic modalities may emerge to incorporate alternative medicine into an integrated medical approach with standard therapy against liver disorders.

- PCR is essential to rule out tick-borne infection in dogs, and flow cytometry is a sensitive method to diagnose IMHA and IMTP.

- Visualization of duodenal epithelium and obtaining intestinal mucosal biopsy by duodenoscopy are an ideal tool in the diagnosis of duodenal disorders.

\section{Author details}

Mani Saravanan

Veterinary Clinical Complex, Veterinary College and Research Institute, Tamilnadu Veterinary and Animal Sciences University (TANUVAS), Thanjavur, India

*Address all correspondence to: sara82vet@yahoo.com

IntechOpen

(C) 2020 The Author(s). Licensee IntechOpen. This chapter is distributed under the terms of the Creative Commons Attribution License (http://creativecommons.org/licenses/ by/3.0), which permits unrestricted use, distribution, and reproduction in any medium, provided the original work is properly cited. (cc) BY 


\section{References}

[1] Hunt GB. Abdominal condition of the dog and cat. In: 27th WSAVA congress. Grananda, Spain; 2002. pp. 3-6

[2] Rutgers C, Biourge V. Nutrition of dogs with liver disease. In: Pibot P, Biourge V, Elliott D, editors. Encyclopedia of Canine Clinical Nutrition. Aimargues, France: Aniwa SAS; 2006. pp. 134-161

[3] Richter KP. Disease of the liver and hepato biliary system. In: Jam TR, editor. Hand Book of Small Animal Gastroenterology. 2nd ed. St. Louish, Missouri: Saunders; 2003. pp. 379-381

[4] Kamble MB, Dumbre RK, Rangari VD. Hepatoprotective activity studies of herbal formulations. International Journal of Green Pharmacy. 2009;20:147-151

[5] El-Segaey O, Ab-Allah A, Al-Nooman SA. Experimental study of antioxidant and hepatoprotective effects of clove and cardamom in ethanol induced hepatoxicity. Tanta Medical Sciences Journal. 2007;2(1):27-36

[6] Banerjee S. Significance of Hepatic Copper Values in Dogs with Hepatitis. Chennai: TANUVAS; 2003

[7] Tiwari P, Varshney JP, Hoque M. Biliary obstruction in dogs: Diagnosis and treatment. Indian Journal of Veterinary Medicine. 2001;21(2):115-116

[8] Varshney JP, Hoque M.

Clinicopathological and ultrasonographic observation in canine hepatopathies. The Indian Journal of Animal Sciences. 2002;72(6):423-427

[9] Bjelakoviv G, Tasie T, Stamenkoviv I, Katie V, Otasinoviv M, Bjelankovic G. Biochemical, cytological and microbiological characteristics of the cirrhotic, malignant and mixed ascites. Archive of Oncology. 2001;9:95-101

[10] Center SA. Fluid, electrolyte and acid-Base disturbances in liver disease. In: Dlbartola SP, editor. Fluid, Electrolyte and Acid Base Disorders in Small Animal Practice. 3rd ed. St. Louis, Missouri: Sanders Elsevier; 2006. pp. 437-473

[11] Salerno F, Guevava M, Bernardi M, Morean R, Wong F, Angeli P, et al. Refractory ascites; pathogenesis, definition and therapy of a severe complication in patients with cirrhosis. Liver International. 2010;30(7):937-947

[12] Bexfield N, Watson P. Treatment of canine liver disease, 2. Managing clinical signs and specific liver disease. In Practice. 2009;31:172-180

[13] Burgees LJ. Biochemical analysis of pleural, peritoneal and pericardial effusion-Review. Clinica Chimica Acta. 2004;343:61-81

[14] Ditmyer H, Craig L. Mycotic mastitis in three dogs due to Blastomyces dermatitidis. Journal of the American Animal Hospital Association. 2011;47(5):356-358

[15] Murai A, Maruyama S, Nagata M, Yuki M. Mastitis caused by Mycobacterium kansasii infection in a dog. Veterinary Clinical Pathology. 2013;42:377-381

[16] Marti JA, Fernandez S. Clinical approach to mammary gland disease. In: England G, von Heimendahl A, editors. BSVA Manual of Canine and Feline Reproduction and Neonatology. ed. 2 ed. Gloucester: British Small Animal Veterinary Association; 2010. p. 155

[17] Trasch K, Wehrend A, Bostedt H. Ultrasonographic description of canine mastitis. Veterinary Radiology \& Ultrasound. 2007;48:580-584 
[18] Kaszak I, Ruszczak A, Kanafa S, Piłaszewicz OW, Sacharczuk M, Jurka P. New insights of canine mastitis-A review. Animal Science Papers and Reports. 2018;36(1):33-44

[19] Breitschwerte E. Babesiosis. In: Clinical Microbiology and Infectious Diseases of the Dog and Cat. Philadelphia: WB Saunders; 1984. pp. 796-805

[20] Norkus C. Chapter 11: Specific organ system disorders. In: Campbell M, editor. Veterinary Technician's Manual for Small Animal Emergency and Critical Care. Ames, Iowa: Wiley-Blackwell; 2012. pp. 243-252

[21] Wingfield W, Raffe M. Chapter 46: Immune-mediated hemolytic anemia. In: Faudskar L, Jackson WY, editors. Veterinary ICU Book. USA: Teton New Media; 2002. pp. 710-720

[22] Di Cicco MF, Birkenheuer AJ. Canine babesiosis-Peer reviewed. In: NAVC Clinician's Brief. 2012. pp. 31-35
[26] Jergens AE. Clinical assessment of disease activity for canine inflammatory bowel disease. Journal of the American Animal Hospital Association. 2004;40:437-445

[27] Day MJ, Bilzer T, Mansell J, Wilcock B, Hall EJ, Jergens A, et al. Histopathological standards for the diagnosis of gastrointestinal inflammation in endoscopic biopsy samples from the dog and cat: A report from the world small animal veterinary association gastrointestinal standardization group. Journal of Comparative Pathology. 2008;138(Suppl. 1):S1-S43

[28] Ridgway J, Jergens AE, NIyo Y. Possible causal association of idiopathic inflammatory bowel disease with thrombo cytopenia in the dog. Journal of the American Animal Hospital Association. 2001;37:65-74

[29] Twet DC. Perspective on gastrointestinal endoscopy. The Veterinary Clinics of North America. Small Animal Practice. 1993;23:481-495

[23] Quigley KA, Chelack BJ, Haines DM, Jackson ML. Application of a direct flow cytometric erythrocyte immunofluorescence assay in dogs with immune-mediated hemolytic anemia and comparison to the direct antiglobulin test. Journal of Veterinary Diagnostic Investigation. 2001;13(4):297-300

[24] Dircks BH, Schuberth HJ, Mischke R. Underlying diseases and clinicopathologic variables of thrombocytopenic dogs with and without platelet-bound antibodies detected by use of a flow cytometric assay: 83 cases (2004-2006). Journal of the American Veterinary Medical Association. 2009;235(8):960-966

[25] Zoran LD. Gastroduodenoscopy in dog and cat. The Veterinary Clinics of North America. Small Animal Practice. 2001;31:631-656 



\title{
An Update on Canine Duodenal Disorders
}

\author{
Mani Saravanan
}

\begin{abstract}
Duodenal disorders are difficult to identify clinically because of the non-specific symptoms. They may or may not be identifiable through routine radiographic, ultrasonographic, or laboratory evaluation methods, because many diseases of duodenum primarily involve the mucosal surface. Duodenal ulcers, inflammatory bowel disease (IBD), and small intestinal bacterial overgrowth (SIBO) are the duodenal disorders. Duodenoscopy is an efficient way of identifying the abnormalities of mucosal irregularities, distortion, ulceration, neoplasia, and inflammation, and it is also useful for obtaining mucosal biopsy and duodenal juice for routine histopathological and bacteriological studies. This paper will provide more detail about the advanced diagnostic methods and therapeutic measures for various duodenal disorders.
\end{abstract}

Keywords: duodenal ulcer, IBD, SIBO, duodenoscopy, malabsorption

\section{Introduction}

Gastrointestinal disorder is one of the commonly encountered problems in canine practice. Chronic disorders of small intestine of dogs are one among the major problems. Majority of the disorders can be successfully managed if diagnosed and treated earlier. If small intestine disorders are not treated appropriately, they may result in severe malabsorptive disease and death. Chronic form of intestinal disease usually disrupts the normal function of the small intestine and results in vomiting, diarrhea, weight loss, and reduced appetite [1]. Duodenal disorders like ulcers, inflammatory bowel disease (IBD), and small intestinal bacterial overgrowth (SIBO) play a major role in the small intestinal disorders [2]. Duodenal disorders are difficult to identify clinically because of the non-specific symptoms. They may or may not be identifiable through routine radiographic, ultrasonographic, or laboratory evaluation methods, because many diseases of duodenum primarily involve the mucosal surface [3]. Thus diagnosis and treatment of the duodenal disorders are challenging for the canine practitioners [4]. Duodenoscopy is an efficient way of identifying the abnormalities of proximal small intestinal mucosa including mucosal irregularities, distortion, ulceration, neoplasia, inflammation, and other mucosal disorders of the duodenum. Duodenosocopy is also useful for obtaining mucosal biopsy and duodenal juice for routine histopathological and bacteriological studies [5]. 


\section{Incidence}

Twet [6] listed out the common duodenal disorders as inflammatory bowel disease, lymphangiectasia, ulcer, foreign body, Giardia, parasites (Strongyloides, Ascaris), bacterial overgrowth, and neoplasia.

\begin{tabular}{|c|c|c|}
\hline Duodenal disorders & Breed & Reference \\
\hline $\begin{array}{l}\text { Gastroduodenal ulceration and erosion } \\
\text { (GDUE) }\end{array}$ & $\begin{array}{l}\text { Mixed breeds }-2 \text { years to } 17 \text { years of age } \\
\text { groups of dogs }\end{array}$ & [7] \\
\hline Spontaneous gastroduodenal perforation & $\begin{array}{l}\text { Rottweiler, Dobermann Pinscher, German } \\
\text { Shepherd, and Labrador Retriever }\end{array}$ & {$[8]$} \\
\hline $\begin{array}{l}\text { Gastrointestinal ulceration with } \\
\text { intervertebral disk prolapse }\end{array}$ & Dachshunds & [9] \\
\hline Congenital form of duodenal diverticulum & Boxer & {$[10]$} \\
\hline $\begin{array}{l}\text { Gastrointestinal perforation by meloxicam } \\
\text { toxicity }\end{array}$ & $\begin{array}{l}\text { Rottweiler, Springer Spaniel, Siberian } \\
\text { Husky, and Newfoundland }\end{array}$ & [11] \\
\hline Inflammatory bowel disease (IBD) & $\begin{array}{l}\text { German Shepherd, Boxers, and Yorkshire } \\
\text { Terriers; Labrador Retrievers and Spitz and } \\
\text { Dobermann Pinscher }\end{array}$ & {$[12,13]$} \\
\hline Chronic lymphocytic-plasmacytic enteritis & Basenji & [14] \\
\hline Small intestinal bacterial overgrowth (SIBO) & German Shepherd Mongrel and Spitz & [15-17] \\
\hline Lymphangiectasia & $\begin{array}{l}\text { Labrador Retriever, Yorkshire Terriers, } \\
\text { Dachshund, and German Shepherd dog }\end{array}$ & [18] \\
\hline Neoplasia—duodenal gastrinoma & No breed specific & [19] \\
\hline Giardia & No breed specific & {$[20,21]$} \\
\hline $\begin{array}{l}\text { Duodenal foreign body } \\
\text { - Bones (Figure 5) \& Thread } \\
\text { (Figure 6) }\end{array}$ & No breed specific commonly in puppies & {$[22,23]$} \\
\hline $\begin{array}{l}\text { Duodenal worms } \\
\text { - Ancylostoma caninum (Figure 1) }\end{array}$ & Spitz & {$[24]$} \\
\hline
\end{tabular}

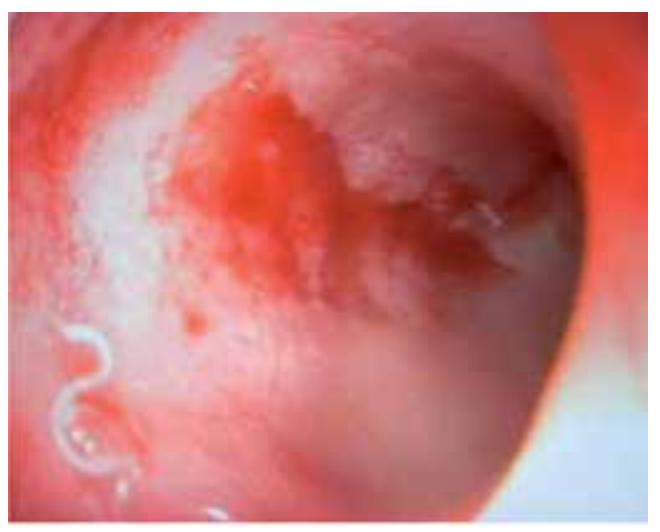

Figure 1.

Duodenoscopy: proximal duodenum-Ancylostoma caninum. 


\section{Pathogenesis}

Neiger et al. [25] and Reed [26] opined that corticosteroids increased the secretion of free and total hydrochloric acid, diminished mucus secretion, and promoted bacterial colonization of peptic ulcers. Hinton et al. [8] reported that the common predisposing factors for gastroduodenal ulcer were nonsteroidal anti-inflammatory drug (NSAID) administration, corticosteroids, hepatic disease, major surgery, shock, decreased gastric circulation, gastric hyper secretions, and gastrointestinal neoplasia and predisposing factors for gastroduodenal perforation were IBD, nonneoplastic infiltrative gastrointestinal disease, Dirofilaria immitis, otitis externa, ulcerative dermatitis, dilated cardio myopathy, polycystic kidney, and thyroid illness. Various authors reported that nonsteroidal anti-inflammatory drug administration resulted in duodenal ulcer formation was primarily due to the inhibition of prostaglandin synthesis via inhibition of cyclooxygenase [26-29]. Roherer et al. [30] recorded that degenerative disk diseases along with corticosteroid administration induced ulceration.

Dossin and Henroteaux [12], Jergens [31], Pibot et al. [32], and Kobayashi et al. [33] described inflammatory bowel disease as a group of idiopathic, chronic, gastrointestinal tract disorders, characterized by infiltration of gastrointestinal tract mucosa by inflammatory cells like lymphocytes, plasma cells, and various forms of IBD including lymphocytic-plasmacytic, eosinophilic, and granulomatous enterocolitis.

Mucosal immune system might play an important role in the pathogenesis of small intestinal enteropathies like IBD and idiopathic SIBO. Increased numbers of $\mathrm{CD}_{4} \mathrm{~T}$ cells, IgA, IgG, and plasma cells were noticed in duodenal mucosa of dogs with IBD [34]. Cave [2] stated that heating the amino acid, lysine, reacted with reducing sugars to form Maillard compounds that cannot be digested or absorbed in a usable form and served as substrate for luminal bacteria in the small intestine, leading to quantitative or qualitative changes in the flora.

Dossin and Henroteaux [12] opined that gastroduodenal ulceration, erosion, delayed gastric emptying, and postprandial discomfort could lead to IBD. Sancho et al. [14] recorded significantly high serum gastrin in chronic lymphocytic-plasmacytic enteritis (LPE)due to duodenogastric reflux and further reported that refluxes of duodenal contents like bile, pancreatic juice, and other duodenal secretions in the stomach damaged the gastric mucosal barriers leading to an antral hypomotility and gastric acid hypersecretion.

Simpson et al. [35] reported that exocrine pancreatic insufficiency also caused small intestinal bacterial overgrowth in dogs. Small intestinal bacterial overgrowth was defined as proliferation of abnormal numbers of bacteria in the upper small intestine. Common bacteria noticed in the proximal small intestine of dog included Streptococcus faecalis, other Streptococcus species, Staphylococcus aureus, Staphylococcus epidermidis, Staphylococcus xylosus, other Staphylococcus spp., Enterobacteriacea, Bacillus sp., Escherichia coli, Corynebacterium sp., Enterobacter cloacae, Pseudomonas sp. and Pasteurella multocida, Clostridium subterminale, Clostridium perfringens, Bifidobacterium sp., Eubacterium sp., Bacteroides fragilis, other Bacteroides spp., Peptostreptococcus tetradius, Peptostreptococcus sp., Propionibacterium acne, and Lactobacillus sp. [60]. In small intestinal bacterial overgrowth, an increased numbers of luminal bacteria in the small intestine could damage the brush border of enterocytes directly or indirectly by attracting polymorphonucleocytes, deconjugating bile acids, producing hydroxylated fatty acid and alcohols, metabolizing dietary nutrients, and altering the absorptive function of the cells [36]. Rinkinen et al. [37] stated that IgA deficiency had been associated with increased susceptibility of small intestinal bacterial overgrowth and inflammatory bowel disease. 
Intestinal lymphangiectasia was characterized by the abnormal dilatation of lymphatic vessels within the mucosa and submucosa, associated with exudation of protein-rich lymph, into the intestine resulting in lipid malabsorptions [32]. Primary or congenital lymphangiectasia was a result of insufficiency or aplasia of lymphatic vessels, and secondary or acquired lymphangiectasia was due to functional obstruction of the lymphatics, and it might be due to the right side heart failure, constrictive heart failure, or intestinal neoplasia and inflammation [37].

Bonfanti et al. [39] reported that adenocarcinoma, carcinoma, leiomyoma, leiomyosarcoma, fibrosarcoma, lymphoma, and extra medullary plasmacytoma were the most common gastrointestinal tumors in dogs.

German [40] reported that Giardia was a flagellate protozoon, transmitted by direct life cycle, and it predominantly inhabit the duodenum of dogs. Giardia duodenalis is the common cause of chronic diarrhea in dogs [41].

Richter [42] and Leib and Matz [43] recorded a variety of foreign bodies like fruit pits, rubber ball, cloth, metal objects, coins, sponges, hair ball, bottle caps, chew toys, marbles, and bones in duodenum.

\begin{tabular}{|c|c|c|c|c|c|c|c|c|}
\hline Clinical signs & IBD & Ulcers & SIBO & Lymphangiectasia & Giardia & Neoplasia & Parasites & $\begin{array}{c}\text { Foreign } \\
\text { body }\end{array}$ \\
\hline Vomiting & 1 & 2 & 5 & 4 & 5 & 2 & 2 & 1 \\
\hline Diarrhea & 2 & & 1 & 1 & 1 & 3 & 1 & 2 \\
\hline $\begin{array}{l}\text { Poor response to } \\
\text { treatment }\end{array}$ & 4 & & & & & & & \\
\hline $\begin{array}{l}\text { Reduced } \\
\text { appetite }\end{array}$ & 5 & & 7 & & 3 & & & 5 \\
\hline Lethargy & 6 & & & 5 & 4 & 4 & 3 & \\
\hline $\begin{array}{l}\text { Previous } \\
\text { steroids/NSAIDs }\end{array}$ & & 1 & & & & & & \\
\hline Abdominal pain & & 3 & & & & & 4 & 4 \\
\hline $\begin{array}{l}\text { Abdominal } \\
\text { distension }\end{array}$ & & 6 & 6 & & & & & 6 \\
\hline Edema/ascites & & & & 3 & & & & \\
\hline Weight loss & 3 & & 2 & 2 & & 1 & & \\
\hline Steatorrhea & & & 4 & & & & & \\
\hline Smell in feces & & & 3 & & & & & \\
\hline Melena & & 4 & & & & 5 & & 7 \\
\hline Hematemesis & & 5 & & & & 6 & & \\
\hline Dehydration & & & & & 2 & & & \\
\hline Anemia & 7 & 7 & & & & 7 & & 8 \\
\hline Potbelly & & & & 6 & & & 5 & \\
\hline Cough & & & & & & & 6 & \\
\hline Constipation & & & & & & & & 3 \\
\hline References & $\begin{array}{l}{[13,} \\
33, \\
44, \\
45]\end{array}$ & {$[7,8]$} & $\begin{array}{l}{[15-} \\
17]\end{array}$ & [38] & {$[46,47]$} & {$[48]$} & {$[49]$} & {$[22]$} \\
\hline
\end{tabular}

Table 1.

Common clinical signs of various duodenal disorders. 


\section{Diagnosis}

\subsection{History}

Diagnosis of duodenal disorder is challenging one, because of the non-specific signs. It requires invasive and noninvasive diagnostic modalities, viz., X-ray, ultrasound, and duodenoscopy, to identify the lesion localization. To confirm the root cause of the duodenal disorder, histopathology, cytology, and culture examination of duodenal aspirates through routine duodenoscopy examination are performed.

\subsection{Clinical signs}

The clinical signs of various duodenal disorders were recorded by various authors in different periods which were presented in the Table 1. The signs of duodenal disorders were arranged serially according to the episode of the disorders from $1,2, \ldots \ldots$. to $7 \& 8$.

\subsection{Hematological changes}

In dogs with prolonged gastrointestinal bleeding, iron deficiency could develop microcytic hypochromic anemia [50]. Normocytic normochromic anemia in dogs due to GI ulceration and contentious administration of NSAIDs [51].

Jergens et al. [52] observed leukocytosis and relative polycythemia in five dogs and non-regenerative anemia in one dog with gastroduodenal ulceration. Leib and Matz [43] recorded regenerative anemia and eosinophilia in Ancylostoma-infected dogs. Ridgway et al. [53] observed thrombocytopenia in dogs with IBD. Ristic and Stidworthy [54] reported severe iron-deficiency (microcytic hypochromic) anemia due to inflammatory bowel disease in the dogs. Dossin and Henroteaux [12] observed chronic anemia with typical feature of iron deficiency (microcytic hypochromic anemia) and thrombocytopenia in IBD-affected dogs.

\subsection{Biochemical changes}

Hall [55] suggested that panhypoproteinemia (hypoalbuminemia and hypoglobulinemia) was typical of protein-losing enteropathy (PLE) and also reported that hyperglobulinemia was noticed in intense inflammatory conditions. Hinton et al. [8] recorded hypoproteinemia and hypocalcemia in gastroduodenal ulcer dogs. Measurement of the serum concentration of unconjugated bile acid was considered as an index for bacterial activity in the small intestine [56]. Dossin and Henroteaux [12] reported that hypoproteinemia and hypoalbuminemia were observed in IBD. Craven et al. [57] recorded hypoalbuminemia, hypoproteinemia, increased serum folate, and decreased serum cobalamin concentration in canine inflammatory bowel disease. Potoenjak et al. [38] and Brooks [58] observed hypoproteinemia, hypocholesterolemia, and hypocalcemia in lymphangiectasia. Marks [59] recorded that decreased serum cobalamin and increased folate concentration in SIBO affected dogs. Johnston [60] stated that indirect diagnosis of SIBO was made by estimation of deconjugated bile acid, serum cobalamin, and folate concentrations. Rutgers et al. [15] reported serum folate and cobalamin were only present in $5 \%$ of dogs with duodenal juice culture proven SIBO. Hall [61] suggested that serum folate and cobalamin concentrations cannot be used to diagnose SIBO because of the poor sensitivity, although a low serum cobalamin still has value as an indication to treat. Allenspach et al. [62] reported hypoalbuminemia and hypoglobulinemia are the important indicators of protein-losing enteropathy in dogs, and in such 
case serum albumin concentration should be measured because hypoalbuminemia has been shown to be a negative prognostic indicator in dogs with chronic enteropathies.

\subsection{Fecal examination}

Berghoff and Steiner [63] reported chronic signs of intestinal disease should be evaluated for endoparasitic infestation before detail diagnostic examination to rule out hookworms (Ancylostoma spp., Uncinaria spp.), roundworms (Toxocara spp.), and whipworms (Trichuris vulpis). Broussard [49] stated that hookworm and Ascaris were diagnosed by standard fecal flotation method. Sokolow et al. [64] reported that Giardia could be diagnosed by the combination of fecal examination and centrifugal flotation.

Cystic stage of Giardia was diagnosed with zinc sulfate centrifugal or simple flotation technique and trophozoite stage by direct smear and detection of trophozoites and cysts in feces with FAT technique $[46,55]$. Direct microscopic examination of fresh fecal samples suspended in saline could detect Giardia trophozoite [40, 59]. Fecal direct immunofluorescence assays were considered to be a golden standard method of diagnosis of Giardia infection in dogs, with a reported sensitivity and specificity of more than $90 \%$ each $[65,66]$. Qualitative enzyme immunoassays (e.g., ProSpecT Giardia Microplate assay) and a SNAP test (SNAP Giardia Test) are also used for Giardia infection [41].

\subsection{Duodenoscopy}

Donaldson et al. [67] and Lamb [68] stated that gastroduodenoscopy was an important tool for examination of a dog with chronic vomiting and diarrhea and also suggested that visualization of duodenum, aspiration of duodenal contents, and microscopic examination of mucosal samples could be useful in diagnosis. Simpson [69] stated that indications for duodenoscopy were small bowel diarrhea, protein-losing enteropathies, chronic vomiting, and melena. Zoran [3] and Willard [70] reported that gastroduodenoscopy was not only valuable in visualization of mucosal irregularities and obtaining biopsies, cytologic samples, or fluids from duodenum but also might reveal anatomical distortions or displacements occurring in those regions.

Hinton et al. [8] reported that endoscopic examination was the diagnostic tool for gastroduodenal perforation. Moore [71] stated that most of the foreign bodies lodged in proximal duodenum could be removed by using endoscopy. Boston et al. $[72,73]$ reported that the endoscopy was commonly used to evaluate gastroduodenal ulceration and erosions induced by nonsteroidal anti-inflammatory drugs and corticosteroids. Endoscopic examination of the upper gastrointestinal tract had been used increasingly as a diagnostic and therapeutic tool in small animal medicine, particularly in the diagnosis of chronic gastrointestinal diseases and in understanding their pathophysiology [74].

\subsubsection{Endoscopic appearance of duodenum}

Peyer's patches (lymph node) are noticed as flattened areas on the lateral aspect of ascending duodenum [48]. Richter [42] reported that the normal duodenum was pink, smooth, and uniform with velvet-like texture. Normal duodenum appeared slightly grainy or roughened because of the presence of mucosal villi and was reddish pink to yellow if bile was present [3]. In descending duodenum, the major duodenal papilla were noticed approximately $4-5 \mathrm{~cm}$ from pylorus on medial aspect 
of duodenum, and minor duodenal papilla was located dorsal to the major papilla. Lymphoid follicle appeared as dished out area, often with white spots [70]. Bexfield [71] stated that the normal duodenum was more red in color than the stomach and had yellow tinge due to bile and also reported that the duodenal mucosa was more friable than that of the stomach and had a fine granular appearance due to the mass of intestinal villi.

\subsubsection{Endoscopic appearance of duodenal disorders}

Roth et al. [72, 73, 75] reported that increased granularity and friability associated with increased cellularity within the lamina propria were due to the inflammation or neoplasm of duodenum. Richter [42] described endoscopic appearance of duodenal ulcer as deep or shallow crater and well demarcated from the surrounding mucosa.

Forsyth et al. [76] described mucosal grading scale for ulceration study as follows: 0 , no visible hemorrhage and erosions/ulcers; $1^{+}, 1-5$ punctate erosions and hemorrhage; $2^{+}, 6-15$ punctate erosions and hemorrhage; $3^{+}, 16-25$ punctate erosions and hemorrhage; $4^{+}, \geq 25$ punctate erosions and hemorrhage and $1-5$ invasive erosions; $5^{+}, \geq 5$ invasive erosions; and $6^{+}$, ulcer of any size (Figure 2 ).

Yamasaki et al. [77] reported that endoscopic appearance of duodenum in lymphocytic-plasmacytic enteritis had mucosal friability and mucosal destruction and hemorrhage when the mucosa was gently touched with endoscope, which was not observed in normal duodenum of dog. Leib and Matz [43] reported that endoscopic appearance of duodenum in IBD-affected dogs was hyperemia, mucosal hemorrhage, ulceration, increased mucosal granularity, and friability. Lecoindre [78] observed a multifocal, pale, papular, and granular appearance of duodenum in lymphangiectasia in dogs. Miura et al. [79] and Snead [80] reported endoscopic appearance of duodenal neoplasia as ulceration, irregular mucosa, hyperemia, cobble stone or granular texture, and friability (Figure 3). Walker [81] recognized the diseased duodenum during duodenoscopy as reddened, ulcerated, thickened (Figure 4), and abnormally fibrosed or friable such that it bled abnormally following contact with the tip of the scope or after taking biopsy.

Freiche and Poncet [82] recorded increased granularity of mucosa and erythema of the proximal duodenum with highly visible Peyer's patches in brachycephalic breeds affected with upper airway and gastrointestinal syndrome. Sancho et al. [83] evaluated the endoscopic appearance of the descending duodenum in lymphocytic-plasmacytic enteritis and scored as follows: $(1)$ intestinal lumen $(0=$ normal, $1=$ narrowed due to

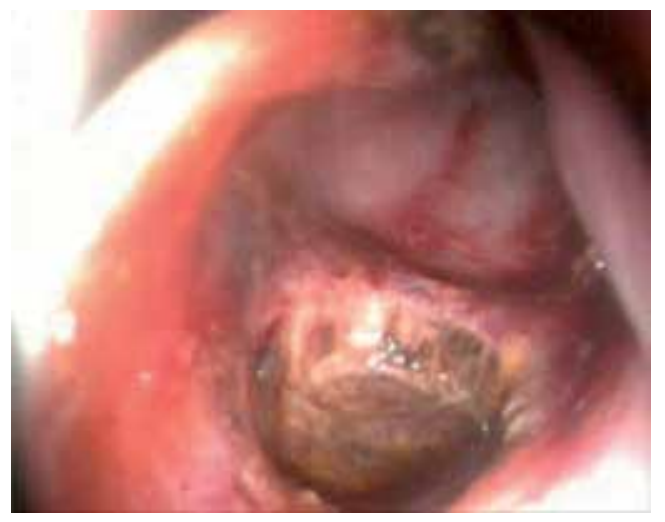

Figure 2.

Duodenoscopy: duodenal ulceration cum perforation. 


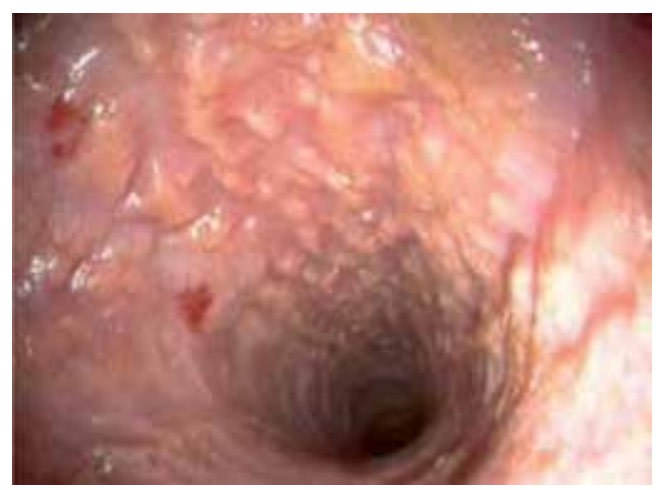

Figure 3.

Duodenoscopy: duodenal ulceration in plasmacytic enteritis.

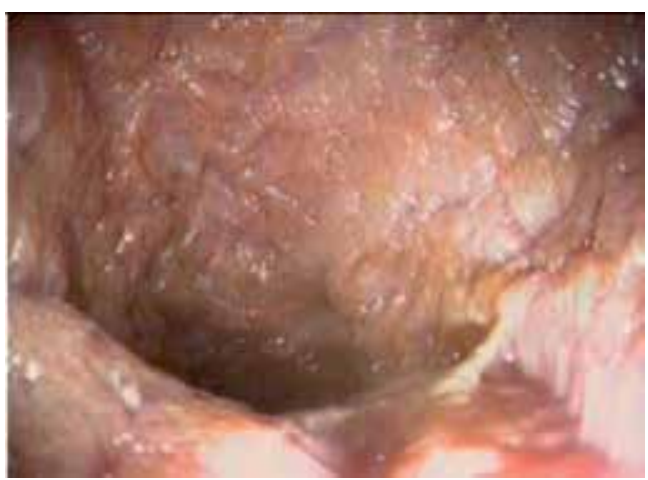

Figure 4 .

Duodenoscopy: highly fragile duodenal mucosa in inflammatory bowel disease.

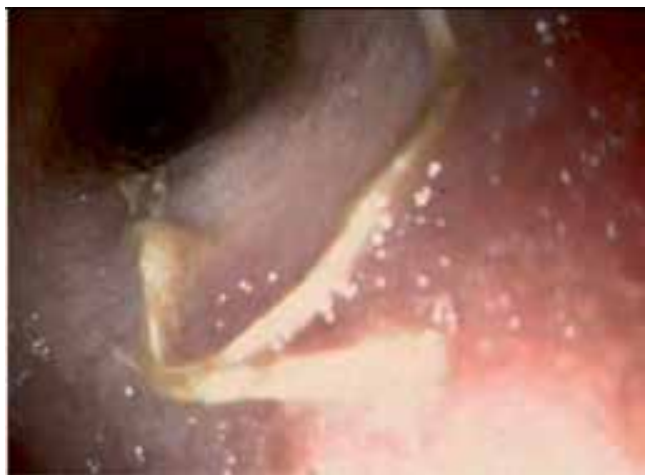

Figure 5.

Duodenoscopy: duodenal foreign body—thread in the proximal duodenum.

lack of elasticity), (2) mucosal erythema (0-3 depending on the degree of alteration), (3) mucosal granularity (0-3 depending on the degree of alteration), (4) irregular mucosa ( $0-3$ depending on the degree of alteration), (5) friable mucosa ( $0-3$ depending on the degree of alteration), and (6) erosions/ulcers (0-3 depending on the degree of alteration). And from this total score, the macroscopic and endoscopic duodenal lesions of the dogs were classified as normal duodenum (0 point), mild LPE (1-4, up to $25 \%$ of the maximum score), moderate LPE (5-8, up to $25-50 \%$ of the maximum score), and severe LPE (9-16, $>50 \%$ of the maximum score). 


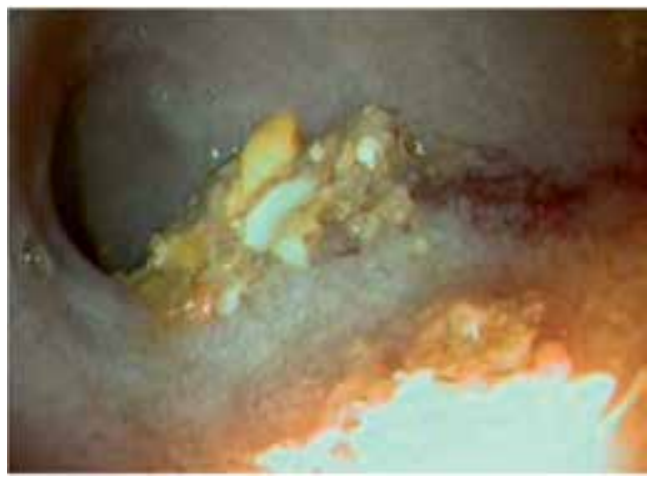

Figure 6.

Duodenoscopy: duodenal foreign body—stones and bone pieces in the proximal duodenum.

\subsubsection{Endoscopy-aided biopsy of duodenum}

Willard et al. [84] and Michael et al. [85] stated that the endoscopic biopsy of the duodenal mucosa had been an important tool in the diagnosis of small intestinal tract diseases of dogs. Obtaining excellent duodenal tissue samples was typically harder than obtaining samples from other portions of the gastrointestinal tract, and they also opined that it was easier to obtain high-quality tissue samples from the descending duodenum than ascending duodenum [86]. Jergens et al. [87] suggested that the multiple mucosal biopsy specimens were required for diagnosis of inflammatory bowel disease. Full-thickness biopsy of intestine was necessary to diagnose alimentary lymphoma, because lesions were usually deep seated and invaded the serosal layer [79].

The definitive diagnosis of IBD was obtained by histological examination of intestinal biopsies [12]. Walker [81] and Spillmann [88] reported that biopsy samples of ulcer condition should be obtained from the periphery of the lesion. Freiche and Poncet [82] observed lymphoplasmacytosis as a principle lesion from duodenal biopsies in brachycephalic dogs affected with upper airway and gastrointestinal syndrome. Bexfield [89] reported that biopsy could be performed by the use of flexible pinch biopsy forceps.

\subsubsection{Endoscopy-aided brush cytology}

Jergens et al. [90] and Zoran [3] observed that endoscopy-aided brush technique was most useful in detecting cellular infiltration in lamina propria and was considered as a reliable adjunct to histological examination of biopsy specimen in the diagnosis of GI diseases of dogs and cats.

\subsubsection{Endoscopy-aided collection of duodenal juice}

Pitts et al. [91], Roudebush and Delivorias [92], and Leib et al. [20] reported that aspirate of duodenal content revealed a Giardia trophozoite on microscopic examination of the sediments and it was more sensitive than zinc sulfate fecal flotation technique. Hall [55] stated that duodenal juice could be collected during duodenoscopy for diagnosis of SIBO.

\subsection{Histopathology and brush cytology}

Dow et al. [93] observed slightly blunted and thickened duodenal villi and increased infiltration of inflammatory cells in the dogs with duodenal ulcer (Figure 7). Willard 
et al. [94] and Rutgers et al. [15] reported that histologic and intestinal mucosal cytologic examinations were not useful in detecting SIBO. Jergens et al. [52] and Yamasaki et al. [77] stated that duodenal mucosa in clinically normal dogs had low numbers of lymphocytes, histiocytes, plasma cells, and eosinophils. The severity of lymphangiectasia was graded by counting the number of dilated lacteals per low-power $(10 \times$ objective) field. Ridgway et al. [53] observed increased mucosal granularity of duodenum, mucosal cellular infiltration, and architectural alteration in lymphocytic-plasmacytic enteritis (Figure 8).

Potoenjak et al. [38] reported histopathological appearances of lymphangiectasia, and there were dilated lacteals of small intestinal villi, lymphatics, focal infiltration of lamina propria with mononuclear cells particularly plasma cells, and mild edema of the lamina propria (Figures 9, 10). Duodenal biopsy revealed severe fibrosis of the submucosa and infiltrate of small pockets and cards of round to polygonal cells with granular cytoplasm in duodenal gastrinomas [19].

Cytological examination of intestinal lymphosarcoma revealed large, atypical granular lymphocytes containing irregularly shaped, magenta cytoplasmic granules, and in histopathologic examination, diffuse infiltration of the lamina propria of duodenum by a population of large lymphocytes was observed [80]. Jergens [95], Sancho et al. [83], and Day et al. [96] suggested the scoring system

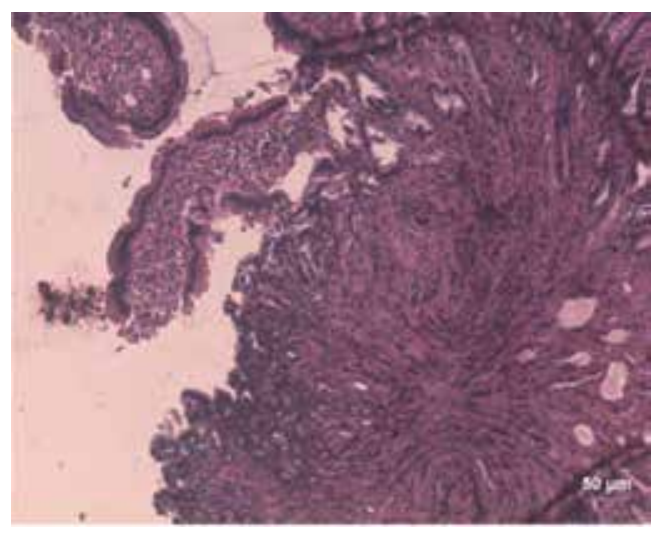

Figure 7.

Excessive loss of duodenal villus epithelium in duodenal ulcer (HङE $10 \mu \mathrm{m}$ ).

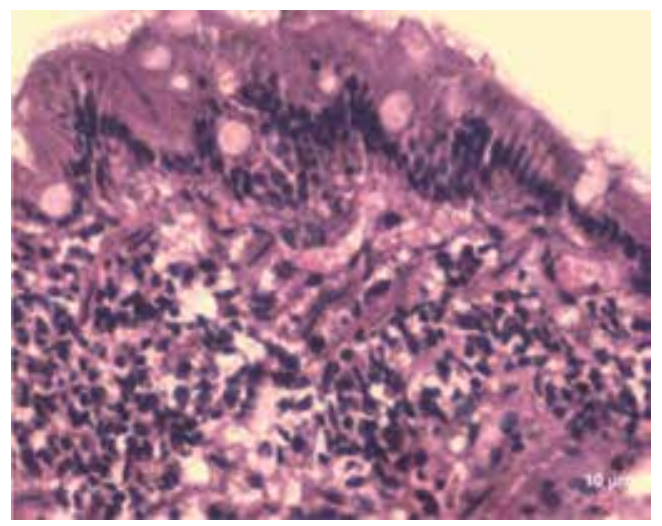

Figure 8.

Lymphoplasmacytic infiltration of lamina propria of duodenum in IBD (HङE $10 \mu \mathrm{m})$. 


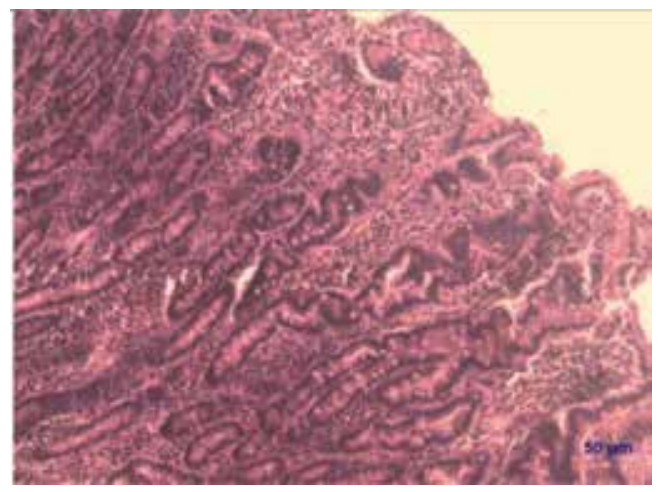

Figure 9.

Ulceration of villus epithelium with lymphoplasmacytic infiltration in IBD (H\&E $50 \mu \mathrm{m}$ ).

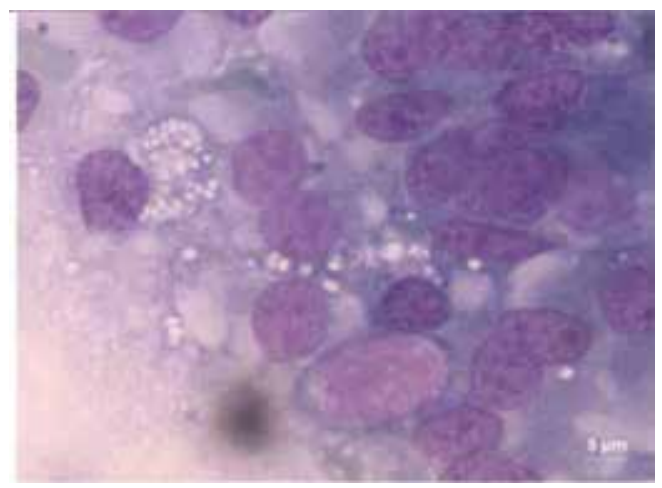

Figure 10.

Duodenal brush cytology — vacuolar degeneration of epithelium and MNC cells ( $5 \mu \mathrm{m})$.

for histopathology of duodenal biopsy samples as follows: intraepithelial lymphocytes, chronic inflammatory cell infiltration, edema, lymphocytic vessel dilation, glandular hyperplasia, and fibrosis scored between 0 and 3 according to the degree of alteration $(0=$ normal and 3 as the maximum alteration $)$, and from the total score, the microscopic duodenal lesions of the dogs were classified as normal ( 0 point), mild (1-5, up to $25 \%$ of the maximum score), moderate $(6-9,25-50 \%$ of the maximum score), and severe (10-18, $>50 \%$ of maximum score).

\subsection{Duodenal juice culture}

Small intestinal bacterial overgrowth was diagnosed by isolation of $\geq 10^{5}$ aerobic bacterial colony-forming units or $\geq 10^{4}$ anaerobic bacterial colony-forming units from duodenal/proximal jejunal fluid obtained from non-fed dogs [55]. Delles et al. [97] and Batt [16] reported that Escherichia coli, Staphylococcus xylosus, Staphylococcus epidermidis, Corynebacterium sp., and Proteus mirabilis were the most commonly isolated bacteria from intestinal fluid.

Willard et al. [94], Rutgers et al. [15], and Lecoindre [78] reported that small intestinal bacterial overgrowth was diagnosed by quantitative bacterial culture of duodenal juice samples obtained endoscopically. Johnston [60], German et al. [98], and Marks [59] opined that culture of duodenal juice had been regarded as the gold standard for detecting elevated bacterial counts in SIBO. German et al. [99] stated that in SIBO of German Shepherd dog, the duodenal juice had reduced IgA concentration. 


\subsection{Ultrasound}

Gastrointestinal ultrasonography has become a supporting noninvasive diagnostic tool for intestinal diseases and disorders in dogs. It is used to differentiate inflammation and neoplastic infiltrative disease of the intestine $[100,101]$. Ultrasonography can be used to inspect the small intestinal wall thickness, dilatation, and peristalsis as well as for intraluminal, intramural, and extraluminal causes of obstruction [102]. Abdominal ultrasonography has become in many instances a part of the minimum database in conjunction with abdominal radiography for the assessment of intestinal disease [103]. The most common ultrasonographic features of intestinal abnormalities are thickening of the bowel wall, loss of its normal layer, and alterations in the contour of the mucosal and/or serosal surfaces [104]. Thickness, altered wall layering appears to be an important finding which differentiates inflammatory from neoplastic and granulomatous infiltration [105]. In dogs, ultrasonographic examination of the small intestine has been successfully used to identify gastrointestinal tumors [104]. Rudorf et al. [100] concluded in his study that ultrasonography should be used to rule out diseases such as intussusceptions and localized tumors in cases of chronic diarrhea.

Ultrasonographic changes were similar in lymphoplasmacytic enteritis and lymphoma of the small intestine, since the overlapping USG findings of inflammatory and neoplastic disease conditions of the intestinal disorders were only confirmed by histopathology examination, which is necessary for differentiating the diseases [106].

Smith et al. [107] reported that hyperechoic mucosal striations are associated with lacteal dilation and are frequently associated with mucosal inflammation and protein-losing enteropathy in dogs.

Gaschen et al. [101] concluded in his study that intestinal mucosal echogenicity could be used for detecting inflammatory bowel disease than bowel wall thickness with chronic diarrhea in dogs.

\subsection{Radiographic examination}

Gaschen [106] reported abdominal survey radiographic examination remains an important part of screening patients with vomiting and diarrhea, and it should be performed in conjunction with the abdominal ultrasonographic examination instances. Radiography of intestine could identify foreign bodies, nails, mass/neoplasia, and obstructions. Contrast radiography can be used as an adjunct in the investigation of GI disease. Barium studies can provide information on GI transit, obstructive lesions, intestinal mass lesions, or disrupted mucosal integrity.

\section{Treatment}

Therapeutic protocols for the gastrointestinal disorders are based on the acute or chronicity of the condition. Mostly duodenal disorders are observed with chronic condition because of the non-specific signs. Hence, therapy initiated with symptomatically and appropriated therapeutic regimen is followed after confirming the disease or disorders which are aided by duodenoscopy, histopathology, and bacteriology studies. Herewith some of the commonly using drugs for the various duodenal disorders are as follows. 
An Update on Canine Duodenal Disorders

DOI: http://dx.doi.org/10.5772/intechopen.86049

\begin{tabular}{|c|c|c|c|}
\hline Name of the drug & Dose & Condition & Reference \\
\hline Azathioprine & $\begin{array}{l}\text { Initially } 2 \mathrm{mg} / \mathrm{kg} \text { q } 24 \mathrm{~h} \text { for } 3 \text { weeks and } \\
\text { then } 1-2 \mathrm{mg} / \mathrm{kg} \mathrm{q} 48 \mathrm{~h} \text { up to } 3 \text { weeks }\end{array}$ & IBD & {$[108]$} \\
\hline Misoprostol & $2-5 \mu \mathrm{g} / \mathrm{kg}$ PO q8 h & $\begin{array}{l}\text { GI protectants and } \\
\text { cytoprotective } \\
\text { agents }\end{array}$ & {$[109]$} \\
\hline Fenbendazole & $50 \mathrm{mg} / \mathrm{kg}$ PO q24 h for 3 days & Giardiasis & {$[110]$} \\
\hline Pyrantel pamoate & $5-10 \mathrm{mg} / \mathrm{kg} \mathrm{PO}$ & $\begin{array}{l}\text { Toxocara and } \\
\text { Ancylostoma } \\
\text { infection }\end{array}$ & {$[110]$} \\
\hline Loperamide & $0.1-0.2 \mathrm{mg} / \mathrm{kg}$ PO q8-12 h & $\begin{array}{l}\text { Motility-modifying } \\
\text { agents }\end{array}$ & [110] \\
\hline $\begin{array}{l}\text { Bismuth } \\
\text { subsalicylate }\end{array}$ & $\begin{array}{l}1 \mathrm{ml} / \mathrm{kg} / \text { day } \mathrm{PO} \text { divided } \mathrm{q} 8-12 \mathrm{~h} \text { for } \\
1-2 \text { days }\end{array}$ & Anti-secretory drug & [109] \\
\hline Metoclopramide & $\begin{array}{l}0.25-0.5 \mathrm{mg} / \mathrm{kg} \text { PO, IM, or IV q8-24h, } \\
1-2 \mathrm{mg} / \mathrm{kg} / \text { day, constant IV infusion }\end{array}$ & Antiemetics & [109] \\
\hline Ondansetron & $0.1-0.2 \mathrm{mg} / \mathrm{kg}$ IV q8-24 h & Antiemetics & [109] \\
\hline Prednisolone & $\begin{array}{l}1 \mathrm{mg} / \mathrm{kg} \text { orally twice daily for } 10 \text { days, } \\
\text { then } 0.5 \mathrm{mg} / \mathrm{kg} \text { orally twice daily for } \\
10 \text { days, then } 0.5 \mathrm{mg} / \mathrm{kg} \text { orally once } \\
\text { daily for } 10 \text { days, and then } 0.5 \mathrm{mg} / \mathrm{kg} \\
\text { orally every other day for } 10 \text { days }\end{array}$ & IBD & [111] \\
\hline \multirow[t]{2}{*}{ Metronidazole } & $15-25 \mathrm{mg} / \mathrm{kg}, \mathrm{PO}, \mathrm{q} 12-24 \mathrm{~h}$, for 5-7 days & Giardiasis & [112] \\
\hline & $10 \mathrm{mg} / \mathrm{kg}$ given orally every $8-12 \mathrm{~h}$ & SIBO/ARD & [61] \\
\hline Oxytetracycline & $10-20 \mathrm{mg} / \mathrm{kg}$ given orally every $8 \mathrm{~h}$ & SIBO/ARD & [61] \\
\hline Omeprazole & $0.7-2 \mathrm{mg} / \mathrm{kg}$ PO q12-24 h & $\begin{array}{l}\text { Antacid/GI } \\
\text { ulceration }\end{array}$ & {$[110]$} \\
\hline Pantoprazole & $1 \mathrm{mg} / \mathrm{kg}$ IV q24 h & $\begin{array}{l}\text { Antacid/GI } \\
\text { ulceration }\end{array}$ & {$[110]$} \\
\hline Sucralfate & $0.5-1$ g per dog & $\begin{array}{l}\text { GI protectants and } \\
\text { cytoprotective } \\
\text { agents }\end{array}$ & [109] \\
\hline Ranitidine & $1-2 \mathrm{mg} / \mathrm{kg}, \mathrm{PO}$ or IV, q8-12 h & $\begin{array}{l}\text { Antacid/GI } \\
\text { ulceration }\end{array}$ & {$[110]$} \\
\hline Tylosin & $20-40 \mathrm{mg} / \mathrm{kg}$ PO q12 h & SIBO and ARD & {$[61]$} \\
\hline Tinidazole & $44 \mathrm{mg} / \mathrm{kg}, \mathrm{PO}, \mathrm{q} 24 \mathrm{~h}$ for 6 days & Giardiasis & {$[112]$} \\
\hline
\end{tabular}

\subsection{Dietary management}

- Marks suggested feeding management is necessary for the management of most chronic small bowel disease of pets. Dogs with small bowel diarrhea can be managed by highly digestible, moderately fat-restricted, lactose-free, and gluten-free dietary supplement $[111,113]$.

- Milk- and lactose-contained diet should be avoided during the diarrhea, because during the diarrhea intestinal mucosal erosion lead reduction in the brush border enzyme especially lactose. Therefore fail to digest lactose leads bacterial degradation of sugar to VFA which causes osmotic diarrhea. 
- Hypoallergenic diet refers to a diet that is generally free of additives and preservatives and contains a single, novel protein source that is highly digestible. Hypoallergenic diet is very much useful for the management canine IBD along with immunosuppressive therapy.

\section{Conclusions}

Duodenal disorders are the one among major gastrointestinal disturbances in dogs and it also interrelated to the other GI disturbances. Diagnosis of these disorders is a challenging one, due to their non-specific signs and hence, contrasts radiography and endoscopy which play a vital role in the diagnosis. Duodenoscopy is an efficient way of identifying the abnormalities of mucosal irregularities, distortion, ulceration, neoplasia, and inflammation of intestines, and it is very much useful for obtaining mucosal biopsy and duodenal juice for histopathological and bacteriological studies.

\section{Acknowledgements}

The author acknowledges Dr. B. Nagarajan, Professor Madras Veterinary College, TANUVAS, Chennai, for his support.

\section{Conflict of interest}

No conflict of interest.

\section{Author details}

Mani Saravanan

Veterinary Clinical Complex, Veterinary College and Research Institute, Tamilnadu Veterinary and Animal Sciences University (TANUVAS), Thanjavur, India

*Address all correspondence to: sara82vet@yahoo.com

\section{IntechOpen}

(C) 2019 The Author(s). Licensee IntechOpen. This chapter is distributed under the terms of the Creative Commons Attribution License (http://creativecommons.org/licenses/ by/3.0), which permits unrestricted use, distribution, and reproduction in any medium, provided the original work is properly cited. (cc) BY 


\section{References}

[1] Tams TR. Small Animal Endoscopy. 2nd ed. St. Luis: C.V. Mosby Company; 1999. pp. 98, 99, 175, 176

[2] Cave NJ. Chronic inflammatory disorders of gastrointestinal tract of companion animals. New Zealand Veterinary Journal. 2003;51:262-274

[3] Zoran LD. Gastroduodenoscopy in dog and cat. The Veterinary Clinics of North America: Small Animal Practice. 2001;31:631-656

[4] Shales CJ, Warren J, Anderson DM, Baines SJ, Whites RA. Complications following full thickness small intestinal biopsy in 66 dogs: A retrospective study. The Journal of Small Animal Practice. 2005;46:317-321

[5] Williams DA. Gastrointestinal endoscopy in dogs and cats. In: The 29th World Congress WSAVA Congress. 2004

[6] Twet DC. Perspective on gastrointestinal endoscopy. The Veterinary Clinics of North America: Small Animal Practice. 1993;23: 481-495

[7] Jergens AE, Moore FM, March P. Idiopathic inflammatory bowel disease associated with gastro duodenal ulceration-erosion: A report of nine cases in the dog and cat. Journal of the American Animal Hospital Association. 1992;28:21-26

[8] Hinton LE, McLoughlin MA, Johnson SE, Weisbrode SE. Spontaneous gastro duodenal perforation in 16 dogs and seven cats (1982-1999). Journal of the American Veterinary Medical Association. 2002;38:176-187

[9] Dowdle SM, Joubert KE, Lambrechts NE, Lobetti RG, Pardini AD. The prevalence of sub clinical gastro duodenal ulceration in dachshunds with intervertebral disc prolapse.
Journal of the South African Veterinary Association. 2003;74:77-81

[10] Klaveren NJV, Grinwis GCM, Brocks BAN, Kirpensteijn J. Collapse following gastro intestinal bleeding secondary to a congenital duodenal diverticulum into two littermate boxer pups. Journal of Small Animal Practice. 2008;49(2):103-106

[11] Enberg TB, Braun LD, Kuzma AB. Gastro intestinal perforation in five dogs associated with the administration of meloxicam. Journal of Veterinary Emergency and Critical Care. 2006;16:34-43

[12] Dossin O, Henroteaux M. Diagnosis and treatment of inflammatory bowel disease in dogs. Waltham Focus. 2004;14:19-24

[13] Saravanan M, Nagarajan B, Kavitha S, Balachandran C, Senthilkumar K, Srinivasan SR. Duodenoscopic evaluation of inflammatory bowel disease (IBD) in dogs. The Indian Veterinary Journal. 2013;90(2):74-76

[14] Sancho MG, Franco FR, Sainz A, Rodriguez A, Silvan G, Carlos Lllera J. Serum gastrin in canine chronic lymphocytic plasmacytic enteritis. The Canadian Veterinary Journal. 2005;46:630-634

[15] Rutgers HC, Batt RM, Elwood CM, Lamport A. Small intestinal bacterial overgrowth in dogs with chronic intestinal disease. Journal of the American Veterinary Medical Association. 1995;206:187-193

[16] Batt RM. Bacterial over growth in dogs. In: 27th WSAVA Congress. 2002

[17] Saravanan M, Nagarajan B, Kavitha S, Balachandaran C, Senthilkumar K, Srinivasan SR. A study on clinico biochemical, endoscopic and duodenal 
aspirate culture of small intestinal bacterial overgrowth affected dogs. Indian Journal of Veterinary Medicine. 2013;33(1):61-63

[18] Kull PA, Hess RS, Craig LE, Saunders HM, Washbao RJ. Clinical, clinicopathologic, radiographic and ultrasonographic characteristics of intestinal lymphangiectasia in dogs: 17 cases (1996-1998). Journal of the American Veterinary Medical Association. 2001;219:197-202

[19] Vergine M, Pozzo S, Pogliani E, Rondena M, Roccabianca P, Bertazzolo W. Common bile duct obstruction due to a duodenal gastrinoma in a dog. Veterinary Journal. 2004;170:141-143

[20] Leib MS, Dalton N, King SE, Zajac AM. Endoscopic aspiration of intestinal contents in dogs and cats: 394 cases. Journal of Veterinary Internal Medicine. 1999;13:191-193

[21] Jacobs SR, Forrester CPR, Yang J. A survey of the prevalence of Guardia in dog presented to Canadian veterinary practice. The Canadian Veterinary Journal. 2001;42:45-46

[22] Leib MS. Disease of stomach. In: Leib MS, Monvoe WE, editors. Practical Small Animal Internal Medicine. Philadelphia: W.B. Saunders; 1997. pp. 640-655

[23] Saravanan M, Nagarajan B, Kavitha S. Duodenal foreign body in dogs: Endoscopic findings. Indian Journal of Veterinary Research. 2011;31(2):134-135

[24] Saravanan M, Nagarajan B, Kavitha S. Endoscopic retrieval of Ancylostoma caninum from duodenum of a dog. Intas Polivet. 2011;12(1):102-103

[25] Neiger R, Gaschen F, Jaggy A. Gastric mucosal lesions in dogs with acute intervertebral disc disease.
Characterizations and effects of omeprazole or misoprostol. Journal of Veterinary Internal Medicine. 2000;14:33-36

[26] Reed S. Non steroidal anti inflammatory drugs induced duodenal ulceration and perforation in a nature rottweiler. The Canadian Veterinary Journal. 2002;43:971-972

[27] Neiger R. Editorial: NSAID-Induced gastro intestinal adverse effects in dogs-Can we avoid them? Journal of Veterinary Internal Medicine. 2003;17:259-261

[28] Duerr FM, Carr AP, Bebchk TN, Pople NC. Challenging diagnosis-Ictus associated with a single perforating duodenal ulcer after long term nonsteroidal anti-inflammatory drug administration in a dog. The Canadian Veterinary Journal. 2004;45:507-510

[29] Hantson SM, Bostwick DR, Twet DC. Clinical evaluation of cimetidine, several fate, and misoprostol for prevention of gastro intestinal tract bleeding in dogs undergoing spinal surgery. American Journal of Veterinary Research. 1997;58:1320-1323

[30] Roherer CR, Hill RC, Fischer A. Gastric hemorrhage and the effect of miso prosol in dogs treated with high doses of methyl prednisolone. Journal of Veterinary Internal Medicine. 1997;11:145

[31] Jergens AE. Inflammatory bowel disease current perspectives. The Veterinary Clinics of North America: Small Animal Practice. 1999;29:501-520

[32] Pibot P, Biourge V, Elliott D. Chronic disease of intestinal tract causing diarrhea. In: Encyclopedia of Canine Clinical Nutrition. Royal Canin; 2006. pp. 111-112

[33] Kobayashi S, Ohno K, Uetsuka K, Nakashima K, Setoguchi A, Fujino $\mathrm{Y}$, et al. Measurement of intestinal 
mucosal permeability in dogs with lymphocytic plasmacytic enteritis. The Journal of Veterinary Medical Science. 2007;69:745-749

[34] German AJ, Hall EJ, Day MJ. Immune cell populations within the duodenal mucosa of dogs with enteropathies. Journal of Veterinary Internal Medicine. 2001;15:14-25

[35] Simpson KW, Batt RM, Jones D, Norton DB. Effects of exocrine pancreatic insufficiency and replacement therapy on bacterila flora of the duodenum in dogs. American Journal of Veterinary Research. 1990;51:203-206

[36] Hall EJ, German AJ. Disease of small intestine. In: Ettinger SJ, Feldman EC, editors. Text Book of Veterinary Internal Medicine Diseases of the Dog and Cat. 6th ed. St. Louis: Elsevier Saunders; 2000. pp. 1332-1374

[37] Rinkinen M, Teppo AM, Wester E. Relationship between canine mucosal and serum immunoglobulin $\mathrm{A}$ (IgA) concentrations; serum IgA does not assess duodenal secretory IgA. Microbial Immunology. 2003;47:155-159

[38] Potoenjak D, Ramadan K, Kucer N, Matijatko V, Curic S, Sabocanec R, et al. Secondary intestinal lymphangiectasia in a dog-A case report. Veterinary Archives. 2001;3:159-171

[39] Bonfanti U, Bertazzolo W, Bottero E, Lorenzi DD, Marconato L, Masserdotti C, et al. Diagnostic value of cytologic examination of gastrointestinal tract tumors in dogs and cats: 83 cases (20012004). Journal of the American Veterinary Medical Association. 2006;229:1130-1133

[40] German AJ. Diseases of the small intestine. In: Hall EJ, Simpson JW, William DA, editors. BASAVA Manual of Canine and Feline Gastro Enterology. 2nd ed. Quedgeley, England: British Small Animal Veterinary Association; 2005. pp. 181-193

[41] Dryden MW, Payne PA, Smith V. Accurate diagnosis of giardia spp and proper fecal examination procedures. Veterinary Therapeutics. 2006;7(1):4-14

[42] Richter KP. An introduction to endoscopy instrumentation and technique. Veterinary Medicine. 1992:1165-1175

[43] Leib MS, Matz ME. Disease of the intestine. In: Leib MS, Monvoe WE, editors. Practical Small Animal Internal Medicine. Philadelphia: W.B. Saunders; 1997. pp. 685-690

[44] Sturgess K. Diagnosis and management of idiopathic inflammatory bowel disease in dogs and cats. In Practice. 2005;27:293-301

[45] German A. Update on inflammatory bowel disease. In: WSAVA Congress. 2006. pp. 15-17

[46] Conboy G. Giardia. The Canadian Veterinary Journal. 1997;38:245-247

[47] Olson ME, Leonard NJ, Strout J. Prevalence and diagnosis of giardia infection in dogs and cats using a fecal antigen test and fecal smear. Canadian Veterinary Journal. 2010;51:640-642

[48] Strombeck DR. Small and large intestine normal structure and function. In: Guilford WG, Center SA, Strombeck DR, William DA, Meyer DJ, editors. Stomberk's Small Animal Gastroenterology. 3rd ed. Philadelphia: W.B. Saunders; 1996. pp. 318-1350

[49] Broussard JD. Optimal faecal assessment. Clinical Techniques in Small Animal Practice. 2003;18:218-230

[50] Twet DC. Gastric ulcers. In: Kirk RW, editor. Current Veterinary Therapy 
VIII. Philadeldelphia: WB Saunders; 1983. pp. $765-770$

[51] Willace MS, Zawie DA, Garvey MS. Gastric ulceration in the dog secondary to the use of non steroidal antiinflammatory drugs. Journal of the American Animal Hospital Association. 1990;26:467-472

[52] Jergens AE, Moore FM, Haynes JS, Miler AKG. Idiopathic inflammatory bowel disease in dogs and cats: 84 cases (1987-1990). Journal of the American Veterinary Medical Association. 1992;201:1603-1608

[53] Ridgway J, Jergens AE, NIyo Y. Possible causal association of idiopathic inflammatory bowel disease with thrombo cytopenia in the dog. Journal of the American Animal Hospital Association. 2001;37:65-74

[54] Ristic JME, Stidworthy MF. Two cases of sever iron-deficiency anemia due to inflammatory bowel disease in the dog. The Journal of Small Animal Practice. 2002;43:80-83

[55] Hall EJ. Clinical laboratory evaluation of small intestinal function. The Veterinary Clinics of North America: Small Animal Practice. 1999;29:441-469

[56] Suchodolski JS, Steiner JM. Laboratory assessment of gasto intestinal function. Veterinary Clinics of North America: Small Animal Practice. 2003;18:203-210

[57] Craven M, Simpson JW, Ridyard AE, Chandler ML. Canine inflammatory bowel disease: Retrospective analysis of diagnosis and outcome in 80 cases (1995-2002). The Journal of Small Animal Practice. 2004;45:336-342

[58] Brooks TA. Case study in canine intestinal lymphangiectasia. The Canadian Veterinary Journal. 2005;46:1138-1142
[59] Marks SL. Chronic diarrhea in dogsmaking the correct diagnosis or avoiding the worng one. In: The Second Royal Canine Scientific Meeting. 2007. pp. 45-51

[60] Johnston EL. Small intestinal bacterial over growth. The Veterinary Clinics of North America: Small Animal Practice. 1999;29:523-550

[61] Hall EJ. Antibiotic-responsive diarrhea in small animals. Veterinary Clinics: Small Animal Practice. 2011;41:273-286

[62] Allenspach K, Wieland B, Grone A, Gaschen F. Chronic enteropathies in dogs: Evaluation of risk factors for negative outcome. Journal of Veterinary Internal Medicine. 2007;21(4):700-708

[63] Berghoff N, Steiner JM.

Laboratory tests for the diagnosis and management of chronic canine and feline enteropathies. Veterinary Clinics: Small Animal Practice. 2011;41:311-328

[64] Sokolow SH, Rand C, Mark SL. Epidemiological evaluation of diarrhea in dogs in an animal shelter. American Journal of Veterinary Research. 2005;66:1018-1024

[65] Rishniw M, Liotta J, Bellosa M, Bowman D, Simpson KW. Comparison of 4 giardia diagnostic tests in diagnosis of naturally acquired canine chronic subclinical giardiasis. Journal of Veterinary Internal Medicine. 2010;24(2):293-297

[66] Geurden T, Berkvens D, Casaert S, Vercruysse J, Claerebout E. A Bayesian evaluation of three diagnostic assays for the detection of giardia duodenalis in symptomatic and asymptomatic dogs. Veterinary Parasitology. 2008;157(1-2):14-20

[67] Donaldson LL, Leib OMS, Boyd C, Burkholder W, Shevidan M. Effect 
of preanesthetic medication on ease of endoscopic incubation of the duodenum in anesthetized dogs. American Journal of Veterinary Research. 1993;54:1489-1495

[68] Lamb CR. Recent developments in diagnostic imaging of the gastro intestinal tract of the dog and cat. The Veterinary Clinics of North America: Small Animal Practice. 1999;29: 307-342

[69] Simpson KW. Gastro intestinal endoscopy in the dogs. The Journal of Small Animal Practice. 1993;34:180-188

[70] Willard MD. Alimentry tract endoscopy. In: Fossum TW, editor. Small Animal Surgery. 2nd ed. St. Luis, Missouri: Mosby; 2002. pp. 109-114

[71] Moore LE. The advantage and disadvantage of endoscopy. Clinical Techniques in Small Animal Practice. 2003;18:250-253

[72] Boston SE, Moens NMM, Kruth SA, Southern EP. Endoscopic evaluation of the gastro duodenal mucosa to determine the safety of short term concurrent administration of meloxicam and dexamethasone in healthy dogs. American Journal of Veterinary Research. 2003;64:1369-1375

[73] Spillmann T. Endoscopy of the gastrointestinal tract when its rarely indicated. In: Proceeding of the WSAVA Congress; Australia. 2007

[74] Bexfield N. Gastro intestinal endoscopy in the dog and cat. Part-1: Upper GI tract. UK Vet. 2007;12:59-67

[75] Roth L, Leib MS, Davenport DJ, Monroe WE. Comparison between endoscopic and histologic evaluation of the gastro intestinal tract in dogs and cats: 75 cases (1984-1987). Journal of the American Veterinary Medical Association. 1990;196:635-638
[76] Forsyth SF, Guilford WG, Lawoko CRO. Endoscopic evaluation of the gastroduodenal mucosa following NSAID administration in the dog. New Zealand Veterinary Journal. 1996;44:179-181

[77] Yamasaki K, Suematsu H, Takahashi T. Comparison of gastric and duodenal lesions in dogs and cats with and without lymphocytic plasmacytic enteritis. Journal of the American Veterinary Medical Association. 1996;209:95-97

[78] Lecoindre P. An atlas of gastro intestinal endoscopy in dogs and cats. Waltham Focus. 1999;9:2-9

[79] Miura T, Maruyama H, Sakai M, Takahashi T, Koie H, Yamaya Y, et al. Endoscopic findings on alimentary lymphoma in 7 dogs. The Journal of Veterinary Medical Science. 2004;66:577-580

[80] Snead ERC. Large granular intestinal lymphosarcoma and leukemia in a dog. The Canadian Veterinary Journal. 2007;48:848-851

[81] Walker MC. Endoscopy of the small and large intestine. In: The North America Veterinary Congress. 2006. pp. $439-440$

[82] Freiche V, Poncet C. Upper air way and gastro intestinal syndrome in brachycephalic dogs. Veterinary Focus. 2007;17:4-10

[83] Sancho MG, Franco FR, Sainz A, Mancho C, Rodriguez A. Evaluation of clinical macroscopic and histopathologic response to treatment in non hypoproteinemia dogs with lymphocytic plasmacytic enteritis. Journal of Veterinary Internal Medicine. 2007;21:11-17

[84] Willard MD, Lovering SL, Cohen ND, Weeks BR. Quality of tissue specimens obtained endoscopically 
from the duodenum of dogs and cats. Journal of the American Veterinary Medical Association. 2001;219:474-479

[85] Michael WD, Lovering LL, Noah CD, Week BR. Quality of tissue specimen obtained endoscopically from duodenum of dogs and cats. Journal of the American Veterinary Medical Association. 2001;299(4):474-479

[86] Mansell J, Willward MD. Biopsy of the gastro intestinal tract. The Veterinary Clinics of North America: Small Animal Practice. 2003;33:1099-1116

[87] Jergens AE, Sohreiner CA, Frank DE, Ahrens EF, Eckersall PD, Benson TJ, et al. A scoring index for disease activity in canine inflammatory bowel disease. Journal of Veterinary Internal Medicine. 2003;17:291-297

[88] Spillmann T. Gastroduodenoscopy in dogs and cats. In: 30th World Congress WSAVA Congress; Mexico. 2005. pp. 11-14

[89] Bexfield N. Gastro intestinal endoscopy in the dog and cat. Part-2: Lower GI tract and biopsy techniques. UK Vet. 2007;12:27-34

[90] Jergens AE, Andreasen CB, Hagemoser WA, Ridgway J, Campbell KL. Cytologic examination of exfoliative specimen obtained during endoscopy for diagnosis of GI tract disease in dogs and cats. Journal of the American Veterinary Medical Association. 1998;213:1755-1759

[91] Pitts RP, Twet DC, Mallie KA. Comparison of duodenal aspiration with faecal floatation for diagnosis of giardiasis in dogs. Journal of the American Veterinary Medical Association. 1985;182:1210-1211

[92] Roudebush P, Delivorias MH. Duodenal aspiration via flexible endoscope for diagnosis of giardiasis in a dog. Journal of the American Veterinary Medical Association. 1985;187:162-163

[93] Dow SW, Rosychuk RAW, McChesney AE, Curtis CR. Effects of flunixin and flunixin plus prednisone on gastro intestinal tract of dogs. American Journal of Veterinary Research. 1990;51:1131-1138

[94] Willard MD, Simpson RB, Fossum TW, Cohen ND, Delles EK, Kolp DI, et al. Characterization of naturally developing small intestinal over growth in 16 German shepherd dogs. Journal of the American Veterinary Medical Association. 1994;204:1201-1206

[95] Jergens AE. Clinical assessment of disease activity for canine inflammatory bowel disease. Journal of the American Animal Hospital Association. 2004;40:437-445

[96] Day MJ, Bilzer T, Mansell J, Wilcock B, Hall EJ, Jergens A, et al. Histopathological standards for the diagnosis of gastrointestinal inflammation in endoscopic biopsy samples from the dog and cat: A report from the world small animal veterinary association gastrointestinal standardization group. Journal of Comparative Pathology. 2008;138(Suppl. 1):S1-S43

[97] Delles EK, Willard MD, Simpson RB, Fossum TW, Slater M, Lees GE, et al. Comparison of species and numbers of bacteria in concurrently cultured samples of proximal small intestinal fluid and endoscopically obtained duodenal mucosa in dogs with intestinal over growth. American Journal of Veterinary Research. 1994;55:957-964

[98] German AJ, Day MJ, Ruanx CG, Steiner JM, Williams DA, Hall EJ. Comparison of direct and indirect test for SIBO with antibiotic responsive diarrhea in dogs. Journal 
of Veterinary Internal Medicine. 2003;17:33-43

[99] German AJ, Hall EJ, Day MJ. Relative deficiency in IgA production by duodenal explants from German Sheperd dogs with small intestinal disease. Veterinary Immunology and Immunopathology. 2000;76:25-43

[100] Rudorf H, van Schaik G, O’Brien RT, Brown PJ, Barr FJ, Hall EJ. Ultrasonographic evaluation of the thickness of the small intestinal wall in dogs with inflammatory bowel disease. The Journal of Small Animal Practice. 2005;46(7):322-326

[101] Gaschen L, Kircher P, Stüssi A, Allenspach K, Gaschen F, Doherr M, et al. Comparison of ultrasonographic findings with clinical activity index (CIBDAI) and diagnosis in dogs with chronic enteropathies. Veterinary Radiology \& Ultrasound. 2008;49(1):56-64

[102] Penninck D, d'Anjou M-A. Gastrointestinal tract. In: Atlas of Small Animal Ultrasonography. 2nd ed. New York, United States: John Wiley \& Sons, Inc; 2015. pp. 259-308

[103] Gaschen L, Rodriguez D. Stomach, small and large intestines. In: Barr F, Gaschen L, editors. BSAVA Manual of Canine and Feline Ultrasonography. Woodrow House: BSAVA; 2011. pp. 124-139

[104] Penninck DG, Smyers B, Webster CRL, Rand W, Moore AS. Diagnostic value of ultrasonography in differentiating enteritis from intestinal neoplasia in dogs. Veterinary Radiology \& Ultrasound. 2003;44:570-575

[105] Agut A. Ultrasonography of the small intestine in small animals. Veterinary Focus. 2009;19(1):20-28

[106] Gaschen L. Ultrasonography of small intestinal inflammatory and neoplastic diseases in dogs and cats. Veterinary Clinics: Small Animal Practice. 2011;41:329-344

[107] Smith JS, Penninck DG, Keating JH, Webster CRL. Ultrasonographic intestinal hyperechoic mucosal striations in dogs are associated with lacteal dilation. Veterinary Radiology \& Ultrasound. 2007;48(1):51-57

[108] Simpson KW, Jergens AE. Pitfalls and progress in the diagnosis and management of canine inflammatory bowel disease. Veterinary Clinics: Small Animal Practice. 2011;41:381-398

[109] Willard MD. Digestive system disorders. In: Richard W, Nelson C, Couto G, editors. Small Animal Internal Medicine. 5th ed. St. Louis, Missouri: Elsevier; 2014. pp. 367-500

[110] Ramsey I. The BSAVA Small Animal Formulary. 6th ed. Quedgeley, England: British Small Animal Veterinary Association; 2008

[111] Hall EJ, Simpson KW. Diseases of the small intestine. In: Ettinger SJ, Feldman EC, editors. Textbook of Veterinary Internal Medicine. Philadelphia: W.B. Saunders; 2000. pp. $1182-1238$

[112] Tangtrongsup S, Scorza V. Update on the diagnosis and management of Giardia spp. infections in dogs and cats. Topics in Companion Animal Medicine. 2010;25(3):155-162

[113] Marks SL. Advances in dietary management of gastrointestinal disease. In: Managing Gastrointestinal Health, Diabetes, and Obesity. WSAVA; 2003 



\title{
Chapter 9
}

\section{Overview of Canine Babesiosis}

\author{
Poonam Vishwakarma and M.K. Nandini
}

\begin{abstract}
Canine babesiosis is a tick-borne, protozoal, haemoparasitic disease that can cause varying degrees of haemolytic anaemia, splenomegaly, thrombocytopenia and fever. There are two hosts for the transmission of Babesia spp., viz. invertebrate (tick) and vertebrate host. Dogs are one among the many targets of Babesia spp., causing canine babesiosis, and now there are clinical evidences of possible vertical transmission too. Dogs of all ages can be affected with Babesia spp., but young puppies are more commonly affected. Considering advanced diagnostic techniques, for an early and specific detection of acute infections, an AgELISA that is potentially translatable to a rapid diagnostic test design is reported. Different molecular techniques used for identification and differentiation of the various species of Babesia are semi-nested PCR, reverse line blotting and PCR-restriction fragment length polymorphism analysis. Treatment consists of three components: treatment with antiprotozoal agents to eliminate the parasite, blood transfusions to treat severe anaemia and supportive care for the complications and metabolic derangements. Blood lactate concentrations can serve as a prognostic indicator in severe or complicated canine babesiosis. For prevention apart from conventional measures, vaccines against Babesia species such as B. gibsoni are currently being developed.
\end{abstract}

Keywords: haemolytic anaemia, babesiosis, reverse line blotting, intraerythrocytic, blood lactate, semi-nested PCR

\section{Introduction}

Canine babesiosis is a clinically significant tick-borne disease caused by apicomplexan parasites of the genus Babesia which has been reported worldwide including India. These verity of the disease depends on multiple factors such as the type of Babesia species involved, the age and the immune status of the host [1,2]. It is caused by different Babesia species with a worldwide distribution characterised by erythrocyte destruction causing mild to severe systemic clinical manifestations [3] like varying degrees of haemolytic anaemia, splenomegaly, thrombocytopenia and fever.

\section{Classification}

Babesia organisms are frequently classified as large or small. Historically, Babesia spp. in dogs was identified by their morphological appearance in erythrocytes of blood smears (intraerythrocytic merozoite stage). Initially, all large forms measuring between 3 and $5 \mu \mathrm{m}$ were classified as $B$. canis, whereas all small forms measuring 1-3 $\mu \mathrm{m}$ were designated as $B$. gibsoni, but molecular analysis and DNA 
sequencing have revealed that there are at least three small piroplasms infecting dogs, viz. B. gibsoni, B. conradae and the recently reported "Babesia vulpes" [4].

In former times, on the basis of cross immunity, serological testing, vector specificity and molecular phylogeny, Babesia canis was categorised into three subspecies (B. canis canis, B. canis rossi, B. canis vogeli) $[5,6]$, but now these subspecies are considered as separate species $[7,8]$.

\section{Prevalence}

Out of three previously considered subspecies, Babesia rossi is the most virulent species and occurs predominantly in southern Africa. Babesia vogeli is the least pathogenic species occurring in France, Australia, Japan, Brazil, South Africa and the USA and usually causes mild disease in adult dogs but severe disease in some puppies [9]. Babesia canis is of intermediate pathogenicity and is widespread in Europe and Asia.

B. gibsoni, the smaller piroplasm is prevalent mainly in the Middle East, southern Asia, Japan, North Africa and South America and is an emerging infectious disease in the USA, as well as having been detected lately in Italy, Hungary and Australia [10]. A more virulent subspecies of B. gibsoni has also been identified in California [11]. Babesia microti-like piroplasma, B. annae (also known as Theileria annae), has been found to be endemic in dogs in northwest Spain [12]. In India both B. canis $[13,14]$ and $B$. gibsoni $[15,16]$ are prevalent, and almost all states of the country are affected.

\section{Zoonotic importance}

Babesia species affecting dogs and/or cats are not reported to be of zoonotic importance [17]. However, dogs and cats are close companions of people and can serve as a source of infected ticks for humans [18]. Human babesiosis is a rare disease and primarily involves just two species of Babesia: Babesia divergens, a parasite of cattle in Europe, and Babesia microti that parasitizes small rodents in the USA.

\section{Transmission}

There are two hosts for transmission of Babesia spp., viz., invertebrate (tick) and vertebrate host. Dogs are one among the many targets of Babesia spp., causing canine babesiosis (formerly called canine piroplasmosis).

Hard ticks are the main vectors for Babesia spp. Species such as Rhipicephalus sanguineus, Dermacentor spp. and Haemaphysalis ellipticum can transmit the large Babesia of dogs, whereas B. gibsoni is transmitted by Haemaphysalis bispinosa and Haemaphysalis longicornis. Babesia annae is thought to be transmitted by Ixodes hexagonus [19]. Both trans-stadial and transovarial transmissions can occur, and ticks are believed to remain infective for several generations.

Babesia spp. undergoes the sexual conjugation and the sporogony portions of their life cycles inside the lumen of the intestine and then within the haemocoel of the tick. Then the sporozoites from the tick's salivary gland are transmitted to their new vertebrate host via a blood meal, and thereafter the protozoan life cycle is completed within the red blood cells by asexual replication (merogony), where the parasites appear as merozoites [20], which leaves the host cell and enters another red blood cell. This cycle continues for the entire life tenure of vertebrate host or 
until the host's immune system terminates the process. However, in many countries for the last one decade, Babesia gibsoni infections have been reported in the absence of tick vectors. There is now convincing evidence that these cases have arisen due to biting and fighting between infected and noninfected dogs [21, 22], but these parasites are primarily transmitted through tick bites. This association arose as a by-product of the tick's adaptation to feed on blood.

The first clinical evidence of possible vertical transmission has been documented for B. canis [23] and B. microti-like spp. [24]. Although Babesia undergoes part of their life cycles in ticks, the merozoites circulating in the blood may be transmitted to a healthy host directly by blood transfusion. This scenario has been described for B. gibsoni infection [25] and by direct contact between dogs through wounds (fighting dogs), saliva or blood ingestion [21, 22, 26].

\section{Clinical signs and pathogenesis}

Dogs of all ages can be affected with Babesia spp., but young puppies are more commonly affected. The incubation period varies from 10 to 21 days for $B$. canis and 14-28 days for B. gibsoni. Mortality for Babesia spp. infections ranges from $12 \%$ for $B$. rossi to approximately $1 \%$ for $B$. vogeli $[19]$.

The most predominant feature of babesiosis in infected dogs are haemolytic anaemia and thrombocytopenia. Multiple causes like extra- and intravascular haemolysis, RBC destruction due to increased osmotic fragility, shortened life span of RBCs, erythrophagocytosis and immune-mediated destruction of RBCs because of parasitic antigens, parasite-induced membrane damage and possibly other membrane-associated antigens leads to anaemia [27-29]. Impaired haemoglobin function, oxidative damage, sludging and sequestration of erythrocytes also likely occur $[27,28,30]$.

Recent study revealed about the renal involvement in babesiosis. Hypoxaemia, glomerulonephritis and haemoglobinuric nephropathy are considered possible mechanisms and supported by histological studies [31].

Pancreatitis is frequently associated with other complications and has a mortality rate of $20 \%$. Common finding includes vomition, melaena, icterus, abdominal pain and diarrhoea. In addition, $65 \%$ of the dogs with pancreatitis also had icterus, $30 \%$ had acute respiratory distress syndrome (ARDS), 30\% had immune-mediated red blood cell destruction (IMHA), and 15\% had acute renal failure (ARF), while $10 \%$ had haemoconcentration, and another $10 \%$ had cerebral syndrome. It is postulated that pancreatitis is formerly described "gut" form of babesiosis [32].

The severe form of disease is characterised by marked haemolytic anaemia and acid-base abnormalities [33] with secondary multiple organ failure and complications such as ARF, hepatopathy, hypoglycaemia [34], ARDS, IMHA and cerebral pathology [35]. Small subset of dogs presents with high haematocrits (relative haemoconcentration), despite vigorous haemolysis, due to shifting of fluid from intravascular to extravascular component. These dogs are at increased risk of developing ARF or cerebral complications, as well as other organ failures [36].

The severity of the disease depends on the species of Babesia, presence of concurrent infections, age and immune status of the host. The disease presentation varies widely from peracute to chronic or even subclinical. Babesia rossi, the dominant species found in South Africa, is very virulent and causes peracute and acute disease. Most common signs include fever, anorexia, weakness, depression, pale mucous membranes, tachycardia, tachypnoea and splenomegaly. Clinical signs are because of tissue hypoxia following anaemia and a concomitant systemic inflammatory response syndrome caused by marked cytokine release [19]. 
Babesia vogeli causes clinically inapparent infection in mature dogs. The parasitaemia is very low, and infection may be missed while routine examination of blood smear. Subclinical infections are common in adult dogs, but puppies tend to present with marked anaemia [37]. It is endemic in greyhound kennels in the USA, and particular care should be taken when relocating greyhounds that can harbour subclinical infections.

Babesia canis infections result in a more variable pathogenicity, intermediate between B. rossi and B.vogeli. Anaemia is reported in majority of dogs and thrombocytopenia in all cases [38].

Babesia gibsoni infection follows either hyperacute, acute or chronic course. Among these acute course is the most common and is characterised by fever, lethargy, haemolytic anaemia, thrombocytopenia, lymphadenopathy and splenomegaly [39]. The hyperacute state is rare and is characterised by shock and extensive tissue damage. Mostly a disease of American Pit Bull and Staffordshire Bull Terriers is transmitted via dog bites [21]. In Australia and the USA, subclinical B. gibsoni infections have been reported, where they are PCR positive, but neither show clinical illness nor microscopic parasitaemia [40]. Such cases can have dire consequences if imported into non-endemic areas.

Babesia conradae is considered to be more pathogenic than B. gibsoni, resulting in higher parasitaemias and more severe anaemia [11].

\subsection{Cardiac dysfunction}

It's a rare complication of canine babesiosis; reported macroscopic cardiac lesions are effusions in pericardium, epicardial and endocardial haemorrhage involving one or more chambers with left ventricle being most commonly affected. Histopathological changes include necrosis, haemorrhage, fibrin micro-thrombi in the myocardium and inflammation. Lesions may be multifocal, but more generally they are limited to one area within the myocardium [41].

\subsection{Consequence of canine babesiosis}

Complicated babesiosis involves clinical manifestations that are not related to haemolytic disease. The most commonly documented complications include coagulopathy, ARF, ARDS, icterus and hepatopathy, haemoconcentration, immunemediated haemolytic anaemia (IMHA), pancreatitis, hypotension, myocardial pathology, cerebral babesiosis and shock. Rare complications include gastrointestinal disturbance, myalgia, ocular involvement, upper respiratory signs, necrosis of the extremities and fluid accumulation. These complications can overlap.

\section{Diagnosis}

A precise and fast diagnosis and prompt treatment is required in critical situations such as hyperacute to acute phase of $B$. canis infection, where high mortality is generally reported.

\subsection{Direct (microscopic) examination}

Historically, Babesia infection in dogs was identified based on the morphologic appearance of the parasite in the erythrocyte; thus, microscopic evaluation for detecting intraerythrocytic parasites in Giemsa or Wright's stained blood smears remains the simplest, most accessible and reasonably sensitive especially during 
acute infections. Differentiation between large and small piroplasms is also relatively simple. Moreover, in many parts of the developing world where babesiosis is endemic, microscopy is still the only viable available option. The likelihood of spotting a piroplasm increases with proper sampling technique, viz. sampling from capillary beds (ear tip, toe nail) or examination of cells from beneath the buffy coat of a haematocrit tube $[37,42]$ or search along the periphery of the blood smear, as parasitized red blood cells tend to marginate while making the smear. For diagnosis of large forms of Babesia (e.g. B. canis) from the majority of sick dogs, light microscopy is highly specific [2, 43], but small piroplasms (B. gibsoni, B. microti-like sp.) are hard to observe by light microscopy, which has a relatively poor to moderate sensitivity [44], and expertise is needed. Moreover due to very low, often intermittent parasitaemias, identification of piroplasms in chronically infected and carrier dogs remains a significant challenge.

Diagnosis is more problematic in chronic cases of infection due to less virulent species such as $B$. canis and $B$. vogeli, where parasitaemia may be below the microscopic detection limit, and in such cases thick smears (not alcohol fixed) may be helpful in detecting the parasite.

\subsection{Haematological changes}

The major haematological changes include mild to moderately regenerative normocytic and normochromic anaemia, leucocytosis with normal to decreased neutrophil counts and most consistent finding thrombocytopenia which is severe in the acute phase of infection [45].

\subsection{Coagulation profiles}

In a recent study, it was reported that there is significantly lower mean platelet count, prolonged activated partial thromboplastin time, higher fibrinogen concentrations and D-dimer value in infected dogs as compared to healthy controls [46].

\subsection{Biochemical abnormalities}

Elevation of liver enzymes such as ALP, ALT and AST. Elevated serum bilirubin concentration is associated with degree and rapidity of the anaemia and accompanying hepatopathy. There will be low total serum protein and albumin level in dogs with babesiosis. Urea is disproportionately raised to creatinine, and this is probably due to increased urea production resulting from gastrointestinal haemorrhage or protein catabolism as a result of febrile inflammatory illness $[47,48]$. In complicated cases with renal dysfunction, there will be proportionate increase in serum urea and creatinine levels indicating decreased renal perfusion, as a result of hypovolaemia, decreased blood pressure and/or decreased myocardial function. Hypokalaemia has been reported in severely affected dog, it has not connected directly with babesiosis, and this could be attributed to decreased potassium intake. Considerable elevation of positive acute phase protein ( $\alpha_{1}$-acid glycoprotein) has been reported in dogs with $B$. rossi infection, but levels do not correlate with severity of disease or outcome [49].

\subsection{Metabolic abnormalities}

The most common complication is hypoglycaemia and is often associated with severe anaemia, icterus, young age ( $<6$ months) and collapse [50]. Reduced survival has been associated with hypoglycaemia $(<59.4 \mathrm{mg} / \mathrm{dL})$ and hyperlactataemia. 
Hypoglycaemia-induced central nervous system signs should not be misdiagnosed as cerebral babesiosis.

\subsection{Electrocardiogram (ECG findings)}

In canine babesiosis, variety of arrhythmias are reported including sinus arrest, sinoatrial block, first- and second-degree atrioventricular block, ventricular tachycardia and ventricular premature depolarizations. ECG abnormalities include prolonged QRS interval, low amplitude and notching of R waves, ST segment deviation and large $T$ waves [41].

\subsection{Urine analysis}

Routine test may reveal presence of bilirubin, haemoglobin and protein in the urine. In a recent study conducted to assess renal dysfunction in Babesia rossi, infection revealed higher concentrations of urinary IgG, urinary CRP and urinary RBP suggestive of both glomerular and tubular dysfunction [51]. These can be used for early detection of Babesia-induced renal dysfunction than serum urea and creatinine and urine specific gravity. There will be minimum and variable changes in urine enzyme activity (GGT and ALP) in babesiosis, thus limiting their use as diagnostic tests [47].

\subsection{Serological diagnosis}

A recent study demonstrated the opportunity of an early and specific detection of acute infections by an AgELISA that is potentially translatable to a rapid diagnostic test design and can be used in an ELISA to detect circulating Babesia antigen during acute infections and can be used to detect parasites $24-48 \mathrm{~h}$ before it could be detected by light microscopy [52].

\subsection{Molecular diagnosis}

Molecular techniques help in refining the diagnosis to the species level and thus provide a more accurate prognosis. Different molecular techniques are used for identification and differentiation of the various species of Babesia, semi-nested PCR [53] reverse line blotting $[9,54]$ and PCR-restriction fragment length polymorphism analysis [55].

Improved PCR techniques have lately allowed for better definition of these parasites [56] and allows for a more reliable identification of the etiological agents compared to direct detection by light microscopy or serology [2]. It is more sensitive and provides an evidence of an active and ongoing infection in a clinical setting.

In addition, several genes are commonly used to discriminate among Babesia species. Typically, these include the nuclear ribosomal RNA genes [7, 8] and the two internal transcribed spacers (ITS1 and ITS2) [7]. PCR DNA amplification can be a useful technique for monitoring treatment [57].

\subsection{Diagnostic imaging}

The most consistent findings on abdominal ultrasonography in dogs with $B$. canis are hepatomegaly and splenomegaly with diffuse, hypoechoic, heterogeneity and renal changes like diffuse homogenous increased cortical echogenicity and increased corticomedullary definition [58]. Dogs infected with B. rossi and $B$. canis having gastrointestinal signs and abdominal pain are reported to have 
ultrasonographic changes in the pancreases $[32,59]$ which are found to be consistent with acute pancreatitis and included duodenal atony and peripancreatic fat hyperechogenicity.

\subsection{Differential diagnosis}

It includes other causes of haemolytic anaemia such as haemobartonellosis, autoimmune haemolytic anaemia, pyruvate kinase deficiency and Heinz body haemolytic anaemia. Other differentials include immune-mediated thrombocytopenia, systemic lupus erythematosus, leptospirosis, rickettsial diseases, dirofilariasis with caval syndrome, leptospirosis, zinc toxicity and neoplasia.

\section{Therapy}

Treatment for canine babesiosis consists of three components:

- Treatment to eliminate the parasite

- Blood transfusions to treat severe anaemia

- Supportive care for the complications and metabolic derangements

\subsection{Main drugs and drug combinations used in the antiprotozoal treatment of babesiosis}

a. Imidocarb dipropionate: It is an aromatic diamidine and is recommended to be used as $6.6 \mathrm{mg} / \mathrm{kg}$ intramuscularly (IM) or subcutaneously (SC) with a repeated dose in 2 weeks in dogs. Among many of the proposed mechanisms of action includes blockage of the entry of inositol into erythrocytes containing Babesia, resulting in starvation of the parasite [60], interference with production [61] or combination with DNA in susceptible Babesia species, causing nucleic acid damage and inhibition of cellular repair and replication [62] (Table1). It is approved for treatment of different forms of Babesia spp. [39, 57, 63]. The adverse effects of this medication include pain during injection and cholinergic effects such as salivation, drooling, nasal drip or vomiting which can be mitigated by premedicating with atropine at $0.05 \mathrm{mg} / \mathrm{kg}$. Additionally some less frequent adverse effects are panting, restlessness, diarrhoea, renal tubular or hepatic necrosis and injection site inflammation and more rarely ulceration, which usually heals within days to weeks.

b. Diminazene aceturate: It is $4,4^{\prime}$-(diazoamino) dibenzamidine diaceturate which is widely used in tropical countries as a first-line agent for the treatment of Babesia gibsoni infection of dogs, usually as an intramuscular injection of $3.5 \mathrm{mg} / \mathrm{kg}$. Although diminazene aceturate has anti-Babesia activity, it often fails to eliminate $B$. gibsoni from affected dogs and a relapse may occur. Furthermore, diminazene has a narrow clinical safety margin and can induce fatal nervous complications after $24-48 \mathrm{~h}$ of overdose. Clinical signs associated with diminazene toxicity are depression or stupor, continuous vocalisation, ataxia, opisthotonos, extensor rigidity, nystagmus and seizures [3]. There are reported toxicity such as acute CNS signs including ataxia, nystagmus and occasional seizures in dogs administered with one recommended intramuscular dose $(3.5 \mathrm{mg} / \mathrm{kg})$ of diminazene for treatment of babesiosis [64]. 


\begin{tabular}{|c|c|c|c|}
\hline $\begin{array}{l}\text { Babesia } \\
\text { species }\end{array}$ & Drug & Dose and duration & Response to treatment \\
\hline \multirow{2}{*}{$\begin{array}{l}\text { B. canis, } \\
\text { B. vogeli and } \\
\text { B. rossi }\end{array}$} & $\begin{array}{l}\text { Imidocarb } \\
\text { dipropionate }\end{array}$ & $\begin{array}{l}5-6.6 \mathrm{mg} / \mathrm{kg} \text { IM once; } \\
\text { may repeat in } 14 \text { days }\end{array}$ & \multirow[t]{2}{*}{ Good } \\
\hline & $\begin{array}{l}\text { Diminazene } \\
\text { aceturate }\end{array}$ & A single dose of $3.5 \mathrm{mg} / \mathrm{kg}$ & \\
\hline \multirow[t]{2}{*}{ B. gibsoni } & $\begin{array}{l}\text { Azithromycin + } \\
\text { atovaquone }\end{array}$ & $\begin{array}{c}10 \mathrm{mg} / \mathrm{kg} \text { PO } \\
\mathrm{SID}+13.3 \mathrm{mg} / \mathrm{kg} \text { PO TID } \\
\text { for10 days }\end{array}$ & \multirow{2}{*}{$\begin{array}{c}\text { Improvement of anaemia and } \\
\text { clinical signs without elimination } \\
\text { of parasite and with occasional to } \\
\text { frequent clinical relapses }\end{array}$} \\
\hline & Clindamycin & $\begin{array}{l}12-25 \mathrm{mg} / \mathrm{kg} \text { PO BID for } \\
7-10 \text { days }\end{array}$ & \\
\hline B. conradae & $\begin{array}{l}\text { Imidocarb } \\
\text { dipropionate }\end{array}$ & $\begin{array}{l}5-6.6 \mathrm{mg} / \mathrm{kg} \mathrm{IM} \text { once; } \\
\text { may repeat in } 14 \text { days }\end{array}$ & $\begin{array}{l}\text { Moderate to poor with frequent } \\
\text { relapses }\end{array}$ \\
\hline B. microti-like & $\begin{array}{c}\text { Imidocarb } \\
\text { dipropionate }\end{array}$ & $\begin{array}{l}5-6.6 \mathrm{mg} / \mathrm{kg} \text { IM once; } \\
\text { may repeat in } 14 \text { days }\end{array}$ & Poor \\
\hline
\end{tabular}

Table 1.

Summary of the treatment protocols with antiprotozoal agents.

\subsection{Combination therapies}

a. Atovaquone and azithromycin: The first treatment that has been shown to be effective against $B$. gibsoni is a combination of an analog of ubiquinone, atovaquone (ATV) and a macrolide antibiotic, azithromycin (AZM) [57]. The use of ATV alone inhibits the growth of Babesia spp. and is presumed to act through blocking protozoan mitochondrial electron transport causing inhibition of pyrimidine and ATP synthesis [62]. Azithromycin acts by inhibiting the translation of mRNA and bacterial protein synthesis by binding to the $50 \mathrm{~S}$ subunit of the prokaryote ribosome. It exerts its antiprotozoal effects by specifically acting on apicoplasts, a non-photosynthetic plastid organelles with a limited genome and found in apicomplexan parasites [65] including Babesia spp. [66]. In addition, the simultaneous use of ATV and AZM produces an additive or synergistic therapeutic effect, while the single use of each drug tends to result in a relapse of signs. Moreover possible emergence of drugresistant variants of B. gibsoni can occur after the use of ATV alone, and these variants might be caused by mutations in the cytochrome $b$ (CYTb) gene, resulting in amino acid substitutions at the putative ATV binding site [67]. Further, the results are not consistent based on molecular analysis [68].

b.Buparvaquone and azithromycin: Buparvaquone is a hydroxynaphthoquinone antiprotozoal drug-related to atovaquone and parvaquone. Buparvaquone (Butalex $\left.{ }^{\circledR}\right)$ is used in the treatment of bovine theileriosis [69]. It is also used to treat B. vulpes infection in dogs at an off-label dose of $5 \mathrm{mg} / \mathrm{kg}$ IM twice $48 \mathrm{~h}$ apart, in combination with azithromycin at $10 \mathrm{mg} / \mathrm{kgPO}$ once daily for 10 days [63]. Buparvaquone's mode of action on piroplasms is probably comparable to atovaquone's.

c. Combination therapy of clindamycin (CLDM), metronidazole (MNZ) and doxycycline (DOXY) is an efficacious alternative treatment strategy for $B$. gibsoni infection [70]. However, this treatment takes a relatively long time to show its therapeutic effect [71]. 


\subsection{Supportive treatment}

Supportive therapy should be based on thorough patient assessment and should be provided for moderate-to-severe infection depending on the type of Babesia spp. infecting the dog which may include:

a. Fluid therapy: In Babesia-infected dogs, intravenous fluid therapy is required for patients in shock, old dogs with history of renal disease, clinically dehydrated patients and dogs with intravascular haemolysis and haemoglobinuria. Mildly dehydrated patients (approximately $5 \%$ ) require $50 \mathrm{ml} / \mathrm{kg}$ body weight, and moderately dehydrated (approximately 10\%) requires $100 \mathrm{ml} / \mathrm{kg}$ body weight, whereas severely dehydrated (15\%) dogs require about $150 \mathrm{ml} / \mathrm{kg}$ body weight of replacement fluid. Usually intravenous crystalloid fluid is indicated with correction of electrolyte and acid-base abnormalities. It is important to maintain blood volume and adequate end-organ perfusion diuresis and prevention of red blood cell sludging in capillaries [72]. Hetastarch (10 to $20 \mathrm{ml} / \mathrm{kg}$ ) causes greater plasma volumes expansion, its beneficial in resuscitative fluid therapy. As fluid therapy can exacerbate ARDS, close monitoring of respiratory rate and pulmonary sounds is crucial.

b. Whole blood/ RBC/plasma transfusion: Need for blood transfusion depends on magnitude of anaemia (haematocrit $\leq 15 \%$ ) and clinical signs such as dyspnoea or tachypnoea. The degree of parasitaemia is not an important factor as it often bears little relation to the degree of anaemia. Packed erythrocytes $(20 \mathrm{~mL} / \mathrm{kg})$ are the component of choice for treating haemolytic anaemia. Crossmatching is not mandatory for the first transfusion, as dogs do not have naturally occurring alloantibodies. Initially blood is transfused slowly at $2 \mathrm{ml} /$ $\mathrm{kg} / \mathrm{h}$ for the first 30-60 min while observing for transfusion reactions, such as a sudden rise in body temperature and/or respiratory rate and lip and ear pinna swelling. Infected dogs with disseminated intravascular coagulation or coagulation disorders may require plasma transfusions.

c. Immunosuppressants: The use of immunosuppressant drugs in dogs with immune-mediated haemolytic anaemia (IMHA) or thrombocytopenia is controversial because these conditions are always associated with infectious disease. But in cases of unresponsiveness to antiprotozoal treatment, the use of $2 \mathrm{mg} / \mathrm{kg} /$ day of prednisone is recommended in infected dogs with moderateto-severe clinical signs [73].

d.Other supportive therapies: Other supportive therapies depend on the clinical signs and/or laboratory abnormalities, for example, oxygen therapy should be used when there is respiratory distress and antiemetics to counter vomiting. If the dog is stable and does not require hospitalization, then treatment should be restricted to antiprotozoal agents [74].

\section{Prognostic indicators}

In a recent study, it was suggested that lactate as a prognostic indicator with mean lactate in complicated cases of canine babesiosis wherein the blood lactate concentration in non-survivors $(145 \mathrm{mg} / \mathrm{dL})$ was higher than in survivors (13.8 mg/ $\mathrm{dL})$. Pretreatment hyperlactataemia $(>45 \mathrm{mg} / \mathrm{dL})$ and subsequent serial lactate concentrations that failed to return to normal reference range (persistently $>40 \mathrm{mg}$ / $\mathrm{dL}$ ) indicate poor prognosis [75]. 


\section{Prevention}

The most effective preventive measures practised worldwide are regular control of the tick vectors by routinely dipping or spraying pets or using tick collars or spot-on preparations. As it takes a minimum of 48 hours for Babesia transmission, so regular examination of dogs for the presence of any ticks and to remove it soon after they attach is important. The merozoites circulating in the blood may be transmitted to a healthy host directly by blood transfusion, so blood donors should be screened negative for babesiosis, preferably by polymerase chain reaction. Moreover, it is also reported that B. gibsoni can be transmitted by transfer of blood during dog fighting, which should be prevented. In Europe a vaccine is available against B. canis with a reported efficacy of 70-100\% [76]. More recently a bivalent vaccine called Pirodog ${ }^{\circledR}$ (Merial) derived from soluble parasite antigens from $B$. canis and B. rossi obtained from culture media supernatant has been shown to reduce duration and severity of clinical signs [77]. Although vaccination against canine babesiosis does not prevent infection, it does seem to block the initiation of pathologic processes involved in the pathogenesis of the disease [78]. This vaccine can be administered from 5 months of age and requires annual revaccination but does not cross-protect against other Babesia species. Vaccines against other Babesia species such as $B$. gibsoni are currently being developed including recombinant antigen and DNA vaccines [79-81]. Although dogs can be vaccinated, the level of protection is highly variable, which might be due to genetic diversity of $B$. canis strains.

\section{Conclusion}

The spectrum of Babesia pathogens that infect dogs is gradually being elucidated with the aid of new molecular techniques and meticulous clinical investigation. Species of Babesia that cannot be distinguished morphologically cause diverse diseases and are transmitted by different vector ticks. Nonvector transmission by blood transfusion and directly from dog to dog is of special concern and could be responsible for the spread of infection to areas that were previously non-endemic. Correctly identifying the infectious agent is important for treatment planning and prognosis.

\section{Acknowledgements}

We would like to acknowledge the Department of Veterinary Medicine, Veterinary College, Bangalore, India.

\section{Conflict of interest}

The authors declare that there is no conflict of interest. 


\section{Author details}

Poonam Vishwakarma ${ }^{1 *}$ and M.K. Nandini ${ }^{2}$

1 Biosafety Support Unit, Government of India, New Delhi, India

2 My Pet’s Çhoice, The Companion Animal Clinic, Bangalore, India

*Address all correspondence to: drpoonamvet@gmail.com

\section{IntechOpen}

(C) 2019 The Author(s). Licensee IntechOpen. This chapter is distributed under the terms of the Creative Commons Attribution License (http://creativecommons.org/licenses/ by/3.0), which permits unrestricted use, distribution, and reproduction in any medium, provided the original work is properly cited. (cc) BY 


\section{References}

[1] Irwin PJ. Canine babesiosis: From molecular taxonomy to control. Parasites \& Vectors. 2009;2(Suppl 1):S4

[2] Solano-Gallego L, Baneth G. Babesiosis in dogs and cats-expanding parasitological and clinical spectra. Veterinary Parasitology. 2011;18:48-60

[3] Boozer AL, Macintire DK. Canine babesiosis. The Veterinary Clinics of North America. Small Animal Practice. 2003 Jul;33(4):885-904

[4] Baneth G, Florin-Christensen M, Cardoso L, Schnittger L. Reclassification of Theileria annae as Babesia vulpes sp. nov. Parasites \& Vectors. 2015;8:207

[5] Reichenow E. Übertagungsweise und Entwicklung der Piroplasmen. ZENTRALBLATT FUR BAKTERIOLOGIE MIKROBIOLOGIE UND HYGIENE SERIE B. 1935;135:108-199

[6] Reichenow E. Über die Entwicklung von Theileriaparva, demErreger des Küstenfiebers der Rinder, in Rhipicephalus appendiculatus. ZENTRALBLATT FUR BAKTERIOLOGIE MIKROBIOLOGIE UND HYGIENE SERIE B. 1937;140:223-226

[7] Zahler M, Schein E, Rinder H, Gothe R. Characteristic genotypes discriminate between Babesia canis isolates of differing vector specificity and pathogenicity in dogs. Parasitology Research. 1998;84:544-548

[8] Carret C, Walas F, Carcy B, Grande N, Precigout E, Moubri K, et al. Babesia canis canis, Babesia canis vogeli, Babesia canis rossi: Differentiation of the three subspecies by a restriction fragment length polymorphism analysis on amplified small subunit ribosomal RNA genes. The Journal of Eukaryotic Microbiology. 1999;46:298-303
[9] Matjila PT, Penzhorn BL, Bekker CP, Nijhof AM, Jongejan F. Confirmation of occurrence of Babesia canis vogeli in domestic dogs in South Africa. Veterinary Parasitology. 2004;122:119-125

[10] Muhlnickel CJ, Jefferies R, Morgan-Ryan UM, Irwin PJ. Babesia gibsoni infection in three dogs in Victoria. Australian Veterinary Journal. 2002;80:606-610

[11] Kjemtrup AM, Wainwright K, Miller M, Penzhorn BL, Carreno RA. Babesia conradae, sp. nov., a small canine Babesia identified in California. Veterinary Parasitology. 2006;138:103-111

[12] Camacho AT, Pallas E, Gestal JJ, Guitian FJ, OlMeda AS, Telford SR, et al. Ixodes hexagonus is the main candidate as vector of Theileria annae in Northwest Spain. Veterinary Parasitology. 2003;112:157-163

[13] Kalra IS, Sing KB. Observations of naturally occurring Babesia canis infection in dog. The Indian Veterinary Journal. 1984;61:98-100

[14] Varshney JP, Kumar A, Hoque M. Ehrlichia platys and Babesia canis infection in a dog: A clinical report. Journal of Veterinary Parasitology. 2004;18:35-37

[15] Sinha BP, Ghosh P. Treatment of clinical cases of canine babesiosis. Indian Journal of Veterinary Medicine. 1986;6:94

[16] Varshney JP, Varshney VP, Hoque M. Clinico-haematological, biochemical, endocrinological and ultrasonographic findings in canine babesiosis. The Indian Journal of Animal Sciences. 2003;73:1099-1101

[17] Homer MJ, Aguilar-Delfin I, Telford SR, Krause PJ, Persing DH. 
Babesiosis. Clinical Microbiology

Reviews. 2000;13:451-469

[18] Lempereur L, De Cat A, Caron Y, Madder M, Claerebout E, Saegerman C, et al. First molecular evidence of potentially zoonotic Babesia microti and Babesia sp. EU1 in Ixodes ricinus ticks in Belgium. Vector Borne and Zoonotic Diseases. 2011;11:125-130

[19] Lobetti RG. Babesiosis. In: Greene CE, editor. Infectious Diseases of the Dog and Cat. 3rd ed. Philadelphia: W.B. Saunders; 2006

[20] LaiaSolano-Gallego ÁS, Roura X, Estrada-Peña A, Miró G. A review of canine babesiosis: The European perspective. Parasites \& Vectors. 2016;9:336. DOI: 10.1186/ s13071-016-1596-0

[21] Birkenheuer AJ, Correa MT, Lev MG, Breitschwerdt EB. Geographic distribution of babesiosis among dogs in the United States and association with dog bites: 150 cases (2000-2003). Journal of the American Veterinary Medical Association. 2005;227:942-947

[22] Yeagley TJ, Reichard MV, Hempstead JE, Allen KE, Parsons LM. Detection of Babesia gibsoni and the canine small Babesia 'Spanish isolate' in blood samples obtained from dogs confiscated from dogfighting operations. Journal of the American Veterinary Medical Association. 2009;235:535-539

[23] Mierzejewska EJ, Welc-Faleciak R, Bednarska M, Rodo A, Bajer A. The first evidence for vertical transmission of Babesia canis in a litter of central Asian shepherd dogs. Annals of Agricultural and Environmental Medicine. 2014;21:500-503

[24] Simoes PB, Cardoso L, Araujo M, Yisaschar-MekuzasY,BanethG.Babesiosis due to the canine Babesia microti-like small piroplasm in dogs-first report from Portugal and possible vertical transmission. Parasites \& Vectors. 2011;4:50

[25] Stegeman JR, Birkenheuer AJ, KrugerJM,BreitschwerdtEB.Transfusion associated Babesia gibsoni infection in a dog. Journal of the American Veterinary Medical Association. 2003;222:959-963

[26] Jefferies R, Ryan UM, Jardine J, Broughton DK, Robertson ID, Irwin PJ. Blood, bull terriers and babesiosis: Further evidence for direct transmission of Babesia gibsoni in dogs. Australian Veterinary Journal. 2007;85:459-463

[27] Taboada J, Merchant SR. Babesiosis of companion animals and man.

Veterinary Clinics of North America: Small Animal Practice. 1991;21:103-123

[28] Taboada J. Babesiosis. In: Greene CE, editor. Infectious Diseases of the Dog and Cat. Philadelphia: WB Saunders; 1998. pp. 473-481

[29] Wozniak EJ, Barr BC, Thomford JW, et al: Clinical, anatomic, and Immunopathologic characterization of Babesia gibsoni infection in the domestic dog (Canis Familiaris). The Journal of Parasitology 1997;83(4):692-699

[30] Jacobson LS, Clark IA. The pathophysiology of canine Babesiosis: New approaches to an old puzzle. Journal of the South African Veterinary Association. 1994;65:134-145

[31] Máthé A, Dobos-Kovacs M, Voros K. Histological and ultrastructural studies of renal lesions in Babesia canis infected dogs treated with imidocarb. Acta Veterinaria Hungarica. 2007;55:511-523. DOI: $10.1556 /$

AVet.55.2007.4.10

[32] Mohr AJ, Lobetti RG, VanDerlugt JJ. Acute pancreatitis: A newly recognized potential 
complication of canine babesiosis. Journal of the South African Veterinary Association. 2000;71:232-239

[33] Leisewitz AL, Jacobson LS, De Morais HS, Reyers F. The mixed acidbase disturbances of severe canine babesiosis. Journal of Veterinary Internal Medicine. 2001;15:445-452

[34] Keller N, Jacobson LS, Nel M, De Clerq M, Thompson PN, Schoeman JP. Prevalence and risk factors of hypoglycemia in virulent canine babesiosis. Journal of Veterinary Internal Medicine. 2004;18:265-270

[35] Jacobson LS. The south African form of severe and complicated canine babesiosis: Clinical advances 1994-2004. Veterinary Parasitology. 2006;138:126-139

[36] Welzl C, Leisewitz AL, Jacobson LS, Vaughanscott T, Myburgh E. Systemic inflammatory response syndrome and multiple-organ damage/dysfunction in complicated canine babesiosis. Journal of the South African Veterinary Association. 2001;72:158-162

[37] Irwin PJ, Hutchinson GW. Clinical and pathological findings of Babesia infection in dogs. Australian Veterinary Journal. 1991;68:204-209

[38] FurlanelloT,FiorioF,CaldinM,LubasG, Solano-Gallego L. Clinicopathological findings in naturally occurring cases of babesiosis caused by large form Babesia from dogs of northeastern Italy. Veterinary Parasitology. 2005;134:77-85

[39] Conrad P, Thomford J, Yamane I, Whiting J, Bosma L, Uno T, et al. Hemolytic anemia caused by Babesia gibsoni infection in dogs. Journal of the American Veterinary Medical Association. 1991;199:601-605

[40] MacIntire DK, Boudreaux MK, West GD, Bourne C, Wright JC, Conrad PA. Babesia gibsoni infection among dogs in the southeastern United States. Journal of the American Veterinary Medical Association. 2002;220:325-329

[41] Dvir E, Lobetti RG, Jacobson LS, Pearson J, Becker PJ. Electrocardiographic changes and cardiac pathology in canine babesiosis. Journal of Veternary Cardiology. 2004;6(1):15-23

[42] Böhm M, Leisewitz AL, Thompson PN, Schoeman JP. Capillary and venous Babesia canis rossi parasitaemias and their association with outcome of infection and circulatory compromise. Veterinary Parasitology. 2006;141:18-29

[43] Solano-Gallego L, Trotta M, Carli E, Carcy B, Caldin M, Furlanello T. Babesia canis canis and Babesia canis vogeli clinicopathological findings and DNA detection by means of PCR-RFLP in blood from Italian dogs suspected of tick-borne disease. Veterinary Parasitology. 2008;157:211-221

[44] Miro G, Checa R, Paparini A, Ortega N, Gonzalez-Fraga JL. Theileria annae (syn. Babesia microti-like) infection in dogs in NW Spain detected using direct and indirect diagnostic techniques: Clinical report of 75 cases. Parasites \& Vectors. 2015;8:217

[45] Scheepers E, Leisewitz AL, Thompson PN, Christopher MM. Serial haematology results in transfused and non-transfused dogs naturally infected with Babesia rossi. Journal of the South African Veterinary Association. 2011;82(3):136-143

[46] Liebenberg C, Goddard A, Wiinberg B, et al. Hemostatic abnormalities in uncomplicated babesiosis (Babesia rossi) in dogs. Journal of Veterinary Internal Medicine. 2013;27(1):150-156

[47] Lobetti RG, Jacobson LS. Renal involvement in dogs with babesiosis. 
Journal of the South African Veterinary Association. 2001;72(1):23-28

[48] Reyers F. Is the Azotaemia in Canine Babesiosis an Indication of Renal Disease. 9th Faculty Day, University of Pretoria, Faculty of Veterinary Science. 1992. p. 17

[49] Lobetti RG, Mohr AJ, Dippenaar T, Myburgh E. A preliminary study on the serum protein response in canine babesiosis. Journal of the South African Veterinary Association. 2000;71(1):38-42

[50] Keller N, Jacobson LS, Nel M, et al. Prevalence and risk factors of hypoglycemia in virulent canine babesiosis. Journal of Veterinary Internal Medicine. 2004;18(3):265-270

[51] Defauw P, Schoeman JP, Smets $P$, et al. Assessment of renal dysfunction using urinary markers in canine babesiosis caused by Babesia rossi. Veterinary Parasitology. 2012;190(3-4):326-332

[52] Eichenberger RM, Štefanić S, Naucke TJ, Šarkūnas M, Zamokase G, Grimma F, et al. An ELISA for the early diagnosis of acute canine babesiosis detecting circulating antigen of large Babesia spp. Veterinary Parasitology. 2017;243:162-168. http://dx.doi. org/10.1016/j.vetpar.2017.06.030

[53] Birkenheuer AJ, Levy MG, Breitschwerdt EB. Development and evaluation of a semi nested PCR for detection and differentiation of Babesia gibsoni (Asian genotype) and B. canis DNA in canine blood samples. Journal of Clinical Microbiology. 2003;41:4172-4177

[54] Yisaschar-Mekuzas Y, Jaffe CL, Pastor J, Cardoso L, Baneth G. Identification of Babesia species infecting dogs using reverse line blot hybridization for six canine piroplasms, and evaluation of co-infection by other vector-borne pathogens. Veterinary Parasitology. 2013;191:367-373

[55] Jefferies R, Ryan UM, Irwin PJ. PCR-RFLP for the detection and differentiation of the canine piroplasm species and its use with filter paperbased technologies. Veterinary Parasitology. 2007;144:20-27

[56] Matjila PT, Leisewitz AL, Jongejan F, Penzhorn BL. Molecular detection of tick-borne protozoal and ehrlichial infections in domestic dogs in South Africa. Veterinary Parasitology. 2008;155:152-157

[57] Birkenheuer AJ, Levy MG, Breitschwerdt EB. Efficacy of combined atovaquone and azithromycin for therapy of chronic Babesia gibsoni (Asian genotype) infections in dogs. Journal of Veterinary Internal Medicine. 2004;18(4):494-498

[58] Fraga E, Barreiro JD, Goicoa A. Abdominal ultrasonographic findings in dogs naturally infected with babesiosis. Veterinary Radiology \& Ultrasound. 2011;52(3):323-329

[59] Mathe A, Voros K, Papp L, Reiczigel J. Clinical manifestations of canine babesiosis in Hungary (63 cases). Acta Veterinaria Hungarica. 2006;54(3):367-385

[60] McHardy N, Woollon RM, Clampitt RB, James JA, Crawley RJ. Efficacy, toxicity and metabolism of imidocarb dipropionate in the treatment of Babesia ovis infection in sheep. Research in Veterinary Science. 1986;41:14-20

[61] Bacchi CJ, Nathan HC, Hutner SH, Duch DS, Nichol CA. Prevention by polyamines of the curative effect of amicarbalide and imidocarb for Trypanosoma brucei infections in mice. Biochemical Pharmacology. 1981;30:883-886 
[62] Plumb DC: Plumb's Veterinary Drug Handbook, 8th edition. WileyBlackwell, Ames; 2015. pp. 1296

[63] Checa R, Montoya A, Ortega N, González-Fraga JL, Bartolomé A, Gálvez R. Marino V and Miró, G: Efficacy, safety and tolerance of imidocarb dipropionate versus atovaquone or buparvaquone plus azithromycin used to treat sick dogs naturally infected with the Babesia microti-like piroplasm. Parasites \& Vectors. 2017;10:145

[64] Han D, Yoon W-K, Hyun C. Cerebellar encephalopathy from diminazene aceturate (beneril)toxicity in a dog. Korean Journal of Veterinary Research. 2014;54(3):193-196. http:// dx.doi.org/10.14405/kjvr.2014.54.3.193

[65] Chakraborty A. Understanding the biology of the Plasmodium falciparum apicoplast;an excellent target for antimalarial drug development. Life Sciences. 2016;158:104-110

[66] Wang T, Guan G, Korhonen PK, Koehler AV, Hall RS, Young ND, et al. The apicoplast genomes of two taxonomic units of Babesia from sheep. Veterinary Parasitology. 2017;233:123-128

[67] Sakuma M, Setoguchi A, Endo Y. Possible emergence of drugresistant variants of Babesia gibsoni in clinical cases treated with atovaquone and azithromycin. Journal of Veterinary Internal Medicine 2009;23:493-498

[68] Jefferies R, Ryan UM, Jardine J, et al. Babesia gibsoni: Detection during experimental infections and after combined atovaquone and azithromycin therapy. Experimental Parasitology. 2007;117:115-123

[69] Wilkie GM, Brown CG, Kirvar BE, Thomas M, Williamson SM, Bell-Sakyi LJ, et al. Chemoprophylaxis of Theileria annulata and Theileria parva infections of calves with buparvaquone. Veterinary Parasitology. 1998;78:1-12

[70] Nandini MK, Vishwakarma P, Kamran CA. New therapeutic protocol for canine babesiosis: A case report. Journal of Dairy, Veterinary \& Animal Research. 2016;3(3):112-113. DOI: 10.15406/jdvar.2016.03.00082

[71] Suzuki K, Wakabayashi H, Takahashi M, et al. A possible treatment strategy and clinical factors to estimate the treatment response in Babesia gibsoni infection. The Journal of Veterinary Medical Science. 2007;69(5):563-568

[72] Ayoob AL, Hackner SG, Prittie J. Clinical management of canine babesiosis. Journal of veterinary emergency and critical care (San Antonio). 2010;20:77-89

[73] Grundy SA, Barton C. Influence of drug treatment on survival of dogs with immune-mediated hemolytic anemia: 88 cases (1989-1999). Journal of the American Veterinary Medical Association. 2001;218:543-546

[74] Kidd L, Mackman N. Prothrombotic mechanisms and anticoagulant therapy in dogs with immune-mediated hemolytic anemia. Journal of Veterinary Emergency and Critical Care (San Antonio, Tex.). 2013;23:3-13

[75] Nel M, Lobetti RG, Keller N, Thompson PN. Prognostic value of blood lactate, blood glucose, and Hematocrit in canine Babesiosis. Journal of Veterinary Internal Medicine. 2004;18:471-476

[76] Moreau Y, Vidor E, Bissuel G. DubreuilN: Vaccination against canine babesiosis: An overview of field observations. Transactions of the Royal Society of Tropical Medicine and Hygiene. 1989;83(Suppl):95-96 
[77] Schetters TP, Kleuskens J, Carcy B, Gorenflot A, Vermeulen A. Vaccination against large Babesia species from dogs. Parasitologia. 2007;49(Suppl 1):13-17

[78] Schetters TP, Kleuskens JA, Scholtes NC, Pasman JW, Goovaerts D. Vaccination of dogs against Babesia canis infection. Veterinary Parasitology. 1997;73(1-2):35-41

[79] Fukumoto S, Tamaki Y, Igarashi I, Suzuki H, Xuan X. Immunogenicity and growth inhibitory efficacy of the primeboost immunization regime with DNA followed by recombinant vaccinia virus carrying the P29 gene of Babesia gibsoni in dogs. Experimental Parasitology.

2009;123:296-301

[80] Fukumoto S, Tamaki Y, Okamura M, Bannai H, Yokoyama N, Suzuki T, et al. Prime boost immunization with DNA followed by a recombinant vaccinia virus expressing P50 induced protective immunity against Babesia gibsoni infection in dogs. Vaccine. 2007;25:1334-1341

[81] Fukumoto S, Tamaki Y, Shirafuji H, Harakawa S, Suzuki H, Xuan X. Immunization with recombinant surface antigen $\mathrm{P} 50$ of Babesia gibsoni expressed in insect cells induced parasite growth inhibition in dogs. Clinical and Diagnostic Laboratory Immunology. 2005;12:557-559 



\title{
Chapter 10
}

\section{Review on Ascites in Pets}

\author{
Rosemary Ijeoma Ogechi Nwoha
}

\begin{abstract}
Ascites is one of the major complications seen in various disease conditions in pets. Ascites is characterised by distension of the abdomen with accumulation of fluid of various colours and consistencies depending on the cause. The most common causes of ascites in pets include but not limited to the following health conditions: hypoproteinaemia, left-sided heart failure, congestive heart failure, cirrhosis, hepatic diseases, renal diseases, ancylostomosis and bacterial infection such as tuberculosis. Pathogenesis of ascites often emanate from portal hypertension, cirrhosis, hepatorenal syndrome, etc. Oftentimes the diagnosis of ascites could be cumbersome considering the myriad of diseases implicated in the condition. Standard diagnostic procedures include the following: physical examination, clinical examination, ultrasonography, computed tomography, serum ascites albumin gradient (SAAG), biochemical analysis such as triglyceride, urea and creatinine concentration, total protein, etc. Novel diagnostic procedures with possible clinical relevance include the following: leucocyte esterase reagent strip, platelet indices, tumour markers, etc. Diagnosis is made through standard diagnostic procedure, while special cases of idiopathic origin are detected through diagnostic laparotomy. Novel diagnostic procedures such as platelet indices, leucocyte esterase reagent strip and tumour markers would aid in easy diagnosis of ascites. Treatment of ascites is dependent on identification of the cause of ascites.
\end{abstract}

Keywords: ascites, SAAG, hepatorenal syndrome, diuretics, portal hypertension, abdominocentesis, hepatic, cardiac, abdominal effusion, abdominal drops

\section{Introduction}

Ascites is a term used to describe the condition of accumulation of fluid in the peritoneal cavity. The word "ascites" could be used interchangeably with other terms such as abdominal dropsy, abdominal effusion, peritoneal fluid excess, hydroperitoneum and peritoneal cavity fluid. Ascites represents a form of general systemic state which could manifest in diverse disease conditions in animals. This implies that ascites is only a clinical manifestation of an underlying disease condition and not a disease in real sense. It further shows that ascites is not a treatable condition except the cause is properly diagnosed and treated accordingly. Ascites is often diagnosed in dogs between the ages of 5 and 7 years [1]. Cases between the ages of 1 and 4 years have also been recorded. The occurrence of ascites in dogs may be breed dependent with higher incidences in Pomeranian (33.35\%) than in Labrador retriever (20\%), Boxer (16.66\%), Doberman pinscher (13.37\%), mongrels (10\%) and least in Alsatian (6.66\%) [1]. Ascites manifests in several disease 
conditions such as hepatic disease, various types of neoplasm, portal hypertension, alteration in serum protein level (hypoproteinaemia), right-sided heart failure, decreased plasma oncotic pressure and increased permeability of capillary endothelium sequel to inflammatory conditions, bacterial infection (tuberculosis), kidney malfunction, pre-hepatic portal hypertension, post-hepatic portal hypertension, trauma (rupture of lymphatic vessels, blood vessels, urinary bladder),

ancylostomosis peritonitis, bleeding disorders and malnutrition [2, 3]. Other conditions may include heartworm infection and pulmonary stenosis [4]. In general, cardiac and hepatic disease conditions ranked highest as the cause of ascites in pets. Other manifesting signs which usually signify an underlying disease condition in ascetic pets may include syncope, vomiting, obtundation, seizure, anaemia which manifests as pale mucous membrane, weakness and rapid panting. The identification and diagnosis of the cause of ascites may not be a straightforward procedure and could be complicated due to the several causative factors. The veterinarian however has to be guided by the medical adage "if you hear the sound of hoof first look for a horse before a zebra". This only means that diagnosis should start with the basis of thorough physical examination of the entire body and clinical examinations. A well and sequential conduction of physical and clinical examinations serves as a pointer to the underlying cause of ascites. However this may not always be so as diagnosis oftentimes is cumbersome. In such situations diagnosis would include a complete blood count which may reveal evidence of bacterial infection. Abdominal ultrasound/sonography is done to determine the abdominal content and aid in differentiating excess fluid accumulation from abdominal masses and organ enlargement. Knowledge of the blood biochemistry including total protein, albumin, creatinine and urea, liver enzymes and coagulation profile would help in revealing cases of hypoalbuminaemia, hypoproteinaemia and hepatic and kidney diseases [5]. Cardiac diseases may be diagnosed with the aid of electrocardiograph. Cardiac auscultation detects cases of cardiac murmurs and arrhythmia. Abdominal paracentesis is a useful procedure usually carried out to reduce the fluid level and alleviate complications of dyspnea. Paracentesis is a useful procedure in the management of ascites which is instituted in conjunction with appropriate treatment of the underlying cause. Once appropriate diagnosis is made, treatment usually comes easy by alleviating life-threatening conditions such as dyspnea and administering appropriate therapy as the case may be.

\section{Classification of ascites}

The purpose of this review is primarily focused on the various causes of ascites with emphasis on the hepatic origin. Based on this premise, ascites is classified broadly into hepatic, pre-hepatic and post-hepatic origin:

i. Pre-hepatic causes emanate from portal vein thrombosis, bacterial infection such as tuberculosis, malnutrition, hypoalbuminaemia and parasitic diseases such as strongyloidosis and entamoeba [6]. Other causes include trauma or rupture of the lymphatic vessels, blood vessels and urinary bladder, renal failure, lymphoma and neoplasm of various kinds including breast, bronchus, ovary, gastric, pancreatic or colonic neoplasms [7]. Up to $20 \%$ of neoplastic ascites arise from tumour of unknown origin [7].

ii. Post-hepatic causes might include congestive heart failure often linked with pulmonary hypertension, left-sided heart failure, right-sided heart failure, 
constrictive pericarditis, Budd-Chiari syndrome and stricture web formation in the inferior vena cava $[8,9]$.

iii. Hepatic origin emanates from various hepatic diseases including cirrhosis, portal hypertension and hepatitis. Approximately $85 \%$ of portal hypertension results in cirrhosis [8-10].

Earlier classification of ascites was centred on two broad categories, transudates and exudates, based on the total protein concentration of ascetic fluid. High total protein $(>2.5 \mathrm{~g} / \mathrm{l})$ was described as exudates, while low total protein $(<2.5 \mathrm{~g} / \mathrm{l})$ as transudate [11]. Both transudates and exudates were subcategorised into modified transudates and exudates based on the level of total protein concentration in the ascetic fluid. Transudates with $<2.5 \mathrm{~g} / \mathrm{l}$ of total protein usually occur with portal hypotension or hypoalbuminaemia [6]. Exudates with $>2.5 \mathrm{~g} / \mathrm{l}$ of total protein are associated with inflammatory disease conditions such as bacteria tuberculosis, neoplasm of unknown origin, pancreatitis, myxoedema, etc. Nevertheless, it has been observed that a total protein concentration of $<2.5 \mathrm{~g} / \mathrm{l}$ has an accuracy of only $56 \%$ [6] in detecting exudates from various conditions such as cardiac ascites and patients on diuretics and neoplasms [11]. The obvious challenge in the use of total protein concentration paved way to the discovery of serum ascites albumin gradient (SAAG) concentration as a more reliable tool in classification of ascites with efficacy ranging from 80 to $100 \%$ [11]. With the advent of SAAG, exudate ascites is replaced with $(>1.1 \mathrm{~g} / \mathrm{l})$ high serum ascites albumin gradient and transudate with low $(<1.1 \mathrm{~g} / \mathrm{l})$ serum ascites albumin gradient. The SAAG $(>1.1 \mathrm{~g} / \mathrm{l})$ shows higher $94 \%$ sensitivity and $90 \%$ specificity in detecting portal hypertension than ascetic fluid total protein concentration of $<2.5 \mathrm{~g} /$ $\mathrm{dl}$ at percentage sensitivity and specificity of 78 and $50 \%$, respectively [12]. The prognostic index value of SAAG was at $82-97 \%$ compared to total protein concentration at $38-85 \%$ [12]. Ascites from cardiac origin produces greater $(>2.5 \mathrm{~g} / \mathrm{dl})$ SAAG compared to cases of cirrhosis [13].

A more recent classification of ascites has endorsed the use of serum ascites albumin gradient (SAAG) in diagnosis of ascites [14]. The SAAG is derived by subtracting the ascetic fluid albumin level from the serum albumin level obtained on the same day [14]. Gradients greater than $1.1 \mathrm{~g} / \mathrm{dl}$ indicate ascites of portal hypertension with an accuracy of 97-100\% [14]. Gradients less than $1.1 \mathrm{~g} / \mathrm{dl}$ are considered ascites of other sources other than portal hypertension such as neoplasm $[15,16]$ (Table 1).

\begin{tabular}{ll}
\hline High gradient $(>\mathbf{1 . 1} \mathbf{g} / \mathbf{l})$ SAAG & Low gradient $(<\mathbf{1 . 1}$ g/l) SAAG \\
\hline Portal hypertension & Bacterial infection \\
\hline Cardiac diseases & Peritoneal tuberculosis \\
\hline Liver cirrhosis & Pancreatic ascites \\
\hline Myxoedema & Parasitic disease \\
\hline Budd-Chiari syndrome & Ancylostomosis \\
\hline Hepatitis & Nephrotic syndrome \\
\hline Portal vein thrombosis & Trauma and rupture of lymphatic and blood vessels \\
\hline Hypoalbuminaemia & $\begin{array}{l}\text { Rupture of the urinary bladder, left-sided heart failure, right-sided } \\
\text { heart failure, congestive heart failure }\end{array}$ \\
\hline
\end{tabular}

Table 1.

Classification of ascites based on SAAG. 


\section{Pathophysiology of ascites in cirrhosis}

Ascites is one of the cardinal complications in liver cirrhosis in most patients [8]. Onset of ascites naturally connotes decompensated underlying liver cirrhosis which also signifies poor prognosis with short life expectancy $[10,17,18]$. Several factors contribute to the development of cirrhosis. The heart, for instance, plays an important role through a complex mechanism in the development of liver disease. The mechanism through which the heart and liver affect each other in the development of ascites is yet to be fully elucidated [14]. Several circulatory abnormalities observed in cirrhotic patients promulgated the peripheral arterial vasodilation hypothesis proposed in the last century [19]. The circulatory abnormalities manifest as increased cardiac output, portal hypertension, peripheral vascular resistance, arterial hypotension and splanchnic vasodilation $[6,20]$. Circulatory abnormalities from cardiac disease affect circulatory volume with a resultant decrease in tissue perfusion affecting majorly the kidney functionality [21]. Earlier in the disease, renal dysfunction is less expressed; however, with disease advancement the patient may experience difficulty in sodium excretion and consequent sodium and water retention [22]. Cirrhotic ascites basically develop from failure in renal excretion of sodium [22]. Different mechanisms also play a role in ascites in cirrhosis. Intrinsic factors including arterial vasodilation affect the blood pressure hormones such as the renin-angiotensin-aldosterone system (RAAS) which stimulates sodium reabsorption from the distal nephron [22]. The sympathetic nervous system (SNS) induces renal constriction and sodium reabsorption from the tubules with ascites [23, 24]. The heart, SNS and RAAS play a synergistic role in sodium retention and development of ascites in cirrhosis.

\subsection{Pathogenesis of portal hypertension in ascites}

The portal vein is a major vein comprising of a group of veins which supply the visceral organs including the abdomen, pancreas, intestine, etc. These veins bifurcate into smaller vessels in the hepatic tissue. Intrinsic factors and disease conditions such as cirrhosis result in blockage of these tiny veins in the hepatic tissue increasing the blood pressure in the veins with resultant portal hypertension. Other causes of portal hypotension include portal vein thrombosis, schistosomosis, idiopathy, etc. Ascites develops in portal hypertension when the post-sinusoidal gradient is above $12 \mathrm{mmHg}$ [25]. Portal hypertension elevates the hydrostatic pressure within the hepatic sinusoids permitting seepage of transudate into the peritoneal cavity [26, 27]. The extent of ascites' development is dependent on the level of hydrostatic pressure [28] and less on oncotic plasma albumin pressure $[26,29]$. Signs and symptoms of portal hypertension include haematuria, dysentery, bloody vomitus due to spontaneous rupture and haemorrhage from varices, encephalopathy due to abnormal liver function and thrombocytopaenia. Factors such as abnormal increase in nitric oxide production and circulation of endogenous vasoconstriction such as catecholamines, leukotrienes and angiotensin II enhance hepatic vascular resistance and portal hypertension [30, 31].

\subsubsection{Pathogenesis of hepatorenal syndrome in ascites}

One of the complications of activation of RAAS and SNS in cirrhosis is the resultant renal vasoconstriction leading to decrease in renal perfusion and glomerular filtrate rate which progresses to renal impairment [21, 22, 32, 33]. In hepatorenal syndrome, there are no significant morphological changes in renal histology, while the patients largely retain normal tubular function $[5,21]$. The kidney analyte and serum creatinine concentration does not increase until the glomerular filtration rate becomes markedly reduced below $40 \mathrm{ml} / \mathrm{min}$ [22]. Most patients with cirrhosis have their creatinine level below $1.2 \mathrm{mg} / \mathrm{dl}$, and diagnosis of HRS is only made when the creatinine concentration 
is higher than $1.5 \mathrm{mg} / \mathrm{dl}$ in the absence of other complicating aetiologies [22]. Hepatorenal syndrome manifests in two different types in cirrhotic patients. Type I HRS is a fulminating form of the disease rapidly progressing to acute renal failure often precipitated by variceal bleeding, septic infection and spontaneous bacteria peritonitis with poor prognosis of days to weeks [22]. Type 2 is a more chronic form of HRS. Most patients with this form of disease have a more stable creatinine concentration with only signs of refractory ascites due to unresponsive diuretics [34, 35].

With advancement in cirrhosis, there is also progressive increase in sodium and water reabsorption and decrease in renal blood flow and glomerular filtration [36]. Approximately $20 \%$ of cirrhotic patients with refractory ascites progress to HRS which results from severe liver and systemic circulatory dysfunction [28]. Hepatorenal syndrome results from marked overactivity of RAAS, SNS, AND and other endogenous vasoconstrictor factors which exceeds renal production of vasodilatory substances [PGE2, prostacyclin, nitric oxide]. The imbalance from renal vasodilatory mechanism and the intrinsic vasoconstrictor enhances vasoconstriction and hypoperfusion and decreases GFR with ultimate result of renal failure [22].

\section{Diagnosis of ascites}

Usually there is no laid down procedure on the steps to diagnose ascites; however a systematic approach applied in various disease conditions is advantageous in making appropriate diagnosis. A step-by-step approach normally starts with physical examination.

\subsection{Algorithm of diagnosis in ascites}
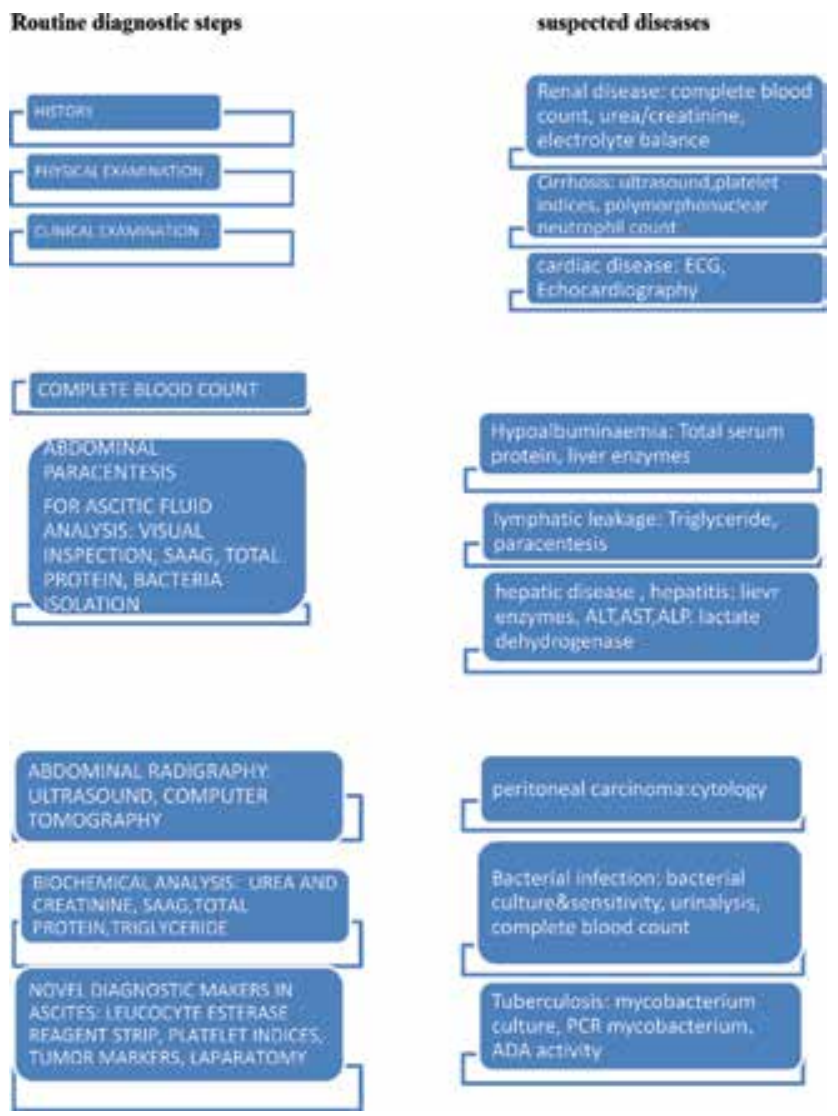


\subsubsection{Physical examinations}

In physical examination, the patient is examined for the presence of ticks and fleas which would contribute in physical discomfort of the pet. Ticks' infestation contributes in depletion of blood volume and anaemia. Anaemia is detected by the appearance of pale mucous membrane of the eye and the gum. Ectoparasitism from ticks' infestation may result in malnutrition due to competition with the host for essential nutrients necessary for the synthesis of protein and albumin. This could result in hypoalbuminaemia/hypoproteinaemia and a decrease in plasma oncotic pressure enhancing vascular permeability and seepage of fluid in the abdominal cavity. A distended or pulsating jugular vein in the neck region may indicate cardiovascular abnormality. Yellowish discoloration of the eye indicates jaundice and hepatic disease. Generalised lymphadenopathy may suggest lymphosarcoma and other inflammatory disease conditions. A "standback" observation reveals cases of dyspnea due to abdominal displacement of the diaphragm into the thoracic cavity compromising respiration. Respiratory distress could manifest in the form of rapid panting. Such condition presents a deviation from the normal respiratory pattern, from coastal to costo-abdominal or abdominal pattern. Black tarry-coloured faeces from gastrointestinal bleeding may signify ancylostomosis and portal hypertension. Physical examination of the trunk reveals a distended abdomen. The content of the abdomen could either be by pregnancy, abdominal masses, fluid of various consistencies or organ enlargement. The diagnosis of ascites starts from differentiating these possibilities through various procedures. First is to carry out abdominal ballottement using clinched fist. This technique can be used to differentiate abdominal masses from fluid. It can be used with other laboratory tests such as pregnancy test to rule out pregnancy. It however has some limitations in differentiating abdominal masses from organ enlargement. Abdominal ultrasound is a better option in differentiating abdominal contents. It has been proven effective in the detection of ascetic fluid, its site of production and differentiation of ascetic nature from transudates and exudates [11]. A recent research has shown the possibility of the use of echotexture of ascetic fluid in the detection of the cause of ascites in patients [11]. Abdominal paracentesis however is a very useful technique in differentiation of ascetic fluid [28].

\subsubsection{Guidelines for paracentesis in a dog (author's personal experience)}

A well-applied paracentesis without contamination of abdominal content is essential in differentiation of ascetic fluid. To achieve this, the following steps should be strictly applied:

1. First apply caution by the use of proper restrain technique on the dog.

2. Gently place the dog on a lateral decumbency exposing the larger part of the ventral abdomen.

3. Swab the ventral abdomen less covered with haircoat, along the linea alba down to the ventral abdomen between the left and right hindlimbs. (Linea alba is the preferred site of paracentesis due to its less vascularisation and less chance of contamination of the fluid with blood from puncture vessels and abdominal organs when approached through a different site on the abdomen.)

4. Puncture the linea alba using a 21 gauge needle and $10 \mathrm{~mL}$ gauge syringe, and aspirate the fluid. 
5. Decant the content of the syringe into a clean and well-labelled tube for laboratory investigation.

\section{Request for cytology of the fluid (Figure 1).}

\subsubsection{Diagnostic fluid markers in ascites}

The colour of ascetic fluid is a very essential marker in the diagnosis of the cause of ascites. The colour ranges from clear fluid to yellowish, reddish and opaque with flakes of fibrin and debris depending on the aetiology. It is therefore important to observe the above guidelines in paracentesis in order to avoid false discolouration of the fluid, thus affecting correct diagnosis. Various colours of ascetic fluid signify a different aetiology as shown below [37]:

1. Pinkish discolouration of the fluid: This is often seen in cases of exudation of fluid from bacterial infection which may become purulent. The exudates are often turbid in consistency and contains more than $2.0 \mathrm{gm}$ of protein and greater than 6000 cells $/ \mu \mathrm{L}$ composed mostly of neutrophils with evidence of +++ bacterial infection. This type of fluid is considered a medical emergency to prevent development of sepsis.

2. Clear straw-coloured fluid: This type of fluid is described as modified transudate often characterised by the presence of fibrin cells and white blood cells such as neutrophils and lymphocytes. It is often seen in cases of long-standing ascites from various conditions including right-sided heart failure, cancerous growth and hepatic disease giving chance to invasion of fibrinogens.

3. Clear opaque fluid: This fluid is described as collection of pure transudate into the peritoneal cavity free from contamination except with few invasions of mesothelial cells and tissue macrophages. This ascites may be seen in cases of portal hypertension, hepatic diseases, osmotic gradient deficit (hypoalbuminaemia), protein losing enteropathy, kidney impairment and albuminuria.

4. Reddish discolouration of fluid: This is seen in cases of haemorrhages and collection of frank blood in the peritoneal cavity due to conditions of trauma, coagulopathies and blood and blood vessel neoplasm. The fluid contains high levels of cells mainly red blood cells with PCV being above $20 \%$.

5. Greenish discolouration of fluid: This is seen in cases of rupture and seepage of bile into the peritoneal cavity.

6. Milky/slightly yellowish discolouration: This describes a condition of collection of lymph in the peritoneal cavity due to trauma, infection, cancer or rightsided heart failure. This type of exudates is turbid and opaque and is often described as chyle. It gives a positive result in Sudan III stain test for lipids due to the high level of lipid in the fluid.

\subsubsection{Clinical examination (author's personal experience)}

Clinical examination is considered a useful tool in the identification of the cause of ascites. An elevated temperature would signify an underlying infectious or inflammatory condition such as bacterial tuberculosis. An elevated capillary refill time would signify a decreased circulatory volume as a result of cancerous or infectious 


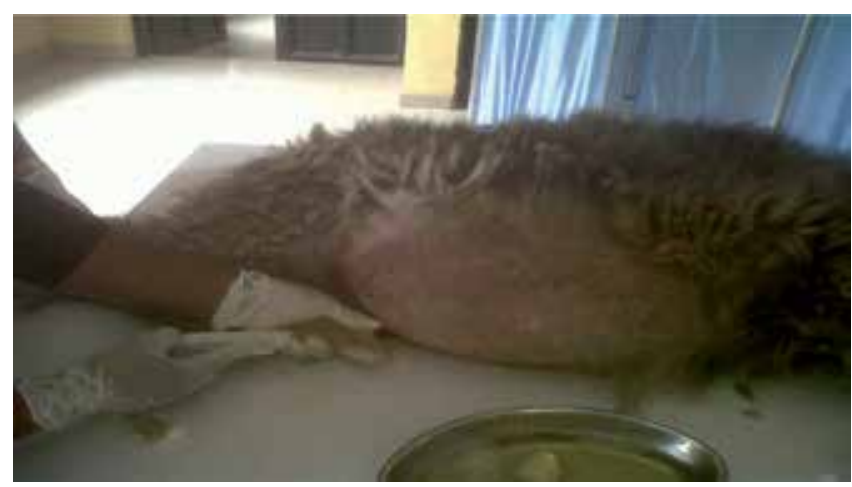

Figure 1.

Removal of ascites through the linea alba in an Alsatian breed of dog.

condition. Auscultation of the heat reveals various cardiovascular diseases such as muffled heart sound which is consistent with pericardial effusion and cardiac tamponade. Heart murmurs or irregular heartbeats are suggestive of right-sided heart failure. An elevated heartbeat or tachypnoea may result from dyspnea due to cranial displacement of the diaphragm into the thoracic cavity. Cardiovascular abnormalities are confirmed through the use of electrocardiograph and echocardiography.

\subsubsection{Biochemical investigation in ascites (author's personal experience)}

The determination of biochemical profile such as the liver enzymes, total protein level, SAAG, albumin concentration, total bilirubin and kidney analytes such as creatinine and urea levels is useful in the diagnosis of the cause of ascites.

\subsubsection{Serum ascites albumin gradient (SAAG)}

Serum ascites albumin gradient is presently the best tool in diagnosis of the cause of ascites especially that from portal hypertension [38]. A SAAG value of $<1.1 \mathrm{~g} / \mathrm{dl}$ or $11 \mathrm{~g} / \mathrm{l}$ indicates causes of non-portal origin such as malignancy, etc. [5]. Gradients $>1.1 \mathrm{~g} / \mathrm{dl}$ or $11 \mathrm{~g} / \mathrm{l}$ indicate ascites of portal hypertension.

\subsubsection{Total protein}

Although the traditional classification of ascites according to the transudate and exudate concept has almost phased out following the introduction of SAAG, it however still has relevance in clinical practice for comparison and prognostic value. Concentrations below $15 \mathrm{~g} / \mathrm{l}$ are often associated with risk of spontaneous bacteria peritonitis in cirrhosis $[5,39]$.

\subsubsection{Triglycerides}

An elevated triglyceride concentration in ascetic fluid above $2.2 \mathrm{mmol} / \mathrm{l}$ indicates chylous ascites [38]. Chylous ascites is common in neoplastic cases although it may occur in $6 \%$ of cirrhosis [40].

\subsubsection{Urea and creatinine}

Elevated levels in urea and creatinine concentrations in ascetic fluid indicate prerenal failure due to peritoneal absorption of urea [41]. Urinary ascites is often associated with bladder changes and urethra obstruction [41, 42]. 


\subsubsection{Cytology}

Cytology of ascetic fluid is often indicated in suspected malignancy and idiopathic cases. Positive cytology is highly indicated in suspected cases of peritoneal carcinomatosis. The sensitivity of cytology can be enhanced by examination of three samples from separate paracenteses [38]. The sensitivity is also enhanced by prompt analysis of ascetic fluid and obtaining large volume of up to $50-1000 \mathrm{ml}$ in patients with initial negative result.

\subsubsection{Diagnostic laparotomy}

Diagnostic laparotomy is indicated in cases of difficulty in identification of the aetiology of ascites. Often laparotomy presents adequate visual inspection of the peritoneal cavity and avenue for biopsy collection for histological and microbiological studies [38]. Diagnostic laparotomy provides ground for effective diagnosis of peritoneal carcinomatosis, tuberculous peritonitis, etc. [43, 44].

\subsubsection{Leucocyte esterase reagent strip}

Several studies have shown the usefulness in the use of leucocyte esterase reagent strip in diagnosing spontaneous bacteria peritonitis and in urinary analysis with sensitivity ranging from 80 to $93 \%$ and specificity $93-98 \%$ [45]. The negative predictive value is markedly high from 97 to $99 \%$, a good measure for an ideal tool to rule out SBP [45]. Recent development has discovered an ascite-specific reagent strip with a cut-off value of 250 cells $/ \mathrm{mm}^{3}$ which would further enhance diagnostic accuracy [46].

\subsubsection{Platelet indices}

Increased platelet indices such as mean platelet volume and platelet distribution width have been observed to increase in cirrhosis. The usefulness of the platelet indices is yet to be fully elucidated but has shown propensity as a potential diagnostic tool [47].

\subsubsection{Tumour markers}

The use of tumour markers such as alpha - feto protein, des-gamma-carboxy prothrombin, cancer antigen 125 , etc. in the diagnosis of cancer in ascetic fluid is presently a subject of controversy among several researchers. Although the increased level of these markers is associated with underlying malignancies, elevated levels are also observed in other conditions such as pancreatitis, gastritis, etc. [48].

\subsubsection{Imaging tools}

Radiographical imaging is useful in detailing small amounts of ascetic fluid as well as diagnosis of aetiology of ascites [49]. Abdominal ultrasonography can detect as little as $100 \mathrm{ml}$ of intraperitoneal fluid [50]. The sensitivity of radiography is enhanced through the use of computed tomography which detects minute quantities of ascetic fluid. Radiography enhances the picture of internal organs and aids in detection of cirrhosis, intra-abdominal tumour and organ enlargements. Thickening of mesentery and bowel wall, matting of bowel loops and enlargement of mesenteric lymph nodes may provide a guide in the diagnosis of tuberculosis 
peritonitis in affected patients. A contrast computed tomography (CT) may be used to demonstrate enhancement of peritoneal lining. Cases of cirrhosis and large hydrothorax can be diagnosed with the aid of scintigraphy with technetium sulphur colloid or radiolabelled albumin [6].

\subsubsection{Bacterial culture}

Spontaneous bacterial peritonitis may arise due to decreased level of compliments which serve as antibacterial factors in ascetic fluid. Suspected cases of SBP are cultured in both aerobic and anaerobic blood media for isolation of organisms [51]. Cultured ascetic fluid should be subjected to sensitivity test to identify effective antimicrobiological agent in treatment.

The DNA of Mycobacterium tuberculosis in ascetic fluid can be detected using polymerase chain reaction in suspected cases. PCR for Mycobacterium tuberculosis offers a high sensitivity (94\%) test compared to microscopic acid-fast bacilli smear $(-0 \%)$ and mycobacterial culture $(-50)[38]$.

\section{General treatment options in ascites}

Ascites is treated symptomatically while addressing the primary cause of the condition. Efforts are geared towards relieving manifesting symptoms and preventing progression of ascites. The main goal in congestive heart failure is to improve cardiac contractility, normalise cardiac arrhythmias and enhance cardiac output. Cardiac drugs such as dopamine and digoxin can be used at recommended dosages in cases of congestive heart failure in dogs. Dogs with right-sided heart failure should be placed on cage rest and on sodium-restricted diet [52]. Paracentesis is applied to relieve abdominal tension on the diaphragm and enhance normal respiration. Repeated paracentesis is not required except in cases of failing treatment [52]. Paracentesis should not exceed $1.0 \mathrm{~kg}$ weight per day for dogs with both ascites and peripheral oedema and less than $0.5 \mathrm{~kg}$ weight per day for patients with only ascites. Serum albumin sometimes is depleted during paracentesis and therefore should be monitored and replaced intravenously in case of depletion at the same quantity of fluid removed. The administration of albumin dosed at $1.5 \mathrm{~g} / \mathrm{kg}$ on the first day and $1.0 \mathrm{~g} / \mathrm{kg}$ on the third day ensured renal preservation and reduced mortality [53]. In cases of syncope, a balanced isotonic crystalloid fluid replacement such as PlasmaLyte A, Normosol R and $0.9 \%$ saline may be used in resuscitation and other conditions such as hypernatraemia, hyponatraemia, hypercalcemia, metabolic alkalosis or oliguria renal failure. Diuretics are used in addition to paracentesis to relieve ascites. Diuretics may be dosed once daily. Spironolactone has a half life of 24 hours and is given at the dose of $100 \mathrm{mg} /$ day max $400 \mathrm{mg} /$ day for response [54]. The dose may be spread out every 2 hours stat in dogs under hospitalisation and close monitoring at $2 \mathrm{mg} / \mathrm{kg} \times \mathrm{im}$ and at $3 \mathrm{mg} / \mathrm{kg} \times$ per os at night. Spironolactone could be substituted with either triamterene or amiloride since both drugs have good antagonistic effect on aldosterone action on the collecting tubules [55]. Furosemide is often the first line of treatment in cases of ascites with a half life of 1.5 hours and given at the dose of $40 \mathrm{mg} /$ day and $\max 160 \mathrm{mg} /$ day in case of nonresponders to furosemide [39]. The dose may also be spread in divided doses of $3 \mathrm{mg} / \mathrm{kg} \times \mathrm{IV}$ every 2 hours and at $4 \mathrm{mg} /$ $\mathrm{kg}$ per os at night. Bumetanide and spironolactone could be used in combination with furosemide at the ratio of 100:40 to reduce chances of furosemide resistance. The dose ratio ensures efficient natriuresis and flow of water and also reduces the risk of potassium deficit from the use of furosemide $[39,56]$. Other diuretics such as torsemide and bumetanide have shown better efficacy than most diuretics [57]. 
Torsemide has a longer half life than both furosemide and bumetanide [57]. Patient with cirrhotic ascites often presents with complications of SBP, portal hypertension and HRS [28]. Cases without such complications are described as "uncomplicated ascites" [58]. The standard treatment for SBP in humans involves immediate administration of third-generation cephalosporin such as intravenous ceftriaxone 1 to $2 \mathrm{~g}$ daily for 5 days [52]. The dose could be given at $1 \mathrm{~g}$ daily in dogs. The use of oral fluoroquinolones is equally effective in the treatment of SBP [59, 60]; alternatively piperacillin and tazobactam could be considered [61]. The choice of antibacterial agent depends on culture and sensitivity test to reduce problems of drug resistance. Antibiotic treatment is usually given for an extended period to ensure complete cure of the bacterial infection.

Portal hypertension is managed by the use of antihypertensive medications. A drug such as metolazone (Mykron, Zaroxolyn) aids in the elimination of oedema in congestive heart failure. It enhances sodium excretion by inhibition of sodium reabsorption from the distil tubules, a function which is beneficial in renal conditions [55]. Mannitol (Osmitrol) inhibits tubular reabsorption of electrolyte by increasing the osmotic pressure of glomerular filtrate and urine output [55]. Cases of recurrent ascites in humans from portal hypertension may require the use of TIPS [28]. TIPS functions as a side-to-side portacaval anastomosis between the high portal pressure end and low hepatic vein pressure end, thereby effectively decongesting the portal system which may be useful in pets. A reduction in the portal hypertension brings a secondary decrease in RAAS activation and consequent increase in sodium excretion [62]. Persistent ascites from cirrhosis may be managed through liver transplant and removal of the damaged liver. The hepatic cells naturally possess high regenerative capacity and can regenerate after undergoing severe degenerative condition. The hepatocytes in addition can perform at full capacity even with few viable cells, and therefore liver transplant is only required as a last resort after application of all remedial medications.

Renal failure is managed by controlling blood pressure with drugs; avoid the use of hepatotoxic medications in treatment of ascites and the use of non-steroidal anti-inflammatory agents (NSAIDs) such as acetaminophen. Kidney dialysis is recommended in severe kidney damage. A continuous venovenous haemodialysis (CVVHD) is recommended compared to intermittent renal dialysis.

Cases of complications of encephalopathies from hepatic failure are best managed in intensive care units (ICU) [18]. Cases of early complication of encephalopathy may be treated as outpatient; nevertheless such a patient is closely monitored for further deterioration to grade II encephalopathy which would require prompt transfer to an intensive care unit. Such a patient is placed on routine check on mental balance, and signs of restlessness could be slightly sedated with low dose of short-acting benzodiazepines. Patients under sedation are placed on undisturbed bed rest avoiding extensive movement which may enhance chances of intracranial pressure/hypertension. Dyspnea is prevented in late encephalopathy through placement of intratracheal intubation to avoid further complications of aspiration pneumonia. The conditions of cerebral oedema and intracranial hypertension manifest at the late phase of encephalopathy and are prevented through routine checks on the patient's renal parameters; biochemical profile including liver enzymes, total protein, glucose, electrolytes and acid/balance; and neurological evaluations for signs of elevated levels [4]. Cases of severe bleeding result from problems of coagulopathies which can be treated by addressing the coagulopathy through transfusion of coagulation products such as fresh frozen plasma and platelets and administration of vitamin K. Severe conditions may be boosted by transfusion of packed red blood cells. Continuous bleeding after massive replacement infusions may indicate possible retroperitoneal bleeding [18]. A good number of herbal and 
antioxidant medications have shown to be beneficial in the treatment of ascites of hepatic origin. The use of these drugs remains controversial, but despite this the drug $\mathrm{N}$-acetylcysteine and Silybum marianum still remain the drug of choice in the treatment of hepatic damage from acetaminophen toxicity and hepatic dysfunction, respectively [63].

Conclusion: Ascites is a disease condition commonly seen in pets of various age brackets with high incidences occurring in middle-aged dogs. Ascites is a common manifestation of a decompensate cirrhosis, cardiac diseases and several other aetiologies and is best diagnosed through established standard procedures of physical and clinical examinations, complete blood picture, cytology and various biochemical analyses. Recent novel techniques such as platelet indices, leucocyte esterase reagent strip, tumour markers, bacterial DNA, cytokines and other proteins are available for the advancement of biochemical laboratory techniques and efficient diagnosis of ascites. Treatment is centred on effective diagnosis of the aetiology.

\section{Acknowledgements}

I sincerely acknowledge the God Almighty for His enablement bestowed upon me during the course of this write-up.

\section{Appendix}

dyspnea
encephalopathies
cholestasis
haemolysis
gastroenterology
haematology
neurology
ascites
effusion
arrhythmia
tamponade
coagulopathy
conjugated
unconjugated
opaque
aetiology
vascularisation
transudate

exudate

renal

hepatorenal syndrome Silybum marianum Amanita phalloides idiopathic difficulty in breathing

degenerative condition in the brain

obstruction of the bile duct

red blood cell destruction

study of both the stomach and intestines

study of the blood

study of the nervous tissues

accumulation of fluid in the abdominal cavity

accumulation of fluid in the abdominal cavity

irregular heartbeat

closure or blockage especially to stop bleeding

problem with blood clotting mechanism

reversibly combined with a compound

compound in its natural form

not transparent, cloudy, filmy

the cause of a disease condition

area supplied with blood vessels

fluid produced from increased pressure in the hepatic, portal vein (>8 mmHg) usually around $20 \mathrm{mmHg}$, low in protein $(<30 \mathrm{~g} / \mathrm{L})$, low in $\mathrm{LDH}$, high $\mathrm{pH}$, normal glucose and fewer cells

fluid actively secreted from inflammation or malignancy, rich in protein, lactate dehydrogenase, low $\mathrm{pH}(<7.30)$, low glucose level and large numbers of white blood cells pertains to the kidney

condition that affects both the liver and kidney active compound in milk thistle herbal preparation a poisonous species of mushroom unknown origin 


\section{Author details}

Rosemary Ijeoma Ogechi Nwoha

Michael Okpara University of Agriculture, Umudike, Abia State, Nigeria

*Address all correspondence to: rosemarynwoha@yahoo.com

\section{IntechOpen}

(c) 2019 The Author(s). Licensee IntechOpen. This chapter is distributed under the terms of the Creative Commons Attribution License (http://creativecommons.org/licenses/ by/3.0), which permits unrestricted use, distribution, and reproduction in any medium, provided the original work is properly cited. $(\mathrm{cc}) \mathrm{BY}$ 


\section{References}

[1] Saravanan M, Sarma K, Kumar M, Mahendran K, Mondal DB. Therapeutic management of ascites in dogs. The Indian Veterinary Journal. 2013;90(2):110-111

[2] Michael PW, Zenoble RD. Canine ascites. Digital Repository Iowa State University. 1982;44(1):3

[3] Pradhan MS, Dakshinkar NP, Naghaye UG, Bodkhe AM. Successful treatment of ascites of hepatic origin in dog. Veterinary World. 2008;1(1):23

[4] Chalasani NP, Hayashi PH, Bonkovsky HL, Navarro VJ, Lee WM, Fontana RJ, et al. ACG clinical guideline: The diagnosis and management of idiosyncratic drug-induced liver injury. American Journal of Gastroenterology. 2014;109(7):950-966

[5] European Association for the study of the liver. EASL clinical practice guideline on the management of ascites, spontaneous bacterial peritonitis and hepatorenal syndrome in cirrhosis. Journal of Hepatology. 2010;53:397-417

[6] Sood R. Ascites: Diagnosis and management. Journal, Indian Academy of Clinical Medicine. 2000;5(1):81-89

[7] Christopher MM, Van Thiel DH. Cirrhotic ascites review: Pathophysiology, diagnosis and management. World Journal of Hepatology. 2013;5(5):251-263

[8] Ginés P, Quintero E, Arroyo V, Terés J, Bruguera M, Rimola A, et al. Compensated cirrhosis: Natural history and prognostic factors. Hepatology. 1987;7(1):122-128

[9] Planas R, Montoliu S, Ballesté B, Rivera M, Miquel M, Masnou H, et al. Natural history of patients hospitalized for management of cirrhotic ascites. Clinical Gastroenterology and Hepatology. 2006;4:1385-1394
[10] Guevara M, Cárdenas A, Uriz J, Ginès $P$. Prognosis in patients with cirrhosis and ascites. In: Ginès $P$, Arroyo V, Rodés J, Schrier R, editors. Ascites and Renal Dysfunction in Liver Disease: Pathogenesis, Diagnosis, and Treatment. 2nd ed. Malden, MA: Blackwell Publishing; 2005. Chapter 21

[11] Mohammed SA, Caroline EA, Boushra HA, Elsafi AA. Radiology, diagnostic imaging and instrumentation. Global Journal of Medical Research. 2013;3:3. version 1.0

[12] Shanker S, Divya J, Pramod Kumar A, Bijoykumar B. Clinicopathological correlation of serum ascites albumin gradient with ascetic fluid total protein in patients of ascites with portal hypertension attending a tertiary care hospital in eastern Bihar India. International Journal of Advances in Medicine. 2017;4(3):842-846

[13] McNally PR. Gastrointestinal/Liver Secrets. 4th ed. Philadelphia, PA: Mosby Elsevier; 2010

[14] Shailja CS, David AS. "Cardiac Hepatopathy": A review of liver dysfunction in heart failure. Liver Research Open Journal. 2015;1(1):1-10

[15] Moitinho E, Escorsell A, Bandi JC, Salmerón JM, García-Pagán JC, Rodés J, et al. Prognostic value of early measurements of portal pressure in acute variceal bleeding. Gastroenterology. 1999;117:626-631

[16] Runyon BA. Ascites and spontaneous bacterial peritonitis. In: Feldman M, Friedman LS, Brandt LJ, editors. Sleisenger and Fordtran's Gastrointestinal and Liver Disease. 9th ed. Philadelphia, PA: Saunders; 2010

[17] Fernandez-Esparrach G, SanchezFueyo A, Gines P, Uriz J, Quinto L, Ventura $\mathrm{P}$, et al. A prognostic model 
for predicting survival in cirrhosis with ascites. Journal of Hepatology. 2001;34:46-52

[18] Gagen KS. Acute Liver Failure, Treatment and Management. 2017. Available from: https:// emedicine.medscape.com/ article/177354-treatment\#d1

[19] Bataller R, Arroyo V, Gines P. Management of ascites in cirrhosis. Journal of Gastroenterology and Hepatology. 1997;12:723-733

[20] Gentilini P, Vizzutti F, Gentilini A, Zipoli M, Foschi M, Romanelli R. Update on ascites and hepatorenal syndrome. Digestive and Liver Disease. 2002;34:592-605

[21] Ginès P, Schrier RW. Renal failure in cirrhosis. The New England Journal of Medicine. 2009;361:1279-1290

[22] Vicente AMD. Pathophysiology, diagnosis and treatment. Annals of Hepatology. 2002;1(2):72-79

[23] Dudley F. Pathophysiology of ascites formation. Gastroenterology Clinics of North America. 1992;21:215-235

[24] Gines P, Fernandez-Esparrach G, Arroyo V, Rodes J. Pathogenesis of ascites in cirrhosis. Seminars in Liver Disease. 1997;17:175-189

[25] Casado M, Bosch J, Garcia-Pagan J, Bru C, Banares R, Bandi J, et al. Clinical events after transjugular intrahepatic portosystemic shunt: Correlation with hemodynamic findings. Gastroenterology. 1998;114:1296-1303

[26] Henriksen J, Siemssen O, Krintel J, Malchow-Møller A, Bendtsen F, Ring-Larsen H. Dynamics of albumin in plasma and ascitic fluid in patients with cirrhosis. Journal of Hepatology. 2001;34:53-60

[27] Kravetz D, Bildozola M, Argonz J, Romero G, Korula J, Munoz A, et al.
Patients with ascites have higher variceal pressure and wall tension than patients without ascites. The American Journal of Gastroenterology. 2000;95:1770-1775

[28] Pedersen JS, Flemming B, Møller S. Management of cirrhotic ascites.

Therapeutic Advances in Chronic Disease. 2015;6(3):124-137

[29] Moore KP, Aithal GP. Guidelines on the management of ascites in cirrhosis. Gut. 2006;55(Supplement vi):vi1-v12

[30] Iwakiri Y, Groszmann R. The hyperdynamic circulation of chronic liver diseases: From the patient to the molecule. Hepatology. 2006;43:S121-S131

[31] Møller S, Henriksen J. The Systemic Circulation in Cirrhosis. Malden, Ma: Blackwell Publishing; 2005

[32] Henriksen J, Møller S. Alterations of Hepatic and Splanchnic Microvascular Exchange in Cirrhosis: Local Factors in the Formation of Ascites. Malden, MA: Blackwell Publishing; 2005

[33] Stadlbauer V, Wright G, Banaji M, Mukhopadhya A, Mookerjee R, Moore $\mathrm{K}$, et al. Relationship between activation of the sympathetic nervous system and renal blood flow autoregulation in cirrhosis. Gastroenterology. 2008;134:111-119

[34] Krag A, Bendtsen F, Henriksen J, Moller S. Low cardiac output predicts development of hepatorenal syndrome and survival in patients with cirrhosis and ascites. Gut. 2010;59:105-110

[35] Ruiz-Del-Arbol L, Monescillo A, Arocena C, Valer P, Gines P, Moreira $\mathrm{V}$, et al. Circulatory function and hepatorenal syndrome in cirrhosis. Hepatology. 2005;42:439-447

[36] Wensing G, Lotterer E, Link I, Hahn E, Fleig W. Urinary sodium balance in patients with cirrhosis: 
Relationship to quantitative parameters of liver function. Hepatology.

1997;26:1149-1155

[37] Ettinger SJ, Feldman EC. Textbook of Veterinary Internal Medicine Diseases of the Dog and Cat. 6th ed. Vol. 1. USA: Elsevier Saunders; 2005

[38] Oey RC, van Buuren HR, de Man RA. The diagnostic work-up in patients with ascites: Current guidelines and future prospects. The Netherlands Journal of Medicine. 2016;74(8):330-338

[39] Runyon BA. Management of adult patients with ascites due to cirrhosis: An update. Hepatology. 2009;49:2087-2107

[40] Laterre PF, Dugernier T, Reynaert MS. Chylous ascites: Diagnosis, causes and treatment. Acta Gastroenterologica Belgica. 2000;63:260-263

[41] Peeters P, Colle II, Serinesael J, Verbeelen D. Relapsing ascites and uremia due to urinary bladder leakage. European Journal of Internal Medicine. 2001;12:60-63

[42] Snauwaert C, Geerts A, Colle I, Van vlierberghe $\mathrm{H}$. Ascites not always the usual suspect. Acta Gastro-Enterologica Belgica. 2012;75:45-48

[43] Han CM, Lee CL, Huang KG, et al. Diagnostic laparoscopy in ascites of unknown origin. Chang gung memorial hospital 20 years experience. Chang Gung Medical Journal. 2008;31:378-383

[44] Yoon YJ, Ahn SH, Park JY, et al. What is the role of diagnostic laparoscopy in a gastroenterology unit? Journal of Gastroenterology. 2007;42:881-886

[45] Rerknimitr R, Limmathurotsakul D, Bhokaisawan N, Kongkam P, Treeprasertsuk S, Kullavainijaya P. A comparison of diagnostic efficacies among different reagent strips and automated cell count in spontaneous bacterial peritonitis. Journal of Gastroenterology and Hepatology. 2010;25:946-950

[46] Mendler MH, Agarwal A, Trimzi $\mathrm{M}$, et al. A new highly sensitive point of care screen for spontaneous bacterial peritonitis using the leukocyte esterase method. Journal of Hepatology.

2010;53:477-483

[47] Abdel-Razik A, Eldars W, Rizk E. Platelet indices and inflammatory markers in diagnostic predicators for ascetic fluid infection. European Journal of Gastroenterology \& Hepatology. 2014;26:1342-1347

[48] Huang LL, Xia HH, Zhu SL. Ascitic fluid analysis in the differential diagnosis of ascites: Focus on cirrhotic ascites. Journal of Clinical and Translational Hepatology. 2014;2:58-64

[49] Theoni RF. The role of imaging in patients with ascites. American Journal of Roentgenology. 1995;165:16-18

[50] Goldberg BB, Goodman GA, Clearfield HR. Evaluation of ascites by ultrasound. Radiology. 1970;96:15-22

[51] Siersema PD, de Marie S, van Zeijl JH, Bac DJ, Wilson JH. Blood culture bottles are superior to lysiscentrifugation tubes for bacteriological diagnosis of spontaneous bacterial peritonitis. Journal of Clinical Microbiology. 1992;30:667-669

[52] Moore CM, Van Thiel DH. Cirrhotic ascites review: Pathophysiology, diagnosis and management. World Journal of Hepatology. 2013;27(5):251-263

[53] Sort P, Navasa M, Arroyo V, Aldeguer X, Planas R, Ruiz-del-Arbol $L$, et al. Effect of intravenous albumin on renal impairment and mortality in patients with cirrhosis and spontaneous bacterial peritonitis. The New England Journal of Medicine. 1999;341:403-409 
[54] Tsochatzis EA, Gerbes AL.

Diagnosis and treatment of ascites. Journal of Hepatology. 2017;67(1):184185. DOI: 10.1016/j.jhep.2017.01.011

[55] Rahil S, Janice MF. Ascite. Drugs and disease. Gastroenterology.

Medscape. 2017. https://emedicine. medscape.com/article/170907-overview

[56] Santos J, Planas R, Pardo A, Durández R, Cabré E, Morillas RM, et al. Spironolactone alone or in combination with furosemide in the treatment of moderate ascites in nonazotemic cirrhosis. A randomized comparative study of efficacy and safety. Journal of Hepatology. 2003;39:187-192

[57] Wargo KA, Banta WM. A comprehensive review of the loop diuretics: Should furosemide be first line? Annals of Pharmacotherapy. 2009;43(11):1836-1847, 2009

[58] Salerno F, Angeli P, Bernardi M, Laffi G, Riggio O, Salvagnini M. Clinical practice guidelines for the management of cirrhotic patients with ascites. Committee on ascites of the Italian Association for the Study of the liver. Italian Journal of Gastroenterology and Hepatology. 1999;31:326-334

[59] Felisart J, Rimola A, Arroyo V, Perez-Ayuso RM, Quintero E, Gines P, et al. Cefotaxime is more effective than is ampicillin-tobramycin in cirrhotics with severe infections. Hepatology. 1985;5:457-462

[60] Navasa M, Follo A, Llovet JM, Clemente G, Vargas V, Rimola A, et al. Randomized, comparative study of oral ofloxacin versus intravenous cefotaxime in spontaneous bacterial peritonitis.

Gastroenterology. 1996;111:1011-1017

[61] Novovic S, Semb S, Olsen H, Moser C, Knudsen J, Homann

C. First-line treatment with cephalosporins in spontaneous bacterial peritonitis provides poor antibiotic coverage. Scandinavian Journal of Gastroenterology. 2012;47:212-216

[62] Rossle M, Siegerstetter V, Huber $\mathrm{M}$, Ochs A. The first decade of the transjugular intrahepatic portosystemic shunt (TIPS): State of the art. Liver. 1998;18:73-89

[63] Chronic Liver Disease. https://en.wikipedia.org/wiki/ chronic_liver_disease 



\title{
Chapter 11
}

\section{Pericardial Effusion in Dogs}

\author{
Gurram Sreeramamurthy Haritha
}

\begin{abstract}
Pericardial disease in dogs is relatively uncommon, but its presence may be life-threatening. It is an incidental finding or manifestation of a systemic or cardiac disease. The spectrum of pericardial effusions ranges from mild asymptomatic effusions to cardiac tamponade. Pericardial effusion in dogs has an overall prevalence of $0.43 \%$ in general and occurs in approximately $7-10 \%$ of the dogs with clinical signs of cardiac disease. More commonly seen in dogs, the clinical signs of pericardial disease can be easily overlooked or mistaken for those of other disease processes. In patients with life-threatening pericardial effusion, which has led to cardiac tamponade, it is important to rapidly identify and treat the elevated intrapericardial pressure. Management is guided by the haemodynamic impact, size, presence of inflammation (i.e. pericarditis), associated medical conditions, and the aetiology whenever possible. In this chapter, pericardial effusion in dogs is emphasized.
\end{abstract}

Keywords: dogs, pericardial effusion, aetiology, pathophysiology, clinical signs, diagnosis, pericardiocentesis, management of pericardial effusion

\section{Introduction}

The thoracic cavity contains two pleural cavities and a third serous membranelined space, the pericardial cavity. The pericardium composed of fibrous and serous layers of the pericardial cavity is situated within the mediastinum. The parietal pericardium forms the superficial wall of the pericardium and is composed of an external fibrous layer and an internal serous layer. The pericardial cavity normally contains only a thin film of fluid positioned between parietal and visceral layers of serous pericardium [1]. These membranes provide the heart with a sac-like protective compartment. The normal pericardial sac contains $2-10 \mathrm{~mL}$ of clear, thin, serous fluid that acts primarily as a lubricant. If the fluid accumulates more than the limit in the pericardial sac, it is defined as pericardial effusion. The effusion usually accumulates slowly and progressively and presents with sign of chronic cardiac tamponade and right-sided heart failure with lethargy, exercise intolerance, or collapse [2].

Further, a rapid accumulation of fluid into the pericardial sac results in a rapid increase in intrapericardial pressure. If the intrapericardial pressure exceeds the pressure within the right atrium, acute compression of the heart (cardiac tamponade) and impairment of ventricular filling may develop. Compression of the heart by this pressure causes a drop in preload and reduces cardiac output [3]. Pericardial effusion usually occurs in middle to older dogs with a mean age of 6 years in large-breed dogs; however, it is found in age groups of 1-14 years. Neoplastic pericardial effusion is seen in brachycephalic breeds and short breeds. 
German shepherds, golden retrievers, Great Danes, and Saint Bernards appear to be predisposed to idiopathic pericardial effusion. Both sexes are said to be affected. The most common causes of pericardial effusion in dogs are cardiac neoplasia, right-sided heart failure, cardiac rupture and idiopathic pericarditis and less commonly congenital pericardial disorders, trauma, or infectious processes [4].

\section{Aetiology}

When a clinician is faced with a dog, which is presented with pericardial effusion, the first challenge is to identify its aetiology. The aetiology of pericardial effusion is idiopathic (unknown cause), congestive heart failure, infectious, neoplasia (cancer), congenital and others (atrial rupture, systemic, hypothyroidism, rarely cirrhosis, etc.).

\subsection{Idiopathic pericardial effusion}

The unknown causes (idiopathic) of pericardial effusion in dogs were accounting for $20-75 \%$. This disorder is more common in large- and giant-breed dogs and is thought to be an inflammatory condition affecting the pericardial sac. One-time pericardiocentesis is curative in about half of cases. If multiple taps are required, pericardiectomy is recommended and is usually curative. The diagnosis is arrived after exclusion of possible causes of intrapericardial fluid accumulation thorough echocardiographic examination.

\subsection{Congestive heart failure}

Although congestive heart failure is a common cause of pericardial effusion in cats, it is a less common cause in dogs. When congestive heart failure leads to intrapericardial fluid accumulation, cardiac tamponade is rare, and pericardiocentesis is almost never indicated. However, in few cases, modification of congestive heart failure medications may be warranted.

\subsection{Infectious}

Pericardial effusion due to infectious cause is not so frequently observed. It may include multiple causes, viz. bacterial infection secondary to migrating foreign bodies. The most commonly isolated bacteria associated with the condition are Actinomyces, Nocardia [5] and Coccidioides immitis [6].

Further, constrictive and septic pericarditis also results in minimal pericardial effusion in dogs, mostly sequelae to infectious diseases.

\subsection{Neoplasia}

In dogs cardiac neoplasia are rare; if present neoplastic pericardial effusion is commonly related with hemangiosarcoma, chemodectoma (common in brachycephalic breeds), and mesothelioma and less commonly related with ectopic thyroid carcinoma, lymphosarcoma and myxosarcoma. Prognosis depends on the type of tumour. Hemangiosarcomas are more aggressive and are likely to metastasize, and these tumours tend to effuse more rapidly. Palliative pericardiectomy is not usually recommended for hemangiosarcoma because the risk of severe and fatal intrathoracic hemorrhage is significant. 
However, in patients with aortic body tumours or mesotheliomas, tumours that effuse more slowly than hemangiosarcomas do, pericardiectomy is often palliative, allowing the fluid to be absorbed through the pleural surface and, thus, preventing the development of cardiac tamponade [4].

\subsection{Other causes}

\subsubsection{Atrial rupture}

In chronic mitral valve disease and severe left atrial enlargement, left atrial tearing is a possible cause of pericardial effusion. The pericardial effusion may contain a clot because hemorrhage is acute. The clot is often visible on an echocardiogram as a hypoechoic structure within the fluid-filled (anechoic) pericardial space. The hemorrhage rapidly leads to cardiac tamponade, cardiogenic shock, and possibly death. Pericardiocentesis in these patients may encourage continued bleeding into the pericardial space. Therefore, in general, pericardiocentesis is not recommended in these patients. If the patient destabilizes because of cardiac tamponade, pericardiocentesis is performed, but the prognosis is guarded at best.

Serositis and myocarditis caused by exposure to toxic metabolites that are eliminated by the kidneys result in uremic pericarditis [4]

There is a possibility of pericardial effusion caused by hypothyroidism, and hypothyroidism in human patients is a well-known cause of pericardial effusion, but cardiac tamponade is not a frequent clinical sign. However, the pathophysiology is not explained [7].

\section{Pathophysiology}

The pericardium normally has minimal elasticity due to its fibrous nature. However, the pericardium can stretch when pressure is slowly placed on it. In pericardial effusion, as the fluid accumulates in the pericardial space, the ability of the pericardium to stretch is eventually exceeded, and further fluid accumulation subsequently results in increases in intrapericardial pressure. When the intrapericardial pressure increases to the pressure of the right atrium and ventricle (normally 4-8 mm Hg), cardiac tamponade develops [4] with variable degrees of haemodynamic collapse. The volume of fluid required to cause cardiac tamponade varies greatly, depending on the speed with which the fluid accumulates. In experimental canine models, as little as $25-100 \mathrm{~mL}$ of fluid rapidly injected into the pericardial space can raise intrapericardial pressure high enough to cause tamponade. In contrast, pericardial effusion that slowly increases in volume can result in a volume as high as $2 \mathrm{~L}$ in a large-breed dog before cardiac tamponade manifests.

Pericardial effusion is a resultant of several etiological factors, and the pathogenesis may vary depending on the aetiology. In neoplasias/nephritic syndrome/toxins, there is direct irritation of pericardium causing inflammation resulting in building of fluid. In case of systemic inflammatory diseases or infections, the inflammatory cells target and gets collected within the pericardium, whereas in atrial/ventricular rupture, direct addition of blood to the pericardial space results in effusion. In congestive heart failure, the fluid accumulation in pericardium is due to increase capillary hydrostatic pressure and altered starling forces.

Depending on the size of the enlarging pericardium (rapid accumulation of low volumes or slow accumulation of high volumes) and activation of pain fibers that are 


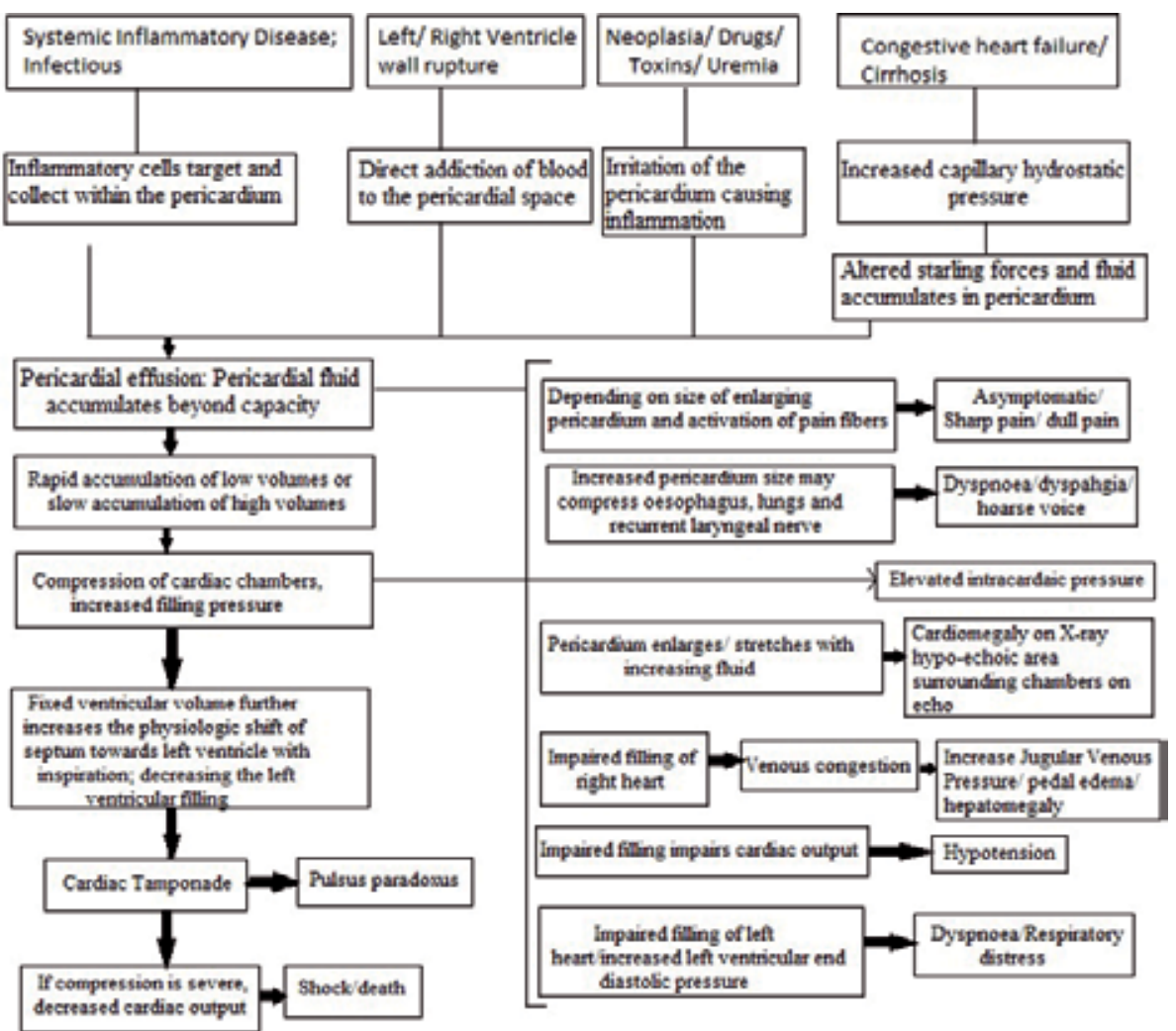

Figure 1.

Pericardial effusion-pathogenesis.

responsible for expression of signs which may vary viz., asymptomatic or sharp pain with inspiration or dull pain. Increase in heart rate and peripheral vascular resistance can initially compensate these changes, thereby maintaining normal blood pressure. As the intrapericardial pressure rises further, left atrial and left ventricular filling are also compromised. Increased pericardium size (cardiomegaly) may compress the oesophagus, lungs and recurrent laryngeal nerve resulting in dysphagia, dyspnoea and hoarse voice. Further increase in the accumulation of pericardial fluid results in the compression of cardiac chambers, thereby increasing the filling pressures resulting in elevated intracardiac pressure. Impaired filling of the right heart results in venous congestion; thereby elevated jugular venous pressure, pedal oedema and hepatomegaly is evinced. Impaired filling of left heart/increased left ventricular end diastolic pressure results in respiratory distress. Impaired filling also impairs the cardiac output; thereby the blood pressure is decreased (hypotension) [8]. However, fixed ventricular volume increases the physiologic shift of septum towards left ventricle with inspiration, thereby lowering the left ventricular filling resulting in cardiac tamponade (Figure 1).

Cardiac tamponade results in decrease venous return, ventricular filling, stroke volume and cardiac output further resulting in shock/death of the patient.

\section{Clinical signs}

Clinical signs of pericardial effusion result from a combination of the volume of effusion, speed with which it accumulated, and underlying cause. Clinical signs may be vague until cardiac tamponade and associated cardiovascular 
decompensation develop. The interplay among these factors determines when, in the clinical course, intrapericardial pressure rise high enough to cause cardiac tamponade.

The most common presenting complaint of dogs with pericardial effusion is collapse, weakness, syncope, or lethargy. Dogs may present with abdominal distension and ascites (Figure 2) secondary to cardiac tamponade. Heart sounds are muffled, and lung sounds may also be muffled if there is associated pleural effusion. Femoral pulses are weak, and sometimes pulsus paradoxus may be palpated when the pulse is stronger during exhalation and weaker during inhalation. If there is cardiac tamponade, the animal may have signs of cardiogenic shock including pale mucous membranes, cold extremities, hypotension, tachycardia and collapse.

Dogs with chronic pericardial effusion typically have signs secondary to rightsided heart failure, including lethargy, exercise intolerance, respiratory difficulty (Figure 3), weight loss and abdominal distention. These signs may be progressive as the ability of the pericardium to stretch is exceeded, whereas dogs with acute pericardial effusion typically present with a history of acute collapse or weakness secondary to decreased cardiac output. Collapse sometimes occurs shortly after physical exertion, and syncope may also be noted.

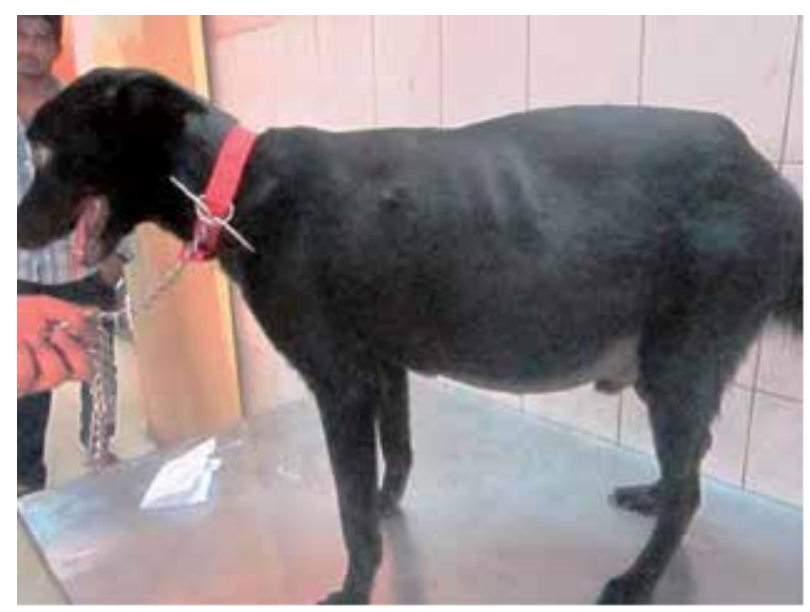

Figure 2.

Distended abdomen in a dog with pericardial effusion.

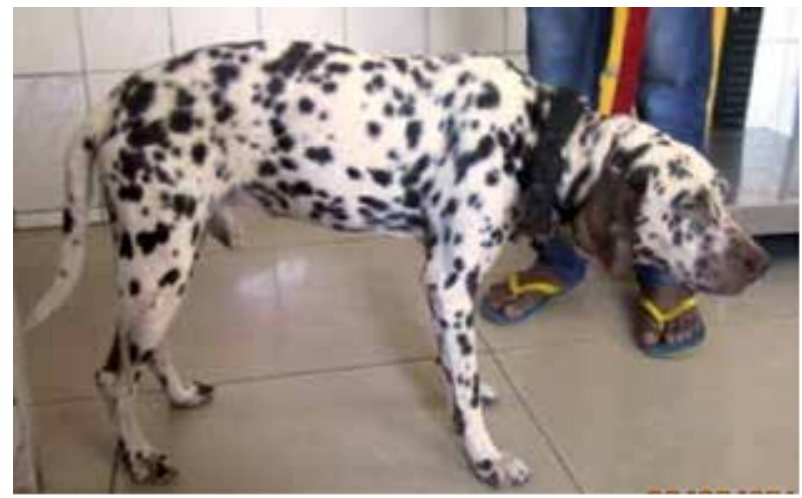

Figure 3.

Pericardial effusion affected dog with respiratory distress. 


\section{Diagnosis}

Physical examination, clinical manifestations, radiography, electrocardiography, echocardiography and estimation of pericardial fluid help in diagnosing the condition. Haematology and serology are not of much significance, and changes in these may reflect the underlying disease process. On physical examination the presence of muffled heart sounds, jugular venous distention, and poor pulse quality or pulsus paradoxus can be suspected for the presence of pericardial effusion. Pulsus paradoxus can best be detected in dogs that are breathing slowly while laterally recumbent. It may not be detected in all affected dogs that are standing or panting. Further, tachycardia, hepatomegaly, ascites, and tachypnoea or dyspnoea can also be noted [9].

\subsection{Radiograph}

Radiographically enlargement of a well-defined cardiac silhouette, globose heart (Figure 4) was evident due to the enlargement of the heart caused by pericardial effusion [9]. The size of the cardiac silhouette increases in conjunction with the chronicity of the effusion and the associated fluid volume.

\subsection{Electrocardiograph}

Sinus tachycardia, QRS complexes of diminished voltage (Figure 5), and the presence of electrical alternans (Figure 6) were the electrocardiographic changes in pericardial effusion. The presence and severity of cardiac tamponade and also inflammatory mechanisms may contribute to the development of low QRS voltage in patients with pericardial effusion [4]. Electrical alternans is the result of a specific type of cardiac motion within the pericardium. The volume of the effusion, viscosity of the fluid, and heart rate are thought to be interrelated in the production of electrical alternans.

\subsection{Echocardiogram}

Echocardiography is the most sensitive method of diagnosing pericardial effusion. It also aids in differential diagnosis from other cardiac diseases.

From the right parasternal view, hypoechoic to anechoic (echo-free space) area between the epicardium and pericardium is evident (Figures 7 and 8 ). In some cases, a left parasternal view may allow better visualization of the right side of the heart, which may aid in identifying right atrial masses. Diastolic collapse of the right atrium or ventricle can be detected and is diagnostic of pericardial tamponade.

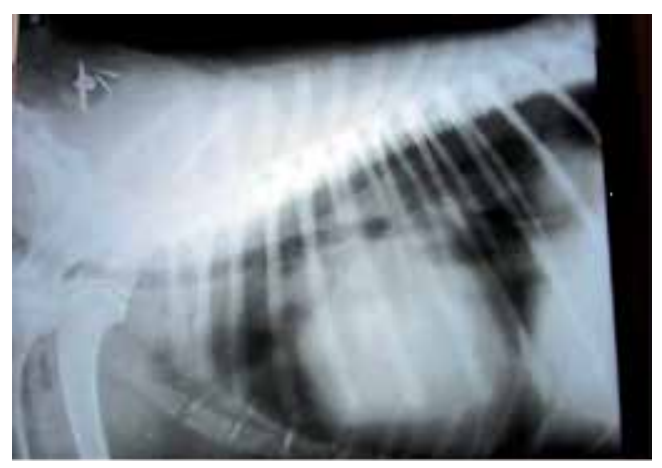

Figure 4.

Globose heart of a dog with pericardial effusion on radiograph-left lateral recumbency. 
Pericardial Effusion in Dogs

DOI: http://dx.doi.org/10.5772/intechopen.89051

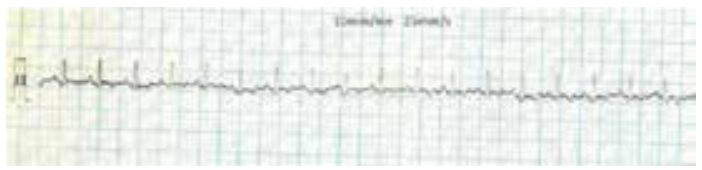

Figure 5.

Low voltage QRS complex (Lead II)_ECG of a dog with pericardial effusion and dilated cardiomyopathy.

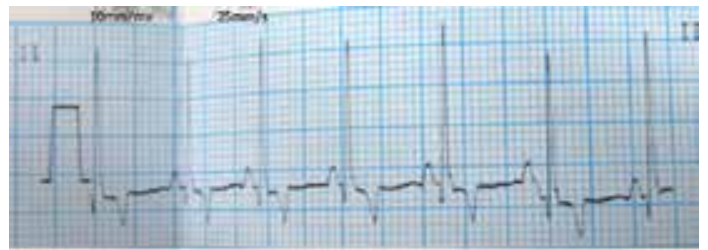

Figure 6.

Electrical alternans with slight wide P wave (Lead II).

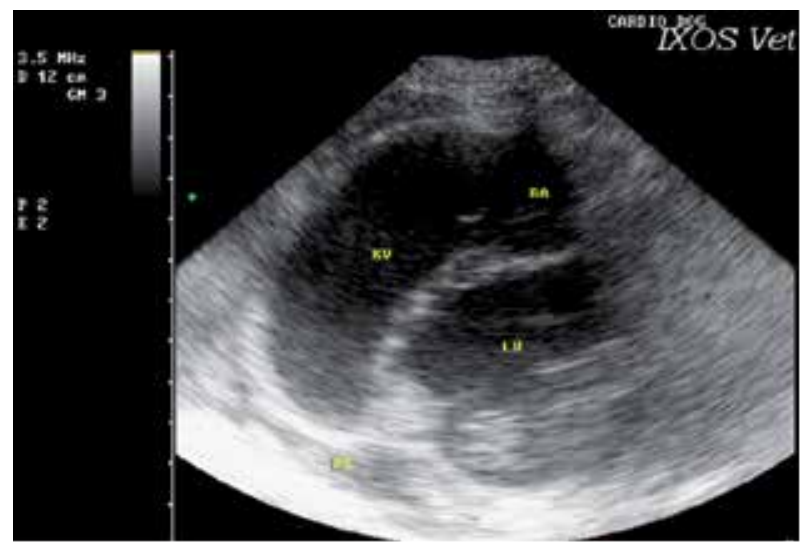

Figure 7.

Dilated right and left ventricle with pericardial effusion (short axis view-B mode).

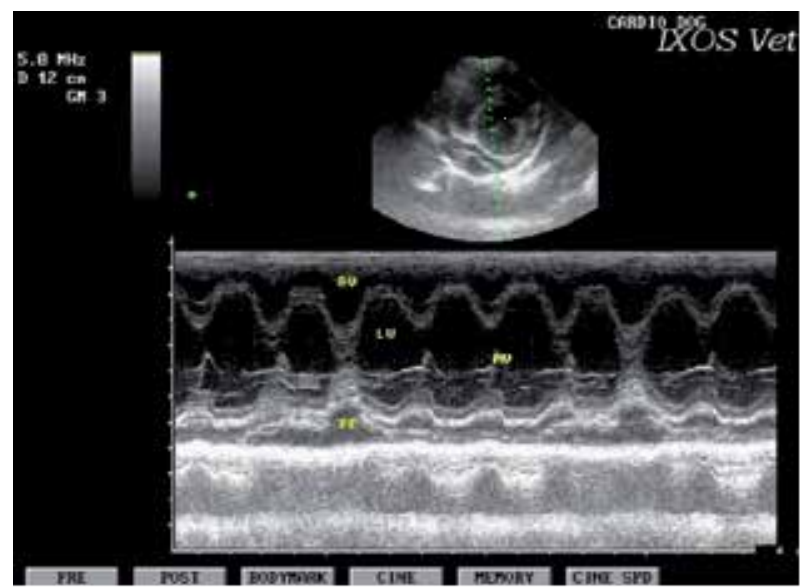

Figure 8.

M-mode image of pericardial effusion dog.

Transthoracic two-dimensional echocardiography reportedly has $80 \%$ sensitivity for a diagnosis of cardiac masses. In most cases, clinicians with basic ultrasonographic skills can readily identify pericardial effusion. However, visualization and definitive 
identification of masses often require an exhaustive echocardiographic examination from both sides of the thorax and a higher level of echocardiographic skill.

\subsection{Pericardiocentesis}

Pericardiocentesis is an important procedure as a diagnostic and as a therapeutic standpoint [10]. When cardiac tamponade is diagnosed, pericardiocentesis should be performed as soon as possible. To perform a pericardiocentesis, the patient should be stabilized first.

\subsubsection{Materials required}

To perform a pericardiocentesis:

- Intravenous catheters (for large dogs, 14G, 5-inches angiocatheters are optimal but 16G, 21/2-inch over-the-needle catheters will suffice and for small dogs, 16-18G, 21/2-inch over-the-needle catheters). Make holes on catheter's side near its tip, so as to maximize the flow if the tip gets occluded while performing the procedure.

- Extension set.

- Three-way stopcock.

- 60-, 12-, and 3-mL syringes.

- 25 G 3/4-inch needle

- $2 \%$ lidocaine.

- Plain (red-top) or serum separator tube.

- EDTA and red-top tubes for cytology samples (and for bacterial culture and antimicrobial sensitivity testing, if indicated).

\subsubsection{Procedure}

Left lateral recumbency (to minimize the movement) and left-side approach are recommended because the right ventricular wall is much thinner than the left ventricular wall, so it is easier to penetrate it unknowingly as you advance the needle and catheter. It is easier to recognize iatrogenic puncture of the left ventricle than of the right ventricle. The oxygenated blood in the left ventricle is bright red. Both right ventricular blood and pleural effusion are dark red, and the high left ventricular pressure usually results in a pulsatile, high-velocity flashback into the catheter, making it obvious if you have penetrated the left ventricle.

If approach is made by the right side, the landmark for performing pericardiocentesis is the "cardiac notch" between the right cranial and caudal lung lobes where the risk of lung puncture is diminished.

\subsubsection{Site of catheterization}

In the seventh and eight intercostal space near the apex beat:

1. Palpate the thoracic wall for the point of maximal intensity (PMI). 
2. Clip and scrub that area.

3. Infiltrate $1-2 \mathrm{~mL}$ of lidocaine using a 3-mL syringe with a $25 \mathrm{G} 3 / 4$-inch needle to create a local block cranial to the rib, so that the skin, intercostal muscle, and pleural lining are desensitized. Also inject lidocaine as you slowly withdraw the needle along the tract.

4. Slowly introduce the catheter ( $14 \mathrm{G} 5$ inch-medium- to large-breed dogs and $16-\mathrm{G}, 2^{1 / 2} /$-inch catheter in smaller dogs) through the skin and thoracic wall at the blocked site (Figure 9) until you feel a "pop" (catheter's entering the pleural space).

5. Advance the catheter needle slowly into the pericardial space. Monitor the heart rate and rhythm while performing the procedure.

6. A flash of fluid (port wine in colour) is obtained, once the catheter is in pericardial space.

7. Hold the stylet in space when the catheter is well placed inside the pericardial sac. Now remove the stylet, and withdraw small amount of fluid to ensure that it is pericardial fluid and not blood from iatrogenic puncture.

8. Now remove the excess pericardial fluid using a $60-\mathrm{mL}$ syringe. Attach the extension set and stopcock to the catheter (Figure 10).

9. Apply suction and evacuate the fluid as soon as possible.

Place the samples of effusion in EDTA and plain tubes for analysis, and record the total volume withdrawn.

The cardiovascular parameters should improve immediately on successful draining of pericardial effusion. The intrapericardial pressure falls, right heart filling improves, cardiac output increases, oxygenation improves, pulse strength improves, and heart rate drops.

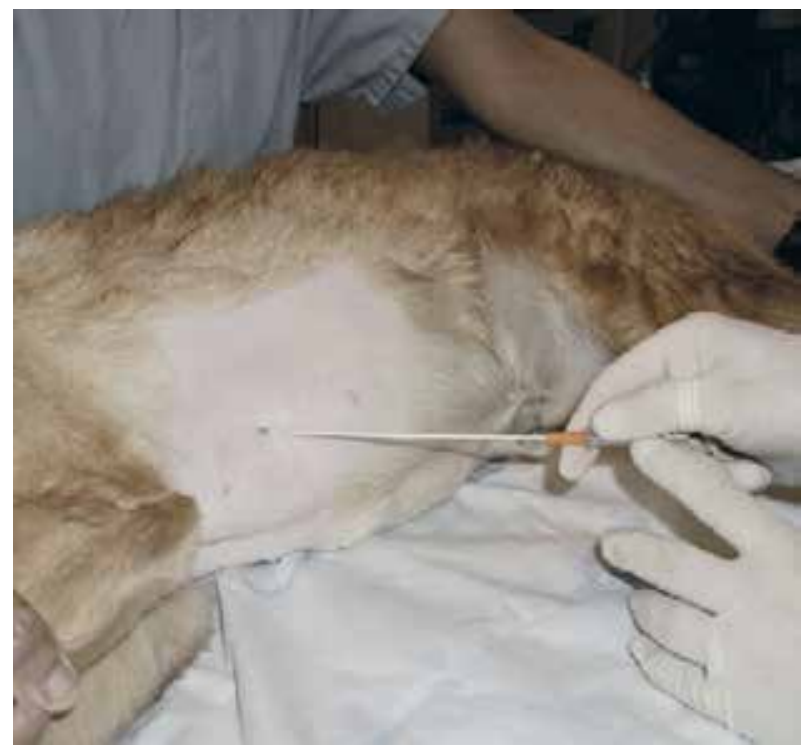

Figure 9.

Pericardiocentesis - Introduction of catheter into the pericardial cavity. Adapted from [10]. 


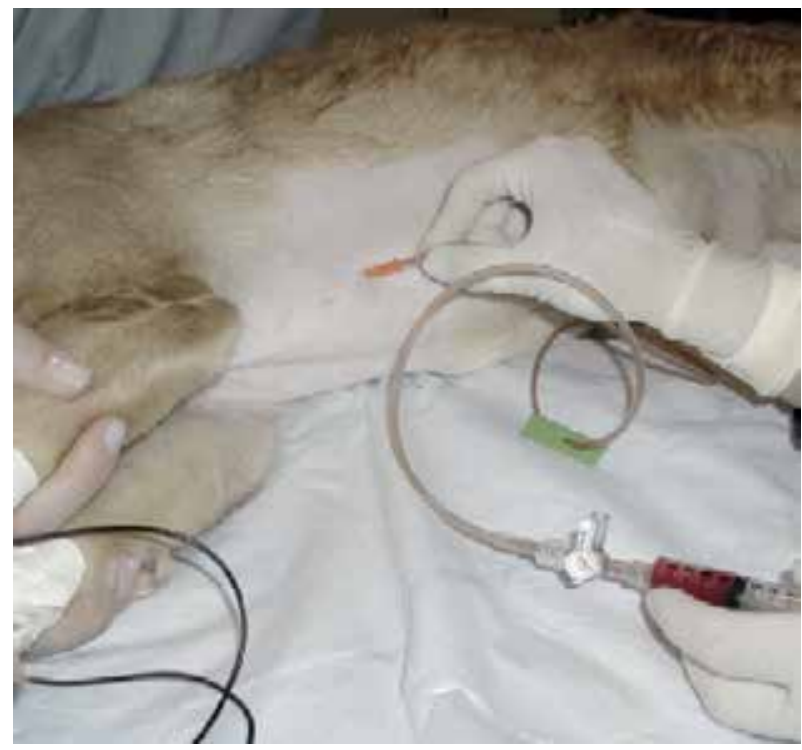

Figure 10.

Pericardiocentesis - Removal of excess pericardial fluid using $60 \mathrm{~mL}$ syringe with attachment of the extension set and stopcock to the catheter. Adapted from [10].

\subsubsection{Potential complications}

- Cardiac arrhythmia due to epicardial irritation or cardiac puncture

- Puncture of the heart or vena cava

- Risk of lung or coronary artery laceration

\begin{tabular}{lccc}
\hline Parameter & $\begin{array}{c}\text { Pericardial fluid } \\
\text { reference range }\end{array}$ & $\begin{array}{c}\text { Pericardial effusion due } \\
\text { to tumours/mass }\end{array}$ & $\begin{array}{c}\text { Other aetiologies of } \\
\text { pericardial effusion }\end{array}$ \\
\hline $\mathrm{pH}$ & $7.34-7.47$ & $6.75-7.53$ & $7.17-7.53$ \\
\hline $\mathrm{PcO}_{2}(\mathrm{~mm} \mathrm{Hg})$ & $34-40$ & $21.1-84.4$ & $26.7-50.4$ \\
\hline $\mathrm{Po}_{2}(\mathrm{~mm} \mathrm{Hg})$ & $48-56$ & $12.0-184.5$ & $15.0-201.6$ \\
\hline $\mathrm{HCO}_{3}{ }^{-}(\mathrm{mEq} / \mathrm{L})$ & $18-24$ & $11.5-24.1$ & $17.5-30.8$ \\
\hline Sodium $(\mathrm{mmol} / \mathrm{L})$ & $147-154$ & $131-154$ & $127-149$ \\
\hline Potassium (mmol/L) & $3.80-4.90$ & $3.1-5.5$ & $3.5-4.9$ \\
\hline Chloride (mmol/L) & $109-120$ & $97-120$ & $0.20-0.50$ \\
\hline $\begin{array}{l}\text { Ionized magnesium } \\
\text { (mmol/L) }\end{array}$ & $0.14-0.42$ & $0.18-0.61$ & $1.11-1.31$ \\
\hline $\begin{array}{l}\text { Ionized calcium } \\
\text { (mmol/L) }\end{array}$ & $1.17-1.38$ & $1.09-1.37$ & $23-128$ \\
\hline \begin{tabular}{l} 
Glucose (mg/dL) \\
\hline Haematocrit (\%)
\end{tabular} & $82-117$ & $10-154$ & $4-48$ \\
\hline $\begin{array}{l}\text { Blood urea nitrogen } \\
\text { (mg/dL) }\end{array}$ & $35-54$ & $3-62$ & $7-30$ \\
\hline Lactate (mmol/L) & $7-28$ & $6-74$ & $1.3-12.7$ \\
\hline The table was taken for reference from Ref. [12]. & $1.9-12.5$ & \\
\hline
\end{tabular}

Table 1.

Comparison of concentrations of variables in pericardial fluid of dogs with a mass compared with the pericardial fluid of those without a mass. 


\subsection{A pericardial fluid analysis}

Pericardial effusion cytology is believed by many to be of limited value, yet few studies have evaluated its diagnostic utility. Cytologic analysis of pericardial effusion provides an accurate and definitive diagnosis when infectious agents or lymphoma are the causative aetiologies. Conversely, neoplastic diagnoses other than lymphoma (hemangiosarcoma, chemodectoma, mesothelioma) are rarely diagnosed based on cytology alone, and additional diagnostic tests performed on fluid or blood samples have a poor ability to distinguish these from non-neoplastic aetiologies (Table 1).

The effusion typically has a haemorrhagic appearance (port wine in colour) despite the underlying cause. Fluid analysis may be diagnostic in cases of infection or lymphosarcoma; therefore, although cytologic evaluation has a low diagnostic yield, it is still recommended [11].

\section{Treatment}

Definitive treatment for pericardial effusion is manual removal of the fluid from the pericardium, i.e. pericardiocentesis. Pericardiocentesis is a method that appears to be of therapeutic value in the management of pericardial effusion patients which are refractory to traditional therapy as the procedure provides immediate relief of cardiac tamponade [8], refer Section 5.4 Pericardiocentesis under Section 5. Diagnosis 5).

Diuretic therapy should be used with caution in cases exhibiting signs of congestive heart failure since their use may result in further reduction in ventricular filling [7]. Mostly, diuretics are not recommended for long-term therapy because diuretics can result in a decrease in preload with a resultant catastrophic decrease in cardiac output if cardiac tamponade recurs.

\subsection{Pericardiectomy}

The surgical removal of part or complete pericardium is pericardiectomy. Pericardiectomy can be a definitive treatment of idiopathic pericardial effusion and a palliative treatment of neoplasia. When pericardial effusion recurs after one or more therapeutic pericardiocenteses, surgical treatment becomes an option. Surgery may be used to remove the pericardium and obtain a biopsy specimen or resect a mass of uncertain origin.

\subsection{Medical management}

The management of pericardial effusion medically is rarely effective. Antiinflammatory therapy may be used to avoid fluid recurrence. Prednisone in antiinflammatory doses may be used to treat idiopathic effusions. Chemotherapy for pericardial effusions due to neoplasia vary for different tumour types. However, the prognosis may vary based on the nature of the tumour. Adriamycin may be given for therapy with hemangiosarcoma [13].

\section{Prognosis}

The prognosis for dogs with pericardial effusion varies depending on the underlying aetiology. In case of neoplastic pericardial effusion, it is poor. Prognosis is very good in idiopathic/infectious pericarditis. The prognosis is good in chronic idiopathic pericardial effusion, but tamponade can occur. 


\section{Conclusion}

Pericardial effusion is the abnormal accumulation of fluid within the pericardial sac. The effusion usually accumulates slowly and progressively and presents with sign of chronic cardiac tamponade and right-sided heart failure with lethargy, exercise intolerance, or collapse. Diagnosis by echocardiography is the gold standard test. Pericardiocentesis along with diuretic therapy is effective. The prognosis associated with pericardial effusion varies greatly, depending on the underlying cause.

\section{Conflict of interest}

I (the author) hereby declare no conflict of interest.

\section{Author details}

Gurram Sreeramamurthy Haritha

SVVU and ANGRAU, Andhra Pradesh, India

*Address all correspondence to: drgsharitha@gmail.com

\section{IntechOpen}

(C) 2019 The Author(s). Licensee IntechOpen. This chapter is distributed under the terms of the Creative Commons Attribution License (http://creativecommons.org/licenses/ by/3.0), which permits unrestricted use, distribution, and reproduction in any medium, provided the original work is properly cited. (cc) BY 


\section{References}

[1] Adams DR. Canine Anatomy-A Systemic Study. 4th ed. Iowa: Iowa State Press, Blackwell; 2004 Chapter. 15 Heart and pericardium. ISBN-13: 978-0813812816

[2] Machida N, Tanaka R, Takemura N, Fujii Y, Ueno A, Mitsumori K. Development of pericardial mesothelioma in Golden retrievers with a long term history of idiopathic haemorrhagic pericardial effusion. Journal of Comparative Pathology. 2004;131(2-3):166-175. DOI: 10.1016/j. jсра.2004.03.002

[3] Jinks J. Pericardial effusion in a mixed breed dog. Canadian Veterinary Journal. 2001;42:877-879

[4] Shaw SP, RushShaw JE. Canine pericardial effusion: Pathophysiology and cause. Compendium of Continuing Education for Veterinarians. 2007;29(7):400-403

[5] Aronson L, Gregory C. Infectious pericardial effusion in 5 dogs. Veterinary Surgery. 1995;24:402-407

[6] Shubitz L, Matz M, Noon T, et al. Constrictive pericarditis secondary to Coccidioides immitis infection in a dog. Journal of the American Veterinary Medical Association. 2001;218:537-540

[7] Ojeda J, Mieres M, Dunner C, Sagredo N, Bustamante H. Pericardial effusion and cardiac tamponade in a dog with hypothyroidism. Archivos de Medicina Veterinaria. 2015;47:391-394

[8] Brett Edwards. Pericardial Effusion \& Tamponade: Pathogenesis and Clinical Findings. The Calgary Guide (CC-BY-NC-SA-3.0). 2015. www. thecalgaryguide.com

[9] Shaw SP, RushShaw JE. Canine pericardial effusion: Diagnosis, treatment and prognosis. Compendium of Continuing Education for Veterinarians. 2007;29(7):405-411

[10] Olcott MD, Sleeper MM. How to perform pericardiocentesis. In: Fertig DL, editor. Veterinary Medicine. Lenexa, KS, USA. 2010. dvm360.com

[11] Satish Kumar K, Amruth Kumar VVV, Nagaraj P, Tirumala Rao DS. Idiopathic pericardial effusion in dogs - a three year study. Vet Scan. 2011;6(1):78

[12] de Laforcade AM, Freeman LM, Rozanski EA, Rush JE. Biochemical analysis of pericardial fluid and whole blood in dogs with pericardial effusion. Journal of Veterinary Internal Medicine. 2005;19:833-836

[13] Weisse C, Soares N, Beal MW, SteffeyMA,DrobatzKJ,HenryCJ.Survival times in dogs with right atrial hemangiosarcoma treated by means of surgical resection with or without adjuvant chemotherapy in 23 cases (1986-2000). Journal of the American Veterinary Medical Association. 2005;226(4):575-579 



\title{
How Reliable Are Laboratory Test When Diagnosing Bitch Mastitis?
}

\author{
Iosif Vasiu, Roman Dabrowski, \\ Flaviu Alexandru Tăbăran, Raul Alexandru Pop, \\ Flore Chirilă, Gheorghe Florinel Brudaşcă, \\ Asta Tvarijonaviciute and Nicodim Iosif Fit
}

\begin{abstract}
Canine mastitis represents a major threat for both pups and nursing bitch. If left untreated, it can complicate with neonatal death, sepsis, and mastitis gangrenosa; for this reason quick and accurate diagnosis and treatment initiation are crucial health restoration. Even though mastitis is considered to be an emergency, most of the time it is overlooked. Henceforth, clinicians should be aware of the clinical importance of mastitis and that laboratory assays such as milk $\mathrm{pH}$, cytology, and biochemistry (milk and serum) are of high utility. Furthermore, milk microbiology and susceptibility tests are still important since they bring additional information about the pathogenesis and the treatment possibilities.
\end{abstract}

Keywords: canine, mastitis, milk, cytology, $\mathrm{pH}$, diagnostic

\section{Introduction}

Mastitis is an inflammation of the mammary glands. It can affect a segment or the entire mammary gland, one or more glands at the same time. Usually, the milk secretion is found modified, with a yellow-greenish to brown color, with a modified consistency, but there are also cases where the milk secretion is grossly unmodified. The ill bitch presents local signs of illness such as painful hot, red, engorged mammary glands, with or without general signs of disease like depression, anorexia, neglecting puppies, tacky mucous membranes, dehydration, delayed capillary refill time with sepsis, and even mastitis gangrenosa. For the litters, the main signs consist of failure to thrive and weight gain [1].

Mastitis has also been reported in lactatio sine graviditate (false pregnancy) bitches, as a result of milk retention and consistent licking of the activated mammary glands. Since this condition is evolving as clinical or subclinical, usually, in pseudocyesis dams, mastitis occurs because of an allergic reaction of the mammary gland to its own milk casein [1]. However, since every bitch undergoes lactatio sine graviditate [2], this condition should be addressed as an atavism and not a pathological behavior.

According to the pathogenesis and clinical signs, mastitis in bitches is classified as mastitis acuta, mastitis gangrenosa, galactostasis, mammae congestion, and 
subclinical mastitis. Furthermore, early recognition of galactostasis and mammae congestion is of great importance since, if not treated accordingly, it could lead to the development of mastitis.

Mastitis acuta cases are characterized by the presence of fever $\left(40-41^{\circ} \mathrm{C}\right)$; hypertrophy of the mammary gland; extremely painful, hot, swollen mammary tissues, with a modified milk secretion (Figures 1 and 2); dehydration; anorexia; pyrexia; depression; and even sepsis in severe cases. Blood examination reveals neutrophilia with a left shift. Bacteriological examination of milk is positive in most cases [3].

Mastitis gangrenosa is described as the presence of severe local and systemic reaction characterized by fever $\left(40-41^{\circ} \mathrm{C}\right)$, while affected mammary glands have a dark to purple color and are extremely painful, hot, and swollen; animals are dehydrated, anorectic, pyretic, and depressed and show signs of sepsis. Blood analysis reveals anemia, leukocytosis, and thrombocytopenia. Milk analysis shows an alkaline milk and presence of active inflammatory cells. Bacteriological examination of milk samples is also positive [3].

Subclinical mastitis is diagnosed based on clinical record, physical examination, and milk analysis ( $\mathrm{pH}$, cytology, and microbiology, among others). Usually, in subclinical mastitis cases, there is no visible alterations in mammary gland or milk secretion, while milk analysis indicates an alkaline $\mathrm{pH}$ and the increased number of

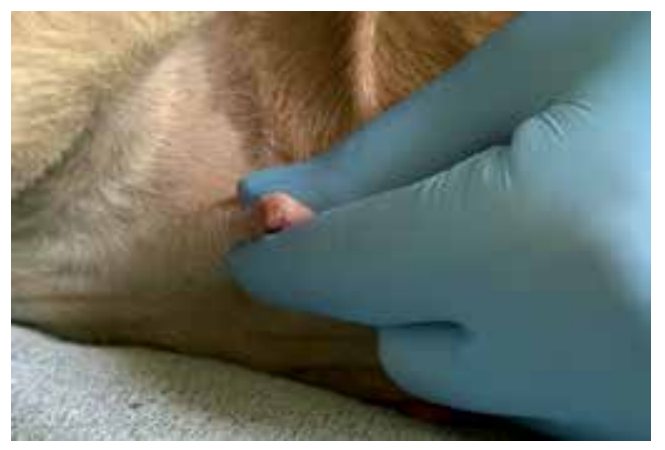

Figure 1.

A serous milk sample from a bitch suffering from mastitis acuta.

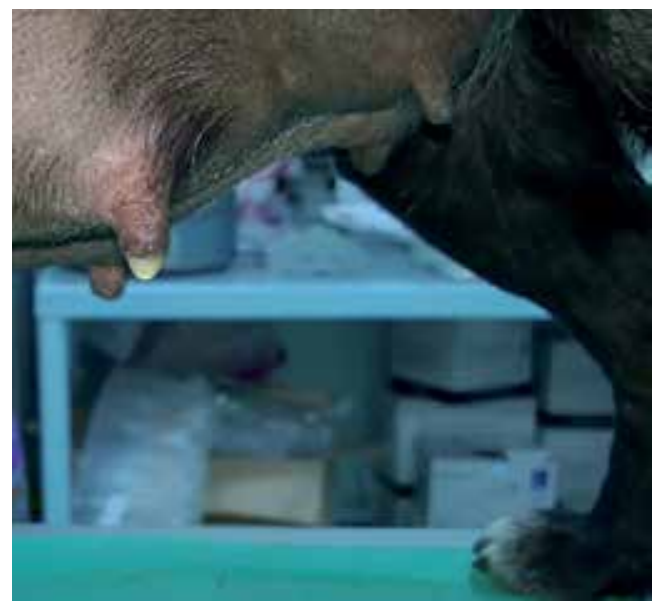

Figure 2.

A mucopurulent milk secretin from a bitch diagnosed with mastitis acuta. 
somatic cell count (SCC; neutrophils, foamy cells, macrophages) (Figures 3 and 4). Bacteriological examinations are positive [3].

In galactostasis cases, there is no sign of infection, but the glandular tissue tends to get distended (Figures 5 and 6 ), warm, and painful. Small litters and absence of puppies will promote the buildup of a high pressure of milk into the undrained mammary glands, which will allow for the milk $\mathrm{pH}$ to become alkaline but will not change the milk chloride levels. Milk cytology will reveal the presence of increased count of eosinophils [3].

Bitches with mammae congestion can present local signs of mastitis including hardened, painful mammary glands and acidic milk $\mathrm{pH}$. However, no inflammatory

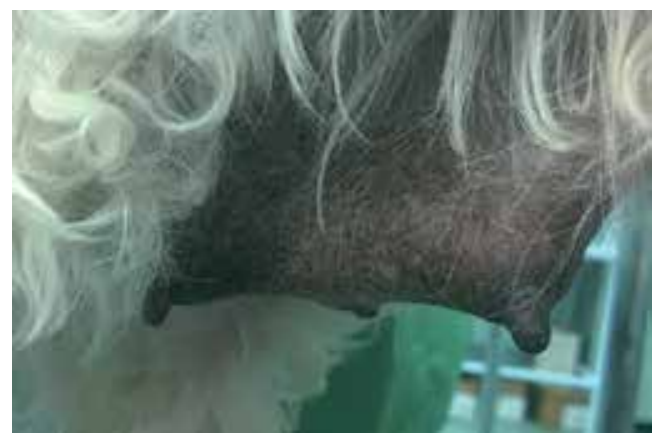

Figure 3.

Clinical aspect of a healthy mammary gland.

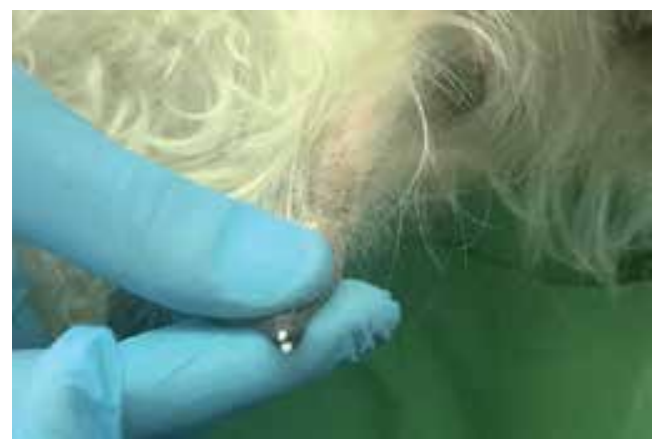

Figure 4.

Milk secretion, from a clinically healthy mammary gland.

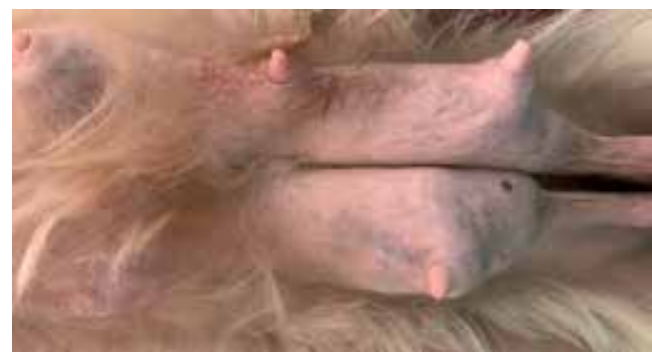

Figure 5.

Distended mammary glands with galactostasis in a bitch that just weaned. Such glands are predisposed to develop retention mastitis. 


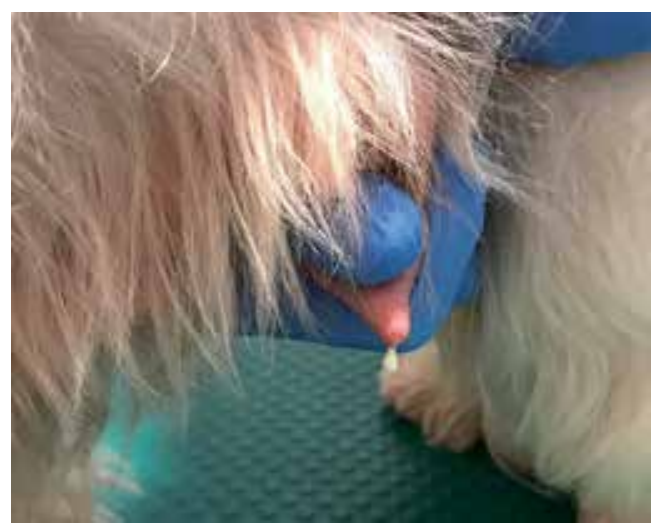

Figure 6.

Normal milk secretion from the same bitch.

cells and phagocytosis are detected in milk smears. Discomfort during nursing is sometimes present. Bacteriological examination of milk samples is positive [3].

\section{Laboratory assays used in the diagnosis of lactating bitch mastitis}

Bitch mastitis diagnostic is performed by laboratory assays such as chloride levels, milk pH [4], and milk cytology [5, 6] alongside microbiology susceptibility testing [7]. Hematology and biochemistry assays such as total solids (TS), total proteins (TP) [8], CRP [3], or haptoglobin (Hp) measurements [4, 9] are also taken into account.

\subsection{Microbiologic analysis of bitch milk}

For microbiology analysis, milk samples have to be collected aseptically into sterile vials manually [10], using sterile swabs impregnated with transport medium [7] or directly onto sterilized bacteriological loops [11]. In all cases a first milk drop has to be discarded. Some authors even describe the use of fine needle aspiration technique to collect milk samples [12], but these can be traumatic and painful.

For bacteria isolation and identification, standard microbiology techniques can be employed. Usually, milk is plated onto different media depending on the agent to isolate. For example, blood agar is used for Staphylococcus and Streptococcus spp., and MacConkey is used for Enterobacteriaceae. The samples are incubated for 24-72 h at $37^{\circ} \mathrm{C}$ in aerobic and modified atmosphere $\left(5 \% \mathrm{CO}_{2}\right)$ conditions [13]. The identification of bacteria can be made initially by macroscopic observation of colonies, Gram stain, cellular morphology, oxidase, catalase, mobility and oxidation-fermentation tests, and in the particular cases of Streptococcus spp. the type of hemolysis and in Staphylococcus spp. the coagulase activity [7].

For the identification of bacterial species, the commercially available biochemical incorporated analytical profile index (API) systems can be used [13]. Additionally, cultural procedures on solid media are performed by 2 days of enrichment in Thioglycollate medium fluid and Trypticase Soy Broth [13].

For the particular case of the isolation of lactobacilli, the procedures consisting in sample culture in aerobic and anaerobic conditions are recommended. The aerobic condition for lactobacilli isolation consists in sample dilution with peptone water and their culture on De Man, Rogosa and Sharpe agar (MRS) plates for $24 \mathrm{~h}$ 
at $37^{\circ} \mathrm{C}$ in aerobic conditions. The anaerobic condition consists of the same sample culture on MRS supplemented with L-cysteine (0.5 g/L) and (MRS-Cys) agar plates, for $48 \mathrm{~h}$ at $37^{\circ} \mathrm{C}$ in anaerobic conditions (85\% nitrogen, $10 \%$ hydrogen, $5 \%$ carbon dioxide) [10].

Recently, milk strains that are also found in human milk secretions [14] were also isolated from the milk of bitches suffering from both clinical and subclinical mastitis [15]. Along standard microbiology techniques [16], after isolation, bacterial strains were identified by using Vitek2 (bioMérieux, l'Étoile, France) technology, respecting the manufacturer's guidelines [15]. A total of 57 different strains were isolated, with Staphylococcus spp., E. coli, and Proteus mirabilis as main isolates (Table 1).

Since they are often isolated from various infection sites, Staphylococcus pseudintermedius and Streptococcus canis are of major importance in companion animals [17]. In addition, other pathogens have been isolated from milk samples of bitches with acute mastitis; these include hemolytic Staphylococcus spp., Staph. intermedius, Staph. haemolyticus, $\beta$-hem. Streptococcus, Klebsiella pneumoniae, E. coli, and Proteus mirabilis [13]. In addition, there have been some case reports that proved that Staph. hyicus can produce mammary gland inflammation accompanied by lymphadenitis. The pathogen was isolated from a 3-year-old pit bull female, which died after a mastitis acuta episode [18].

Also in cases of asymptomatic females, Staph. intermedius, hem. Staphylococcus spp., Staph. epidermidis, Staph. simulans, $\beta$-hem. Streptococcus, E. coli, Enterococcus durans, P. stutzeri, Shigella spp., Acinetobacter anitratus, and Bacillus spp. have been isolated [13]. Jung et al. also isolated $\alpha$-hemolytic Streptococci and $\gamma$-hemolytic Streptococci $[19]$.

Nevertheless, some authors suggest that exogenous infections of the mammary glands are rare and mainly are due to endogenous pathogens [20]. This hypothesis would be supported by Martín et al., who described the presence of lactobacilli

\begin{tabular}{ccc}
\hline No. & Milk bacterial pathogens & Percentage (\%) \\
\hline 1. & Staphylococcus spp. & 27.17 \\
\hline 2. & Escherichia coli & 25.00 \\
\hline 3. & Proteus mirabilis & 9.24 \\
\hline 4. & Enterococcus faecium & 7.61 \\
\hline 5. & Staphylococcus pseudintermedius & 7.07 \\
\hline 6. & Staphylococcus simulans & 5.43 \\
\hline 7. & Agrobacterium radiobacter & 4.89 \\
\hline 8. & Pseudomonas aeruginosa & 3.80 \\
\hline 9. & Staphylococcus $x y l o s u s$ & 3.80 \\
\hline 10. & Staphylococcus hominis subsp. hominis & 3.26 \\
\hline 11. & Bacillus spp. & 2.72 \\
\hline 12. & Enterococcus faecalis & 2.72 \\
\hline 13. & Micrococcus luteus & 2.72 \\
\hline 14. & Staphylococcus intermedius & 2.72 \\
\hline 15. & Streptococcus spp. & 2.72 \\
\hline
\end{tabular}

Table 1.

Main milk isolates from lactating bitches in the periparturient period [15]. 
(L. murinus, L. animalis, L. reuteri, L. johnsonii, and L. fermentum) E. faecium, E. faecalis, Strep. salivarius, Staph. epidermidis, Strep. bovis, Staph. simulans, Staph. pseudintermedius, W. viridescens, and yeast in milk of healthy bitches [10]. Furthermore, many of the bacterial pathogens involved are part of the urogenital microflora and, therefore, are opportunistic pathogens that cause a disease in the presence of other predisposing factors. It should be noted that enterococci, E. faecalis, and E. faecium strains constitute a pathogenic reservoir for offsprings [21] and, thus, could be responsible for neonatal infections [22, 23].

Ascending mammary gland infections can be caused by poor hygiene and/or the exogenous transmission by both skin and oral mucosa bacteria strains of both bitch and the offsprings [24]. This kind of infection is especially frequent in lactatio sine graviditate cases, where the bitch frequently licks affected mammary glands [19]. Furthermore, some reports identified the same bacterial strains from the serum of puppies diagnosed with septicemia and bitch milk [23, 25]. Reproductive track disorders including pyometra, metritis, or vaginitis can predispose to inflammation of mammary gland tissue resulting in "fading puppy syndrome," endotoxemia, or septicemia development in litter and neonatal mortality [7, 13, 20, 26]. Special care should be also taken by owners and veterinary specialists when handling mammary glands of lactating bitch and puppies [27], since a risk of pathogen transfer from people to bitch milk is high $[28,29]$.

An adequate management of mammary gland infection is of major importance. Milk samples should be aseptically obtained for cytology analysis and microbial cultures and before initiation of therapy with antibiotics [30]. Subclinical mammary infection can result in postpartum complications (i.e., mortality in pups, antibiotic resistance); for this reason many dog breeders treat bitches before and after parturition with antibiotics to reduce the neonatal mortality risk. But this practice is not recommended since it will predispose to vagina colonization by opportunistic pathogens and will increase antibiotic resistance [25, 27, 31].

After the milk samples are collected for analysis, mastitis treatment may be empirically initiated $[2,24]$. However, caution should be taken when selecting the optimal antibiotic. Weak base antibiotics, like trimethoprim-sulfonamide, distribute and get trapped into milk due to the acidic nature of the milk. As milk pH will generally become alkaline due to bacterial infections, macrolides or amoxicillinclavulanate and cephalosporins may be used before culture results arrive [2, 24]. Irrespective of milk $\mathrm{pH}$, enrofloxacin can be used to start treatment, even in patients that continue to nurse by weighing the pros and cons, regarding puppy cartilage abnormalities [24].

\subsection{Bitch milk biophysical analysis}

Usually, due to the low volume of milk acquired from bitches, milk $\mathrm{pH}$ is evaluated using litmus paper [4]. Healthy bitches have slightly acid $\mathrm{pH}$ of about 6.3 similar to that recorded in cows $(\mathrm{pH}=6.63)$ [32]. In terms, animals suffering from mastitis acuta have an alkaline milk $(\mathrm{pH}=7)$, while females diagnosed with lactatio sine graviditate present $\mathrm{pH}$ similar to healthy ones $(\mathrm{pH} \sim 6.7)[4,33]$. There is also a report of a milk $\mathrm{pH}$ value of 8 , for a mastitis obliterans case reported in a dog with diabetes [34]. Chloride levels registered show an increase in ( mean $=199 \mathrm{mg} \%$ ) cases of mastitis. Healthy females and females with lactatio sine graviditate have been found to have similar results for chloride levels, 84.3 and $84.1 \mathrm{mg} \%$, respectively [4].

Recent research [15] shows that milk $\mathrm{pH}$ value is influenced by the lactation period and each specific type of mastitis. 
In the antepartum period, milk $\mathrm{pH}$ values ranged between 6 and 7. A total of $75 \%$ of tested samples had an acidic milk $\mathrm{pH}$ reaction [15].

In the postpartum period, milk $\mathrm{pH}$ obtained values ranged between 6 and 8.5 . An alkaline milk reaction was obtained in $83 \%$ of retention mastitis cases, $80 \%$ of mammary congested and subclinical cases of mastitis, respectively, and $75 \%$ of mastitis acuta cases. Healthy mammary glands had an acidic milk $\mathrm{pH}$ in $73 \%$ of examined milk secretions [15] (Table 2).

\begin{tabular}{|c|c|c|c|c|c|}
\hline Postpartum & Acidic & Alkaline & Mammae diagnostic & Acidic & Alkaline \\
\hline Healthy mammae & $73 \%$ & & & $73 \%$ & \\
\hline Mastitis acuta & & $75 \%$ & & & $67 \%$ \\
\hline Mammary congestion & & $80 \%$ & & & $80 \%$ \\
\hline Subclinical mastitis & & $80 \%$ & & & $81 \%$ \\
\hline Retention mastitis & & $83 \%$ & & & $96 \%$ \\
\hline
\end{tabular}

Table 2.

Milk $p H$ reaction according to the postpartum period (left) and to the mammary gland diagnostic $p H$ reaction (right).

From lactatio sine graviditate bitches, milk $\mathrm{pH}$ values ranged between 6.5 and 9.5. All (100\%) tested samples from retention mastitis glands in this period had an alkaline milk $\mathrm{pH}$ reaction [15].

Irrespective of the lactation period, an alkaline milk $\mathrm{pH}$ reaction was obtained in $96 \%$ of retention mastitis cases, $81 \%$ of subclinical mastitis cases, $80 \%$ of mammary gland congestion cases, and $67 \%$ of mastitis acuta suffering mammary glands. For healthy mammary glands, about $73 \%$ of tested samples had an acidic milk reaction (Table 2).

For the antepartum period, the normal mean $\mathrm{pH}$ value was 6.5 , followed by the postpartum period with a mean normal $\mathrm{pH}$ value of 6.57 [15].

In the antepartum period for mastitis acuta, mean $\mathrm{pH}$ value was 6 . In the postpartum period, the mean $\mathrm{pH}$ value for congested mammary glands was 6.6 , for subclinical cases it was 7, and for mastitis acuta, the mean value was 7.04, while for retention mastitis, the mean value was 7.5 [15].

For lactatio sine graviditate, the mean $\mathrm{pH}$ value for retention mastitis was 7.9 [15].

Results show that an alkaline milk $\mathrm{pH}$ is prone to be developed in undrained mammary glands, in cases of retention mastitis and pseudopregnancy or in cases of small litters [6], where milk spends more time in the glandular tissue, thus explaining why, in some cases of mastitis acuta, milk $\mathrm{pH}$ is still acidic during the time of examination.

Care should be taken whenever one evaluates bitch milk $\mathrm{pH}$ reaction, since interpretation of results by litmus paper is very subjective and can be very deceiving to the naked eye. Future research should better adapt to the morphophysiological particularities of the bitch mammary gland in order to obtain irrefutable results whenever one should interpret bitch milk $\mathrm{pH}$ reaction [6].

\subsection{Bitch milk cytology analysis}

Only few studies focused on bitch milk cytology and only two of them evaluated canine milk cytology in deep $[5,6]$.

Smears for milk cytology are carried out using squash technique [35]. The squash technique is a procedure used for semisolid, mucus-like, or pelleted by 
centrifugation cytology specimens. In case of milk analysis, a drop $(\sim 20 \mu \mathrm{L})$ of milk is plated onto objective glass slide, approximately $1 \mathrm{~cm}$ from the frosted end, covered by the second slide, gently but firmly compressed, and the sample is extended over the bottom slide by pulling the top one along the surface. In this way, the sample is redistributed, turning a multicellular mass into a thin monolayer ideal for stain penetration and optical assessment of individual cell morphology by a microscope. Properly prepared smears present a feather-shaped area with a monolayer end referred to as the "sweet spot" [35].

Smears are stained by using the Giemsa [11], Wright-Giemsa [5], WrightLeishman [12], and Romanowsky-type stains; these last ones are preferred due to easy use and rapid turnaround [35]. Stained smears permit evaluation of different types of inflammatory cells and calculation of their amounts in percent within the smear [11].

For total SCC in milk determination, white blood cell (Unopette-Becton Dickinson) and hemocytometer counting chambers are used [5]. Diff-Quick solution II was recommended to be used in order to differentiate inflammatory milk cells from fat droplets. Total SCC of milk samples are expressed as cells $/ \mu \mathrm{L}$ of milk [5].

In milk of healthy bitches, although cytology variations among mammary glands of the same animal are described, commonly somatic cells, accompanied by a high amount of cellular debris, many squamous epithelial cells (Figure 7), few neutrophils, macrophages, erythrocytes, and foamy cells are detected [6]. Polymorphonuclear leukocytes with pyknotic nuclei can be also present [5]. SCC is lower after delivery and increases afterward (mean SCC 2 weeks after delivery, $3 \times 106 / \mathrm{mL}$; 3-5 weeks after, $<3.8 \times 106 \mathrm{~mL} / \mathrm{L}$; and 6-8 weeks after delivery, $<4.9 \times 106 / \mathrm{mL}$ ) [4]. Milk samples collected from milking bitches present more fat droplets than samples collected from females' resorbing milk. Usual findings in milk smears from healthy bitches are bacteria, resulting from skin contaminants. However, caution should be taken when bacteria are detected, since if this observation is accompanied by increased SCC, it would indicate infection of mammary gland $[5,36]$.

In dams with mammae congestion, the milk smear is characterized by few numbers of somatic cells, accompanied by increased numbers of cellular debris (Figure 8), few neutrophils, inactivated macrophages, and epithelial cells [6].

In subclinical mastitis cases, the presence of somatic cells is moderate to high, accompanied by slightly elevated numbers of degenerated neutrophils, many foamy (Figure 9) and epithelial cells along with activated macrophages, bacteria, and phagocytosis. Scattered cellular debris, erythrocytes, and eosinophils can also be encountered [6].

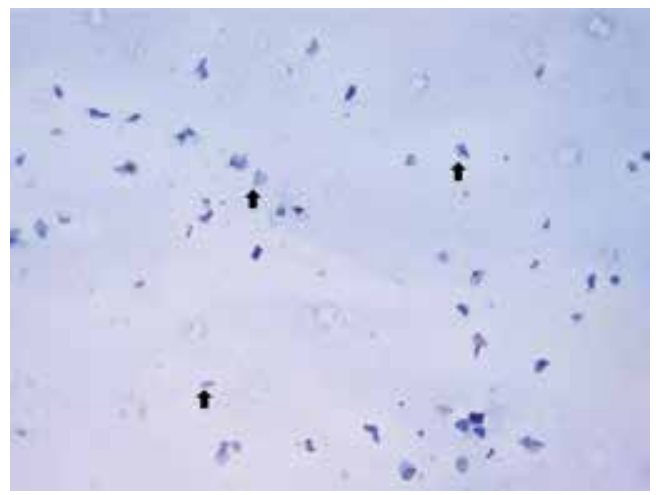

Figure 7.

Presence of many squamous epithelial cells on a basophilic background (black arrows) (MGG, ×10) [6]. 
How Reliable Are Laboratory Test When Diagnosing Bitch Mastitis? DOI: http://dx.doi.org/10.5772/intechopen.86151

Episodes of galactostasis are characterized by the presence of eosinophils (Figure 10), activated macrophages, foamy cells, and degenerated neutrophils, accompanied by bacteria and phagocytosis. Cellular debris and erythrocytes had also been identified $[5,6]$.

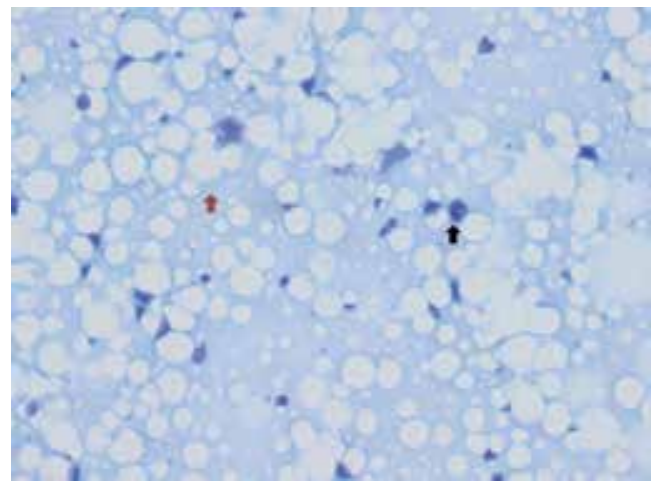

Figure 8.

Presence of cellular debris on a basophilic background (red arrow) with variable-sized lipid droplets (black arrow) $(M G G, \times 40)[6]$.

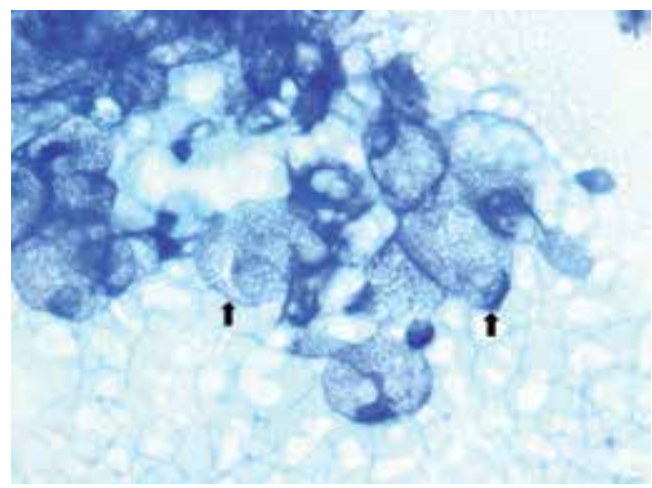

Figure 9.

Presence of agglutinated foamy cells on a vacuolar background (black arrows) (MGG, ×100) [6].

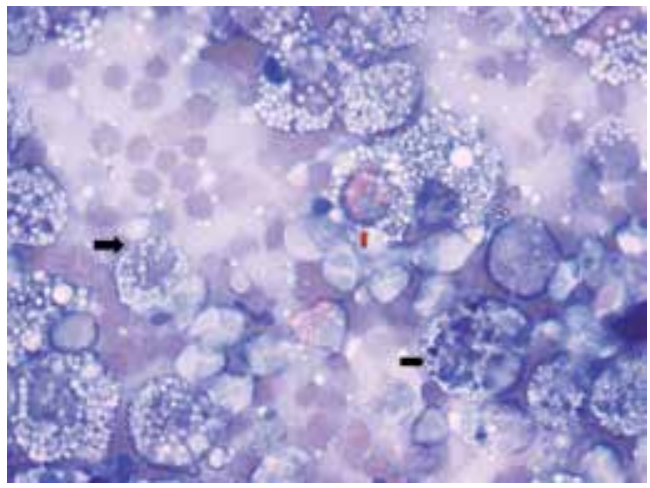

Figure 10.

Presence of eosinophils (red arrow), erythrocytes, and foamy cells (black arrow) with hemosiderin phagocytosis (arrow head) (MGG, ×100) [6]. 
Episodes of mastitis acuta (including mastitis gangrenosa) are accompanied by an increase in SCC and are characterized by an increased number of foamy cells, degenerated neutrophils (Figure 11), cellular debris, and bacteria accompanied by phagocytosis (Figures 12-14). The presence of small numbers of activated macrophages, eosinophils, and erythrocytes was also reported $[6,12]$.

In human medicine, in cases of breast inflammatory lesions due to acute actinomycosis, numerous polymorphonuclear leukocytes, scattered ductal cells, and necrotic material are found on milk smears [37], while in chronic pathologies, such as breast tuberculosis lesions, columnar, oddly shaped, and multinucleated giant cells surrounded by inflammatory infiltrate can be detected in milk smears [38].

Experimental inoculation of Staph. intermedius in the mammary gland of six female Beagle dogs resulted in increased SCC in milk $12 \mathrm{~h}$ after in infected and control glands [11]. At initial stages, smears performed with milk from affected mammary glands predominantly contained neutrophils ( $>75 \%)$. From day 3 post-challenge, degenerated neutrophils were present on smears, and on day 6, lymphocytes were also present (20\%) that began to predominate from day 14 . Smears performed with milk obtained from control glands showed similar findings [11]. Besides these evidences, some authors still opine that cytology of bitch milk has no clinical importance $[24,39,40]$. Nevertheless, the use of milk cytology has proven

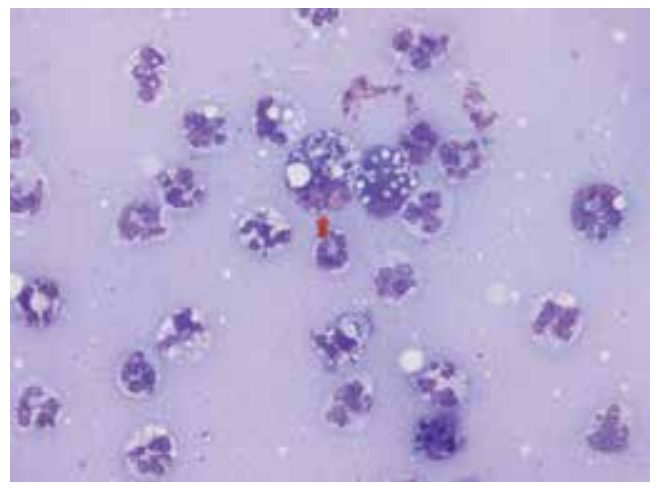

Figure 11.

Presence of many neutrophils and foamy cells (red arrow) on a basophilic background with discrete lipid droplets $(M G G, \times 100)[6]$.

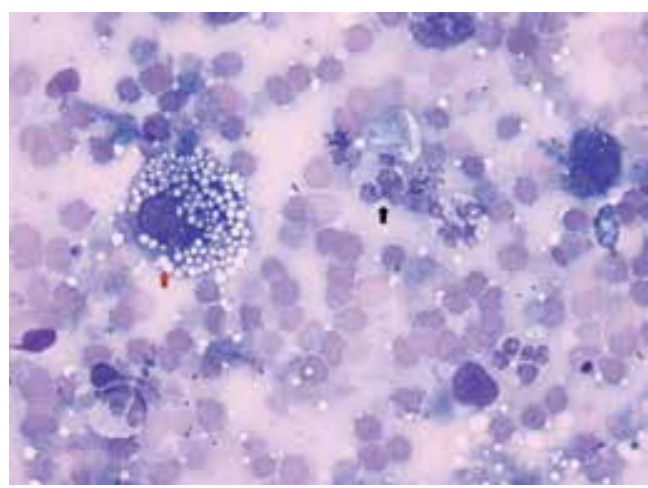

Figure 12.

Presence of foamy cells (red arrow), erythrocytes, and degenerated neutrophils with bacterial phagocytosis (black arrow) on an eosinophilic, vacuolar background $(M G G, \times 100)$ [6]. 


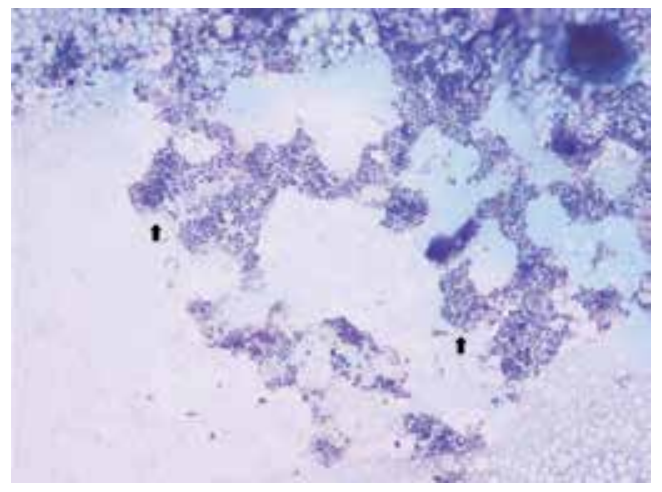

Figure 13.

Presence of cluster-organized round-shaped bacteria (black arrow) on a milk smear from a septic mammary gland $(M G G, \times 100)[6]$.

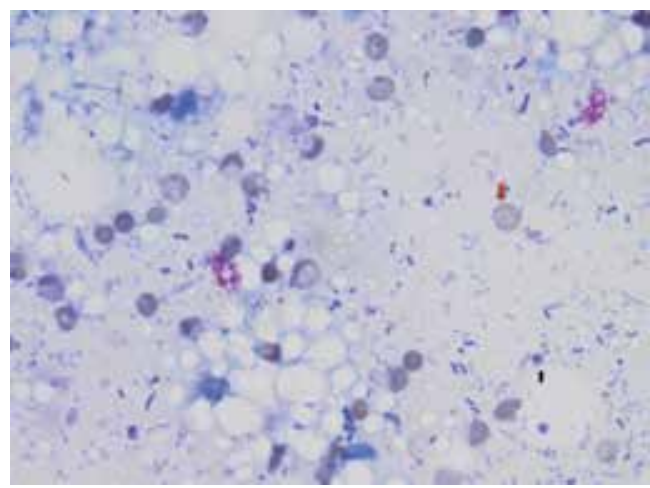

Figure 14.

Presence of erythrocytes (red arrow), cell debris, and many rod-shaped, respectively, round bacteria (black arrow) in a milk sample from a septic mammary gland (MGG, ×100) [6].

to be of aid whenever a mastitis diagnostic protocol was required [6, 41, 42]. Milk cytological evaluation can be helpful in diagnosing mammary gland inflammations, by helping clinicians to confirm the presence of clinical mastitis and avoid agalactia in the most developed mammary glands as well as secondary bacterial infections in infrequently milked mammary glands [6].

Milk cytology can be of help in parasitic disease diagnosis, e.g., nematodes (Dirofilaria repens of about $350 \mu \mathrm{m}$ in length) were detected in nipple secretion fluid smears of a 6 -year-old Bernese female dog. Glandular cell clusters and inflammatory cell including macrophagic foamy cells, neutrophils, and eosinophils were also detected in milk of this dog [43].

Furthermore, milk cytology helps to discriminate between mammary cancer and mastitis cases. While the prognosis is guarded to poor in cancer [44], it is usually good in mastitis, except for gangrenous cases. Thus, it is of high importance to differentiate the two pathologies, and a correct interpretation of mammary or milk cytology will lead to a correct diagnosis [27].

\subsection{Hematological and biochemical analyses}

Hematological and biochemical analyses are recommended to evaluate the general health status of the patient and specially to evaluate and monitor the degree of inflammation that can be done by the study of the leukocytes in the hematology 
and the acute-phase proteins and electrophoretic separation of the proteins in the biochemical profile.

Mastitis gangrenosa in bitch was characterized by the presence of leukocytosis $(36,300 / \mu \mathrm{L})$; increased $\alpha-, \beta$-, and $\gamma$-globulins; anemia; and increase in plasma analytes (alkaline phosphatase and creatine phosphokinase) and electrolytes (sodium and potassium) [33]. In an experimental infection, a significant increase in total leukocyte counts and neutrophils that returned to pre-challenge values after the sixth day has been reported [11]. In addition to total leukocyte and neutrophil increases, other changes that can occur in analytes in mastitis are monocytosis (for chronic cases), hypoalbuminemia, hyperglobulinemia, and mild dilutional normochromic, normocytic, and non-regenerative anemia due to precedence of pregnancy, eosinophilia, and changes in markers of the liver and kidney and in electrolytes. In severe cases that develop SIRS or sepsis, hypoglycemia, hypoalbuminemia, and leukopenia with consecutive coagulopathies are also encountered $[36,40]$.

Recent data [8] shows that hematology and other blood tests such as packed cell volume (PCV) and TP are not very reliable $(\mathrm{p}>0.05)$ when trying to diagnose or evaluate the mammary gland health status in bitch [8]. However, there are isolated cases of mastitis acuta described in bitch that evolved with lymphocytosis with a degenerative left shift [41] or with normocytic normochromic anemia, lymphopenia, and reactive thrombocytosis [42].

In the last years, acute-phase proteins (APPs) that can be major such as serum amyloid A (SAA) and C-reactive protein (CRP); moderate such as $\alpha 1$-acid glycoprotein (AGP), fibrinogen (Fb), and haptoglobin ( $\mathrm{Hp}$ ); and negative such as albumin [45] had started to be used to assess and monitor inflammatory diseases in veterinary medicine [46]. Acute-phase proteins are sensitive and non-specific markers of inflammation. They indicate the existence of an inflammatory stimulus $[45,46]$ and cannot diagnose a specific pathology; thus the final diagnostic should be pronounced according to other laboratory assays (Table 4) and clinical status.

The acute-phase response is induced by any type of tissue injury or infections that stimulate the release of different cytokines from macrophages and monocytes [47] that induce the synthesis of APPs by hepatocytes [46, 47]. In dogs, increases in APPs (SAA, CRP, Hp, Fb, and ceruloplasmin) in response to ovariohysterectomy in both healthy and with pyometra bitches have been reported. In the same sense, altered APP levels in pregnancy and estrus have been described in healthy female dogs [48-52].

Recently, by using the time-resolved immunofluorometric assay (TR-IFMA) method [53], CRP levels in bitch milk and serum were evaluated [3]. In both clinical and subclinical mastitis (Table 2), CRP milk $(0.3-40.0 \mu \mathrm{g} / \mathrm{mL}$ ) and serum levels $(0.3-162.3 \mu \mathrm{g} / \mathrm{mL})$ were elevated than levels obtained from milk $(0.1-4.9 \mu \mathrm{g} / \mathrm{mL})$ and serum $(2.0-8.6 \mu \mathrm{g} / \mathrm{mL})$ of healthy bitches. Research shows that milk CRP levels are more specific than blood levels. However, there were no differences detected in this APP between clinical and subclinical cases of mastitis.

Taking into account this novel finding, an increase in milk and serum CRP level reveals the presence of both systemic and local inflammations (mastitis), thus providing a new specific and noninvasive method of diagnosis [3] (Table 3).

$\mathrm{Hp}$ was also studied in milk of bitches [4]. The Hp peaks on 3-5 days after tissue injury with values between 4 and $9 \mathrm{mg} / \mathrm{mL}[4,46,54]$. Hp concentration reflects the intensity of inflammation and is correlated with the degree of tissue damage [52]. Since its concentrations increase two- to threefold in response to injury, Hp in dogs is considered a moderate APP $[45,55]$. In serum of healthy dogs, circulating Hp levels range between 0 and $1.69 \mathrm{mg} / \mathrm{mL}$.

In cases of mastitis acuta, the serum Hp concentrations range between 5.3 and $7.5 \mathrm{mg} / \mathrm{mL}$, while in bitches with mastitis cronica between 2.2 and $2.5 \mathrm{mg} / \mathrm{mL}$. In terms, in cases of lactatio sine graviditate, Hp presents normal values [4]. On the other 
How Reliable Are Laboratory Test When Diagnosing Bitch Mastitis?

DOI: http://dx.doi.org/10.5772/intechopen.86151

\begin{tabular}{lcc}
\hline Mammary gland diagnostic & Milk CRP levels & Serum CRP levels \\
\hline Healthy & $2.1(0.1-2.5)$ & $5.6(3.9-8.0)$ \\
\hline Subclinical mastitis & $11.3(2.9-20.7)$ & $21.9(8.1-67.9)$ \\
\hline Mastitis acuta & $6.5(2.4-23.7)$ & $7.1(8.1-67.9)$ \\
\hline Mammary retention & $6.3(3.8-10.9)$ & $14.6(4.1-51.8)$ \\
\hline Mammary congestion & $1.7(0.7-3.7)$ & $11.4(8.2-39.0)$ \\
\hline Mastitis gangrenosa & $8.0(7.9-8.0)$ & $113.4(112.2-113.4)$ \\
\hline
\end{tabular}

Table 3.

Mean value of milk and serum CRP levels $(\mu \mathrm{g} / \mathrm{mL})$ in bitches suffering from clinical and subclinical mastitis [3].

hand, recent study could not find correlation between serum Hp levels in bitches with mastitis and to the extent of the mammary gland inflammation degree [9].

In ruminants, $\mathrm{Hp}$ is considered a major APP and a valuable marker of inflammatory disease $[47,56]$. In healthy cows, Hp levels range between 22 and $47 \mathrm{mg} / \mathrm{L}$. During experimental E. coli mastitis infection in cows, the Hp level started to increase $12 \mathrm{~h}$ after challenge and reached the maximum (52 folds) $48-120 \mathrm{~h}$ after the inoculation [57]. It was also shown that Hp levels have predictive accuracy [58].

However, serum Hp level does not always correlate with the intensity of inflammation of mammary glands and could not discriminate the fatal E. coli cases [59]. Furthermore, rapid increase of somatic cells in milk after repeated challenges shows that the laboratory methods which have been adaptable for milk examination and used for early diagnosis in cow mastitis cells are primed by previous $E$. coli challenge. Subsequent $\mathrm{Hp}$ challenges do not increase at the same level as in the first challenge scenarios [57].

Based on literature data, it is known that in the course of subclinical infections, the levels of pro-inflammatory cytokines increase. Henceforth, determinations of APPs in slaughter houses are very common as indicators of food safety. Furthermore, mean Hp herd levels were suggested to be related to the hygiene level $[54,60,61]$.

\section{Conclusions}

Evaluating laboratory assays such as milk and serum CRP, milk microbiology, cytology, and $\mathrm{pH}$ proves to be of great help when trying to early diagnose, treat, or even avoid episodes of clinical or subclinical mastitis in bitches (Table 4).

Healthy mammary glands are characterized by the presence of low levels of both milk $(2.1 \mu \mathrm{g} / \mathrm{mL})$ and serum $(5.6 \mu \mathrm{g} / \mathrm{mL}) \mathrm{CRP}$, with a normal blood count; with the presence of somatic cells, cellular debris, squamous cells, and few neutrophils and macrophages; with an acidic milk pH; and with the presence of different milk bacterial strains.

Mammary congestion is characterized by slightly elevated levels of serum $(11.4 \mu \mathrm{g} / \mathrm{mL}) \mathrm{CRP}$, with normal blood counts; with the presence of low numbers of somatic cells, high amount of cellular debris, few neutrophils, and inactivated macrophages; with an acidic milk $\mathrm{pH}$; and with the presence of different milk bacterial strains.

Subclinical mastitis is characterized by the presence of elevated milk $(11.3 \mu \mathrm{g} / \mathrm{mL})$ and serum $(21.9 \mu \mathrm{g} / \mathrm{mL})$ CRP levels, with a modified blood count; with the presence of moderate to high levels of somatic cells; with the presence of degenerated neutrophils, many activated (foamy) macrophages and epithelial cells, bacteria, and 


\begin{tabular}{|c|c|c|c|c|c|}
\hline & $\begin{array}{c}\text { Median } \\
\text { CRP } \mu \mathrm{g} / \mathrm{mL} \\
\text { Milk/serum }\end{array}$ & Hematology & Cytology & $\mathrm{pH}$ & Milk microbiology \\
\hline $\begin{array}{l}\text { Healthy } \\
\text { mammae }\end{array}$ & $2.1 / 5.6$ & - & $\begin{array}{c}\text { Few } \\
\text { somatic } \\
\text { cells and } \\
\text { cellular } \\
\text { debris }\end{array}$ & $<6.5$ & $\begin{array}{c}\text { Staph. simulans; B.cereus; } \\
\text { E. faecalis; Acinetobacter } \\
\text { ursingii }\end{array}$ \\
\hline $\begin{array}{l}\text { Mammary } \\
\text { congestion }\end{array}$ & $1.7 / 11.4$ & - & $\begin{array}{l}\text { Increased } \\
\text { number } \\
\text { of cellular } \\
\text { debris }\end{array}$ & $<6.5$ & $\begin{array}{l}\text { E. faecium; Staph. } \\
\text { pseudintermedius }\end{array}$ \\
\hline $\begin{array}{l}\text { Subclinical } \\
\text { mastitis }\end{array}$ & $11.3 / 21.9$ & $\begin{array}{l}\text { Leukocytosis } \\
\text { with left shift }\end{array}$ & $\begin{array}{l}\text { Increased } \\
\text { cell counts }\end{array}$ & $\geq 7$ & $\begin{array}{c}\text { Staph. xylosus; } \\
\text { Agrobacterium radiobacter; } \\
\text { E. coli }\end{array}$ \\
\hline $\begin{array}{l}\text { Retention } \\
\text { mastitis }\end{array}$ & $6.3 / 14.6$ & $\begin{array}{l}\text { Leukocytosis } \\
\text { with left shift }\end{array}$ & $\begin{array}{l}\text { Increased } \\
\text { cell counts }\end{array}$ & $>7$ & P. vulgaris; B. pumilus \\
\hline $\begin{array}{l}\text { Mastitis } \\
\text { acuta }\end{array}$ & $6.5 / 7.1$ & $\begin{array}{l}\text { Leukocytosis } \\
\text { with left shift }\end{array}$ & $\begin{array}{l}\text { Increased } \\
\text { cell counts }\end{array}$ & $>7$ & $\begin{array}{c}\text { E. coli; Staph. intermedius; } \\
\text { Ps. aeruginosa }\end{array}$ \\
\hline
\end{tabular}

Table 4 .

Laboratory values of different bitch mastitis diagnostics.

phagocytosis; with an alkaline milk $\mathrm{pH}$; and with the presence of many different milk bacterial strains.

Retention mastitis is characterized by the presence of elevated milk $(6.3 \mu \mathrm{g} / \mathrm{mL})$ and serum $(14.6 \mu \mathrm{g} / \mathrm{mL})$ CRP levels, with a modified blood count; with the presence of erythrocytes, eosinophils, foamy cells, degenerated neutrophils, bacteria, and phagocytosis; with an alkaline milk $\mathrm{pH}$ (up to 9.5); and with the presence of different milk bacterial strains.

Mastitis acuta (including Mastitis gangrenosa) episodes are characterized by the presence of elevated levels of both milk $(6.5 \mu \mathrm{g} / \mathrm{mL})$ and serum $(7.1 \mu \mathrm{g} / \mathrm{mL})$ CRP, with a modified blood count and with the presence of high numbers of foamy cells, degenerated neutrophils, cellular debris, bacteria, phagocytosis, and few numbers of erythrocytes.

The use of APPs in the diagnostic strategy of mastitis in bitch proves to be of great benefit since it provides a precise, quick, and noninvasive tool of diagnostic. Milk cytology evaluation helps to establish a definitive diagnostic, by characterizing the type of inflammatory response on milk smears.

Milk $\mathrm{pH}$ evaluation, alongside milk microbiology and susceptibility tests, helps establish a correct treatment strategy, by choosing the correct type of antibiotic according to its $\mathrm{pH}$ asset (acidic/alkaline) and antibiogram susceptibility results.

Mammary infections of bitches are widely overlooked; thus extra care should be taken to adequately revise status of mammary glands during postpartum since bacterial pathogens can migrate from the uterus and vagina to the mammary glands and cause their infection (hematogenous transmission) [39].

Laboratory analysis including determination of milk $\mathrm{pH}$ together with performance of biochemistry, hematology, milk cytology, and microbiology tests should be a golden standard for mammary gland infection management in dogs [27]. Taking into account the scarce milk quantities obtained from lactating bitches, further research should be carried out, in order to establish a more applicable method to evaluate bitch milk $\mathrm{pH}$ values. Different APP ( $\mathrm{Hp}, \mathrm{SAA}, \mathrm{AGP}, \mathrm{Fb}$, etc.) diagnostic potentials should also be assessed, in order to complete the picture that CRP levels started to draw, regarding this novel, noninvasive diagnostic protocol. 


\section{Acknowledgements}

The authors would like to express their warmest thanks to Ioana Adriana MateiBuzura, who had helped with an excellent advice and statistical analyses; to all of our colleagues from Infectious Diseases, Microbiology, Parasitology, Necropsy, Morphopathology, Reproduction and Internal Diseases departments; and, last but not least, to the emergency hospital from the University of Agricultural Sciences and Veterinary Medicine, Cluj-Napoca, Romania, all who had helped with all the financial, moral, and logistic support.

\section{Conflict of interest}

The authors of this chapter declare that they have no conflict of interest, whatsoever.

\section{Dedication}

My dear family, Cristina, Rebeca, and Filip.

In loving memory of the one we once called mother, our beautiful, kind, and gentle LIVIA.

\section{Abbreviations}

$\begin{array}{ll}\text { AGP } & \alpha 1 \text {-acid glycoprotein } \\ \text { API } & \text { analytical profile index } \\ \text { APPs } & \text { acute-phase proteins } \\ \text { CRP } & \text { C-reactive protein } \\ \text { Fb } & \text { fibrinogen } \\ \text { Hp } & \text { haptoglobin } \\ \text { MGG } & \text { May-Grünwald Giemsa } \\ \text { MRS } & \text { De Man, Rogosa and Sharpe agar } \\ \text { PCV } & \text { packed cell volume } \\ \text { SAA } & \text { serum amyloid A } \\ \text { TP } & \text { total proteins } \\ \text { TR-IFMA } & \text { time-resolved immunofluorometric assay } \\ \text { TS } & \text { total solids }\end{array}$




\section{Author details}

Iosif Vasiu ${ }^{1 *}$, Roman Dąbrowski ${ }^{2}$, Flaviu Alexandru Tăbăran ${ }^{1}$, Raul Alexandru Pop ${ }^{1}$, Flore Chirilă ${ }^{1}$, Gheorghe Florinel Brudaşcă ${ }^{1}$, Asta Tvarijonaviciute ${ }^{3}$ and Nicodim Iosif Fiț

1 University of Agricultural Sciences and Veterinary Medicine, Cluj-Napoca, Romania

2 University of Life Sciences, Lublin, Poland

3 University of Murcia, Murcia, Spain

*Address all correspondence to: iosif.vasiu@usamvcluj.ro

\section{IntechOpen}

(C) 2019 The Author(s). Licensee IntechOpen. This chapter is distributed under the terms of the Creative Commons Attribution License (http://creativecommons.org/licenses/ by/3.0), which permits unrestricted use, distribution, and reproduction in any medium, provided the original work is properly cited. (cc) BY 


\section{References}

[1] Johnston DS, Root Kustritz MV, Olson Patricia NS. Periparturient disorders in the bitch. In: Johnston DS, Root Kustritz MV, Olson Patricia NS, editors. Canine and Feline Theriogenology. 1st ed. Philadelphia: Saunders Company; 2001. pp. 129-145.

[2] Martí AJ. Clinical aspects of mammary disease in the bitch and queen. In: Proceeding of the Southern European Veterinary Conference \& Congreso Nacional AVEPA; 2-4 October 2009; Barcelona, Spain. Available from: http://www.ivis.org/proceedings/ sevc/2009/eng/arus1.pdf

[3] Vasiu I, Dąbrowski R, MartinezSubiela S, Ceron JJ, Wdowiak A, Pop $\mathrm{AR}$, et al. Milk C-reactive protein in canine mastitis. Veterinary Immunology and Immunopathology. 2017;186:41-44. DOI: 10.1016/j.vetimun.2017.02.005

[4] Dziecioł M, Stefaniak T, Twardon J, Kozdrowski R. Wybrane wskaźniki mleka i krwi suk ze zdrowym i chorym gruczołem sutkowym [Chosen parameters of the milk and blood of bitches with healthy mammary glands and those suffering from mastitis]. Medycyna Weterynaryjna. 2006;62(1):59-61

[5] Patricia ON, Olson AL. Cytologic evaluation of canine milk. Veterinary Medicine, Small Animal Clinician. 1984;79:641-646

[6] Vasiu I, Tăbăran F, Pop AR, Brudaşcă GF, Tvarijonaviciute A, Dąbrowski R. Usefulness of cytological evaluation of milk in diagnosing mastitis in bitches. Medycyna Weterynaryjna. 2018;74(10):640-645. DOI: 10.21521/ mw.5963

[7] Milani C, Corrò M, Drigo M, Rota A. Antimicrobial resistance in bacteria from breeding dogs housed in kennels with different neonatal mortality and use of antibiotics. Theriogenology. 2012;78:132-1328. DOI: 10.1016/j. theriogenology.2012.05.033

[8] Vasiu I, Sarpataki O, Bedecean I, Pop AR, Brudaşcă GF. Haematologic and biochemical changes in bitches with clinical and subclinical mastitis. Bulletin UASVM Veterinary Medicine. 2016;73(2):1-4. DOI: 10.15835/ buasvmcn-vm:11995

[9] Vasiu I, Pop AR, Matei-Buzura IA, Brudaşcă GF. Nivelul seric al Haptoglobinei la cățelele cu mamite aflate în lactație [Haptoglobin serum levels in lactating bitches with mastitis]. Romanian Journal of Veterinary Medicine \& Pharmacology. 2018;13(5):316-321

[10] Martín R, Olivares M, Pérez M, Xaus J, Torre C, Fernández L, et al. Identification and evaluation of the probiotic potential of lactobacilli isolated from canine milk. Veterinary Journal. 2010;185:193-198. DOI: 10.1016/j.tvjl.2009.04.014

[11] Ververidis HN, Mavrogianni VS, Fragkou IA, Orfanou DC, Gougoulis DA, Tzivara A, et al. Experimental Staphylococcal mastitis in bitches: Clinical, bacteriological, cytological, hematological, and pathological features. Veterinary Microbiology. 2007;124:95-106. DOI: 10.1016/j. vetmic.2007.03.029

[12] Sangha S, Singh A, Sood NK, Gupta K. Specificity and sensitivity of cytological techniques for rapid diagnosis of neoplastic and nonneoplastic lesions of canine mammary gland. Brazilian Journal of Veterinary Pathology. 2010;4:13-22

[13] Schäfer-Somi S, Spergser J, Breitenfellner J, Aurich JE. Bacteriological status of canine milk and septicaemia in neonatal 
puppies-A retrospective study. Journal of Veterinary Medicine. 2003;50:343-346. DOI: 10.1046/j.1439-0450.2003.00672.x

[14] Rodríguez JM, Jiménez E, Merino V, Maldonado A, Marín ML, Fernández L, et al. Microbiota de la leche humana en condiciones fisiológicas [Microbiota of human milk in physiological conditions]. Acta Pediátrica Española. 2008;66(2):27-31

[15] Vasiu I. Diagnostic de laborator în inflamaţiile mamare la căţele aflate în lactaţie [Laboratory diagnostic of mammary gland inflammations in lactating bitches] [thesis]. Cluj-Napoca: University of Agricultural Science and Veterinary Medicine; 2016

[16] Quinn PJ, Carter ME, Markey B, Carter GR, editors. Clinical Veterinary Microbiology. 1st ed. Edimburgh: Mosby; 1994. 648 p

[17] Weese SJ. Antimicrobial resistance in companion animals. Animal Health Research Reviews. 2008;9(2):169-176. DOI: $10.1017 /$ S1466252308001485

[18] Araújo RM, Preis SI, França AS, Paniago GJ, Costa CM, Oliveira SVJ, et al. Mastitis accompanied by lymphadenitis in a dog caused by Staphylococcus hyicus. Brazilian Journal of Veterinary Pathology. 2011;4:52-57

[19] Jung C, Wehrend A, König A, Bostedt H. Untersuchung zu vorkommen, differenzierung und erregerspektrum caniner mastitiden [Investigations about the incidence, differentiation and microbiology of canine mastitis]. Praktische Tierarzt. 2002;83:508-511

[20] Graham EM, Taylor DJ. Bacterial reproductive pathogens of cats and dogs. Veterinary Clinics of North America: Small Animal. 2012;42:561582. DOI: 10.1016/j.cvsm.2012.01.013
[21] Jiménez E, Ladero V, Chico I, Madonado-Barragán A, López M, Martín V, et al. Antibiotic resistance, virulence determinants and production of biogenic amines among enterococci from ovine, feline, canine, porcine and human milk. BMC Microbiology. 2013;13:288. DOI: 10.1186/1471-2180-13-288

[22] Sager M, Remmers C. Perinatal mortality in dogs. Clinical, bacteriological and pathological studies. Tierärztliche Praxis. 1990;18:415-419

[23] Münnich A, Lübke-Becker A. Escherichia coli infections in newborn puppies-Clinical and epidemiological investigations. Theriogenology. 2004;62:562-575. DOI: 10.1016/j. theriogenology.2003.11.012

[24] Grundy SA. Metritis and mastitis. In: Dobratz KJ, Hopper K, Rozanski E, Silverstein DC, editors. Textbook of Small Animal Emergency Medicine, I \& II. 1st ed. New Jersey: Wiley Blackwell; 2019. pp. 791-794. DOI: 10.1002/9781119028994

[25] Rota A, Milani C, Drigo I, Drigo $\mathrm{M}$, Corrò $\mathrm{M}$. Isolation of methicillinresistant Staphylococcus pseudintermedius from breeding dogs. Theriogenology. 2011;75:115-121. DOI: 10.1016/j. theriogenology.2010.07.016

[26] Vela IA, Falsen E, Simarro I, Rollan E, Collins MD, Domínguez L, et al. Neonatal mortality in puppies due to bacteremia by Streptococcus dysgalactiae subsp. dysgalactiae. Journal of Clinical Microbiology. 2006;44(2):666-669. DOI: $10.1128 /$ jcm.44.2.666-668.2006

[27] Vasiu I, Spînu M, Nicule M, Pop AR, Balaci I, Brudaşcă GF. Laboratory methods used for early diagnosis in bitch mastitis. Bulletin UASVM Veterinary Medicine. 2015;72(1):1-8. DOI: 10.15835/buasvmcn-vm: 11026 
[28] Lam MM, Clarridge JE 3rd, Young EJ, Mizuki S. The other group G Streptococcus: Increased detection of Streptococcus canis ulcer infections in dog owners. Journal of Clinical Microbiology 2007;45(7):2327-2329. DOI: 10.1128/JCM.01765-06

[29] Wedley AL, Maddox TW, Westgarth C, Coyne KP, Pinchbeck GL, Williams NJ, et al. Prevalence of antimicrobial-resistant Escherichia coli in dogs in a cross-sectional, communitybased study. The Veterinary Record. 2011;168:354. DOI: 10.1136/vr.d1540

[30] Casal LM. Mastitis. In: Silverstein D, Hopper K, editors. Small Animal Critical Care Medicine. 2nd ed. Philadelphia: Elsevier Saunders; 2014. pp. 527-530. DOI: $10.1016 /$ B978-1-4557-0306-7.00216-6

[31] De Graef EM, Decostere A, Devriese LA, Haesebrouck F. Antibiotic resistance among fecal indicator bacteria from healthy individually owned and kennel dogs. Microbial Drug Resistance. 2004;10:65-69. DOI: 10.1089/107662904323047826

[32] Tsioulpas A, Lewis JM, Grandison AS. A study of the $\mathrm{pH}$ of individual milk samples. International Journal of Dairy Technology. 2007;60(2):96-97. DOI: 10.1111/j.1471-0307.2007.00308.x

[33] Hasegawa T, Fuji M, Fukada T, Tduji C, Fujita T, Goto Y, et al. Platelet abnormalities in a dog suffering from gangrenous mastitis by Staphylococcus aureus infection. The Journal of Veterinary Medical Science. 1993;55: 169-171. DOI: 10.1292/jvms.55.169

[34] Akhtardanesh B, Hejazi SM, Kheirandish R, Oloumi MM, Moghadaszadeh M, Hosseini HS. Mastitis obliterans in a diabetic dog: bacteriological and pathological findings. Online Journal of Veterinary Research. 2013;17(7):396-401
[35] Meyer JD, Connolly SL, Heng HG. The acquisition and management of cytology specimens. In: Raskin ER, Meyer DJ, editors. Canine and Feline Cytology, a Color Atlas and Interpretation Guide. 2nd ed. Missouri: WB Saunders; 2010. pp. 1-15

[36] Lopate C. Reproductive physiology of canine pregnancy and parturition and conditions of the periparturient period. In: Lopate C, editor.

Management of Pregnant and Neonatal Dogs, Cats and Exotic Pets. 1st ed. Iowa: Wiley-Blackwell; 2012. pp. 25-41. DOI: 10.1002/9781118997215

[37] Koss LG, Melamed MR. The breast. In: Koss LG, Melamed MR, editors. Diagnostic Cytology and Its Histopathologic Base. 5th ed. Lippincott: Williams \& Wilkins; 2006. pp. 1082-1147

[38] Shinde SR, Chandawarkar RY, Deshmukh SP. Tuberculosis of the breast masquerading as carcinoma: A study of 100 patients. World Journal of Surgery. 1995;19:379-381. DOI: 10.1007/ bf00299163

[39] Fontaine E, Tanneur ML, Josien A. Mammite gangreneuse chez la chienne reproductrice. Le Point Vétérinaire. 2007;276:25-29

[40] Davidson A. Mastitis. Standards of Care: Emergency and Critical Care Medicine. 2008;10(1):1-4

[41] Vasiu I, Spînu M, Pop AR, Bedecean I, Sarpataki O, Brudaşcă GF. Un caz de mamită acută semnalată la o cățeae de Viszla maghiară, produsă de o infecţiecu Staphylococcus intermedius [Mastitis acuta in a Hungarian Viszla bitch, caused by a Staphylococcus intermedius infection]. Revista Romana de Medicina Veterinara. 2015;25:51-54

[42] Vasiu I, Pop AR, Chirilă F, Tăbăran F, Taulescu M, Brudaşcă GF. 
Mastitis acuta in a pure breed cane corso female. A case report. Bulletin UASVM Veterinary Medicine. 2017;74(1):30-34. DOI: 10.15835/ buasvmcn-vm: 12461

[43] Manuali E, Eleni C, Giovannini P, Costarelli S, Ciorba A. Unusual finding in a nipple discharge of a female dog: Dirofilariasis of the breast. Diagnostic Cytopathology. 2004;32:2. DOI: 10.1002/dc.20181

[44] von Euler H. Tumors of the mammary glands. In: Dobson MJ, Lascelles BDX, editors. BSAVA Manual of Canine and Feline Oncology. 3rd ed. Quedgeley: BSAVA; 2011. pp. 237-247. DOI: $10.22233 / 9781905319749.16$

[45] Eckersall PD. Acute phase proteins as markers of inflammatory lesions. Comparative Haematology International. 1995;5:93-97. DOI: $10.1007 / \mathrm{bf} 00638925$

[46] Cerón JJ, Eckersall PD, MartínezSubiela S. Acute phase proteins in dogs and cats: Current knowledge and future perspectives. Veterinary Clinical Pathology. 2005;34:85-99. DOI: 10.1111/j.1939-165x.2005.tb00019.x

[47] Eckersall PD. Recent advances and future prospects for the use of acute phase proteins as markers of disease in animals. Revue de Médecine Vétérinaire. 2000;151(7):577-584

[48] Ulutaş PA, Ulutaş B, Sarirler M, Bayramli G. Serum haptoglobin and ceruloplasmin concentrations in dogs with various diseases. Journal of The Faculty of Veterinary Medicine. Istanbul University. 2007;33(2):35-42. DOI: 10.1016/j.rvsc.2008.09.001

[49] Dąbrowski R, Wawron W, Kostro K. Changes in CRP, SAA and haptoglobin produced in response to ovariohysterectomy in healthy bitches and those with pyometra.
Theriogenology. 2007;67:321-327. DOI: 10.1016/j.theriogenology.2006.07.019

[50] Ulutaş PA, Musal B, Kiral F, Bildik A. Acute phase protein levels in pregnancy and oestrus cycle in bitches. Research in Veterinary Science. 2009;86:373-376. DOI: 10.1016/j. rvsc.2008.09.001

[51] Serin G, Ulutaş PA. Measurement of serum acute phase proteins to monitor postoperative recovery in anoestrous bitches after ovariohysterectomy. The Veterinary Record. 2010;166:20-22. DOI: 10.1136/vr.b5585

[52] Dabrowski R, Kosto K, Szczubiał $\mathrm{M}$. Concentrations of C-reactive protein, serum amyloid $\mathrm{A}$ and haptoglobin in uterine arterial and peripheral blood in bitches with pyometra. Theriogenology. 2013;80:494-497. DOI: 10.1016/j. theriogenology.2013.05.012

[53] Parra MD, Tecles F, MartinezSubiela S, Cerón JJ. C-reactive protein measurement in canine saliva. Journal of Veterinary Diagnostic Investigation. 2005;17:139-144. DOI: $10.1177 / 104063870501700207$

[54] Kostro K, Sobieska M, Wiktorowicz K, Wołoszyn S. Białka ostrej fazy u zwierząt-występowanie i charakterystyka [The acute phase proteins in animals-Occurrence and characteristics]. Medycyna Weterynaryjna. 1996;52(3):152-155

[55] Eckersall PD, Conner JG. Bovine and canine acute phase proteins.

Veterinary Research Communications. 1988;12:169-178. DOI: 10.1007/ BF00362798

[56] Eckersall PD, Duthie S, Safi S, Moffatt D, Horadagoda NU, Doyle S, et al. An automated biochemical assay for haptoglobin: Prevention of interference from albumin. Comparative Haematology 
International. 1999;9:117-124. DOI:

$10.1007 / \mathrm{bf0} 2600369$

[57] Salonen M, Hirvonen J, Pyörälä S, Sankari S, Sandholm M. Quantitative determination of bovine serum haptoglobin in experimentally induced Escherichia coli mastitis. Research in Veterinary Science. 1996;60:88-91. DOI: $10.1016 / \mathrm{s} 0034-5288(96) 90138-1$

[58] Hirvonen J, Pyörälä S, JousimiesSomer H. Acute phase response in heifers with experimentally induced mastitis. The Journal of Dairy Research. 1996;63:351-360

[59] Hirvonen J, Eklund K, Teppo AM, Huszenicza G, Kulcsar M, Saloniemi $\mathrm{H}$, et al. Acute phase response in dairy cows with experimentally induced Escherichia coli mastitis. Acta Veterinaria Scandinavica. 1999;40:35-46

[60] Eurell TR, Bane DP, Hall WF, Schaeffer DJ. Serum haptoglobin concentration as an indicator of weight gain in pigs. Canadian Journal of Veterinary Research. 1992;56:6-9

[61] Petersen HH, Nielsen JP, Heegaard $\mathrm{PMH}$. Application of acute phase protein measurements in veterinary clinical chemistry. Veterinary Research. 2003;35:163-117. DOI: 10.1051/ vetres:2004002 
ISBN 978-1-83880-062-8

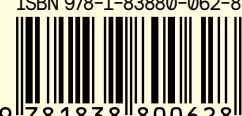

